\title{
WestVirginiaUniversity
}

THE RESEARCH REPOSITORY @ WVU

Graduate Theses, Dissertations, and Problem Reports

2003

\section{Implementation and application of NDE on ceramic candle filters}

Alejandro C. Kiriakidis

West Virginia University

Follow this and additional works at: https://researchrepository.wvu.edu/etd

\section{Recommended Citation}

Kiriakidis, Alejandro C., "Implementation and application of NDE on ceramic candle filters" (2003).

Graduate Theses, Dissertations, and Problem Reports. 2496.

https://researchrepository.wvu.edu/etd/2496

This Dissertation is protected by copyright and/or related rights. It has been brought to you by the The Research Repository @ WVU with permission from the rights-holder(s). You are free to use this Dissertation in any way that is permitted by the copyright and related rights legislation that applies to your use. For other uses you must obtain permission from the rights-holder(s) directly, unless additional rights are indicated by a Creative Commons license in the record and/ or on the work itself. This Dissertation has been accepted for inclusion in WVU Graduate Theses, Dissertations, and Problem Reports collection by an authorized administrator of The Research Repository @ WVU.

For more information, please contact researchrepository@mail.wvu.edu. 


\title{
IMPLEMENTATION AND APPLICATION OF NDE ON CERAMIC CANDLE FILTERS
}

\author{
Alejandro C. Kiriakidis \\ Dissertation submitted to the \\ College of Engineering and Mineral Resources \\ at West Virginia University \\ in partial fulfillment of the requirements \\ for the degree of
}

\begin{abstract}
Doctor of Philosophy
in

Civil Engineering
\end{abstract}

\author{
Roger H.L Chen, Ph. D., Chair \\ Hema J. Siriwardane, Ph. D \\ Eric Johnson, Ph. D \\ Victor H. Mucino, Ph. D \\ Syd Peng, Ph. D \\ Department of Civil and Environmental Engineering
}

Morgantown, West Virginia

2003

Keywords: Ceramic Candle Filters, Nondestructive Evaluation, Natural Frequencies, Finite Element Analysis, Timoshenko Beam Equation 


\title{
ABSTRACT \\ IMPLEMENTATION AND APPLICATION OF NDE ON CERAMIC CANDLE FILTERS
}

\author{
Alejandro C. Kiriakidis
}

A nondestructive evaluation (NDE) technique has been developed to determine the deterioration and remaining life of full-size ceramic candle filters used at the Power System Development Facility (PSDF) in Alabama. Ceramic candle filters are hollow cylindrical structures made of porous ceramic materials used in advanced coal-fired power generation systems. They protect power plant's gas turbine components from damage due to erosion. In general, advanced coal-fired power systems operational conditions include extreme thermal/pressure environment and vibration-induced stresses over a great period of time. The knowledge of the dynamic behavior of ceramic candle filters is essential and can be used to measure changes in the mechanical properties of the filters, nondestructively. The NDE technique developed can help ensure the efficiency and safe performance of the ceramic candle filters and the power plant systems. More than 140 candle filters have been nondestructively evaluated and the results are presented in this study. Fifty-two of these filters having various in-service exposure times were used at the PSDF and the rest were new filters. The candle filters are tested using a laser/accelerometer setup with various boundary conditions. The evaluation of experimental results is processed using digital signal analysis techniques including various forms of data transformation. Finite element models are built to calculate the filter's dynamic response. A general Timoshenko beam equation that includes different boundary restraints is derived to simulate the dynamic behavior of the candle filters. Results from this study indicate that dynamic characterization is a feasible NDE technique for studying structural properties of ceramic candle filters. It has been shown that the vibration signature could be used as a tool to evaluate both the material properties of the ceramic candle filters and the boundary restraints. The degradation of the filters due to long working hours is reflected in the shift of natural vibration frequencies. These shifts are due to changes in structural properties such as stiffness, which are directly related to the Young's modulus of the candle filters. A relationship between the stiffness reduction and the reliability of the ceramic candle filters due to exposure hours is presented. Fatigue results from the present study show the importance of considering the operational vibration as well as the temperature gradient due to back-pulse as the factors that may cause failure of the ceramic candle filters. 


\section{ACKNOWLEDGEMENTS}

I wish to express my gratitude and appreciation to my research advisor and committee chairman, Dr. Roger H.L Chen, for his invaluable constant guidance, encouragement and support throughout the completion of this research work. I also extend a special appreciation to Dr. Hema J. Siriwardane, Dr. Eric Johnson, Dr. Victor H. Mucino, and Dr. Syd Peng, members of the advisory committee, for their constructive comments and suggestions.

Special words of thanks go to my officemates: Dr. Komwut Wissawapaisal, Mr. Jeon-Hoon Choi, Mr. Joseph Sweet, Mr. Joshua Cook, Mr. Tuan-Chun Fu, and Mr. Ryan Arnold for their help and encouragement.

I wish to express my deep gratitude to my family for their unconditional love, encouragement and understanding. I would also like to convey a special word of thanks to Reem Kayali and Ricardo Kiriakidis for their constant help and seeing me through this ordeal.

Finally, I wish to acknowledge the financial support provided by the National Energy Technology Laboratory (NETL), Department of Energy, for this study under the contracts DE-FG26-99FT40202 and DE-FG21-97MC34160. Special thanks are extended to Mr. Ted McMahon of NETL/DOE for his valuable comments and technical support throughout this study. I also wish to acknowledge the help from Mr. Richard Dennis of NETL /DOE and Mr. Howard Hendrix of Southern Company Services for his help in providing the ceramic candle filter specimens. This dissertation is essentially the same as the final report submitted to the DOE. 


\section{TABLE OF CONTENTS}

ABSTRACT

ACKNOWLEDGEMENTS iii

TABLE OF CONTENTS iv

LIST OF TABLES viii

LIST OF FIGURES $\quad$ x

CHAPTER I INTRODUCTION

1.1 General Remarks $\ldots \ldots \ldots \ldots \ldots \ldots \ldots \ldots \ldots \ldots \ldots \ldots \ldots \ldots \ldots \ldots \ldots$

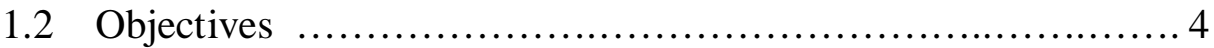

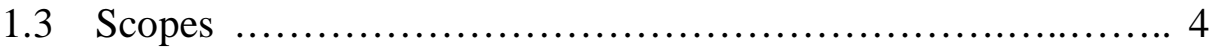

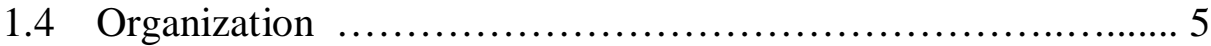

1.5 Project Description $\ldots \ldots \ldots \ldots \ldots \ldots \ldots \ldots \ldots \ldots \ldots \ldots \ldots \ldots \ldots \ldots$

\section{CHAPTER II LITERATURE REVIEW}

2.1 Hot Gas Filter System $\ldots \ldots \ldots \ldots \ldots \ldots \ldots \ldots \ldots \ldots \ldots \ldots \ldots \ldots \ldots$

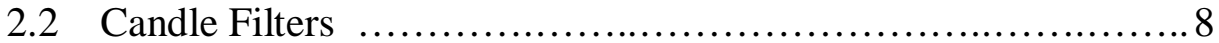

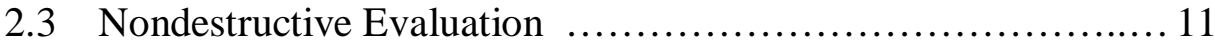

2.4 Dynamic Property Measurement Methods ......................12

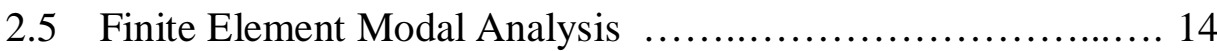

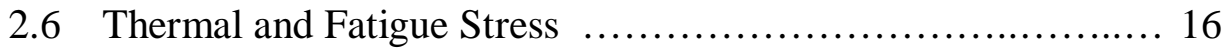

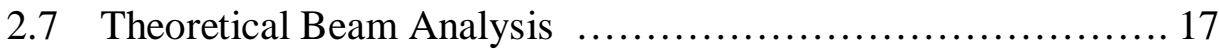

2.8 Reliability of Used Ceramic Candle Filters $\ldots \ldots \ldots \ldots \ldots \ldots \ldots 19$ 
CHAPTER III STRUCTURAL PROPERTIES AND DETERIORATION OF NEW AND USED CERAMIC CANDLE FILTERS

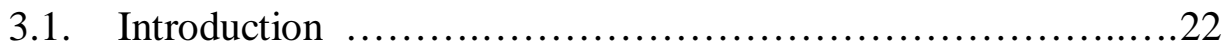

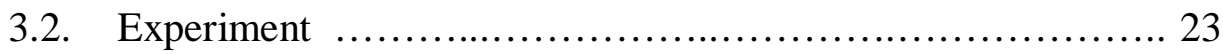

3.3. Theoretical Analysis ........................................... 24

3.3.1. Localized damage detection ......................... 26

3.4. Finite Element Analysis ...................................27

3.5. Results .............................................. 27

3.5.1. Natural frequencies .............................. 27

3.5.2. Mode shapes ..................................... 29

3.5.3. Stiffness of new filters ............................. 30

3.5.4. Stiffness degradation .............................. 31

3.5.5. Damage detection .................................. 33

3.5.6. Dust cake effect ................................... 36

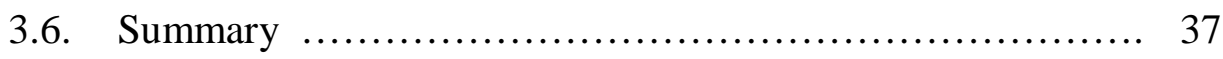

\section{CHAPTER IV EVALUATION OF CERAMIC CANDLE FILTERS WITH VARIOUS BOUNDARY CONDITIONS}

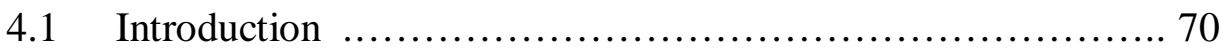

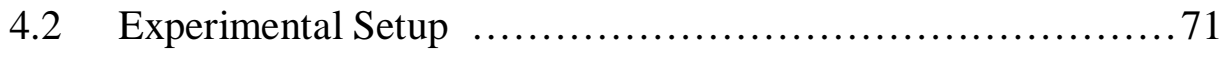

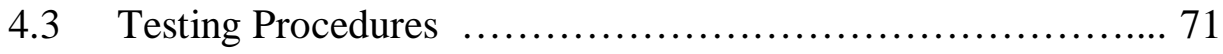

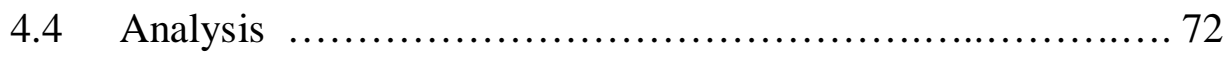

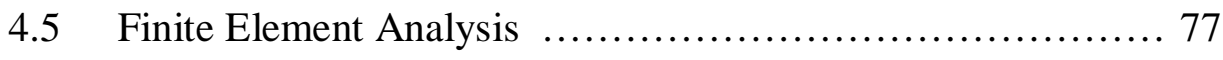




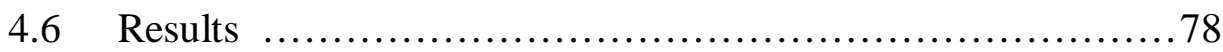

4.6.1 Natural frequencies ........................... 78

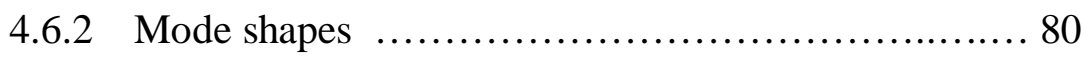

4.6.3 Axisymmetry of candle filters $\ldots \ldots \ldots \ldots \ldots \ldots \ldots . . . \ldots 1$

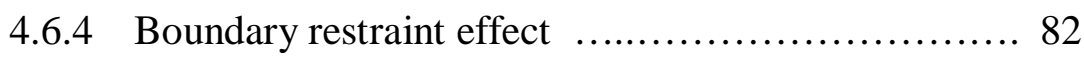

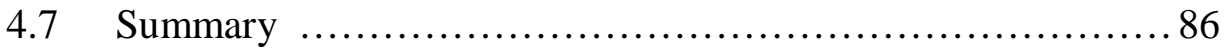

CHAPTER V STIFFNESS OF CERAMIC CANDLE FILTERS AT ELEVATED TEMPERATURE UNDER VIBRATIONAL ENVIRONMENT

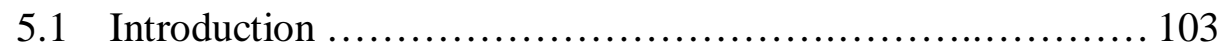

5.2 Experimental Setup and Testing Procedure ................. 103

5.3 Formulation of the Problem f.............................. 106

5.4 Finite Element Analysis................................ 110

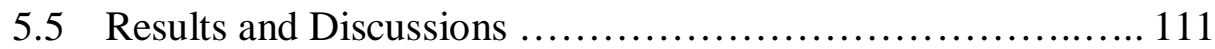

5.5.1 Thermal dynamic characterization $\ldots \ldots \ldots \ldots \ldots \ldots 111$

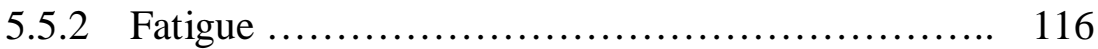

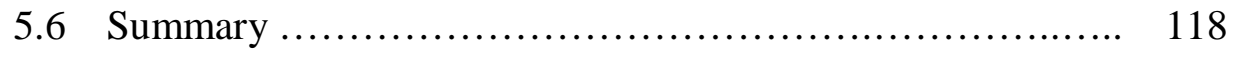

\section{CHAPTER VI REMAINIG LIFE IDENTIFICATION OF CERAMIC CANDLE FILTERS}

6.1 Introduction......................................... 148

6.2 Determination of Probability of Failure ................. 148

6.3 Safety Analysis of Ceramic Candle Filters .................. 151 
6.4 Results............................................ 152

6.5 Example........................................... 155

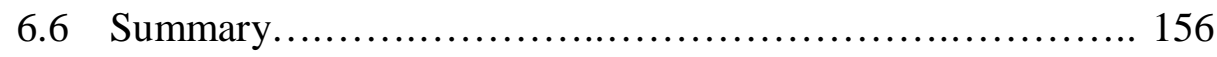

\section{CHAPTER VII CONCLUSIONS AND RECOMMENDATIONS}

7.1 Conclusions........................................... 165

7.2 Application and Recommendations .................... 167

$\begin{array}{ll}\text { REFERENCES } & \mathbf{1 7 0}\end{array}$

$\begin{array}{lll}\text { APPENDIX A } & \text { STRUCTURAL DAMAGE METHODS }\end{array}$

\section{APPENDIX B NATURAL FREQUENCIES FROM FINITE ELEMENT}

MODAL ANALYSIS $\quad 183$

VITA

184 


\section{LIST OF TABLES}

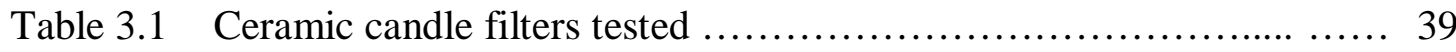

Table 3.2 Natural frequencies (Hertz) of new ceramic candle filter........... 40

Table 3.3 Natural frequencies of used Schumacher TF-20 filters .............. 40

Table 3.4 Frequency values (Hertz) used Refractron 326 filters .............. 41

Table 3.5 Frequency values (Hertz) of used Refractron 442T and Coors

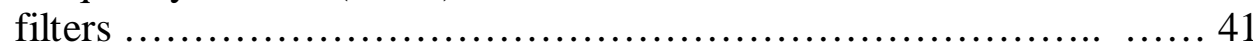

Table 3.6 Flexural mode frequencies in undamaged/damaged aluminum

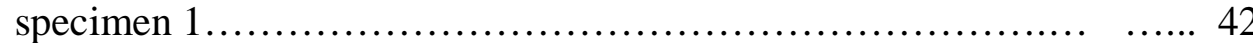

Table 3.7 Flexural mode frequencies in undamaged/damaged aluminum

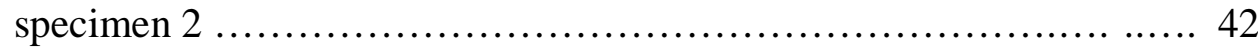

Table 3.8 Experimental and FEM natural frequencies for undamaged/damaged trials ................................... 43

Table 3.9 Comparison of dusted and clean used filters ...................... 44

Table 4.1 Dimensionless frequency $(\gamma)$ of Bernoulli-Euler beam with

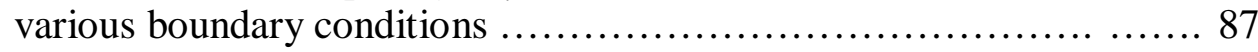

Table 4.2 Free-free experimental frequencies using laser vibrometer and accelerometer ................................................... 87

Table 4.3 Fixed-free experimental frequencies using laser vibrometer and

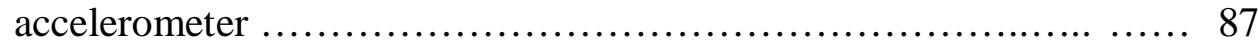

Table 4.4 Natural frequencies for free-free tests on X1 and X2 axes ............ 88

Table 4.5 Vibration frequencies of fixed-free test (X1 and $\mathrm{X} 2$ axis) for a Pall 442T filter 88

Table 4.6 Young's modulus comparison between fixed-free and free-free tests

Table 5.1 Thermal properties of Pall 326, Pall 442T and Schumacher TF20 (Spain and Starret 1999) 
Table 5.2 Natural frequencies (Hertz) of a Sch TF20 filter at different temperatures ................................................... 121

Table 5.3 Natural frequencies (Hertz) of a Pall 326 filter at different temperatures ................................................. 121

Table 5.4 Natural frequencies (Hertz) of two ceramic candle filter at

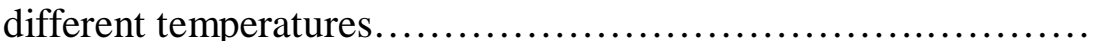

Table 5.5 Sch TF20 natural frequencies (Hertz) using FEM's steady-state

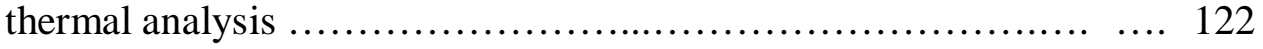

Table 5.6 Pall 326 natural frequencies (Hertz) using FEM's steady-state

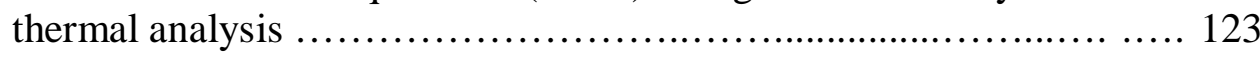

Table B.1 FEM natural frequencies $(\mathrm{Hz})$ for the Schumacher TF-20 mode

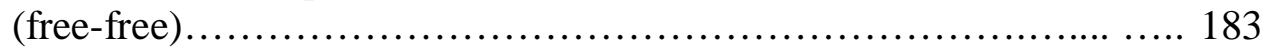

Table B.2 FEM natural frequencies (Hz) for the Pall 326 model (free-free) ........ 183 


\section{LIST OF FIGURES}

Figure 2.1 Westinghouse Barrier Filter - Hot Gas Cleaning System (Galloway and Hendrix 1997, with re-sketch)

Figure $3.1 \quad$ Free-free boundary condition experimental set up $\ldots \ldots \ldots \ldots \ldots \ldots \ldots . \ldots 4$

Figure 3.2 Scheme of candle filter's nondestructive evaluation procedures ... ... 46

Figure $3.3 \quad$ Finite element model of ceramic candle filter .................... 47

Figure 3.4 Natural frequencies of the SCH TF-20 group compared with the theoretical and FEM results .................................... 48

Figure 3.5 Modes shapes comparison of a typical new Sch TF20 filter with the FEM results

Figure 3.5 Modes shapes comparison of a typical new Sch TF20 filter with the FEM results (continued)

Figure 3.6 Mode shapes comparison between new and 982 exposure hour of a typical Sch filter

Figure 3.6 Mode shapes comparison between new and 982 exposure hour of a typical Sch 2 filter (continued) 52

Figure 3.7 Young's modulus of new ceramic filters $\ldots \ldots \ldots \ldots \ldots \ldots \ldots \ldots \ldots \ldots . \ldots 3$

Figure 3.8 Young's modulus deterioration of SchTF-20 filters............... 54

Figure 3.9 Young's modulus deterioration of not traced Sch TF-20 filters (Previous Studies data from Chen and Kiriakidis 2000).

Figure 3.10 Young's modulus of new and used Refractron 326-A filters (Previous Studies data from Chen and Kiriakidis 2000) 56

Figure 3.11 Young's modulus of new and used Refractron 326-\# filters (Previous Studies data from Chen and Kiriakidis 2000) 57

Figure 3.12 Young's modulus of new and used Refractron 442T filters (Previous Studies data from Chen and Kiriakidis 2000) 58

Figure 3.13 Young's modulus of new and used Coors P-100A-1 filters (Previous Studies data from Chen and Kiriakidis 2001). 
Figure 3.14 Damage location of Pall 2-24A Filter........................... 60

Figure 3.14 Damage location of Pall 2-24A Filter (continued) .................. 61

Figure 3.15 FEM simulations and experimental mode shapes used for

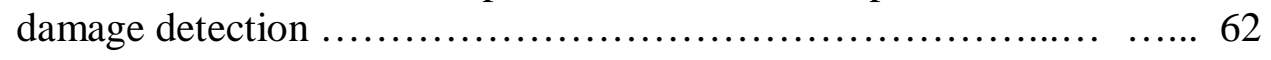

Figure 3.16 Damaged aluminum pipes ............................... ..... 63

Figure 3.17 Mode shapes comparison between undamaged and two damaged

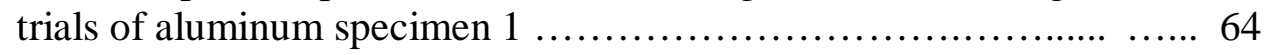

Figure 3.17 Mode shapes comparison between undamaged and two damaged trials of aluminum specimen 1 (continued) ...................... 65

Figure 3.17 Mode shapes comparison between undamaged and two damaged trials of aluminum specimen 1 (continued) .......................66 66

Figure 3.18 Strain-Energy difference in mode 3 for aluminum specimen $1 \ldots . \ldots \ldots 67$

Figure 3.18 Strain-Energy difference in mode 3 for aluminum specimen 1

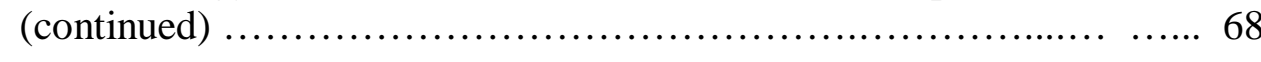

Figure 3.19 Averaged Young's modulus deterioration of ceramic candle filter ..... 69

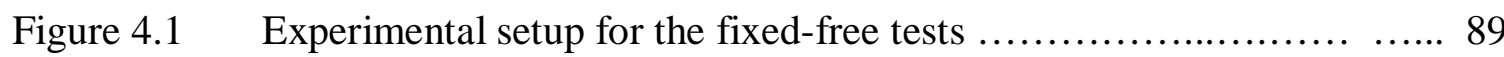

Figure $4.2 \quad$ Modified candle filter mounting-head .......................... 90

Figure 4.3 Tenth point of contact and non-contact tests of fixed-free 335I-

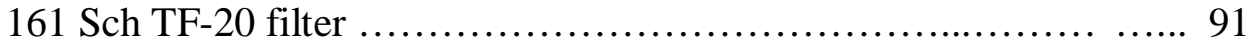

Figure 4.4 Boundary Controllability of a vibrating Timoshenko beam

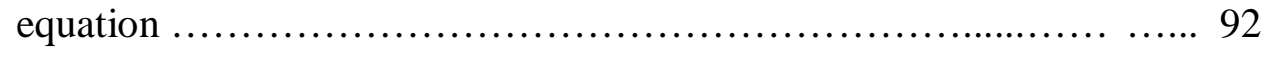

Figure $4.5 \quad$ Boundary condition setup of FEM model $\ldots \ldots \ldots \ldots \ldots \ldots \ldots \ldots \ldots \ldots$

Figure 4.6 Natural frequencies difference between Timoshenko beam and Bernoulli-Euler due to dimensionless rotational spring, $\mathrm{K}^{\wedge}$ and

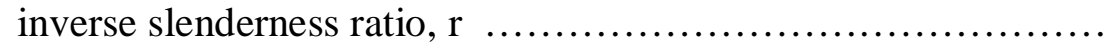

Figure 4.7 Experimental and FEM mode shapes of 2-1355 Pall 326 filter (fixed-free condition) 95

Figure 4.8 Typical mode shapes from FEM simulations with different $\mathrm{K}^{\wedge}$ values 96 
Figure 4.9 Analytical and FEM frequency ratios vs. different $\mathrm{K}^{\wedge}$ values for Sch TF-20, Pall 326, and Pall 442T 97

Figure 4.10 Analytical and FEM $b$ results vs. various $\mathrm{K}^{\wedge}$ values for Sch TF20, Pall 326, and Pall 442T 98

Figure 4.11 Experimental f3/f2 and $\mathrm{K}^{\wedge}$ values for Sch TF-20, Pall 326 and 442T filters using FEM curve

Figure 4.12 Experimental $\mathrm{K}^{\wedge}$ and $b$ values for Sch TF-20, Pall 326 and 442T filters using FEM curve 100

Figure 4.13 Experimental f3/f2 and $\mathrm{K}^{\wedge}$ values for the Sch F-40 filter using FEM curve

Figure 4.14 Experimental $\mathrm{K}^{\wedge}$ and $\mathrm{b}$ values for the Sch F-40 filter using FEM curve

Figure 5.1 Test setup for the thermal and fatigue tests. Picture notation: 1) Ceramic Candle Filter, 2) Heating Panels, 3) Laser Vibrometer, 4) Signal Conditioners, 5) Spectrum Analyzer - SRS 785, 6) Oscilloscope, 7) Shaking Table. 124

Figure 5.2 Test setup for the dynamic damage procedure 125

Figure 5.3 SDOF system exited by harmonic base motion .... 126

Figure 5.4 Percentage frequency shift along the first six flexural modes ..... ..... 127

Figure 5.5 FEM temperature distribution for the Pall 326 model at 0.5-sec 128

Figure 5.6 Pall 326 temperature distribution time history along the thickness - back pulse temperature $70^{\circ} \mathrm{F}$ (PIP from Alvin 1999)

Figure 5.7 Schumacher TF-20 temperature distribution time history along the thickness - back pulse temperature $70^{\circ} \mathrm{F}$

Figure 5.8 Maximum principal stresses (psi) of the Pall 326 FEM model after 0.5 -sec of the back pulse

Figure 5.9 Thermal stresses of the Pall 326 model - back pulse temperature $70^{\circ} \mathrm{F}$

Figure 5.10 Thermal stresses distribution of the Sch TF20 model - back pulse temperature $70^{\circ} \mathrm{F}$ 
Figure 5.11 Pall 326 temperature distribution time history along the thickness

- back pulse temperature $400^{\circ} \mathrm{F}$....

Figure 5.12 Sch TF-20 temperature distribution time history along the thickness - back pulse temperature $400^{\circ} \mathrm{F}$

Figure 5.13 Thermal stresses of the Pall 326 model - back pulse temperature $400^{\circ} \mathrm{F}$

Figure 5.14 Thermal stresses distribution of the Sch TF20 model - back pulse temperature $400^{\circ} \mathrm{F}$

Figure 5.15 Frequency response curve for the Sch TF20 326I-147 ............... 138

Figure 5.16 Frequency response curve for the Sch TF20 335I-159 ................ 139

Figure 5.16 Frequency response curve for the Sch TF20 379H-129 (continued)

Figure 5.16 Frequency response curve for the Sch TF20 335I-173

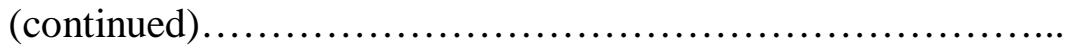

Figure 5.17 Stress / number of cycles $(\mathrm{S} / \mathrm{N})$ curve for four Schumacher TF20 filters

Figure 5.18 Frequency response curve for the Pall 326 5-1365

Figure 5.18 Frequency response curve for the Pall 326 2-1355

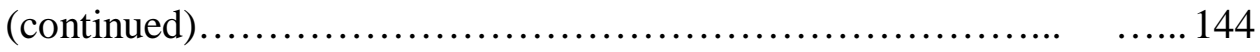

Figure 5.19 S/N curve for two Pall 326 filters.............................. 145

Figure 5.20 Fatigue fracture profile of four Sch-TF20 filters .................... 146

Figure 5.21 Fatigue fracture profile of two Pall 326 filters ....................... 147

Figure $6.1 \quad$ Weibull Hazard functions..................................... 157

Figure 6.2 Percentage deterioration of Sch TF-20 filters with respect to exposure hours............................................ 158

Figure 6.3 Deterioration of Pall 326 \#-Series filters with respect to exposure hours 
Figure 6.4 Deterioration of Pall 326 A-Series filters with respect to exposure hours................................................ 160

Figure 6.5 Deterioration of Pall 442T filters with respect to exposure hours...................................................... 161

Figure 6.6 Reliability of Sch TF-20 filters ................................ 162

Figure 6.7 Reliability of Pall 326 \#-Series filter............................ 163

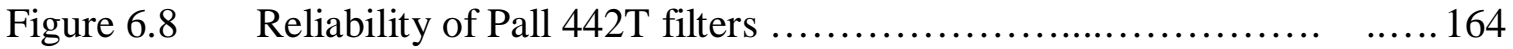




\section{CHAPTER 1}

\section{INTRODUCTION}

\subsection{GENERAL REMARKS}

To expand the utilization of U.S. coal reserves, it is necessary to develop an effective and economical coal-fired power generation technology (Dahlin et al., 1998). Advanced coal-fired power generation systems use a combination of a steam turbine and a gas turbine. It is necessary to filter coal ash from high-temperature, high-pressure gas streams to protect the gas turbine from erosive damage. In general, process conditions may include temperatures up to about $1500^{\circ} \mathrm{F}$ with pressures up to about 300 -psi, and potentially corrosive components in the gas stream (Lippert et al. 1994).

The particulate removal of coal-based hot gas cleanup systems is often based on ceramic materials. In recent years a significant amount of effort has been devoted to develop damage-tolerant hot gas filter elements, which can withstand chemical, high pressure and extreme thermal cyclic loading in the coal-based environment (Alvin 1999, Dennis et al 1999; Kamiya et al. 1998; Spain and Starrett 1999). Ceramic candle filters have proven to be an effective filter for the ash laden gas streams (Lippert et al. 1994). The most common ceramic candle filters can be divided into two different types: monolithic oxide filter elements like Coors P-100A-1 filters and monolithic silicon carbide filter elements such as Pall 326, 442T and Schumacher TF20, F40 and T10-20 (Davidson 1999). Both types have worked well under the coal-based environment. Failure of these ceramic filters can be attributed to thermal stresses during transient events, excessive ash accumulation, pulse cleaning and vibration-induced stresses near the flange of the elements. Destructive and nondestructive tests have been used to 
describe physical, mechanical and thermal properties of the filters and to relate these properties and behaviors to in-service performance, and ultimately to predict the useful life of the filter materials (Chen and Kiriakidis 1999).

Nondestructive evaluation (NDE) techniques have been chosen because these techniques do not cause damage or destroy the specimen being inspected. Therefore repeated checks of a given specimen over a period of time can be made. In this way, the rate of service damage and its correlation with failure may be established clearly. A dynamic characterization technique has been used to evaluate about 150 ceramic candle filters at West Virginia University (WVU) during the past five years. Ceramic candle filters from Coors, Schumacher and Pall companies have been nondestructively inspected using contact and non-contact measurements. Free-free vibration tests have indicated that vibration frequency shifts for ceramic candle filters can be used to assess the level of degradation of the filters. These changes in frequencies are due to changes of structural properties, such as stiffness reduction, which are directly related to the safety of the structure. A modal strain energy procedure has been developed and can be used to detect a damaged section in a filter that has been exposed to some extreme coal-fired conditions.

The NDE technique developed worked successfully in determining vibration frequencies with free-free boundary condition at room temperature (Chen and Kiriakidis 1999). However, they do not correspond to the real operating conditions such as fixedfree restraint, plenum vibrations and high temperature. The mechanical properties of the ceramic candle filters under service conditions are major aspect for improving the reliability of ceramic filters. Therefore, studies are needed to determine the effect of actual in-situ conditions on the filter natural frequencies and boundary conditions. 
Nondestructive methods for in-situ testing of ceramic candle filters do not exist, but are needed for a quick and inexpensive test on the filter elements. Besides studies on the filters' degradation with respect to exposure time, investigations on others factors that may increase ceramic filter failure are needed. Thermal stresses due to temperature shift during back pulse cleaning and fatigue due to cyclic loading during regular operational conditions are important factors need to be investigated.

This report is focused on the development and application of a nondestructive evaluation technique to inspect new and used ceramic candle filters and to describe the relationships between the candle's structural deterioration and exposure hours. The ceramic filters evaluated in this study have been exposed to different periods of time at the Power Systems Development Facility (PSDF) in Wilsonville, Alabama. The ceramic candle filters tested are divided into three different groups: Refractron (Pall), Schumacher (Sch) and Coors filters. Vibration frequencies and mode shapes of the candle filters at different temperatures are established using an impact-excitation technique. Vibration frequency changes due to dust cake accumulation, candle's axisymmetry, boundary conditions, and elevated temperatures are presented. Vibration fatigue stresses are also presented. Stiffness of the candle filters is calculated using the natural frequencies. The experimental natural frequencies of the candle filters were also compared with an analysis of a general Timoshenko beam equation that includes various boundary restraints.

The proposed nondestructive evaluation technique can be helpful to both the candle filter manufacturer and the end user. The NDE method can be used in the quality control of the new filters and the prediction of the filter's useful life. 


\subsection{OBJECTIVES}

The present research is focused on the development of an effective nondestructive evaluation technique (NDE) based on dynamic characterization to evaluate the relationship between changes in the vibration frequencies and remaining useful life of the ceramic candle filters. It aims at enhancing the NDE technique for inspection process during power plant annual maintenance shutdowns. The objectives of the present study are:

- Establishment of the vibration signatures of new ceramic candle filters from various manufacturers.

- Study the symmetry of the filter elements by evaluating the vibrational spectra generated along perpendicular axes of symmetry.

- Study the material property degradation of ceramic candle filters as a function of exposure time in advanced fossil fuel power generation systems.

- Study of various factors involved in the establishment of the vibration signatures (i.e. dust cake, thermal stress, boundary conditions, and plenum vibrations).

- Development of an effective non-destructive evaluation technique to predict the remaining useful life of ceramic candle filters.

\subsection{SCOPE}

The scope of the present work includes the experimental, theoretical and finite element model analysis of new and used ceramic candle filters. The experimental study includes both dynamic characterization method and fatigue testing. More than 146 ceramic candle filters have been tested. These filters include new and used Coors P- 
100A-1 filters, new and used Sch filters, and new and used Pall filters. Laboratory dynamic characterization method is used to obtain the vibrational properties of the ceramic filters at different sets of exposure times from PSDF. The effect of cyclic loading forces acting on the ceramic filters during operational conditions is studied using laboratory fatigue tests. The finite element analysis is conducted using a commercially available FEM package - ALGOR (ALGOR, Inc.). FEM results, along with the results obtained from the dynamic and fatigue testing, are utilized to evaluate the remaining life of the ceramic candle filters.

\subsection{ORganizATION}

The content of this work includes 7 chapters. Chapter 1 presents the introduction of this research work and its use in nondestructive evaluation of ceramic candle filters. In addition, this chapter presents the objectives and scope of this research. Chapter 2 briefly describes ceramic candle filters and their importance in coal-fired power generation technology. It also has a comprehensive literature review summarizing previous studies accomplished by many researchers. Chapter 3 presents the structural properties of the new ceramic candle filters and the stiffness deterioration of used filters due to exposure hours. Chapter 4 focuses on the study of the boundary condition effects on the candle filter's vibration response and the dynamic response of the filters at two different axes. Chapter 5 assesses the temperature and vibration fatigue parameters that affecting filter element deterioration. Chapter 6 describes the remaining life assessment of used ceramic candle filters trough the application of system identification techniques using various 
damage factors input and measured response data. Chapter 7 presents conclusions and recommendations.

\subsection{Project DeSCRIPTION}

This project was conducted under DOE/NETL support, under the contract DEFG26-99FT40202. New and used ceramic candle filters from various manufacturers are used. The work performed in this study can be divided into two major tasks: a) Data synthesis and evaluation and b) Analyses. The NDE testing and analysis of 146 ceramic candle filters shipped from PSDF is presented in Chapters 3 and 4. The data synthesis and evaluation of parameters affecting the filter element deterioration, the assessment of filters from different manufactures and the dust cake effects on the vibration signatures are presented in chapter 3 . The assessment of simulated in-situ boundary conditions and the assessment of bending stiffness at different axes of symmetry are presented in Chapter 4. The fatigue and thermal stress parameters, which are factors that affect the filter element deterioration, are presented in Chapter 5. The analyses tasks are spreader through out Chapters 3, 4, and 5. The dynamic strain energy damage analysis is shown in Chapter 3. The analytical equations for Young's modulus calculation and the analysis of fixed-free boundary conditions are presented in Chapter 4. FEM analysis can be found in Chapters 3, 4, and 5. The useful life prediction of the ceramic candle filters are shown in Chapter 6. 


\section{CHAPTER 2}

\section{LITERATURE REVIEW}

\subsection{Hot GAS Filter SySTEM}

Coal based advanced power generation technology have the potential to achieve high cycle efficiencies whilst maintaining low environmental emissions. Central to these technologies is the utilization of the coal-derived gas to drive a gas turbine. Their success relies upon removal of particulates from the gas to prevent damage to the gas turbine system.

The Westinghouse Advanced Particle Filter (APF) design consists of stacked arrays of filter elements supported from a common tube-sheet structure. Each of these arrays is formed by individual candle elements attached to a common plenum section. Figure 2.1 shows a sketch of the Westinghouse candle filters system used at PSDF (Galloway and Hendrix 1997). The individual arrays are stacked vertically from a common supporting pipe, forming a filter cluster. The cluster is then supported by a high alloy tube-sheet structure with an expansion assembly that spans the pressure vessel and divides the vessel into "clean" and "dirty" gas sides. The cluster holds one plenum with 36 candles in the upper part and one plenum with 55 candles in the lower part. The cluster attaches to the tube-sheet structure by a specially designed split ring assembly. The plenum discharge pipes, ducting the filtered gas to the clean side of the tube-sheet structure, are contained within the cluster support pipe and terminated at the tube-sheet structure (Bruk et al. 1995). 
During filtration process, the dirty gas flowing inwards, along the inner clean side of the candle and out of the plenum chamber is collected in the plenum section. The clean gas is then discharged through a pipe to the clean side of the tube-sheet structure. Dust deposited on the outer candle surface during the filtration process builds up into a cake. This cake is periodically detached by a reverse pulse of gas. Typical operating conditions of this hot gas filter system at PSDF are plenum temperature up to $1500^{\circ} \mathrm{F}$ and system pressure up to 300 psi. The typical back pulse pressure is about 565 psi.

\subsection{CANDle Filters}

Effective hot gas filtration is a technology used in advanced power systems that has been studied since the late 1970's. In general, process conditions include hightemperature, high-pressure and potentially corrosive components in gas stream. High temperature particulate filters are a key component in advanced, coal gas turbine system. The filtration media are normally ceramic materials in the form of candles. Ceramic candle filters protect the gas turbine components from particle fouling and erosion effects. They have proven to be efficient filters for the ash laden gas streams, meeting particulate emission requirements (Lippert et al. 1994).

Candle filters are generally long cylinders with permeable walls, closed at one end with a cap of the same material and open at the other end. The open end is usually flanged to allow for the mounting of the candle on a header. The use of alumino silicate fibers, clay binded alumina, silicon carbide, and continuous fiber ceramic composites for candle filters were under development. The ceramic filters tested in this research study

are divided into monolithic oxide filter elements (Coors P-100A-1) and monolithic 
silicon carbide filter elements (Pall 326, Pall 442T, Sch TF20, and Sch T10-20). These filters are relatively stable at high temperatures and can operate continuously at temperatures of up to $1500^{\circ} \mathrm{F}$. They are inert to aggressive chemicals like steam and acid gases. Davidson et al. (1999) underline some of the strengths and weaknesses of each type of candle filters.

The Sch TF20 consists of a porous, clay-bonded, high temperature resistant silicon carbide structure coated with a membrane. This membrane is made of ceramicbonded aluminum oxide fibers and silicon carbide grains. The Sch T10-20 consists of the same kind of body but has a ceramic-bonded mullite membrane, which has a smoother surface and a narrow pore size distribution. The nominal length for the TF-20 and T1020 filters is 59.8in, with an outer diameter of 2.36in and inner diameter of 1.57in. The wall thickness along the length is 0.39in. For the F-40 filters, the nominal length is 59.8in, with an outer diameter of 2.36in and inner diameter of 1.18in. The wall thickens along the length is 0.59in.

Pall 326 filters are constructed of granulated silicon carbide bonded with aluminum silicate binder phase. These filters are constructed employing a fine pore surface layer over a relatively open pore substrate. Each group of filter elements has advantages and disadvantages when used in advanced coal-fired power generation system. The nominal dimensions of these filters are 59.25in long, 2.36in outer diameter and 1.57in inner diameter. The wall thickness along the length is 0.39 in.

The Coors alumina/mullite filter matrix consists principally of mullite, which coexists within an amorphous phase that also contains anorthite and corundum (Alvin 1995). These filters do not have an external membrane or coating. The nominal 
dimensions of these filters are 59.65in long, 62.37in outer diameter and 1.62in inner diameter. The wall thickness along the length is $0.37 \mathrm{in}$.

Spain and Starrett (1994) used mercury porosimetry to study the pore size of new Coors P-100A-1, Sch F40, and Pall 326 filters. The results indicate that nearly all the pores are about 10 microns or larger in diameter. In general, the open porosity of these ceramic candle filters varies between $30 \%$ and $40 \%$. Profilometry measurements were also used, showing that these candle filters are essentially straight. After being used in the demonstration plants, alumina/mullite and clay bonded silicon carbide filters have shown strength degradation and crack growth. Crack growth was found to have generally originated from the internal diameter surface implying that thermal fatigue has occurred due to the contact with cold pulse cleaning gas (Alvin et al. 1994). Breakage of these candle filters can be attributed to overheating, thermal shocks from back pulsing, and excessive pressure drop (Huynh et al. 1998). Studies have been conducted to develop more durable candle filter elements by optimizing material properties with respect to mechanical, chemical and thermal resistance (Alvin et al. 1995, Sawada et al. 1999, Lippert et al. 1999).

Alternative candle filter barriers such as fiber reinforced ceramic composite and sintered metal candle have also been studied. Wagner (1998) demonstrated a hot gas filter concept that resulted in a composite based filter with improved strength and toughness compared to monolithic filter materials. In addition, the fiber distribution resulted in a performance improvement. Sawyer and June (1997) studied physical and mechanical properties of iron aluminide filter materials. They show that heat-treated $2 \%$ chromium iron aluminide porous metal media is acceptable for use in advanced coal-fired 
power system, based on the combined strength, modulus of rupture and corrosion test results.

\subsection{NONDESTRUCTIVE EVALUATION}

Nondestructive evaluation (NDE) is a field of study for the examination of materials and structures by noninvasive means. Quantitative NDE plays an important role in the development and understanding of advanced composite materials as well as traditional materials. With NDE tests, repeated checks of a given structure over a period of time can be made. In this way, the rate of service damage and its correlation with failure can be established clearly. Some of the most commonly used NDE techniques can detect structure imperfections and presence of cracks, determine structural properties, and measure geometric characteristics. NDE has also been used to assure the safety and reliability of a product by discarding or repairing defective components.

Ceramic candle filters have been tested using different kind of NDE tests. High frequency ultrasonic tests $(>100 \mathrm{kHz})$ can not yield accurate result due to the porous nature of the ceramic material. Short wavelengths can not reliably distinguish damage in the candle filter since the size of pores and the size of the cracks are of the same order of magnitude. Low frequency testing $(<20 \mathrm{kHz})$ is much more effective in these highly attenuative ceramic materials. Large wavelengths are associated with low energy dissipation. Therefore, this wave can travel long distances. Dynamic characterization tests have been conducted to evaluate the structural integrity and the material properties of candle filters. The vibration signatures have been used to compare the candle filters' 
properties at varying degradation levels due to different operating hours (Kiriakidis 1998).

Other tests like bulk density, radiography, and spectral acoustic analysis have also been conducted to determine mechanical properties and anomalies on ceramic candle filters (Pontius and Starret 1994). The experimental results showed that the X-ray technique is a useful evaluation method for identifying anomalies of the candle filters before they have been put into service. They also found that the spectral acoustic testing was not a useful technique in detecting irregular regions in the candle filters. However a baseline set of outputs was obtained for comparison with used candle filters. Helanti et al. (1999) used scanning electron microscopy and X-ray diffraction for structural characterization of ceramic candle filters. They show that in the microscopy scale there is a material variation between different areas of a ceramic filter. The most common source of variations is the uneven distribution of binders.

\subsection{Dynamic Property Measurement Methods}

Certain properties of material can be evaluated nondestructively using dynamic testing techniques. The dynamic tests are carried out by applying a known forced vibration to a structure and observing its vibrational response. The structure can be excited using inputs such as steady state or impact forces. Dynamic characterization tests involve the measurement of either the natural frequencies of the material or the rate of vibration's attenuation of the material. The results from these tests are function of the physical configuration and composition of the specimens and can therefore be analyzed for property determinations and flaw detection purposes. 
In the impact vibration test, the structure is excited by a short duration force. The measurement of the vibration response of the structure due to this impact can be measured using contact or non-contact sensors. The responses obtained are the results of the superposition of various natural vibration modes of the structure. Impact excitation offers the advantage of quick setup time, mobility, and the ability to excite a broad range of frequencies. Precaution must be taken to avoid multiple impacts at the same time. This type of test was usually used on a small structure or structural components of a large structure. Dynamic characterization using contact measurements has been performed on ceramic candle filters. Chen and Kiriakidis (2001) used an instrumented impact hammer and an accelerometer to study the vibration behavior of ceramic candle filters. Conclusions based on these studies indicated that impact dynamic testing is a feasible NDE technique for studying structural properties of ceramic candle filters. It also indicated that the degradation of the filters due to long working hours could be reflected by a shift of vibration frequency. These changes are due to changes of structural properties such as stiffness reduction, which are directly related to the safety of the structure.

The non-contact nature of remote sensing using laser vibrometry has become useful for vibrational measurements on structures that are difficult to test with traditional accelerometers. Remote vibration technique has been applied in the testing of large civil and mechanical engineering structures. Venkatappa et al. (1999) reported a damage detection technique using a scanning laser vibrometer. The study was conducted on aluminum plates, for different damaged scenarios. They were able to experimentally determine the vibration mode shapes and identify the damages. Application of non- 
contact sensing using a laser vibrometer provides attractive features for in-situ ceramic filter evaluation, particularly when the filters are subjected to a high temperature environment. Chen et al. (1999) used a laser vibrometer to study the potentiality of noncontact vibration measurements of ceramic filter vibration as a NDE technique. They show that contact and non-contact measurements under different boundary condition were fundamentally similar in terms of frequency components.

\subsection{Finite Element Modal Analysis}

Finite Element Analysis (FEA) is a numerical technique for solving engineering problems like strength and behavior of structures. It can be used to calculate deflection, stress, vibration, and many other phenomena. It has been used to analyze problems involving either small or large-scale structures under loading or applied displacement. In the finite element model, a structure is discretized into many small simple elements. Each element behavior can be described with a set of equations. In order to describe the behavior of the whole structure, the algebraic equations for each individual element are combined to obtain the solution of the entire body. Due to the improvement of computers, FEM has now become an important structural analysis and design tool.

Jaleel and Sundararajan (1993) developed a plane strain finite-element model to study the elastic propagation and scattering of waves in general anisotropic media. They conclude that simulation can play an important role in understanding the wave propagation phenomenon, and help in the planning of NDE experiments in such complicated media as orthotropic plates. Chen et al. (1995) used a finite element model to investigate the changes in modal properties due to damages on a simple steel structure. 
The results show that the correlation between the numerically obtained modal properties and the experimentally determined properties was good. Chen and Kiriakidis (2000) used strain energy damage detection on used ceramic candle filters based on FEM analysis and vibration test data. The strain energy damage detection procedure worked successfully in detecting the location and size of the damage in candle filters.

Finite element analysis has also been used to simulate the ceramic candle filters behavior during thermal operational conditions. Huque et al. (1996) performed thermal numerical simulations on candle filters. The analysis was focused on temperature distribution within filter during back pulse cleanup process. Half of the filter cut along the vertical plane of symmetry was used as the calculation domain. It was concluded that micro-cracks produced during back pulsing could be reduced by providing heated back pulse stream to reduce the temperature gradient within the filter.

Vaubert et al. (1999) developed a thermo-mechanical FEA modeling analysis on a cross-flow filter to determine the response of the filter to a series of thermal and mechanical loads. The initial temperature was assumed to be $1600^{\circ} \mathrm{F}$ for the entire filter. Thermal loading conditions were imposed to the middle layers of the model. FEA was able to determine the temperature differentials throughout the filters during back pulse simulations. Results indicate that the temperature gradient over the member was about $61^{\circ} \mathrm{F}$. Although the temperature gradient was small, the thermal stresses generated by the cold-gas pulse in alumina material were as high as $51.5 \mathrm{ksi}$. In other materials, like mullite and CS-50, the thermal stresses were 10.9 and $2.18 \mathrm{ksi}$, respectively. 


\subsection{Thermal ANd FAtigue STRESS}

The plenum vibration and back pulse cleaning expose the candle filters to thermal and cyclic mechanical fatigue stresses that may ultimately lead to fracture of the specimen. Therefore, the candle filters must have good thermal shock resistance and toughness. Alvin (1999) studied the high temperature filtration characteristics, mechanical integrity, and general operating performance of various advanced candle filters. The operation conditions were about $1500^{\circ} \mathrm{F}$ and $68 \mathrm{psig}$. Candle filters were subjected to $\sim 20,089$ accelerated pulse cycles and $\sim 79$ thermal transients in order to demonstrate the viability of various matrices to extended thermal fatigue.

Spain and Starrett (1999) measured physical, mechanical, and thermal properties of ceramic candle filters. They reported the coefficient of thermal expansion and thermal conductivity values of several candle filter materials. Kamiya et al. (1998) focused on the thermal stress fracture of rigid ceramic filters in high temperature gas clean up systems. The thermal stress of various ceramic filter elements was calculated. In some of the ceramic filters the thermal stresses exceeded the fracture strength. They conclude that the thermal stress fracture due to char combustion was the important fracture mechanism of ceramic filters.

Damage associated with cyclic loading in many ceramics is generally attributed to deterioration in grain binder that leads to microcrack formations. Gilbert et al. (2000) investigated the fracture and cyclic fatigue crack growth behavior in a reactively hotpressed monolithic ceramic with both fine and coarse-grained microstructures. They found that fatigue crack growth was associated with wear degradation at active bridging sites behind the crack tip. Alvin et al. (1995) estimated the threshold stress intensity for 
alumina/mullite and silicon carbide materials using a combination of dynamic and interrupted fatigue testing. The results indicate that both materials exhibit slow crack growth. At temperatures between $1400^{\circ} \mathrm{F}$ and $1600^{\circ} \mathrm{F}$, the alumina/mullite material shows a large change in susceptibility to slow crack growth, while the silicon carbide material shows a small change in susceptibility.

\subsection{Theoretical Beam ANaLysis}

While the experimental techniques for vibration testing are well developed (Ewins 1985), the interpretation of the measurement to derive, analyze and solve applied mathematical models of complex structures is far from being unique. The principle of using a vibration technique for measuring structural deterioration relies on the fact that dynamic response can be a sensitive indicator of the structural properties. The natural vibration modes are constituted basically by modal frequencies and mode shapes, which depend on the structural mass and stiffness characteristics. Mathematical models for flexural vibrations, which consider the structural mass and stiffness, are based on beam theories. The simplest and best known beam models are the Bernoulli-Euler beam, also called classical beam theory, and the Timoshenko Beam theory. The assumptions for these beam models are that the displacement, slope and curvature of the beam are small.

The Timoshenko model improves upon the classical beam theory by including the first-order shear deformation effects. The effect of rotary inertia and shear deformation on the first mode of vibration is small, but increases rapidly for the second and higher modes (Chen and Kiriakidis 2001). Besides these effects in frequency domain, in time domain Timoshenko beam theory has a hyperbolic character opposite to the parabolic 
character in the Bernoulli-Euler theory, resulting in two wave fronts in a transient loaded beam (Schanz and Antes 1999).

An especially important aspect in dynamic analysis of structures is the prediction of natural frequencies and mode shapes. Frequency equations and normal modes of free flexural vibrations of finite beams including the effect of shear and rotary inertia for various cases of boundary conditions have been studied. Huang (1961) obtained frequency equations for six common types of simple, finite beams. The solutions were obtained for two complete differential equations considering homogeneous boundary conditions. Littman and Taylor (1992) introduced a technique that involves the boundary controllability of a vibrating Timoshenko beam with physical characteristic that varied along the length of the beam. They controlled the boundary condition at one end by using a torque/transverse force.

The application of Timoshenko beam solutions to transient response of structures as well as free and forced vibrations have been implemented in the evaluation of the dynamic properties of engineering structures. Usually these studies concern simple structures where the theoretical model can provide a good description of the experimental circumstances. Venkatesh (1990) used two different simplified analytical models (beams on an elastic foundation with various boundary conditions) to relate the vibration frequencies resulting from experimental investigations on post-tensioned rods in stressed timber systems.

The frequency equations of the beam theories show that changes in stiffness and/or mass will result in changes of natural frequencies for a specific structure. Defects and deterioration in a structure are characterized by the reduction in stiffness, which is 
usually much greater than the influence from changes in the structure mass. Therefore, the change in natural frequency is directly related to structural damage. Hearn and Testa (1991) used a sensitivity analysis to relate damages in a structure to the changes of natural frequencies. This method was found to be suitable where damage affects a single member of a skeletal structure, but not for structures with plates or shell elements where the vibration responses are affected by geometrical parameters.

\subsection{Reliability of USEd Ceramic Candle Filters}

The mechanical properties of the ceramic candle filters under service conditions are a major aspect in determining the reliability of ceramic filters. Hence, it is desirable to evaluate the damage state of used ceramic candle filters exposed to advanced power generation system conditions. With such a measure of the structural damage, the safety of a specific candle filter can be assessed and appropriate decisions regarding the specimen replacement can be made. When the candle filter is inspected for the purpose of assessing damage, a sequence of tests can be conducted to estimate its mechanical properties and dynamic characteristics. System identification techniques have been widely used in civil engineering to identify various characteristics of different structures (Yao 1985). The primary objective of applying system identification in structural engineering is to obtain a mathematical or analytical model that can best represent the characteristics of the structure.

The properties of structural elements subjected to external forces will not necessarily remain the same as when the structure was new. It has been found that when a structure undergoes various degrees of damage, certain dynamic characteristics change. 
Wang et al. (1975) performed tests on a reinforced concrete shear wall under reverse loading conditions to estimate the fundamental natural frequency. Results indicate that the frequency decreases monotonically with damage while the damping ratio increases initially and then decreases. Chen (1980) develops simple methods for identification of degrading structural characteristics and their changes due to destructive excitation. Results show that the fundamental natural frequency and the maximum plastic deformation are important indicators for dynamic damage of structures. 


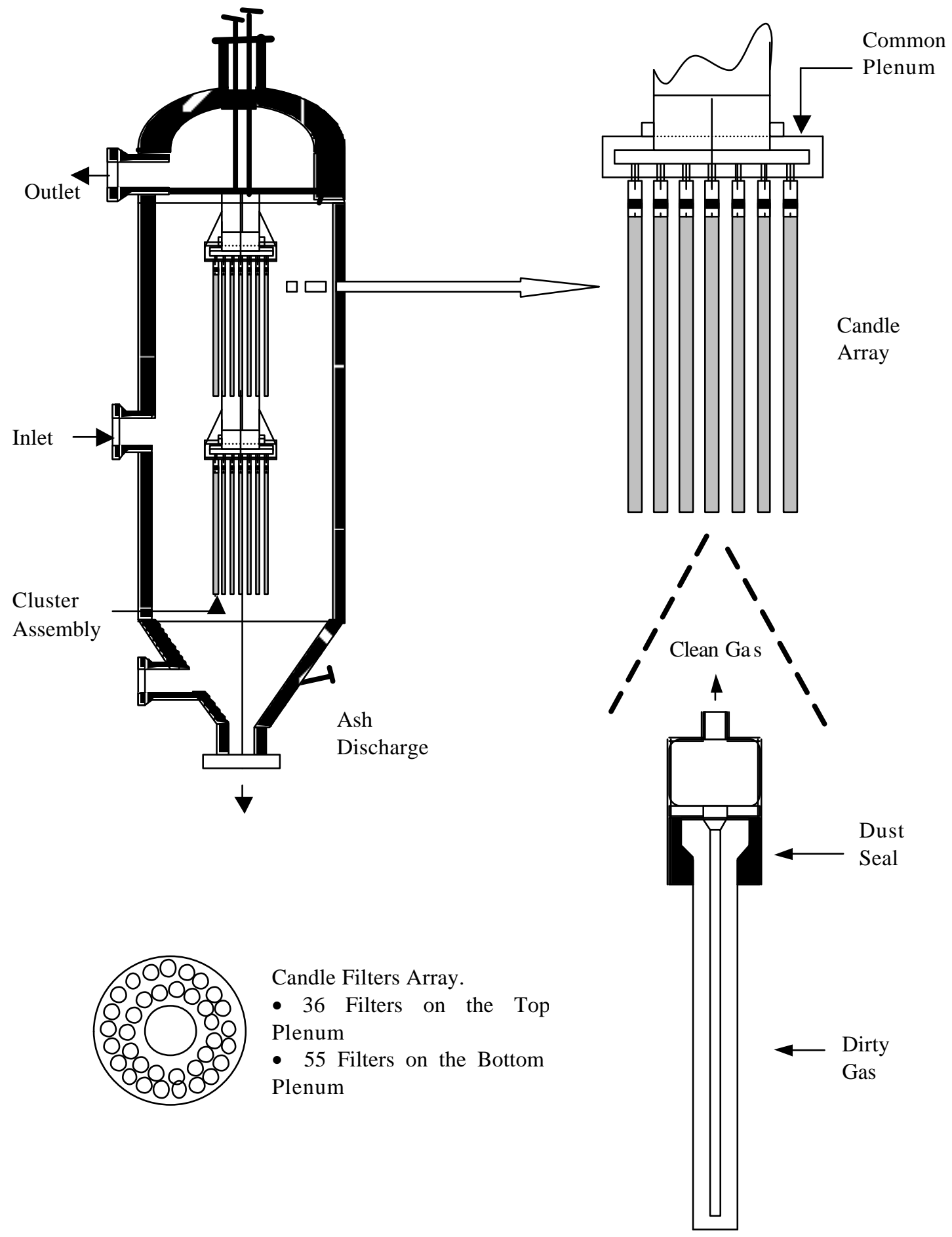

Figure 2.1 Westinghouse Barrier Filter - Hot Gas Cleaning System (Galloway and Hendrix 1997, with re-sketch). 


\section{CHAPTER 3}

\section{STRUCTURAL PROPERTIES AND DETERIORATION OF NEW AND USED CERAMIC CANDLE FILTERS}

\subsection{INTRODUCTION}

This chapter presents a nondestructive evaluation method for identifying the structural stiffness of ceramic candle filters. Forty-six ceramic candle filters have been tested nondestructively using a dynamic characterization technique. They are divided in Pall, Schumacher and Coors filters. Twenty-eight of these filters were used having various in-service exposure times at the PSDF. The stiffness degradation of the filters due to exposure time is described in this chapter. The effect of dust-cake accumulation on the filter specimens is also presented in this chapter. The results of the filters tested in this research are compiled together with the results of more than 90 ceramic candle filters previously tested nondestructively at WVU.

All filters are tested under simulated free-free boundary conditions. The frequency response function and vibration mode shapes of each filter were obtained. Beam vibration equations and FEM under free-free restraint were formulated. Experimental, theoretical and FEM dynamic characterization were used to obtain the stiffness of the candle filters. The results show a trend of stiffness degradation in the used filters, which is related to the filter's exposure time. This stiffness degradation of a filter can be successfully determined by its dynamic response. 


\subsection{EXPERIMENTS}

The experimental setup for the nondestructive testing of ceramic candle filters consisted of excitation, sensing, and signal analysis Figure 3.1. The filter was supported by elastic strings hanging from a rigid support. Since the filter was suspended using elastic strings, free-free end conditions of the filter were assumed. Excitation of the filter was performed using an instrumented impact hammer. Each impact forcing function was recorded. The impact blow was performed as normal to the filter surface as possible. Plastic hammer tips were used in this study. A typical impact forcing function is similar to a mono peak Hanning function with impact duration of about 2-msec. Hammer blows were given at ten impact locations, beginning at one-tenth from the filter head and following every $\mathrm{L} / 10$ until reaching the bottom (L) of the filter.

Table 3.1 list the filters tested with their respective exposure times. Some of these filters were tested on more than one occasion to study different factors that affect the vibration behavior of the filter. All the filters were tested with free-free boundary conditions. The additional tests performed on some of the filters are listed in the same table.

The testing procedure is summarized in Figure 3.2. The vibration response of the filter was measured at the $0.55 \mathrm{~L}$ location using a piezoelectric accelerometer. To check the repeatability, impact at each impact location was conducted three times. Details of similar experimental procedures can be found in Kiriakidis (1998). The time domain waveforms from both impact and acceleration responses were processed using signal processing software. Fourier Transform was performed on the signals to get the Frequency Response Function (FRF). The FRF was obtained from the imaginary part of 
the transfer function, which is the ratio between the dynamic response and the excitation force.

Typical FRFs of a ceramic candle filter with free-free boundary condition have a frequency range up to $4000 \mathrm{~Hz}$ with a frequency resolution of $1.36 \mathrm{~Hz}$. The FRF plots show various peaks that correspond to the modal frequencies at each mode of vibration. The first five flexural vibration modes were analyzed in detail. From the FRF plots at each impact location, the frequency and amplitude values at each peak were collected and the mode shapes were constructed.

\subsection{TheORETICAL ANALYSIS}

Fundamental beam vibration equations were used to analyze the modal frequencies and mode shapes obtained from experiments. The candle filters were assumed to be isotropic and homogeneous. This simplification allowed us to understand the vibration behavior of the candle filter in an average sense. The transverse vibration of a beam is analyzed assuming free-free boundary conditions. The solution of the Timoshenko beam equation for free-free boundary (for details, refer to Chapter 4) conditions can be expressed as:

$$
\operatorname{det}=1-\operatorname{Cosh}(b \alpha) \operatorname{Cos}(b \beta)+\frac{1}{2}\left(\left(\alpha^{2}-\beta^{2}\right) / \alpha \beta\right) \operatorname{Sinh}(b \alpha) \operatorname{Sin}(b \beta)=0
$$

By neglecting the rotary inertia and shear effect from Equation (3.1), the Bernoulli-Euler (B-E) beam vibration frequencies, $\omega$, can be shown as 


$$
\omega_{n}=C_{n} \sqrt{\frac{E I}{m L^{4}}}
$$

where $\mathrm{C}_{\mathrm{n}}$ is a frequency parameter that depends on $n$-natural frequency and boundary restraint. $\mathrm{E}$ and $\mathrm{m}$ are the candle filter's Young's modulus and mass per unit length, respectively. I is the moment of inertia of the filter's cross-section and $\mathrm{L}$ is the length of the candle filter. The mode shapes for the free-free boundary conditions can be calculated as follows

$$
\phi_{n}(x)=\cosh \left(a_{n} x\right)+\cos \left(a_{n} x\right)-\frac{\cosh \left(a_{n} L\right)-\cos \left(a_{n} L\right)}{\sinh \left(a_{n} L\right)-\sin \left(a_{n} L\right)}\left(\sinh \left(a_{n} x\right)+\sin \left(a_{n} x\right)\right)
$$

with $a_{\mathrm{n}}$ being the solution of $\cos \left(a_{n} L\right) * \cosh \left(a_{n} L\right)=1$

The modal assurance criterion (MAC) is used to compare the correlation between two mode shapes. The MAC value provides a measure of the difference between the two sets of mode shapes. The MAC takes value from 0 to 1 , where a value of 1 indicates identical mode shapes. The MAC that compares two mode shapes, $\varphi_{\mathrm{a}}$ and $\varphi_{\mathrm{b}}$ is

$$
\operatorname{MAC}\left(\varphi_{\mathrm{a}} \varphi_{\mathrm{b}}\right)=\frac{\left|\left(\varphi_{\mathrm{a}}\right)_{\mathrm{k}}\left(\varphi_{\mathrm{b}}\right)_{\mathrm{k}}\right|^{2}}{\left(\varphi_{\mathrm{a}}\right)_{\mathrm{k}}^{\mathrm{T}}\left(\varphi_{\mathrm{a}}\right)_{\mathrm{k}}\left(\varphi_{\mathrm{b}}\right)_{\mathrm{k}}^{\mathrm{T}}\left(\varphi_{\mathrm{b}}\right)_{\mathrm{k}}}
$$

where $\left(\varphi_{b}\right)_{k}$ is the vector of the $k^{\text {th }}$ mode shape in a set of mode shapes $\left(\varphi_{a}\right)$, and $\left(\varphi_{b}\right)_{k}$ is the vector of the $\mathrm{k}^{\text {th }}$ mode shape in a set of mode shapes $\left(\varphi_{\mathrm{b}}\right)$. 


\subsubsection{Localized Damage Detection}

The damage detection algorithm used in this study is based on the dynamic modal strain energy measured under free-free boundary conditions used by Chen and Kiriakidis (2000). A localized damage in the ceramic candle filter introduces a local stiffness reduction, which is directly related to the curvature of the mode shapes. Hence, the measured mode shapes and their curvatures are used to perform damage detection.

The strain energy distribution on a whole candle filter is calculated as the superposition of the strain energy of discrete segments. The dynamic strain energy (U), which involves the multiplication of the squares of the modal curvatures (second derivative of the mode shape, $\left.\varphi^{\prime \prime}\right)$ is expressed as:

$$
\mathrm{U}_{\mathrm{ab}}(\mathrm{x})=\frac{1}{2} \int_{\mathrm{a}(\mathrm{x})}^{\mathrm{b}(\mathrm{x})} \operatorname{EI}\left(\varphi^{\prime \prime}(\xi)\right)^{2} \mathrm{~d} \xi
$$

The strain energy distribution along the structure is defined in a segment between two finite locations $a(x)$ and $b(x)$. A constant segment length between $a(x)$ and $b(x)$ was chosen to calculate strain energy. The segment length is $1 / 30$ of the entire candle length. The strain energy distribution on the whole span is calculated as the superposition of each segment.

A plot of these strain energy values with respect to span location gives the strain energy distribution for the particular mode. The same parameter can be determined for undamaged and damaged structures. Defining the strain energy distribution for 
undamaged and damaged specimens as $\mathrm{U}^{0}$ and $\mathrm{U}^{\mathrm{d}}$, the strain energy difference is calculated as

$$
\Delta \mathrm{U}=\mathrm{U}^{\mathrm{d}}-\mathrm{U}^{\mathrm{o}}
$$

\subsection{Finite Element ANALYSIS}

In order to consider the complex geometry of the candle filter and its threedimensional behavior, analyses using finite element method (FEM) were conducted. Finite element models were built for each specimen type (ALGOR user's manual) to simulate the free vibration response. Linear elastic modal analysis was performed. Eight-node, three-dimensional isotropic solid elements were used. The created elements are distributed uniformly along the 3-D structure. The geometry used in each model was obtained using the nominal dimensions of each type of filter. Figure 3.3 shows a typical ceramic candle filter FEM model. The material properties such as Young's modulus, Poisson's ratio and weight density were given as input to the program, while the damping was neglected. FEM analysis was conducted using free-free support constraints. The details of the FEM models will be discussed in the Results section.

\subsection{Results}

\subsubsection{Natural Frequencies}

The experimentally measured natural frequencies and mode shapes of the ceramic candle filters were used to evaluate the material properties of the candle filters. The selfweight of each candle filter was measured to calculate the mass density of the filter. 
Nominal dimensions of the filter were used to estimate the total volume and cross sectional properties.

Figure 3.4 shows the natural frequencies of the SCH TF-20 group compared with the FEM results. The experimental frequencies and FEM simulation are within 1\% in each of the first eight bending modes. The experimental natural frequencies are also compared with the results from Equations 3.1 and 3.2. It is shown that the frequency results from both equations are equal in the first few modes when the shear effect is less significant. The progressive frequency shift along the vibration modes from these equations confirms the influence of the rotary and shear effects. The frequency difference between the experimental and the Timoshenko results, in the higher modes, is large when the nominal length (L) of the candle filters is used in both theoretical equations. Therefore an effective length $\left(\mathrm{L}_{\mathrm{eff}}=\right.$ volume $/$ area $)$ that considers the change of the candle filter's cross-section at the ends is used. The Timoshenko frequencies using $\mathrm{L}_{\text {eff }}$ compare better with the experimental results than when the $\mathrm{L}$ dimension is used. The maximum percentage difference is about $1 \%$ and $5 \%$, respectively. Similar behavior is seen for all the filter groups.

Table 3.2 shows the natural frequencies of the new ceramic filters tested. It is noticed that similarities exist between the natural frequencies of ceramic candle filters from same group. New Refractron candle filters have higher natural frequencies than Schumacher filters.

Table 3.3 lists the natural frequencies of six used Schumacher filters. The frequencies of first 4 filters are compared with the frequency values of the same filters obtained when they were new (Chen and Kiriakidis 2001). The next 2 filters are 
compared with filter $379 \mathrm{H}-129$ from Table 3.2 and the last filter (i326-081) is compared with filter i326-147. It is noticed that all filters present a progressive reduction of their natural frequency with respect to exposure time. Table 3.4 shows the natural frequency of 17 used Pall 326 filters with different exposure hours. The last 4 filters in this Table were exposed to different serviceability conditions (Pinion Pine power plant environment). These filters have been used, but the exposure time is not known. Table 3.5 shows the natural frequencies of 3 used Pall $442 \mathrm{~T}$ and 2 used Coors filters with different exposure hours. Filters from Tables 3.4 and 3.5 have not been tested previously (at new conditions). Therefore their deterioration will be estimated by comparing their frequency values with the results from previous studies of new candle filters in the similar groups (Chen and Kiriakidis 2001).

\subsubsection{Mode shapes}

The experimental mode shapes are compared with the mode shapes obtained from Equation 3.3 and FEM simulations. The experimental and FEM mode shapes data points are collected along a longitudinal axis. For the purpose of comparison, the three sets of mode shapes are normalized at the same location (point of maximum amplitude), depending on the vibrational mode studied. The correlation between the sets of mode shapes from each vibration mode is obtained from Equation 3.4.

Figure 3.5 shows the first four bending mode shapes with MAC values of a typical Sch TF20 filter in comparison with the FEM results. For the purpose of comparison, both the experimental and FEM mode shapes were normalized at the same location. The MAC values were greater than 0.998 for each mode. For the new filters, 
the average MAC values are greater than 0.996 for the first four vibration modes studied. For the used filters, the FEM modeling is conducted assuming homogeneous deterioration of the candle filters properties. Same result is obtained for the vibration mode shapes of the used filters. The first four bending mode shapes of this filter specimen (new and after $982 \mathrm{hrs)} \mathrm{were} \mathrm{plotted} \mathrm{in} \mathrm{Figure} \mathrm{3.6.} \mathrm{The} \mathrm{mode} \mathrm{shapes} \mathrm{between}$ new and after 982 hours were very close, the Mac values were 0.999 for all the modes.

Therefore under normal operational environment at the PSDF the filters show uniform deterioration along the entire length. The FEM mode shapes matched well with the experiments, verifying the accuracy of the current dynamic characterization technique.

\subsubsection{Stiffness of New Filters}

Finite element analysis is used to calculate the overall bending stiffness in terms of Young's modulus values assuming a constant mass density and Poisson's ratio. The experimental frequency values are compared to the FEM results at each vibration mode for the refinement of Young's modulus values. Following this procedure, the Young's Modulus of each candle filter is calculated using its vibration frequencies.

Figure 3.7 shows a scatter plot of the Young's Modulus obtained for each new ceramic candle filter tested. The E values of the Pall 326 (A series) vary from 6.42 Mpsi to $8.18 \mathrm{Mpsi}$, with an average of 7.40 Mpsi. Pall 442T group has the highest averaged E value (8.08 Mpsi) of all the groups tested. The E values of this group vary from 7.60 Mpsi to $8.90 \mathrm{Mpsi}$. For the Sch TF-20, the highest E value is $7.03 \mathrm{Mpsi}$ and the lowest value is $5.82 \mathrm{Mpsi}$, with an averaged Young's modulus of about 6.23 Mpsi. For the 
Coors alumina/mullite, E values vary from 4.08 Mpsi to $4.44 \mathrm{Mpsi}$, with an average of 4.26 Mpsi. Both Pall groups have higher averaged E value than Sch, which in turn is higher than Coors. It is also noted that the distribution of Young's modulus values for the Coors filters are narrow while the Sch and both Pall groups are disperse reflecting the filter variation among these ceramic candle filters. It should be noted that the Young's modulus value obtained is just an averaged property of the entire candle filter, which can only be used as an index of the candle filter's overall stiffness.

The Young's modulus values published by the filter's manufacturers and other researchers using destructive tests are also shown in Figure 3.7. Hendrix (1998) reported the data from Schumacher (SUT), Southern Research Institute (SRI) and Coors. For example, a general E value of Sch TF20 filter is about 5.7 Mpsi to 6.5 Mpsi (by Sch), Coors filter is about 4.3 Mpsi (by SRI) or $4.7 \mathrm{Mpsi}$ (by Coors) and Refractron filter is about 5.7 Mpsi (by SRI). The destructive tests were conducted on different samples than those evaluated in this study. The current filter specimens were sent to PSDF and were traced using NDE to understand their performance in HTHP conditions. The advantage of nondestructive evaluation has an obvious benefit for both the filter manufacturer and the user.

\subsubsection{Stiffness Degradation}

The Young's modulus of the used filters was evaluated using the same procedure as for the new filters. The vibration results for some filters were obtained when the filters were new and again after being used for different periods of time. For other filters that were not tested in their new conditions, the stiffness results were compared with the 
average result of new filters of the same kind. Uniform reduction of the frequency values among the vibration modes indicates uniform stiffness degradation along the filter length.

Figure 3.8 shows the frequency difference of ten Schumacher TF-20 filters. The four Sch filters of the current study have been tested new and after two different exposure time (Chen and Kiriakidis 2000). The stiffness reductions for filters H04 and H07 after 500hr are about $5.6 \%$ and $4.8 \%$, respectively. After filter H04 was exposed for an additional $734 \mathrm{hr}$ and filter $\mathrm{H} 07$ for $2150 \mathrm{hr}$, the reductions of stiffness are an extra $14.4 \%$ and $5.37 \%$, respectively. The stiffness reduction of the filter $\mathrm{H} 03$ after $1000 \mathrm{hr}$ is about $13.8 \%$, and after 1410 extra hours the stiffness decreases another $2.6 \%$. It is noted that the stiffness of the filter 344E232 increases at 500hr and then it reduces after another 2150hr. This initial increase of stiffness may be due to some temperature dependent toughening mechanism such as particle transformation.

In general, all of these filters had frequency reductions with respect to exposure time. The stiffness reduction of filters $\mathrm{H} 03$ and $\mathrm{H} 07$ follows an exponential curve pattern. In the case of filter H04, the abrupt reduction of stiffness between $500 \mathrm{hr}$ and 1234hr may be due to an unusual operation condition at the PSDF (fire Oct.98).

Figure 3.9 shows the Young's modulus of seventeen new and three used Schumacher TF20 filters. The used filters had not been tested in their new conditions. Therefore, they are compared with the average results of new filters of same kind. These used filters present a clear reduction of stiffness with respect to exposure hours. An exponential and a linear trend-line are used to simulate the pattern of deterioration of these filters. It is seen that the exponential trend-line is closer to the stiffness degradation of these filters. 
The Refractron 326 filters are divided in two different categories (A-series and \# series) due to large difference in natural frequencies observed between them. The Young's modulus values for four used Pall 326-A filters are compared with previous results from twenty-seven Pall 326 filters are shown in Figure 3.10. The deterioration of these filters may be assumed to follow a linear pattern. After about $1300 \mathrm{hr}$ the stiffness reduction is about 5.3\%. Figure 3.11 shows the Young's modulus results for 16 Pall 326\# filters. The used filters also seem to follow a linear deterioration pattern. It is noted that there are four used filters in this group that have very high stiffness when compared with the rest of the group. For the rest of the used filters, the stiffness reduction at 1200hr is about $1.6 \%$ and an extra $3.7 \%$ for $3200 \mathrm{hr}$.

The Young's moduli of 14 Pall 442T filters are shown in Figure 3.12. When linear deterioration is assumed, the $\mathrm{E}$ value of the used filters with $1240 \mathrm{hr}$ reduces about $6.1 \%$ and an extra $10.5 \%$ with $3200 \mathrm{hr}$. Figure 3.13 shows the stiffness reduction of two Coors P-100 compared with twelve new ones. The Young's moduli of these used filters drop 5.5\% after 622 exposure hours.

In general, more data points are required to confirm the statistical significance of these trends.

\subsubsection{Damage Detection}

The Refractron 2-24A filter is used to study the localized damage detection algorithm. This filter survived an unusual thermal transient accident at the PSDF. The filter's surface, still in one piece, showed no abnormal defect and no visible damage could be identified from the appearance. However, after the inspection of its vibration 
response, one can clearly see the deviation of the natural frequency values when compared with a good filter. The modal strain energy distributions of an undamaged and the 2-24A filter are used calculated to determine the damage zone in the filter.

A localized damage in the ceramic candle filter introduced a local stiffness reduction, which is directly related to the curvature of the mode shapes. Hence, the measured mode shapes and their curvatures can be used to perform the damage detection. Using Equation (3.5), the modal strain energy distribution of the damaged filter and undamaged filter was calculated first. Then, the difference of the strain energy was plotted to detect the damaged location and size. Figure 3.14 show the plot of the measured mode shapes of the damaged and the undamaged filters. Specimens 2-24A and 2-49A are two different filters.

The strain energy difference between the damaged and undamaged filter was also plotted, and a possible damage location and size was identified at the spatial location between $26 / 60 \mathrm{~L}$ to $35 / 60 \mathrm{~L}$ along the filter length. To refine the damage detection and to identify the properties of the damaged zone, three finite element filter models were used.

FEM models are constructed to study the influence of the damage location and size of damage on the candle filter's modal response. The results are also used to verify the strain energy algorithm. The FEM models were one undamaged model and two damaged models (damage case 1 and damage case 2). The damage case 1 consisted of 3390 brick elements with 4985 nodes with a damaged zone at around the mid-span. The length of the damaged section was about 8.9 in starting at 25.7 in from the closed end of the filter. The Young's modulus and weight density used in the damaged section are $40 \%$ smaller than in the undamaged zone. The damaged zone is maintained as the original 
cross section. The damage case 2 was made of 3060 brick elements with 4668 nodes. The thickness of the cross section of the damaged zone is reduced by $50 \%$. The damaged section is 5.9 in long, starting at 25.7 in from the closed end. The Young's modulus of the damaged zone is reduced by $30 \%$ and the weight density is kept constant in the entire filter.

The results from the FEM calculation are shown in Figure 3.15. The vibration mode shapes of the first and third bending modes are plotted. There is an obvious change in frequency values and mode shapes between undamaged and damaged filters. Both FEM simulation cases showed a close match of the natural frequencies with the experimental values. However, the comparison of the mode shapes showed that the damage case 1 simulation had a better match with the experimental mode shapes, as shown in Figure 3.15, especially at location between 30/60L and 40/60L. Hence, the size and properties of the damaged zone of this candle filter was estimated to be similar to the FEM model in the damage case 1.

In order to verify the damage evaluation technique described in this section two aluminum pipes were tested using the impact excitation method of nondestructive evaluation under free-free boundary conditions. The specimens were first tested in undamaged condition and then were submitted to damage and re-tested. The method of damaging the pipe was making cuts $1 / 4$ of the diameter deep ( 1.5 inch deep), transverse to the length of pipe. In both specimens the initial damage was made at one inch above the midpoint of the pipe. The specimens were tested after making one cut and then cuts covering $1 / 2$ inch, 1 inch, and 2 inches along the length of the pipe as shown in Figure 3.16. This process was performed to see if progressive increase in the damaged area 
could be detected. For multiple damages detection in one of the specimens a $1 / 2$ in long cut was also made at $1 / 4$ of the length.

In both specimens, differences could be seen between undamaged and damaged shapes of the first, third, and fifth modes as seen in Figure 3.17. The second and fourth mode shapes showed no change because their amplitudes were near zero in the area of the damage. The detection of progressive damage also seemed successful because as the specimen had more damage done to it, the difference between the undamaged and the damaged natural frequencies grew (Tables 3.6 and 3.7).

The strain-energy analysis of the mode shapes also proved to be successful. Indication of damage in the pipe would be shown if energy differences were present at the damage location. These energy differences did appear when comparing the undamaged with the damaged data from both specimens, as shown in Figure 3.18. The experimental natural frequencies match with less than $1 \%$ difference with the natural frequencies obtained with the FEM undamaged model, as shown in Table 3.8. The Young's modulus, Poisson ratio and mass density used in the FEM model were $10.1 \times 10^{6} \mathrm{psi}, 0.33$, and $0.98 \mathrm{lb} / \mathrm{in}^{3}$, respectively. Aluminum T6 6061, which is the material used for the two pipes, has the same materials properties as the FEM simulated values. The results of these experiments show promise that nondestructive evaluation could prove successful in detecting damage in specimens with tubular shapes.

\subsubsection{Dust Cake Effect}

After been used for a period of time, candle filters present ash accumulation. In order to determine its influence on the dynamic behavior of the candle filters, 12 candle 
filters were tested before and after cleaning with water. Table 3.9 shows the vibration frequencies obtained before and after the filters were cleaned. Although dust-cake does not produce any significant change $(<1 \%)$ of the specimen's weight, the vibration frequency values are always higher for the filters before cleaning than after cleaning. The percentage difference of vibration frequencies between clean and unclean varies.

Such anomalies in results are possible due to the formation of temporary, stiffer particulate layers on the walls of the ceramic candle filters when the filters were exposed to the humidity. These temporary layers are washable.

\subsection{SUMMARY}

A nondestructive evaluation technique has been developed to investigate the natural frequencies and mode shapes of new and used ceramic candle filters under freefree boundary conditions. The vibration signatures of the candle filters were used to quantify the structural stiffness and the degradation levels. Results showed that used filters have lower natural frequencies, which also indicate lower stiffness, than the new filters of their own type.

The deterioration of all ceramic candle filters due to different exposure hours is summarized in Figure 3.19. The three groups of candle filter tested can be clearly seen. After a few hundred hours of exposure, all filters groups deteriorate in a linear pattern. The maximum stiffness reduction of a Pall 326-\# and a Pall $442 \mathrm{~T}$ filter, after 3200 exposure hours is about $8.7 \%$ and $10.5 \%$, respectively, while the averaged deterioration of four Pall 326-A at $1300 \mathrm{hr}$ is about 5.3\%. For two Sch TF-20 324 filters used for more than $2600 \mathrm{hr}$, the stiffness deterioration is about $10.5 \%$, while for seven Sch F40 
$(\sim 1860 \mathrm{hr})$ and one Sch TF-20 379H ( 1350hr) the average stiffness decreased about $8.4 \%$ and $17.1 \%$, respectively. Finally, the maximum averaged stiffness reduction for two Coors P100A filters after $622 \mathrm{hr}$ is about $5.5 \%$.

The FEM models built in this study can accurately simulate the vibration response of new as well as used ceramic candle filters. A combination of mode shape and strain energy analysis worked successfully in detecting damaged zone along the filter span. The Nondestructive evaluation technique used in this study is useful for the estimation of stiffness degradation of used candle filters. It can also be used as a tool for quality control of new ceramic candle filters. 
Table 3.1 Ceramic candle filters tested.

\begin{tabular}{|c|c|c|c|c|}
\hline Filter Group & \multicolumn{2}{|c|}{ Filter \# } & Exposure Time & Test Conducted \\
\hline \multirow{6}{*}{ Schumacher } & T05-20 & $\begin{array}{l}\mathrm{H} 01, \mathrm{H} 02 \\
\mathrm{H} 03, \mathrm{H} 04 \\
\mathrm{H} 05, \mathrm{H} 07 \\
\mathrm{H} 08, \mathrm{H} 09\end{array}$ & \multirow{3}{*}{ New } & \\
\hline & TF-20 379 & H129 & & 2-Axis, Fati. \\
\hline & TF-20 i3 & $\begin{array}{l}26-147 \\
35-159 \\
35-161 \\
35-173\end{array}$ & & $\begin{array}{l}\text { 2-Axis, Fixed-free, Fati. } \\
\text { 2-Axis, Fati } \\
\text { 2-Axis,Fixed-free,Temp } \\
\text { 2-Axis, Temp, Fati. }\end{array}$ \\
\hline & TF-20 & $\begin{array}{c}\mathrm{H} 03 \\
\mathrm{H} 04 \\
\mathrm{H} 07 \\
\text { 3.44E-230 }\end{array}$ & $\begin{array}{l}2410 \mathrm{hrs} \\
1234 \mathrm{hrs} \\
2650 \mathrm{hrs} \\
2650 \mathrm{hrs} \\
\end{array}$ & Dust-Clean \\
\hline & TF-20 379 & $\begin{array}{l}\text { H126 } \\
\text { H159 } \\
\end{array}$ & $\begin{array}{c}798 \mathrm{hrs} \\
1356 \mathrm{hrs}\end{array}$ & $\begin{array}{l}\text { Dust-Clean } \\
\text { Dust-Clean }\end{array}$ \\
\hline & TF-20 i3 & $26-081$ & $1241 \mathrm{hrs}$ & Dust-Clean \\
\hline \multirow{4}{*}{ Refractron 326} & \# & $\begin{array}{l}2-1355 \\
5-1340 \\
5-1358 \\
5-1365 \\
\end{array}$ & New & $\begin{array}{l}\text { 2-Axis, Fixed-free, Fati. } \\
\text { 2-Axis, Fixed-free } \\
\text { 2-Axis, Temp } \\
\text { 2-Axis, Temp, Fati. }\end{array}$ \\
\hline & A & $\begin{array}{l}1-83 \mathrm{~A} \\
2-42 \mathrm{~A} \\
2-55 \mathrm{~A} \\
2-90 \mathrm{~A}\end{array}$ & $1301 \mathrm{hrs}$ & $\begin{array}{l}\text { Dust-Clean } \\
\text { Dust-Clean } \\
\\
\text { Dust-Clean }\end{array}$ \\
\hline & \# & $\begin{array}{c}1-1368 \\
2-1311 \\
3-1293 \\
6-1340 \\
2-992 \\
2-977 \\
2-980 \\
4-980 \\
6-1075\end{array}$ & $\begin{array}{l}1241 \mathrm{hrs} \\
1284 \mathrm{hrs} \\
1355 \mathrm{hrs} \\
2208 \mathrm{hrs} \\
2640 \mathrm{hrs} \\
2830 \mathrm{hrs}\end{array}$ & $\begin{array}{l}\text { Dust-Clean } \\
\text { Dust-Clean }\end{array}$ \\
\hline & $\begin{array}{l}\text { Pinion-Pine } \\
\text { Plant }\end{array}$ & $\begin{array}{l}1-1366 \\
2-1348 \\
3-1349 \\
6-1314 \\
\end{array}$ & $\begin{array}{l}- \\
- \\
- \\
- \\
\end{array}$ & \\
\hline \multirow[t]{2}{*}{ Refractron $442 \mathrm{~T}$} & \multirow[t]{2}{*}{ \# } & $\begin{array}{l}3-763 \\
3-737\end{array}$ & $1241 \mathrm{hrs}$ & $\begin{array}{l}\text { Dust-Clean } \\
\text { Dust-Clean }\end{array}$ \\
\hline & & $1013-7$ & $3262 \mathrm{hrs}$ & Dust-Clean \\
\hline Coors P-100 & $\overline{\mathrm{K \textrm {KC }}}$ & (2012,019 & $622 \mathrm{hrs}$ & \\
\hline
\end{tabular}


Table 3.2 Natural frequencies (Hertz) of new ceramic candle filters.

\begin{tabular}{|c|c|c|c|c|c|c|c|c|c|}
\hline & \multicolumn{8}{|c|}{ Schumacher T 05 - 20} & \multirow{2}{*}{$\begin{array}{c}\text { SCH TF } 20 \\
379 H 129\end{array}$} \\
\hline MODE & H01 & H02 & H03 & H04 & H05 & H07 & H08 & H09 & \\
\hline 1 & 116.0 & 114.6 & 114.4 & 114.4 & 112.9 & 116.0 & 116.0 & 116.0 & 115.9 \\
\hline 2 & 318.9 & 312.0 & 311.3 & 311.3 & 311.3 & 320.4 & 320.4 & 318.9 & 318.9 \\
\hline 3 & 619.5 & 610.2 & 608.8 & 608.8 & 608.8 & 627.1 & 624.1 & 624.1 & 622.6 \\
\hline 4 & 1008.6 & 992.5 & 990.3 & 990.3 & 988.8 & 1019.3 & 1017.8 & 1013.2 & 1011.7 \\
\hline \multirow[t]{2}{*}{5} & 1470.9 & 1446.5 & 1443.5 & 1443.5 & 1443.5 & 1486.2 & 1483.2 & 1477.1 & 1475.5 \\
\hline & \multicolumn{4}{|c|}{ Schumacher TF-20 } & \multicolumn{4}{|c|}{ Pall 326} & \\
\hline MODE & 326i-147 & $335 i-159$ & $335 \mathrm{i}-161$ & $335 i-173$ & 2-1355 & $5-1340$ & $5-1358$ & $5-1365$ & \\
\hline 1 & 119.0 & 116.0 & 115.9 & 115.4 & 139.2 & 137.3 & 140.4 & 137.3 & \\
\hline 2 & 326.5 & 317.4 & 317.4 & 314.9 & 377.0 & 370.2 & 379.9 & 373.8 & \\
\hline 3 & 634.8 & 619.5 & 621.0 & 610.5 & 732.3 & 720.2 & 738.5 & 726.3 & \\
\hline 4 & 1029.9 & 1004.0 & 999.5 & 993.0 & 1180.3 & 1164.7 & 1191.7 & 1171.9 & \\
\hline 5 & 1501.5 & 1464.8 & 1454.2 & 1452.6 & 1715.5 & 1691.2 & 1734.9 & 1705.9 & \\
\hline
\end{tabular}

Table 3.3 Natural frequencies of used Schumacher TF-20 filters.

\begin{tabular}{|c|c|c|c|c|c|c|c|c|}
\hline \multirow{2}{*}{ MODE } & \multicolumn{2}{|c|}{ 344-E-232 } & \multicolumn{2}{|c|}{ 324-H03 } & \multicolumn{2}{|c|}{ 324-H04 } & \multicolumn{2}{|c|}{ 324-H07 } \\
\hline & $\begin{array}{c}2650 \mathrm{hrs} \\
\mathrm{Hz}\end{array}$ & $\%$ & $\begin{array}{c}2410 \mathrm{hrs} \\
\mathrm{Hz}\end{array}$ & $\%$ & $\begin{array}{c}1234 \mathrm{hrs} \\
\mathrm{Hz}\end{array}$ & $\%$ & $\begin{array}{c}2650 \mathrm{hrs} \\
\mathrm{Hz}\end{array}$ & $\%$ \\
\hline 1 & 111.4 & -6.8 & 111.39 & -9.6 & 110.5 & -10.5 & 112.9 & -4.1 \\
\hline 2 & 303.6 & -6.0 & 306.70 & -8.5 & 303.3 & -11.2 & 309.9 & -3.4 \\
\hline 3 & 585.9 & -7.0 & 596.62 & -8.4 & 589.6 & -11.0 & 604.2 & -3.3 \\
\hline 4 & 962.8 & -5.9 & 971.98 & -8.3 & 960.7 & -10.7 & 982.7 & -3.4 \\
\hline 5 & 1402.3 & -6.0 & 1416.02 & -8.5 & 1400.8 & -10.8 & 1432.8 & -3.6 \\
\hline \multirow[b]{2}{*}{ MODE } & \multicolumn{2}{|c|}{ 379-H126 } & \multicolumn{2}{|c|}{ 379-H159 } & \multicolumn{2}{|c|}{ i326-081 } & & \\
\hline & $\begin{array}{c}798 \mathrm{hrs} \\
\mathrm{Hz}\end{array}$ & $\%$ & $\begin{array}{c}1356 \mathrm{hrs} \\
\mathrm{Hz}\end{array}$ & $\%$ & $\begin{array}{c}1241 \mathrm{hrs} \\
\mathrm{Hz}\end{array}$ & $\%$ & & \\
\hline 1 & 109.9 & -5.3 & 109.9 & -5.3 & 111.4 & -6.4 & & \\
\hline 2 & 303.6 & -4.8 & 301.1 & -5.6 & 306.7 & -6.1 & & \\
\hline 3 & 590.5 & -5.1 & 587.5 & -5.6 & 595.1 & -6.3 & & \\
\hline 4 & 962.8 & -4.8 & 959.8 & -5.1 & 972.0 & -5.6 & & \\
\hline 5 & 1403.8 & -4.7 & 1393.1 & -5.5 & 1414.5 & -5.8 & & \\
\hline
\end{tabular}


Table 3.4 Frequency values (Hertz) used Refractron 326 filters.

\begin{tabular}{|c|c|c|c|c|c|c|c|c|c|}
\hline \multirow{2}{*}{ MODE } & $1-83 A$ & $2-42 A$ & $2-55 A$ & $2-90 A$ & 3-1293 & $2-1311$ & $1-1368$ & $6-1340$ & 2-992 \\
\hline & $1301 \mathrm{hrs}$ & $1301 \mathrm{hrs}$ & $1301 \mathrm{hrs}$ & $1301 \mathrm{hrs}$ & $1241 \mathrm{hrs}$ & $1241 \mathrm{hrs}$ & $1241 \mathrm{hrs}$ & $1241 \mathrm{hrs}$ & $1284 \mathrm{hrs}$ \\
\hline 1 & 137.3 & 129.7 & 138.9 & 134.3 & 141.9 & 137.3 & 137.3 & 138.9 & 147.7 \\
\hline 2 & 372.5 & 354.0 & 378.4 & 366.2 & 387.0 & 372.3 & 372.3 & 383.0 & 403.7 \\
\hline 3 & 720.2 & 685.1 & 730.9 & 711.1 & 750.6 & 723.3 & 723.3 & 738.5 & 782.0 \\
\hline 4 & 1164.2 & 1106.3 & 1181.0 & 1149.0 & 1213.1 & 1165.8 & 1165.8 & 1193.2 & 1262.2 \\
\hline 5 & 1693.7 & 1608.3 & 1718.1 & 1672.4 & 1762.4 & 1696.8 & 1707.5 & 1734.9 & 1831.3 \\
\hline \multirow{2}{*}{ MODE } & 2-977 & $2-980$ & 4-980 & $6-1075$ & $2-1348$ & $1-1366$ & 3-1349 & $6-1314$ & \\
\hline & $1355 \mathrm{hrs}$ & $2208 \mathrm{hrs}$ & $2640 \mathrm{hrs}$ & $2830 \mathrm{hrs}$ & N/A & N/A & N/A & N/A & \\
\hline 1 & 149.5 & 143.4 & 147.2 & 146.7 & 149.5 & 146.5 & 145.0 & 143.4 & \\
\hline 2 & 405.9 & 389.3 & 401.7 & 399.7 & 408.9 & 402.8 & 395.2 & 390.6 & \\
\hline 3 & 787.4 & 758.2 & 778.0 & 774.0 & 790.0 & 781.3 & 766.0 & 758.4 & \\
\hline 4 & 1269.5 & 1222.2 & 1256.2 & 1250.2 & 1274.4 & 1260.4 & 1236.0 & 1220.7 & \\
\hline 5 & 1846.3 & 1779.2 & 1822.3 & 1812.3 & 1853.0 & 1837.2 & 1796.0 & 1779.2 & \\
\hline
\end{tabular}

Table 3.5 Frequency values (Hertz) of used Refractron 442T and Coors filters.

\begin{tabular}{||c||c|c|c||c|c||}
\cline { 2 - 6 } \multicolumn{1}{c||}{} & \multicolumn{3}{c||}{ Pall 442T } & \multicolumn{2}{c||}{ Coors P-100-A } \\
\hline \hline \multirow{2}{*}{ MODE } & $\mathbf{3 - 7 6 3}$ & $\mathbf{3 - 7 3 7}$ & $\mathbf{7 - 1 0 1 3}$ & Kc-012 & Kc-019 \\
\cline { 2 - 6 } & $1241 \mathrm{hrs}$ & $12411 \mathrm{hrs}$ & $3262 \mathrm{hrs}$ & $622 \mathrm{hrs}$ & $622 \mathrm{hrs}$ \\
\hline $\mathbf{1}$ & 138.9 & 129.7 & 131.2 & 111.4 & 109.9 \\
$\mathbf{2}$ & 378.4 & 354.0 & 355.9 & 303.6 & 297.1 \\
$\mathbf{3}$ & 730.9 & 685.1 & 706.0 & 589.0 & 581.4 \\
$\mathbf{4}$ & 1182.6 & 1106.3 & 1121.5 & 952.1 & 941.5 \\
$\mathbf{5}$ & 1722.7 & 1608.3 & 1640.3 & 1382.4 & 1365.7 \\
\hline
\end{tabular}


Table 3.6 Flexural mode frequencies in undamaged/damaged aluminum specimen 1.

\begin{tabular}{|c|c|c|c|c|}
\hline & \multicolumn{4}{|c|}{ Frequency $(\mathrm{Hz})$} \\
\hline Mode & Undamaged & Damage 1 & Damage 2 & Damage 3 \\
\hline 1 & 189.2 & 189.2 & 170.9 & 160.2 \\
\hline 2 & 509.6 & 509.6 & 508.1 & 506.6 \\
\hline 3 & 964.4 & 964.4 & 904.8 & 878.9 \\
\hline \multirow[t]{2}{*}{4} & 1527.4 & 1527.4 & 1515.2 & 1495.4 \\
\hline & \multicolumn{4}{|c|}{ Frequency $(\mathrm{Hz})$} \\
\hline Mode & Damage 4 & Damage 5 & Damage 6 & Damage 7 \\
\hline 1 & 158.7 & 152.6 & 149.5 & 148 \\
\hline 2 & 505.1 & 500.5 & 462.3 & 451.7 \\
\hline 3 & 874.3 & 869.8 & 804.1 & 795 \\
\hline 4 & 1478.6 & 1449.6 & 1449.6 & 1448.1 \\
\hline
\end{tabular}

Table 3.7 Flexural mode frequencies in undamaged/damaged aluminum specimen 2.

\begin{tabular}{|c|c|c|c|}
\cline { 2 - 4 } \multicolumn{1}{c|}{} & \multicolumn{3}{c|}{ Frequency $(\mathrm{Hz})$} \\
\hline Mode & Undamaged & Damage 1 & Damage 2 \\
\hline 1 & 189.2 & 183.1 & 166.3 \\
\hline 2 & 509.6 & 509.6 & 508.1 \\
\hline 3 & 965.9 & 943 & 892.6 \\
\hline 4 & 1528.9 & 1525.8 & 1518.2 \\
\hline Mode & Damage 3 & Damage 4 & Damage 5 \\
\hline 1 & 163.3 & 160.2 & 155.6 \\
\hline 2 & 508.1 & 506.6 & 502 \\
\hline 3 & 886.5 & 878.9 & 875.8 \\
\hline 4 & 1504.5 & 1487.7 & 1457.2 \\
\hline
\end{tabular}

Note:

Damage 1 is a surface cut (about 0.12 in deep) one inch above the midpoint.

Damage 2 is a $1 / 4$ diameter (1.5 in) deep cut one inch above the midpoint.

Damage 3 is a series of cuts covering $1 / 2$ in along the length up from Damage 2.

Damage 4 is a series of cuts covering 1 in along the length up from Damage 2.

Damage 5 is a series of cuts covering 2 in along the length up from Damage 2.

Damage 6 is a $1 / 4$ diameter (1.5 in) deep cut at L/4.

Damage 7 is a series of cuts covering $1 / 2$ in along the length up from Damage 6.

Each cut is about $1 / 25$ in width. 
Table 3.8 Experimental and FEM natural frequencies for undamaged/damaged trials.

\begin{tabular}{|c|c|c|c|c|c|}
\hline \multicolumn{3}{|c|}{ New (undamaged) } & \multicolumn{3}{c|}{ Damage 2 } \\
$\begin{array}{c}\text { Exp } \\
\mathrm{Hz}\end{array}$ & $\begin{array}{c}\text { FEM } \\
\mathrm{Hz}\end{array}$ & $\%$ & $\begin{array}{c}\text { Exp } \\
\mathrm{Hz}\end{array}$ & $\begin{array}{c}\text { FEM } \\
\mathrm{Hz}\end{array}$ & $\%$ \\
\hline 189.20 & 189.41 & 0.11 & 170.90 & 171.39 & 0.29 \\
\hline 509.60 & 508.89 & -0.14 & 508.10 & 508.31 & 0.04 \\
\hline 964.40 & 962.86 & -0.16 & 904.80 & 906.36 & 0.17 \\
\hline 1527.40 & 1524.13 & -0.21 & 1515.20 & 1513.29 & -0.13 \\
\hline 2172.90 & 2168.05 & -0.22 & 2087.40 & 2090.18 & 0.13 \\
\hline
\end{tabular}


Table 3.9 Comparison of dusted and clean used filters.

\begin{tabular}{|c|c|c|c|c|c|c|c|c|c|c|c|}
\hline \multicolumn{3}{|c|}{ Pall 326 1-83A } & \multicolumn{3}{|c|}{ Pall 326 2-90A } & \multicolumn{3}{|c|}{ Pall 326 2-980 } & \multicolumn{3}{|c|}{ Pall 326 6-1075 } \\
\hline Dust (10.281b) & Clean (10.201b) & \multirow{2}{*}{$\%$} & Dust (10.15lb) & Clean (10.04lb) & \multirow{2}{*}{$\%$} & Dust (10.24lb) & Clean (10.131b) & \multirow{2}{*}{$\%$} & Dust (10.15lb) & Clean (10.081b) & \multirow{2}{*}{$\%$} \\
\hline $\mathbf{H z}$ & $\mathbf{H z}$ & & \begin{tabular}{|c|}
$\mathbf{H z}$ \\
\end{tabular} & $\mathbf{H z}$ & & $\mathbf{H z}$ & $\mathbf{H z}$ & & \begin{tabular}{|l|}
$\mathbf{H z}$ \\
\end{tabular} & $\mathrm{Hz}$ & \\
\hline 141.9 & 137.3 & -3.2 & 137.2 & 134.3 & -2.2 & 148.0 & 143.4 & -3.1 & 152.6 & 149.5 & -2.0 \\
\hline 384.7 & 372.5 & -3.2 & 375.4 & 366.2 & -2.4 & 404.5 & 389.3 & -3.8 & 413.5 & 407.4 & -1.5 \\
\hline 743.1 & 720.2 & -3.1 & 729.4 & 711.1 & -2.5 & 784.2 & 758.2 & -3.3 & 798.0 & 788.9 & -1.1 \\
\hline 1200.9 & 1164.2 & -3.0 & 1178.0 & 1149.0 & -2.5 & 1261.9 & 1222.2 & -3.1 & 1289.4 & 1272.6 & -1.3 \\
\hline 1745.6 & 1693.7 & -3.0 & 1718.1 & 1672.4 & -2.7 & 1837.2 & 1779.2 & -3.2 & 1875.3 & 1850.9 & -1.3 \\
\hline \multicolumn{3}{|c|}{ Pall 326 2-42A } & \multicolumn{3}{|c|}{ Pall 442T 3-763 } & \multicolumn{3}{|c|}{ Pall 442T 3-737 } & \multicolumn{3}{|c|}{ Pall 442T 7-1013 } \\
\hline Dust (10.05Ib) & Clean (9.96lb) & \multirow{2}{*}{$\%$} & | Dust (10.74lb) & Clean (10.69lb) & \multirow{2}{*}{$\%$} & | Dust (10.81lb) & Clean $(10.711 \mathrm{~b})$ & \multirow{2}{*}{$\%$} & Dust (10.861b) & Clean (10.781b) & \multirow{2}{*}{$\%$} \\
\hline $\mathbf{H z}$ & $\mathbf{H z}$ & & $\mathbf{H z}$ & $\mathbf{H z}$ & & $\mathbf{H z}$ & $\mathbf{H z}$ & & $\mathbf{H z}$ & $\mathbf{H z}$ & \\
\hline 134.3 & 129.7 & -3.4 & 140.4 & 138.9 & -1.1 & 143.4 & 140.4 & -2.1 & 132.8 & 131.2 & -1.1 \\
\hline 367.7 & 354.0 & -3.7 & 381.5 & 378.4 & -0.8 & 389.3 & 378.4 & -2.8 & 360.1 & 355.9 & -1.2 \\
\hline 715.6 & 685.1 & -4.3 & 737.0 & 730.9 & -0.8 & 758.2 & 737.0 & -2.8 & 712.6 & 706.0 & -0.9 \\
\hline 1153.6 & 1106.3 & -4.1 & 1193.2 & 1182.6 & -0.9 & 1222.2 & 1187.1 & -2.9 & 1133.7 & 1121.5 & -1.1 \\
\hline 1680.0 & 1608.3 & -4.3 & 1736.5 & 1722.7 & -0.8 & 1779.2 & 1730.3 & -2.7 & 1655.6 & 1640.3 & -0.9 \\
\hline \multicolumn{3}{|c|}{ SCH TF 20 324-H03 } & \multicolumn{3}{|c|}{ SCH TF 20 379-H126 } & \multicolumn{3}{|c|}{ SCH TF 20 379-H159 } & \multicolumn{3}{|c|}{ " SCH TF $20326 \mathrm{i081}$} \\
\hline Dust (10.67lb) & Clean (10.59lb) & \multirow{2}{*}{$\%$} & Dust (10.82lb) & Clean (10.74lb) & \multirow{2}{*}{$\%$} & Dust (10.80lb) & Clean (10.73lb) & \multirow{2}{*}{$\%$} & Dust (10.85lb) & Clean (10.75lb) & \multirow{2}{*}{$\%$} \\
\hline $\mathbf{H z}$ & $\mathbf{H z}$ & & $\mathbf{H z}$ & $\mathrm{Hz}$ & & $\mathbf{H z}$ & $\mathbf{H z}$ & & $\mathbf{H z}$ & $\mathbf{H z}$ & \\
\hline 122.1 & 111.4 & -8.8 & 111.4 & 109.9 & -1.4 & 122.2 & 109.9 & -10.1 & 123.7 & 111.4 & -9.9 \\
\hline 334.2 & 306.7 & -8.2 & 306.7 & 303.6 & -1.0 & 334.2 & 301.1 & -9.9 & 338.7 & 306.7 & -9.5 \\
\hline 654.6 & 596.6 & -8.9 & 596.6 & 590.5 & -1.0 & 651.6 & 587.5 & -9.8 & 660.2 & 595.1 & -9.9 \\
\hline 1059.0 & 972.0 & -8.2 & 968.9 & 962.8 & -0.6 & 1057.4 & 959.8 & -9.2 & 1063.1 & 972.0 & -8.6 \\
\hline 1544.2 & 1416.0 & -8.3 & 1413.0 & 1403.8 & -0.6 & 1545.9 & 1393.1 & -9.9 & 1561.0 & 1414.5 & -9.4 \\
\hline 2096.6 & 1922.6 & -8.3 & 1919.6 & 1907.3 & -0.6 & 2102.7 & 1904.3 & -9.4 & 2114.9 & 1922.6 & -9.1 \\
\hline
\end{tabular}




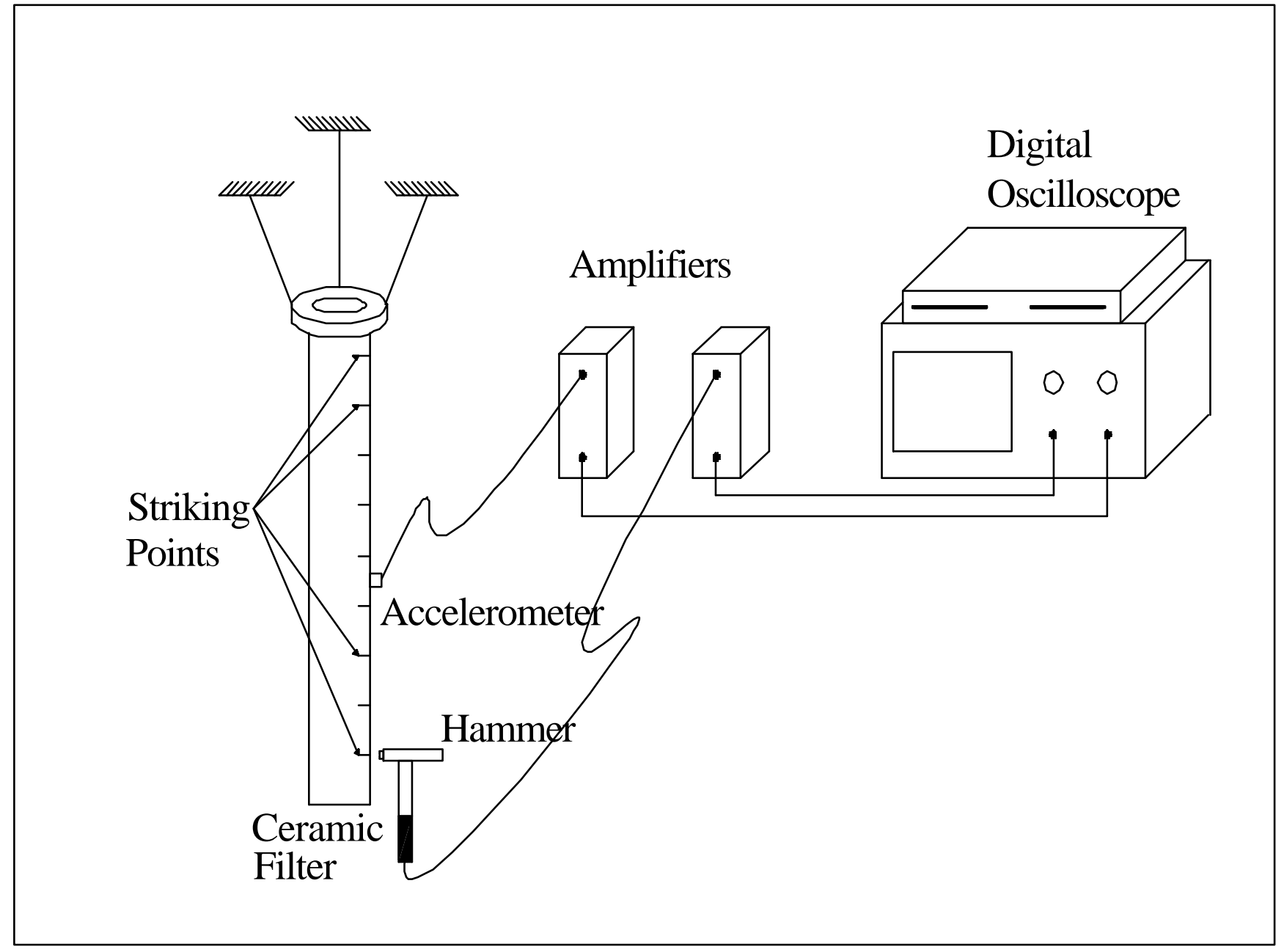

Figure 3.1 Free-free boundary condition experimental set up. 


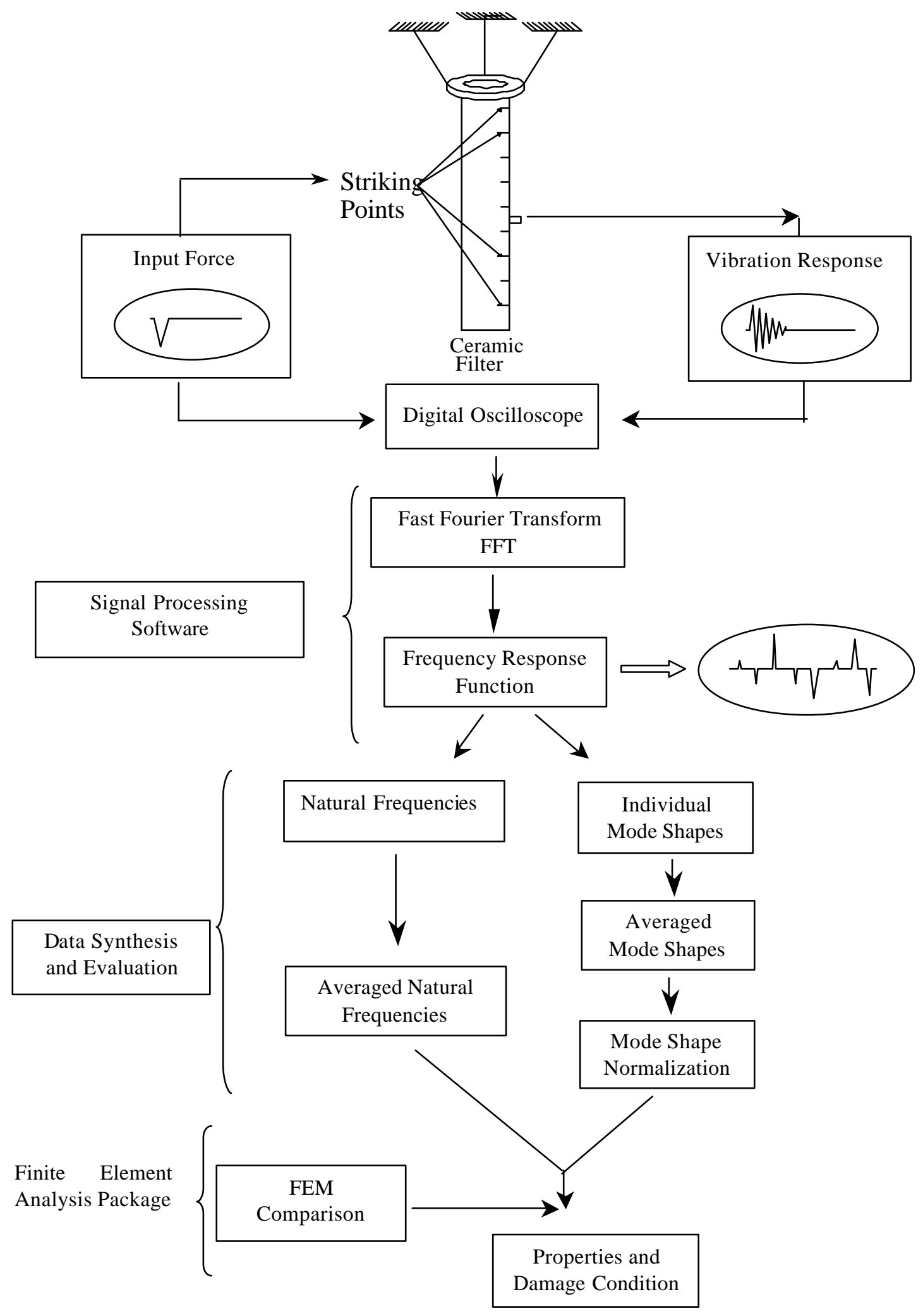

Figure 3.2 Scheme of candle filter's nondestructive evaluation procedures. 


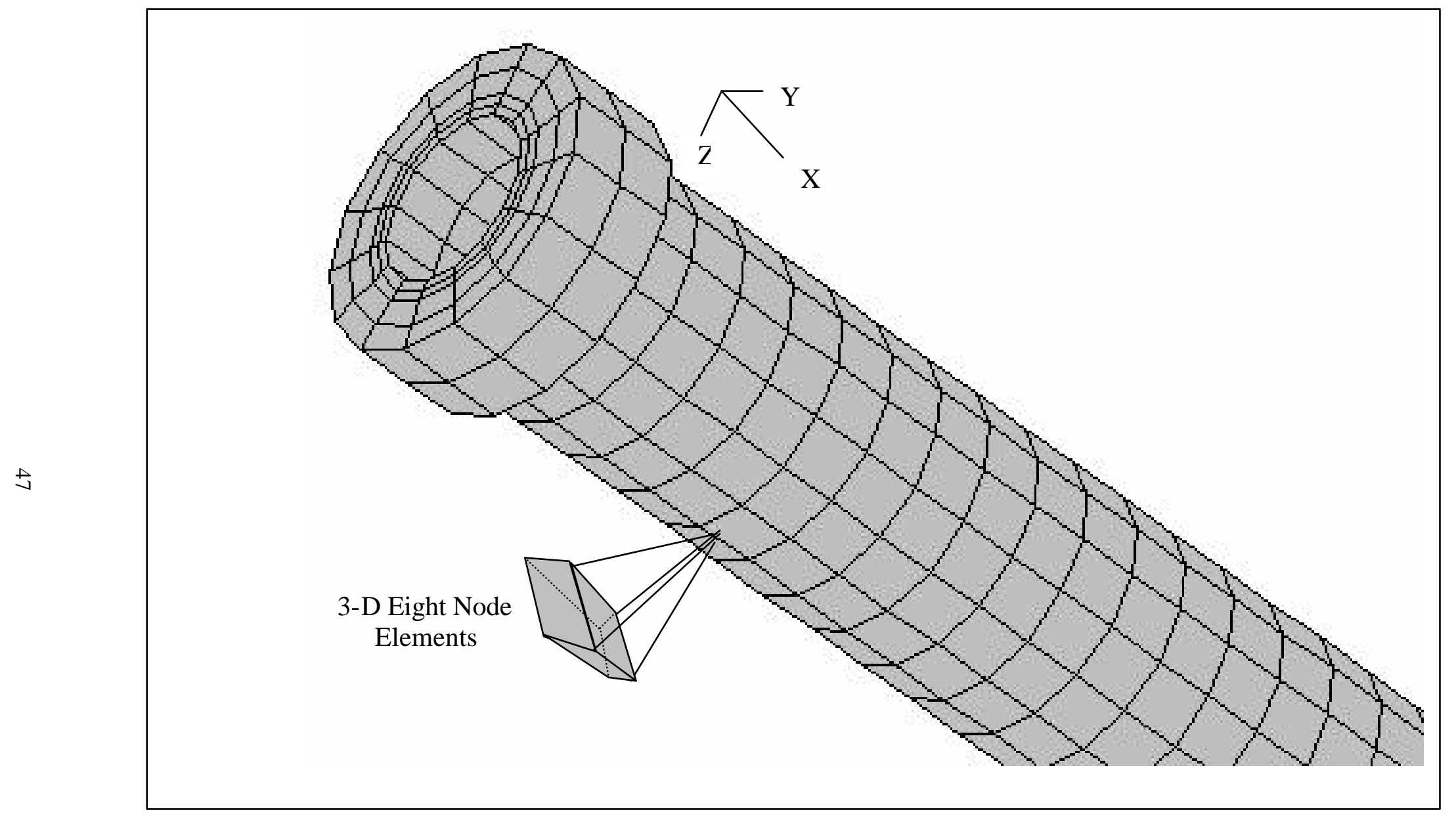

Figure 3.3 Finite element model of ceramic candle filter. 


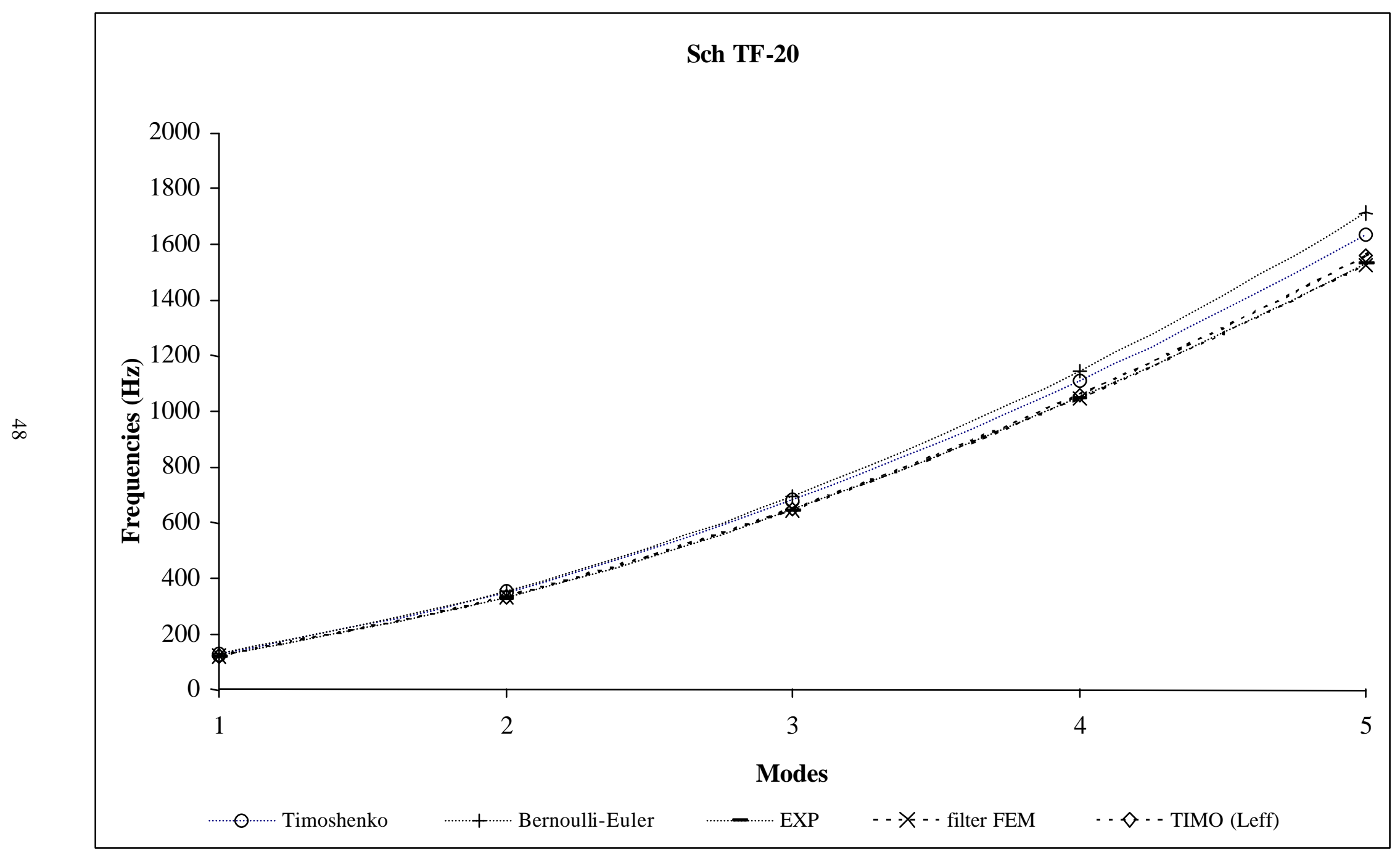

Figure 3.4 Natural frequencies of the SCH TF-20 group compared with the theoretical and FEM results. 

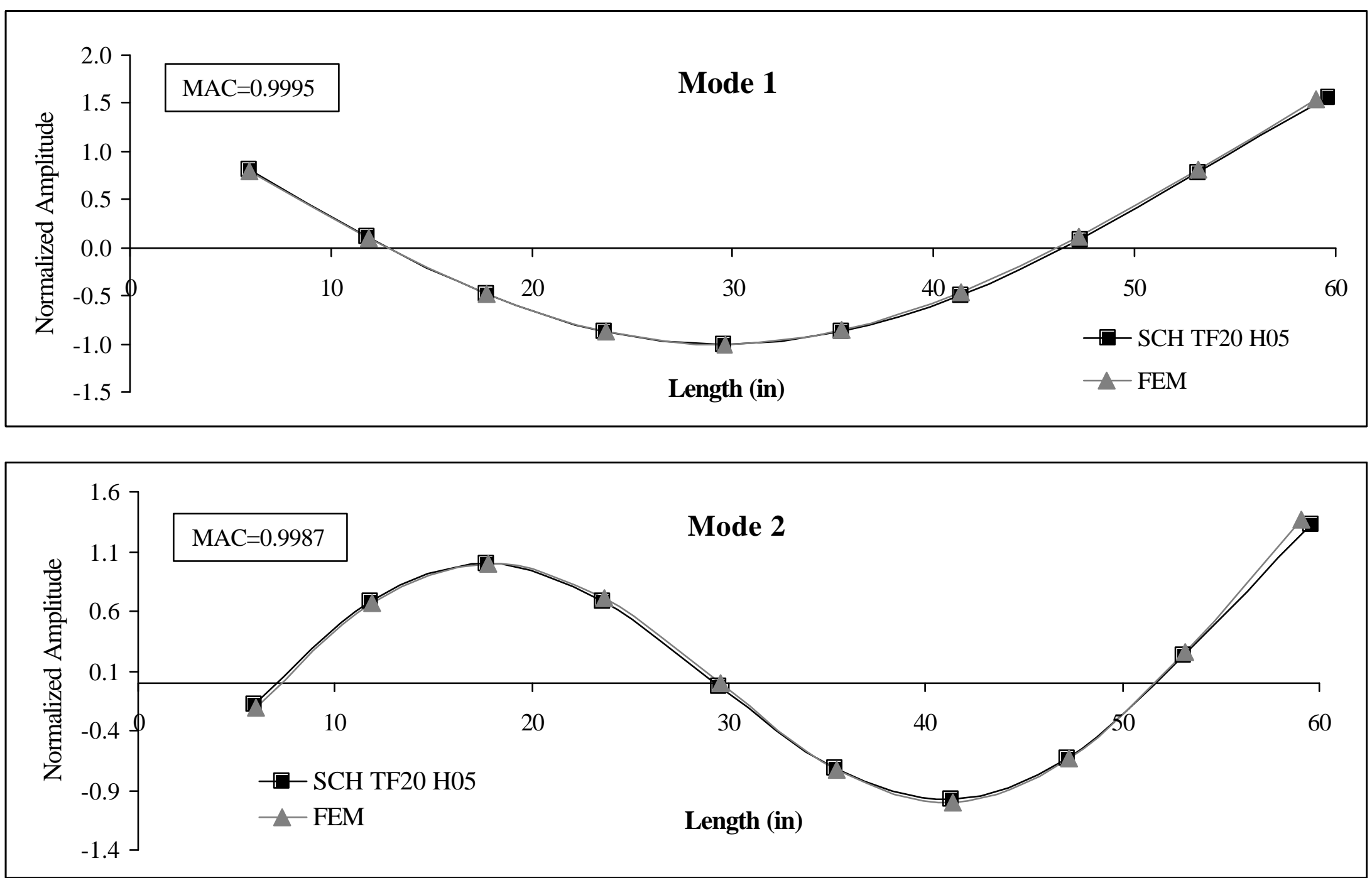

Figure 3.5 Modes shapes comparison of a typical Sch TF20 filter with the FEM results. 


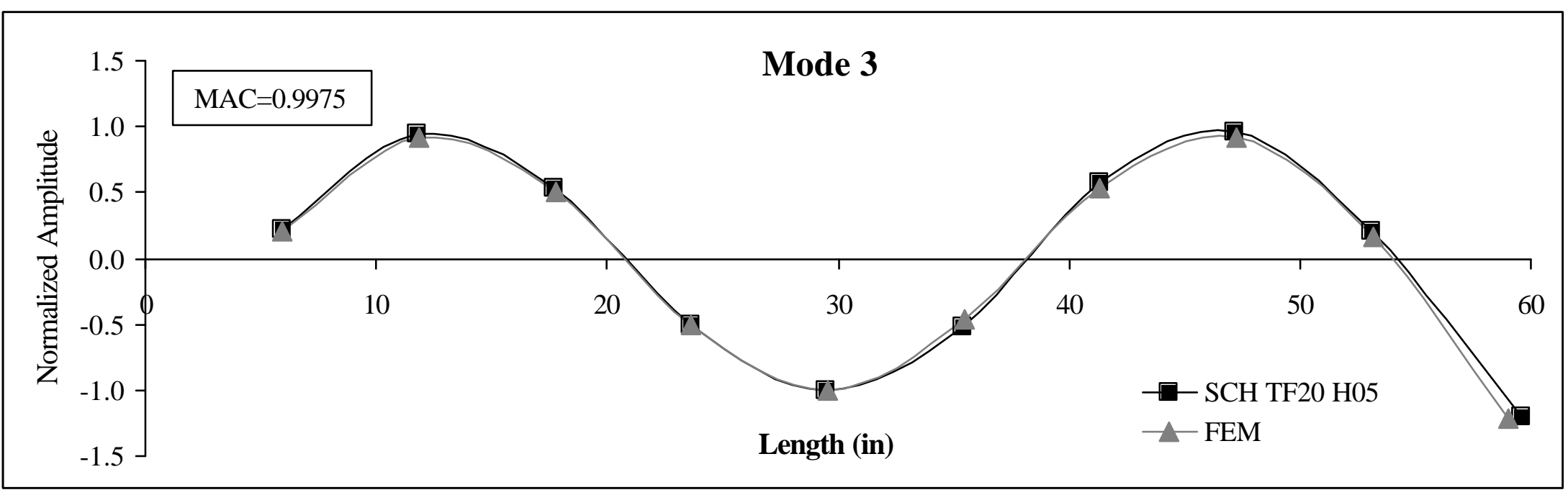

UI

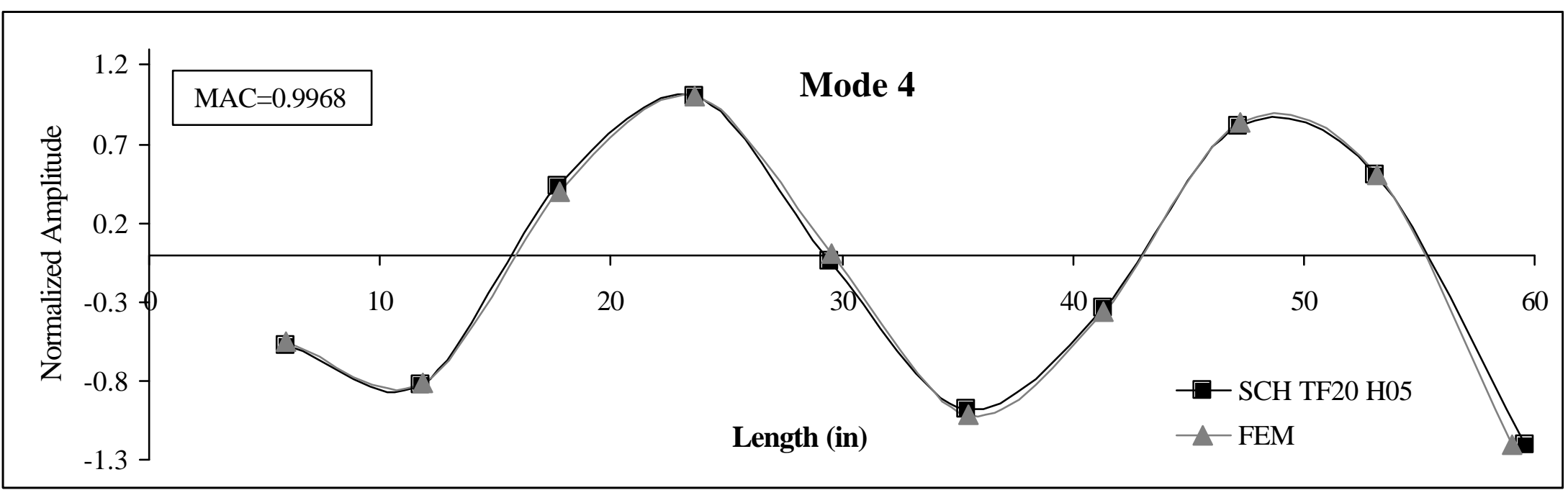

Figure 3.5 Modes shapes comparison of a typical new Sch TF20 filter with the FEM results (continued). 


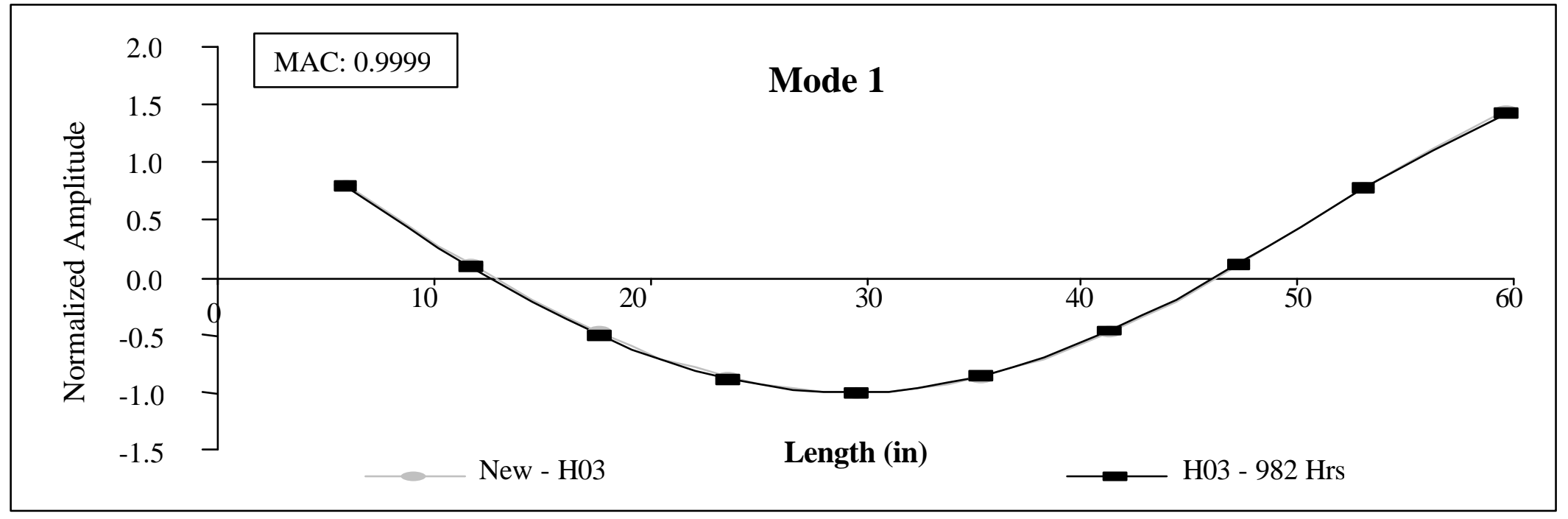

$u$

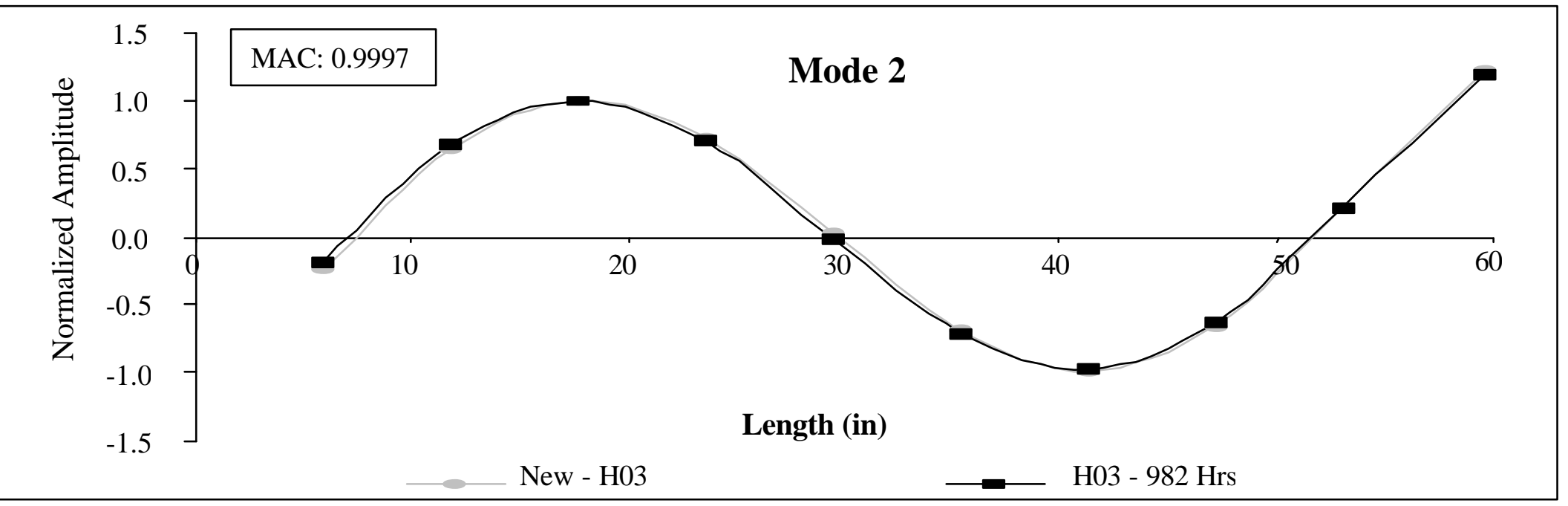

Figure 3.6 Mode shapes comparison between new and 982 exposure hour of a typical Sch filter. 


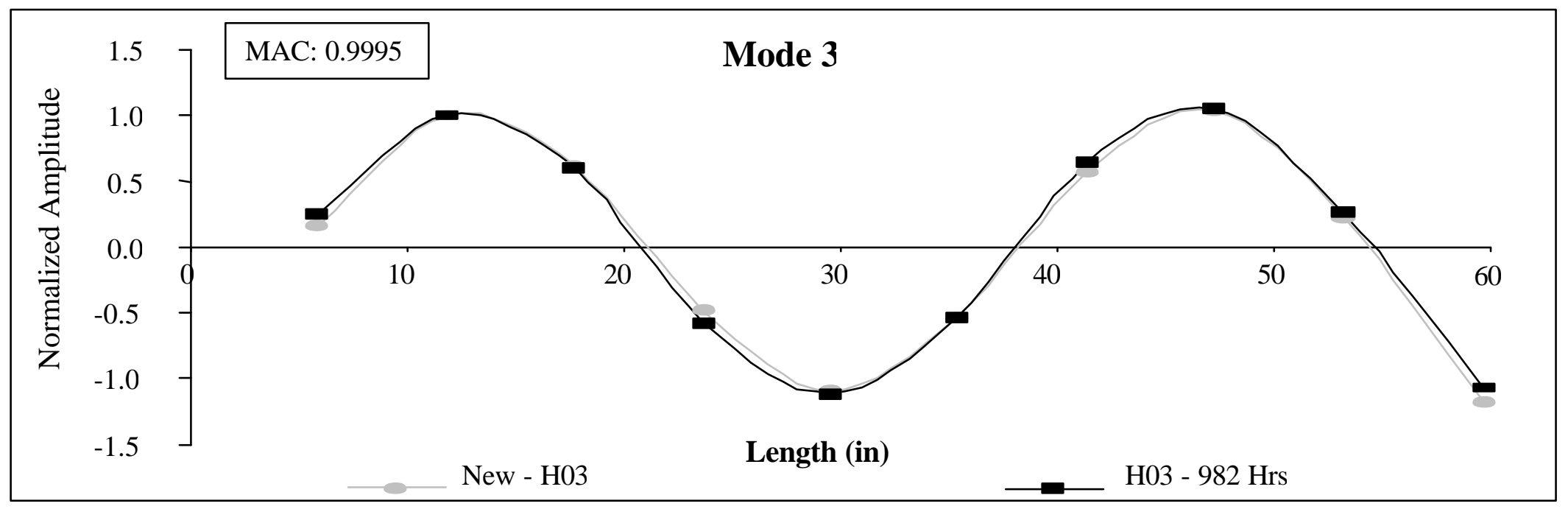

N

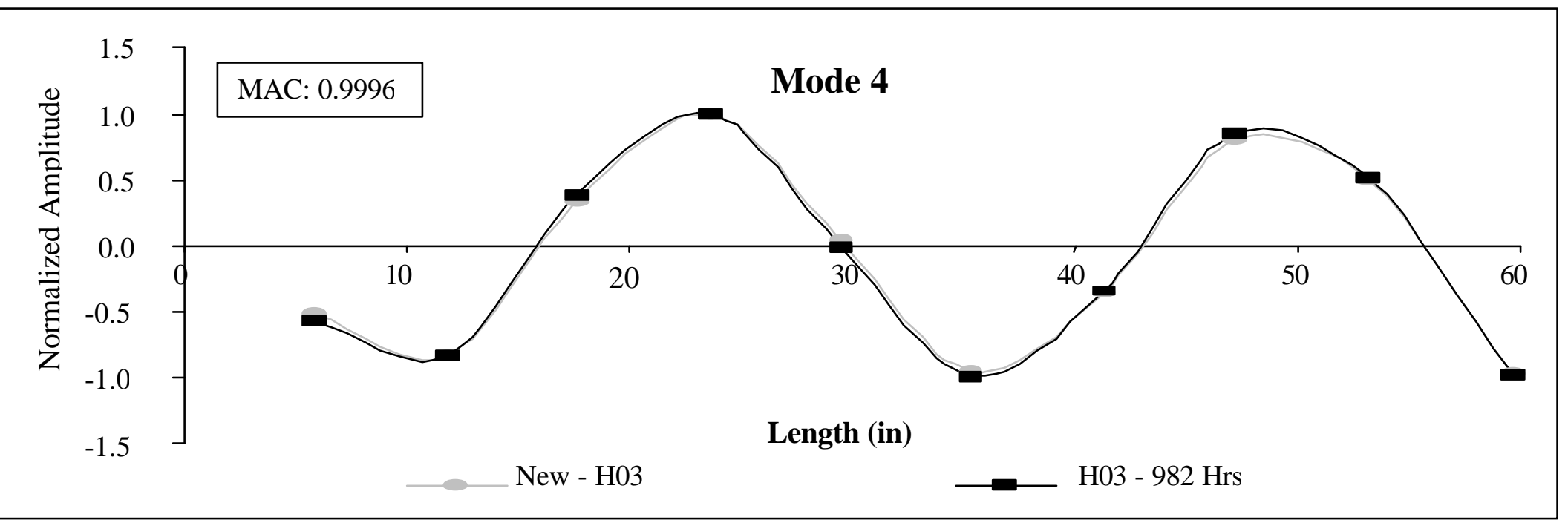

Figure 3.6 Mode shapes comparison between new and 982 exposure hour of a typical Sch 2 filter (continued). 


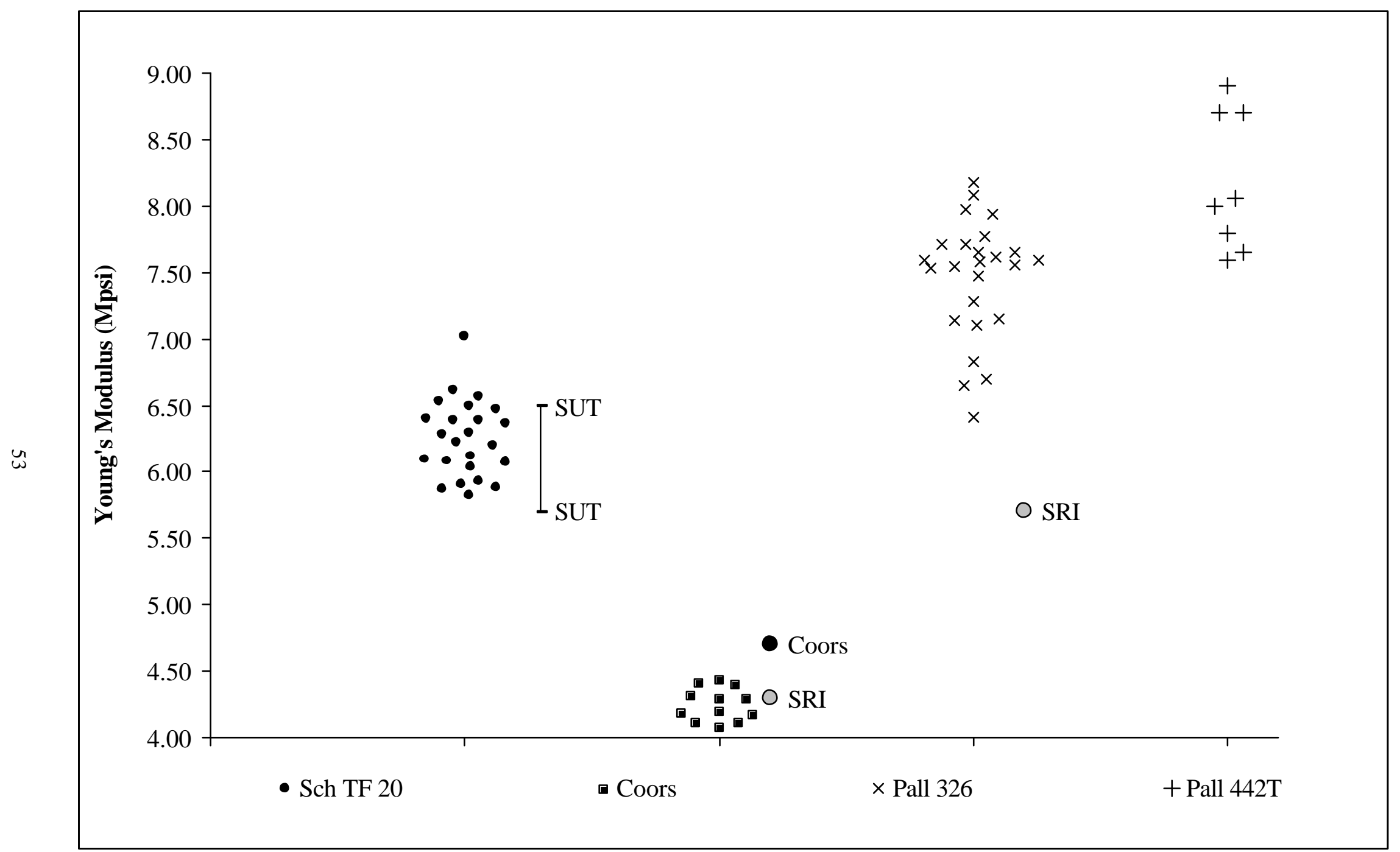

Figure3.7 Young's modulus of new ceramic filters. 


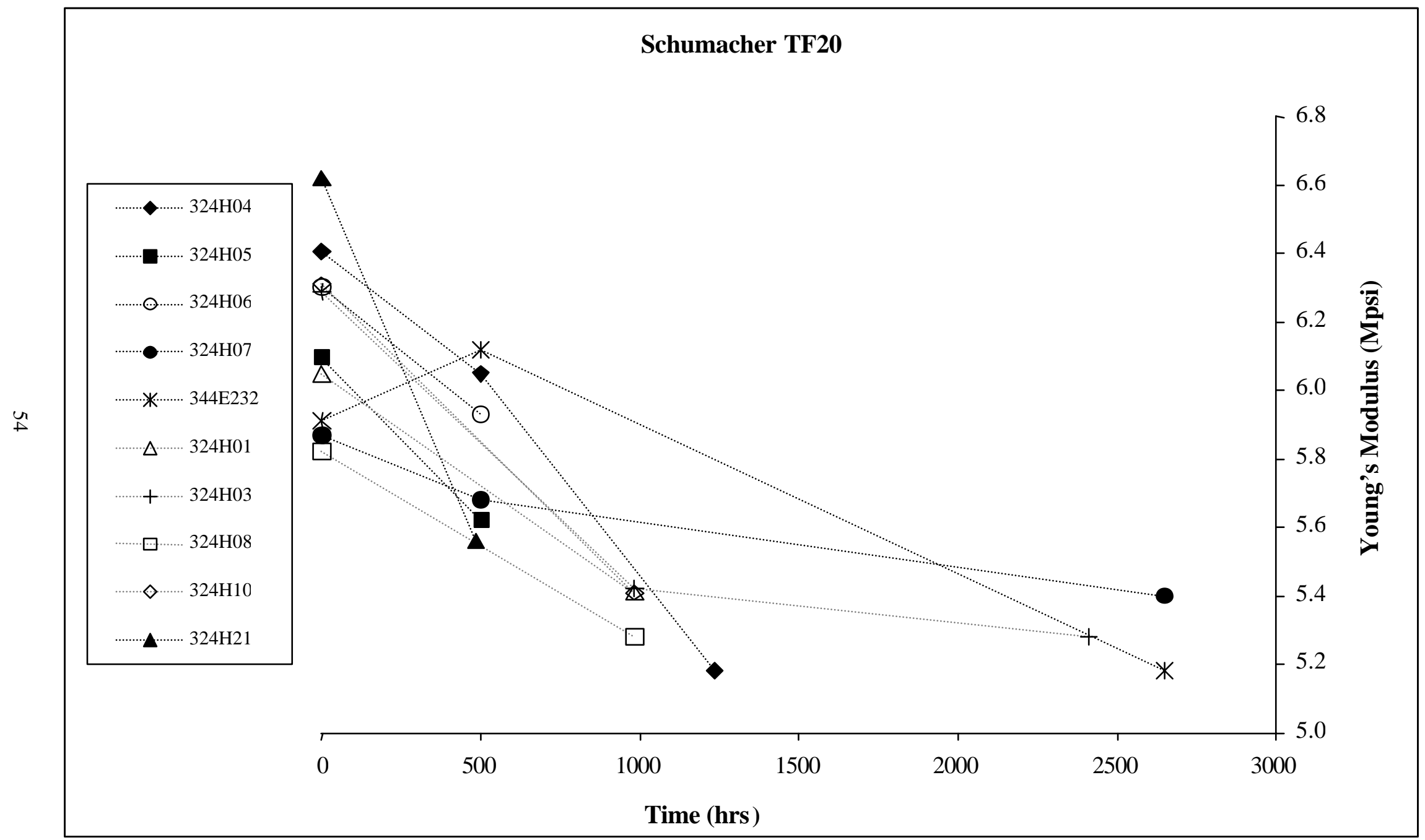

Figure 3.8 Young's modulus deterioration of SchTF-20 filters. 


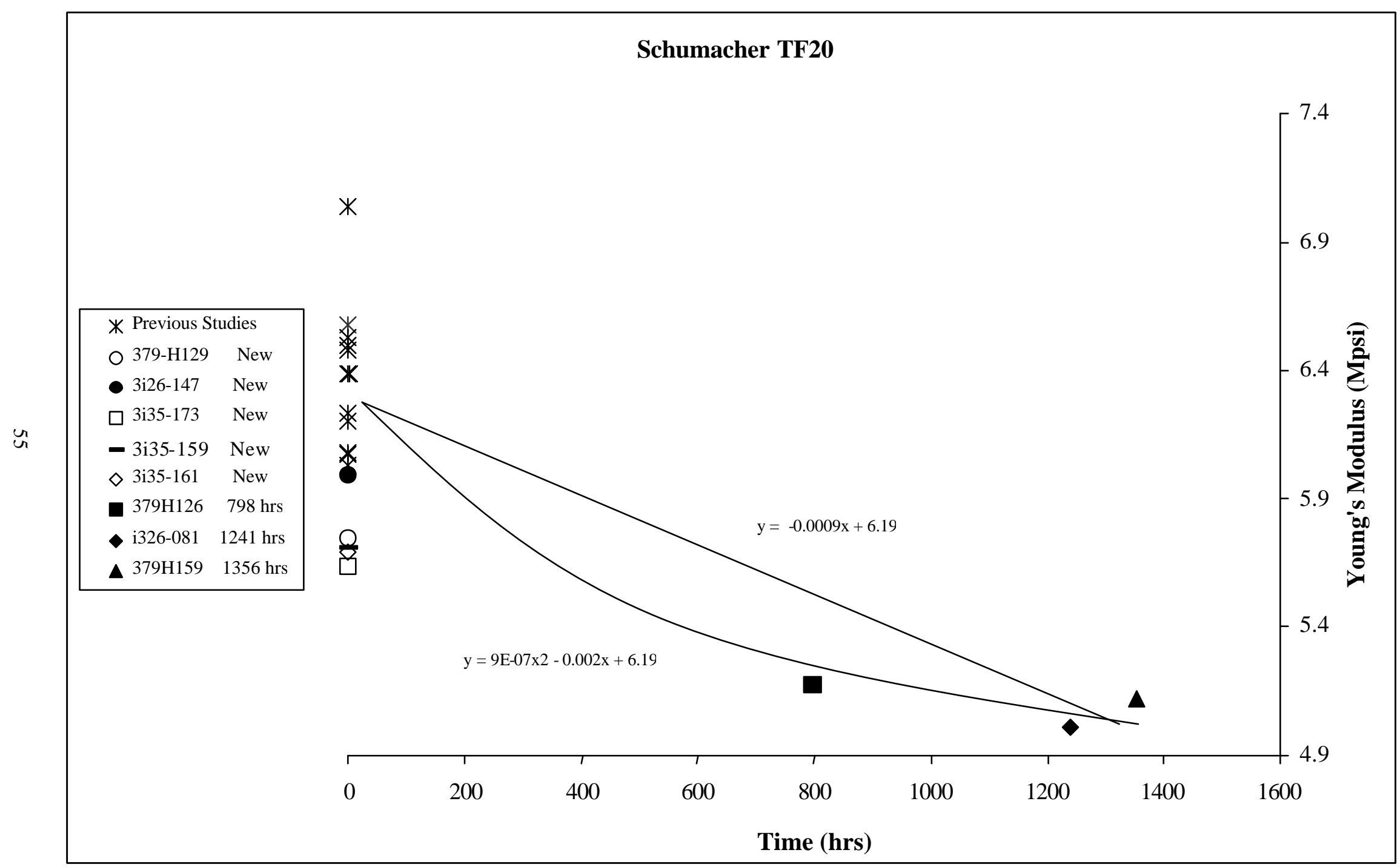

Figure 3.9 Young's modulus deterioration of not traced Sch TF-20 filters (Previous Studies data from Chen and Kiriakidis 2000). 


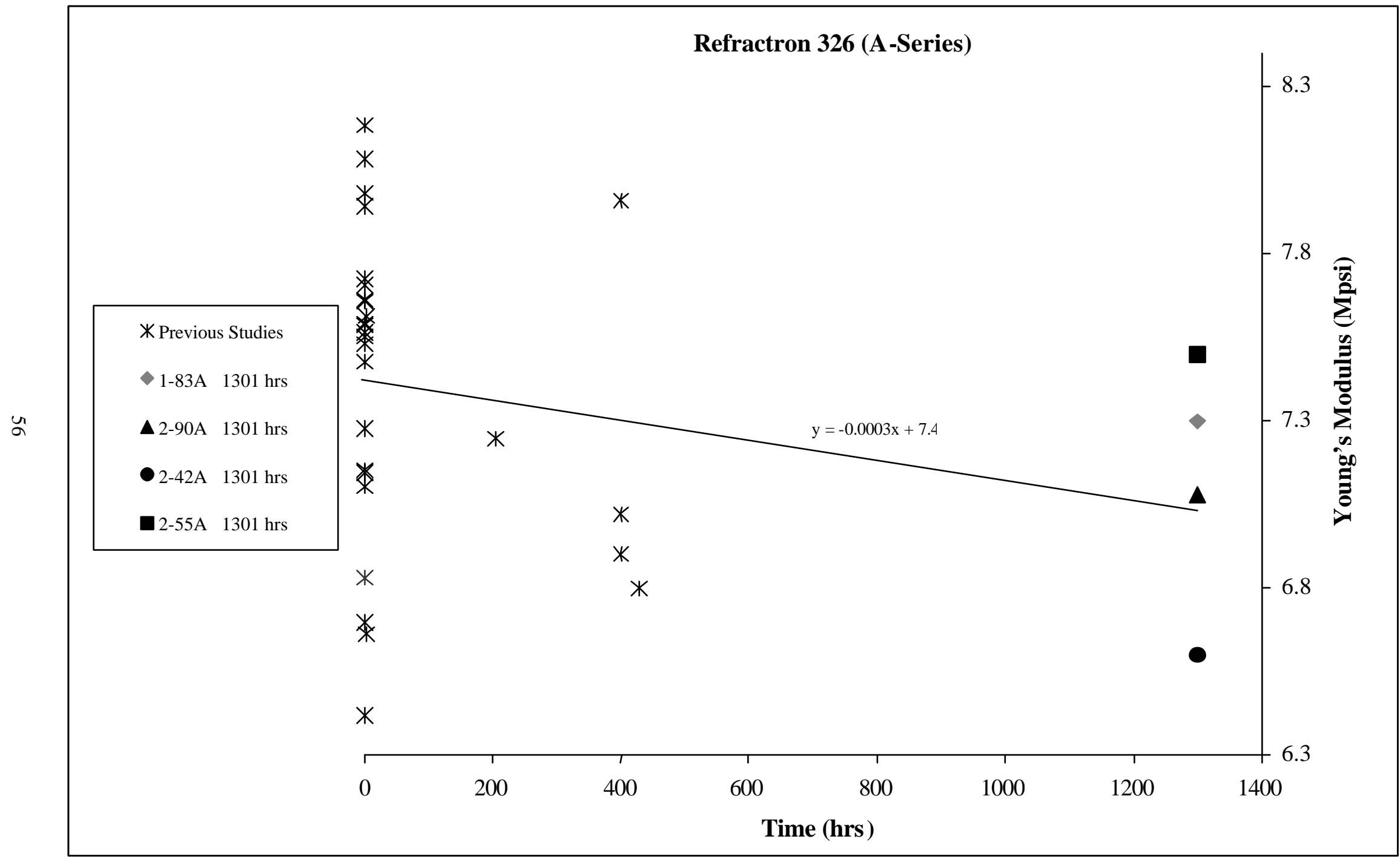

Figure 3.10 Young's modulus of new and used Refractron 326-A filters (Previous Studies data from Chen and Kiriakidis 2000). 


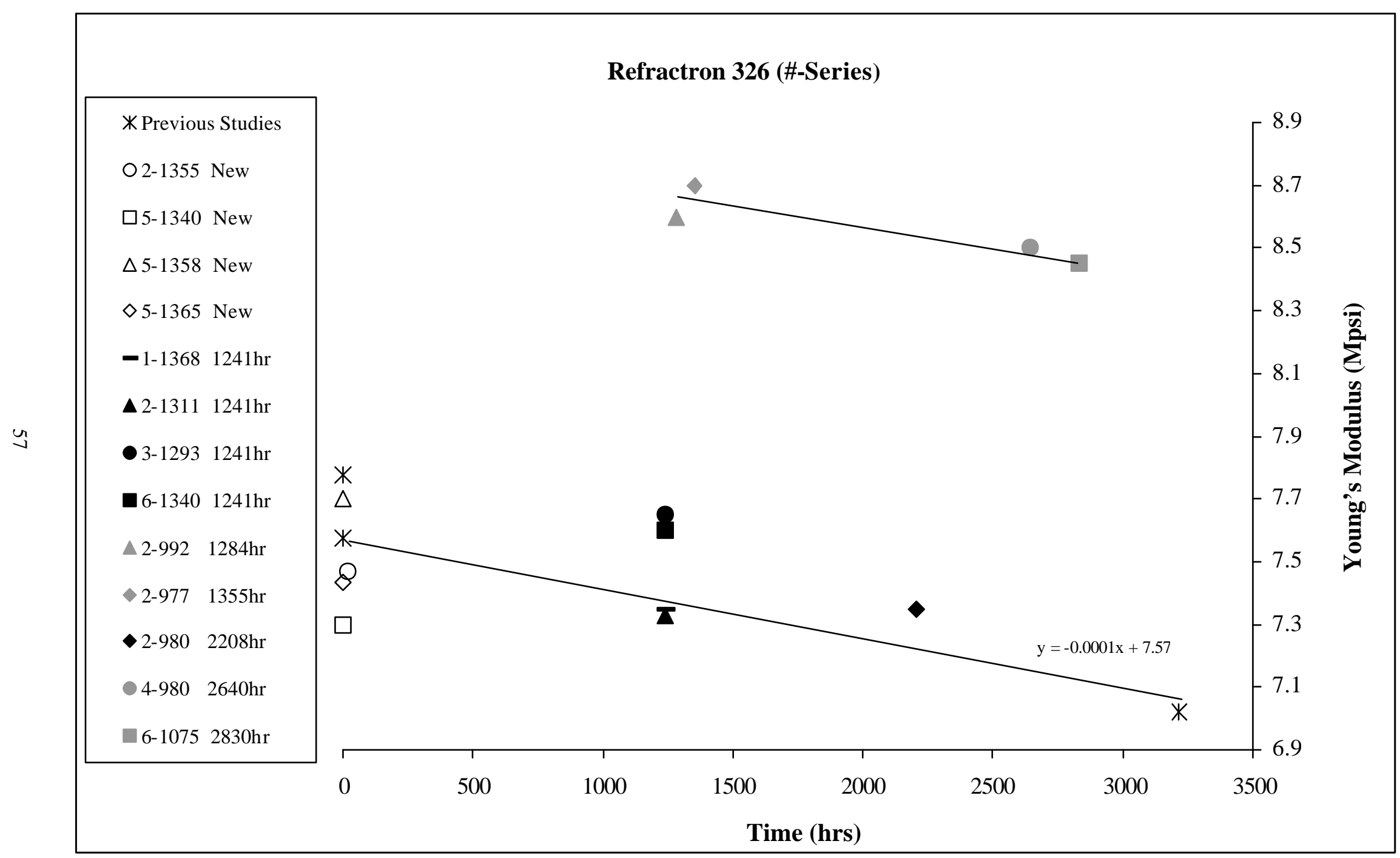

Figure 3.11 Young's modulus of new and used Refractron 326-\# filters (Previous Studies data from Chen and Kiriakidis 2000). 


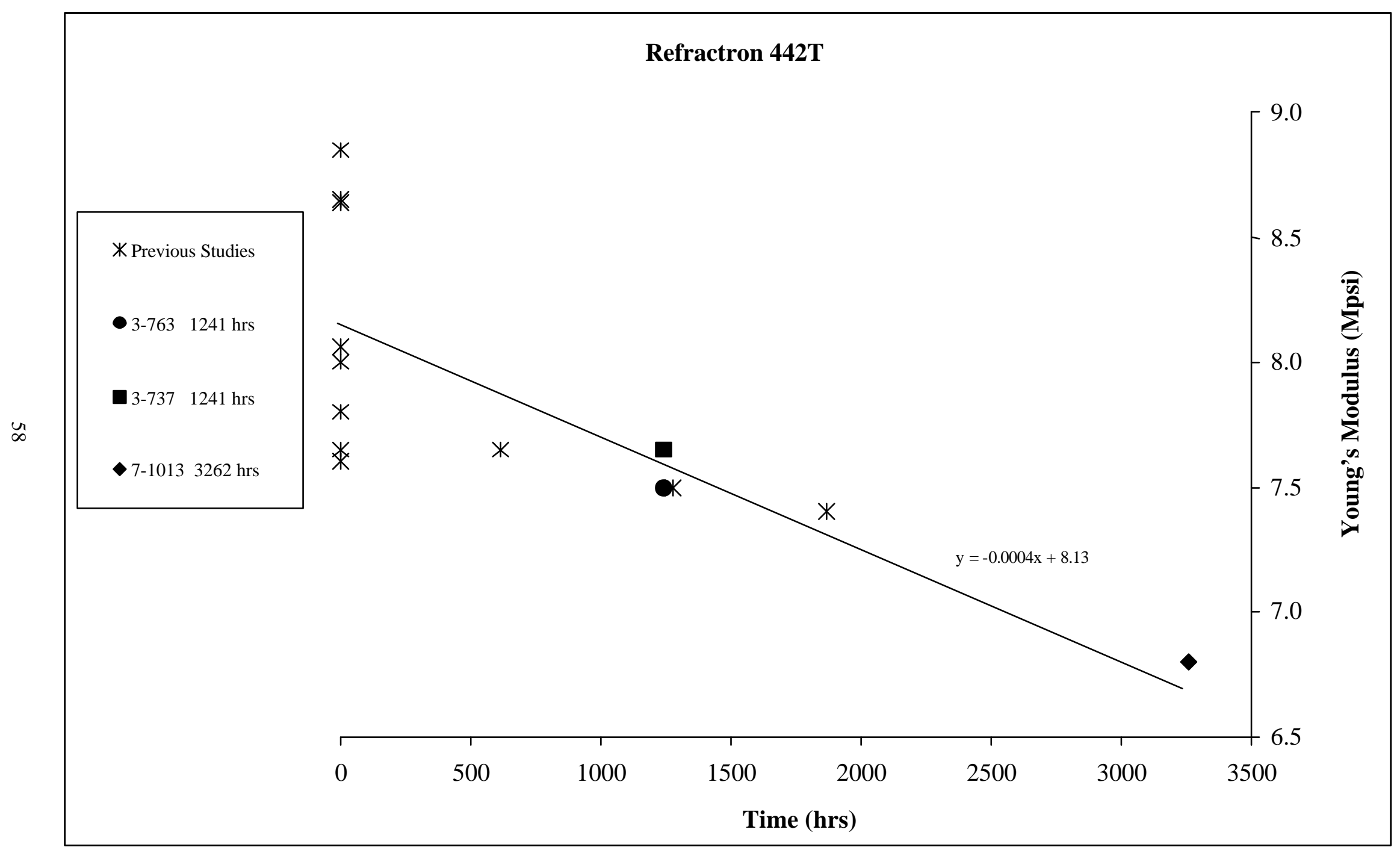

Figure 3.12 Young's modulus of new and used Refractron 442T filters (Previous Studies data from Chen and Kiriakidis 2000). 


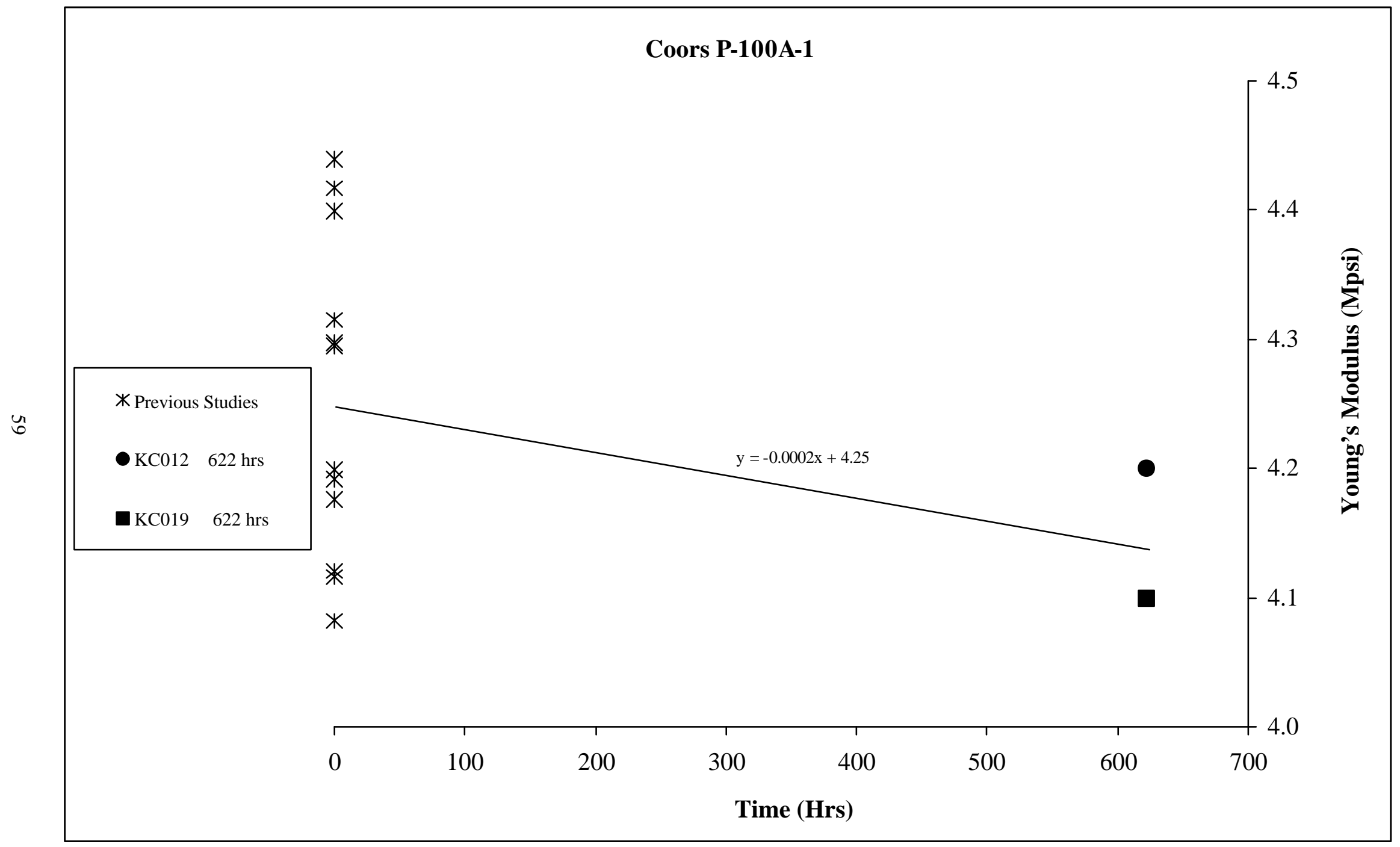

Figure 3.13 Young's modulus of new and used Coors P-100A-1 filters (Previous Studies data from Chen and Kiriakidis 2001). 

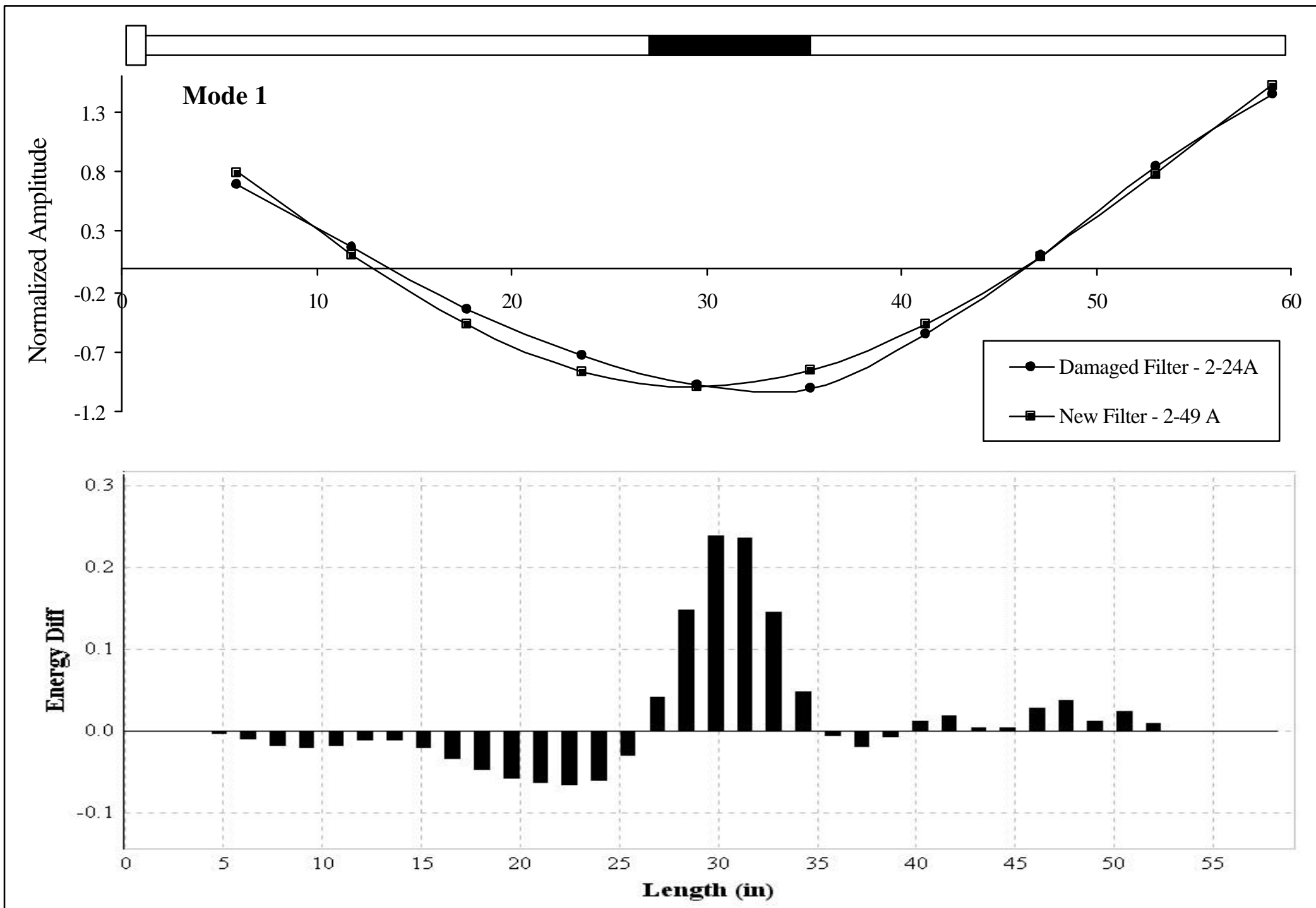

Figure 3.14 Damage location of Pall 2-24A Filter. 


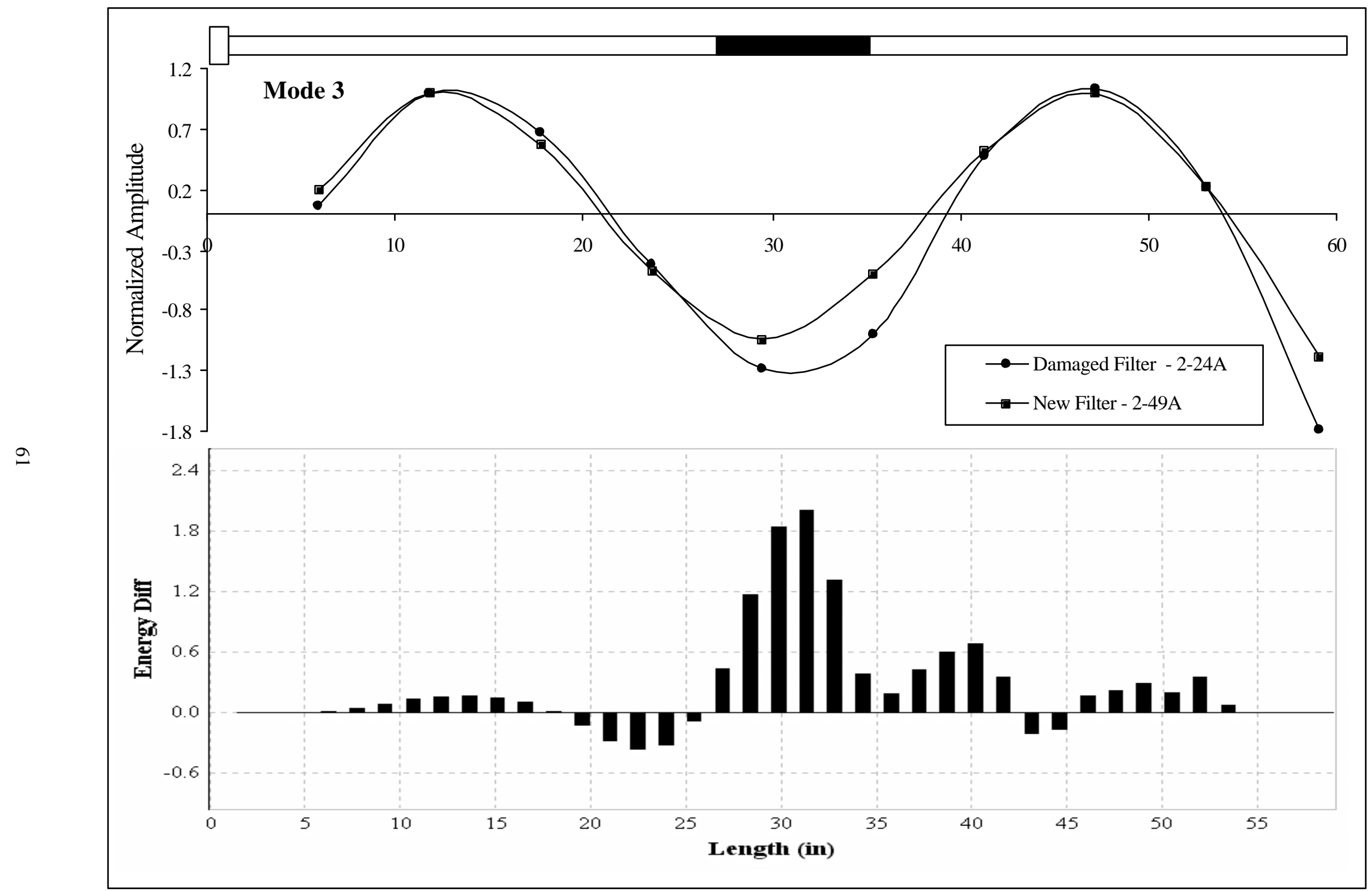

Figure 3.14 Damage location of Pa 2-24A Filter (continued). 

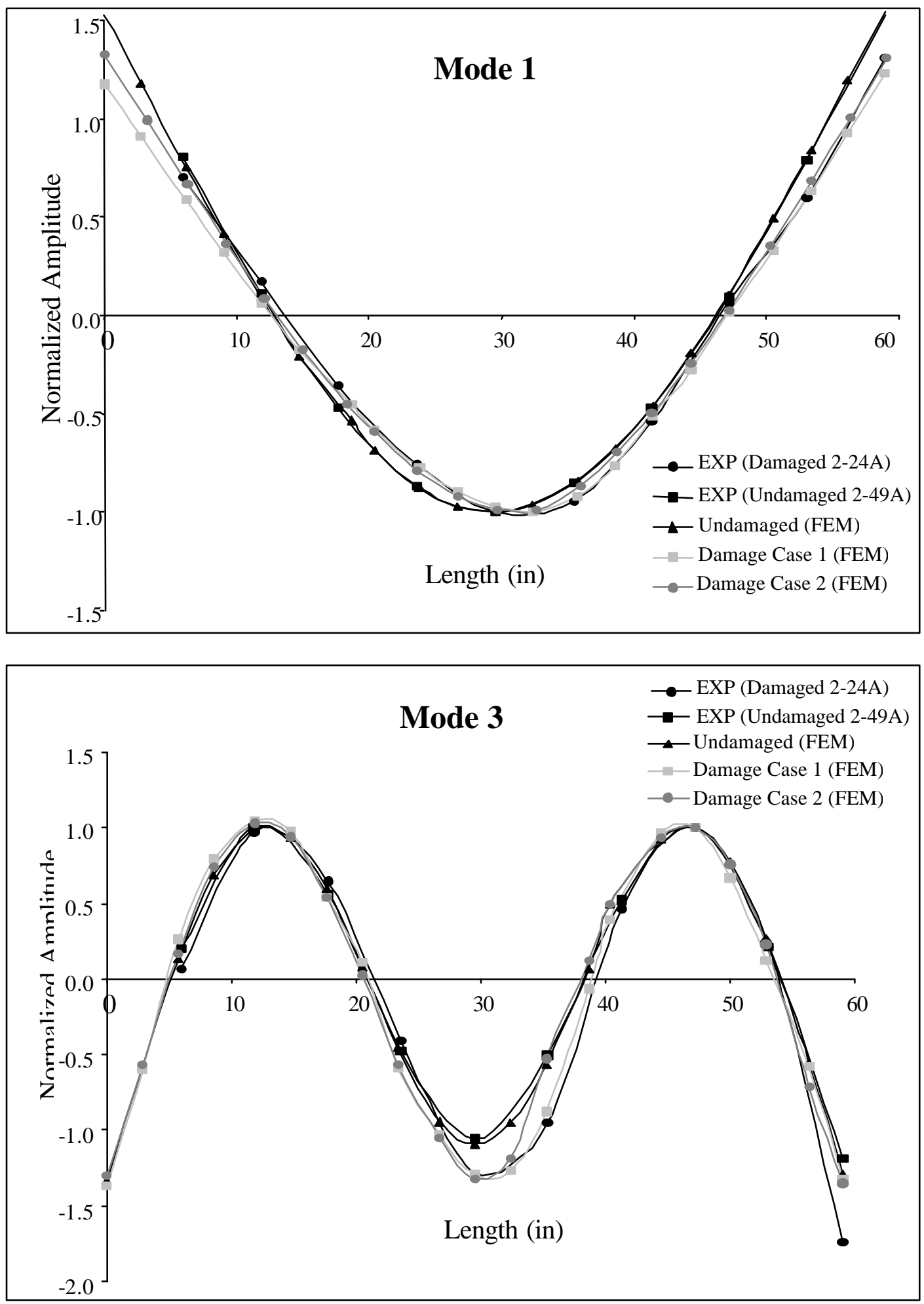

Figure 3.15 FEM simulations and experimental mode shapes used for damage detection. 


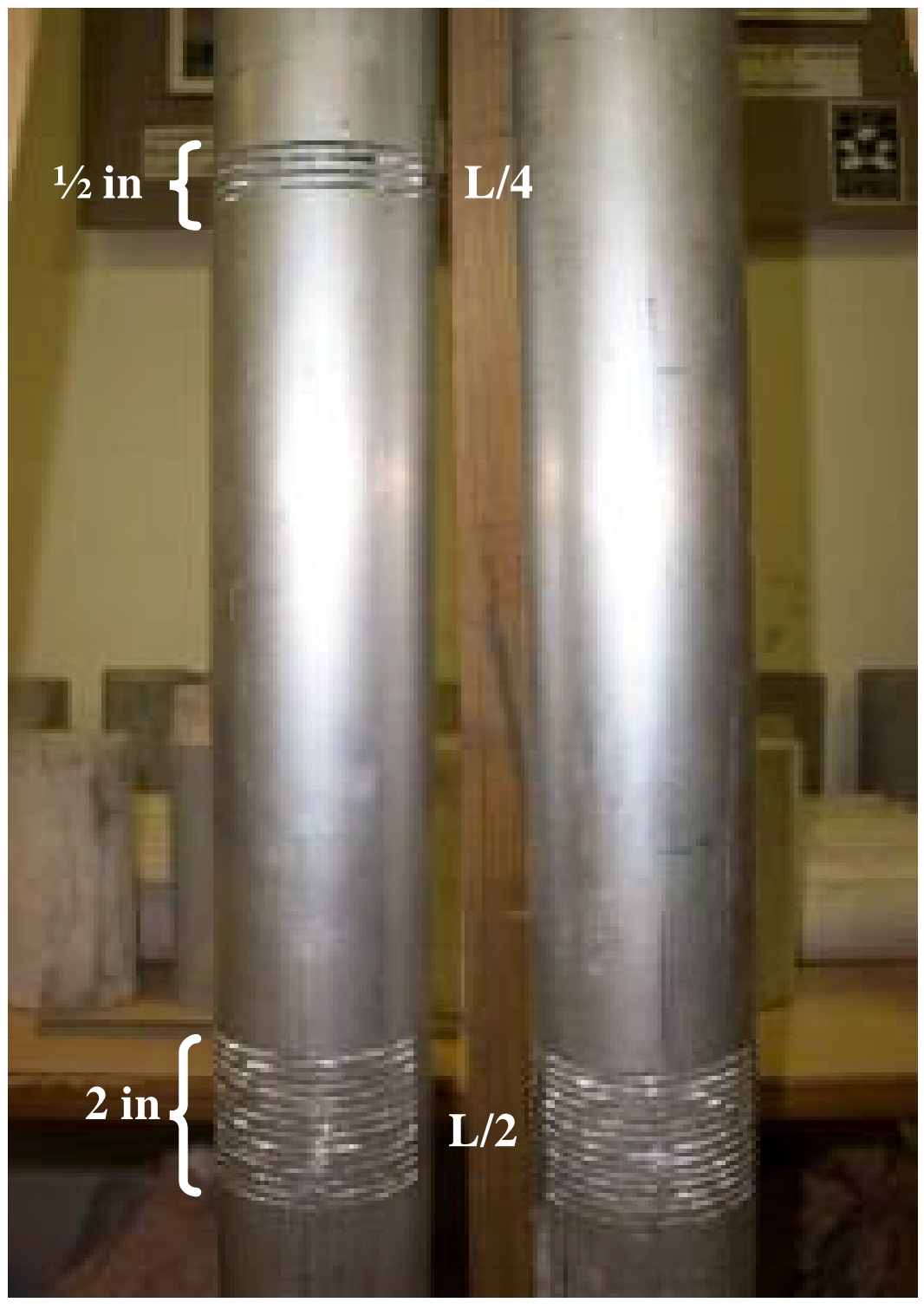

Figure 3.16 Damaged aluminum pipes. 


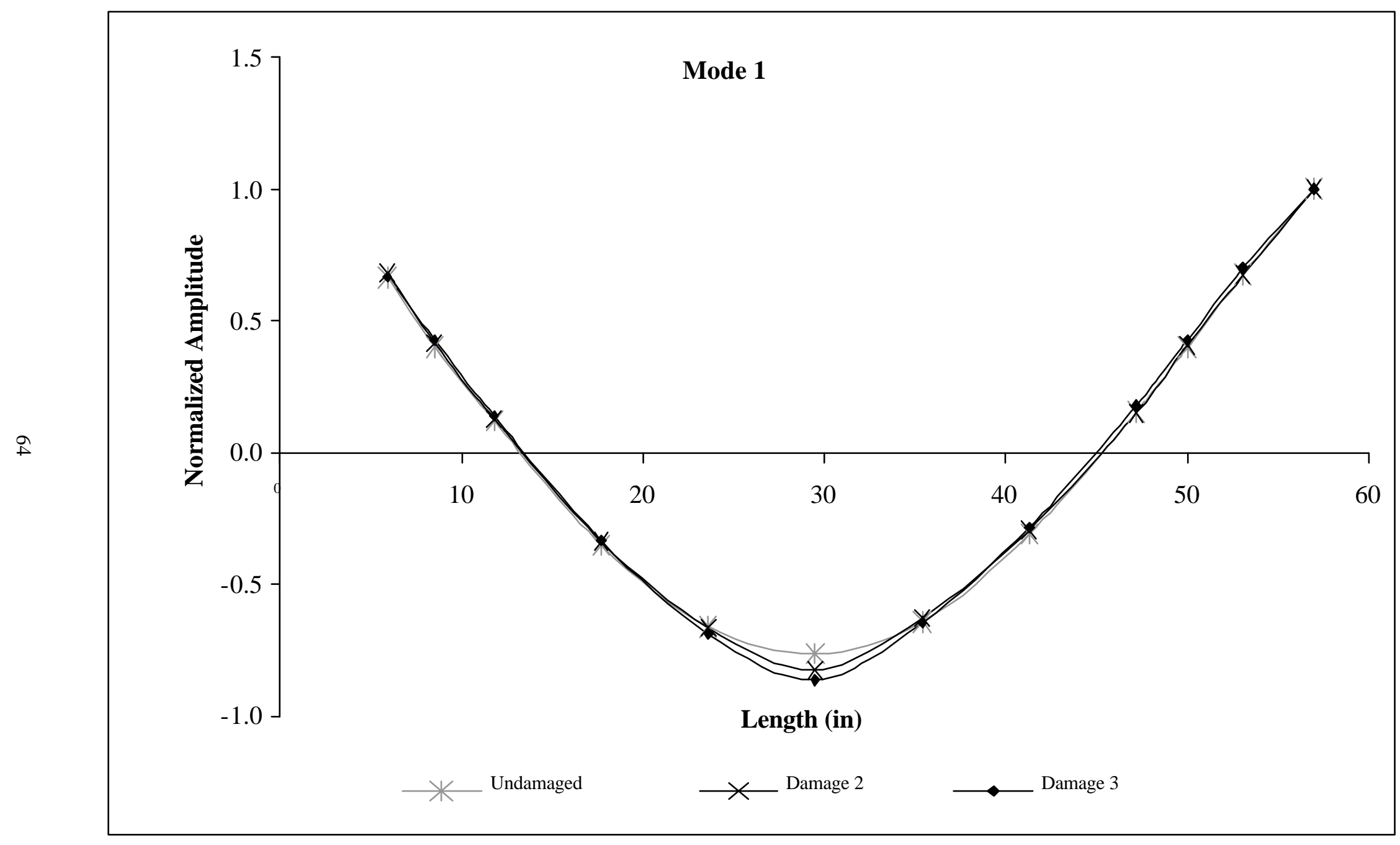

Figure 3.17 Mode shapes comparison between undamaged and two damaged trials of aluminum specimen 1. 


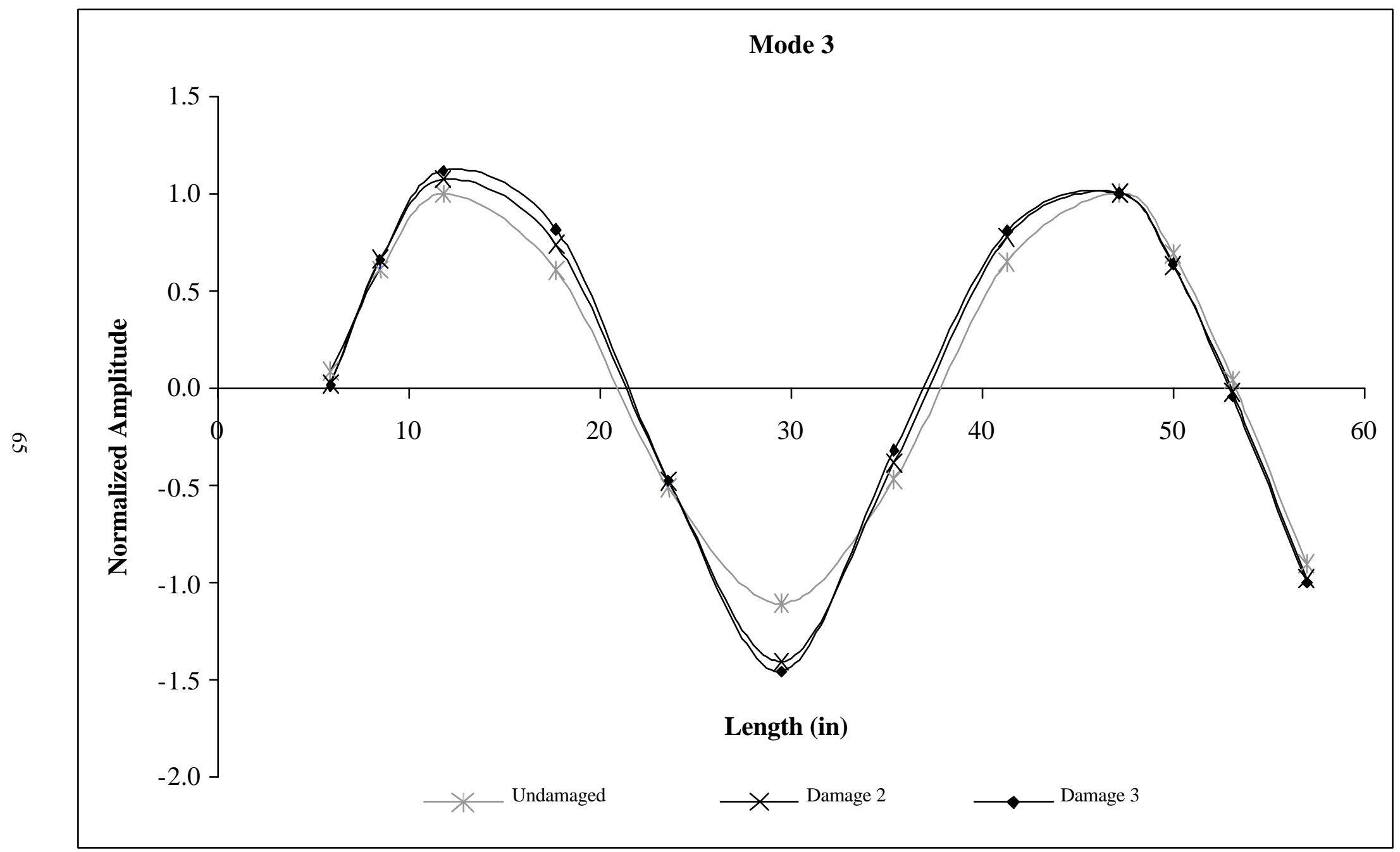

Figure 3.17 Mode shapes comparison between undamaged and two damaged trials of aluminum specimen 1 (continued). 


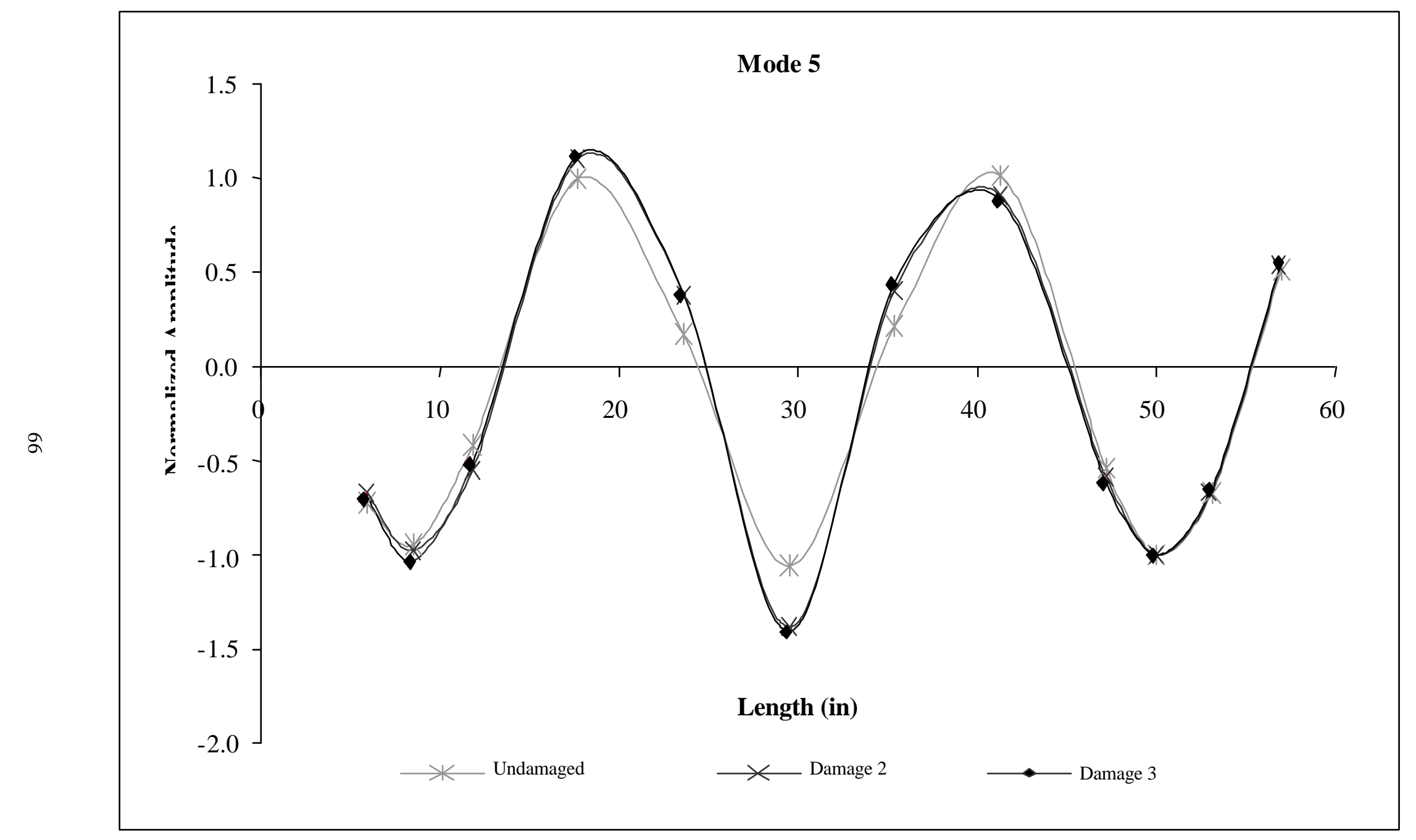

Figure 3.17 Mode shapes comparison between undamaged and two damaged trials of aluminum specimen 1 (continued). 


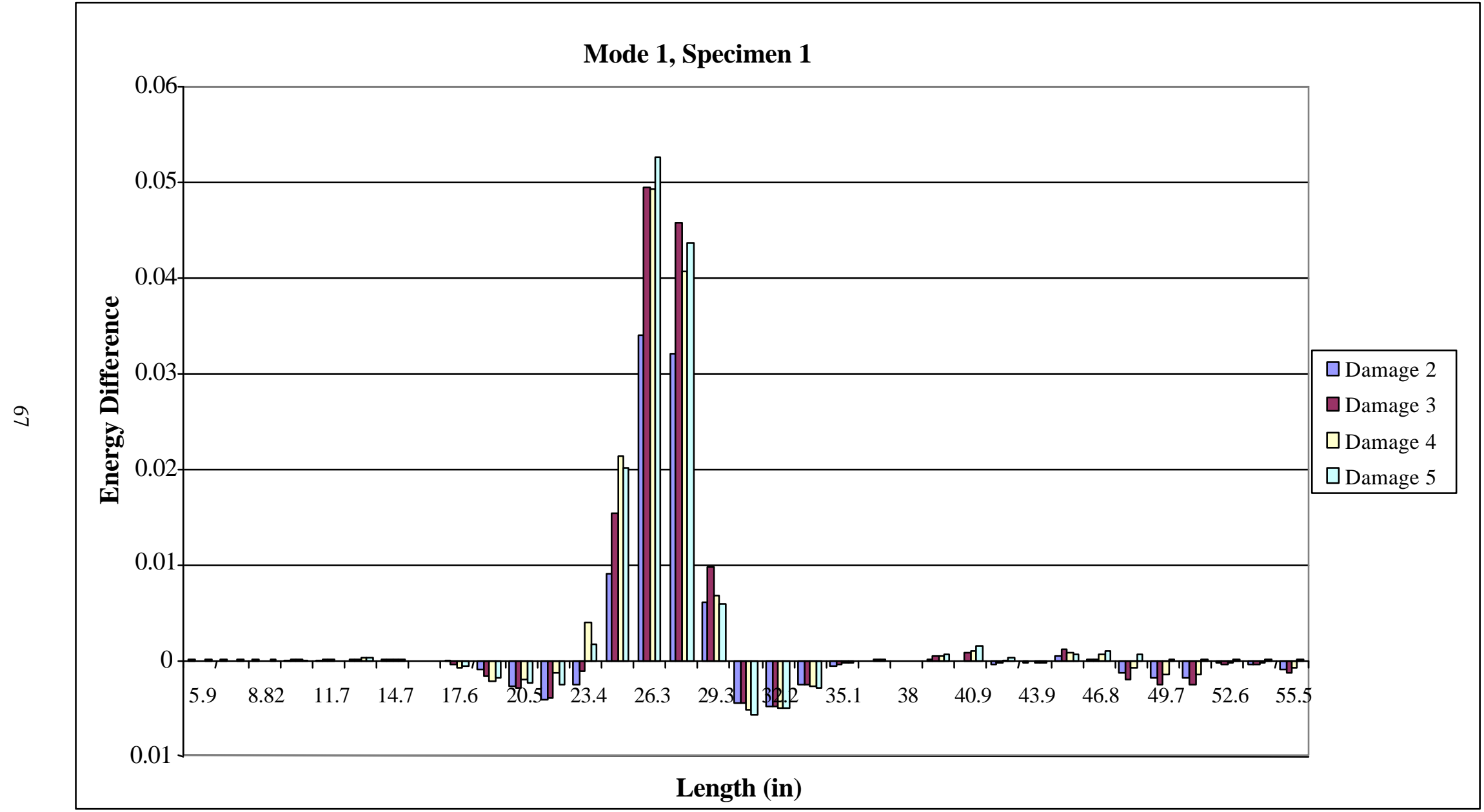

Figure 3.18 Strain-Energy difference in mode 1 for aluminum specimen 1. 


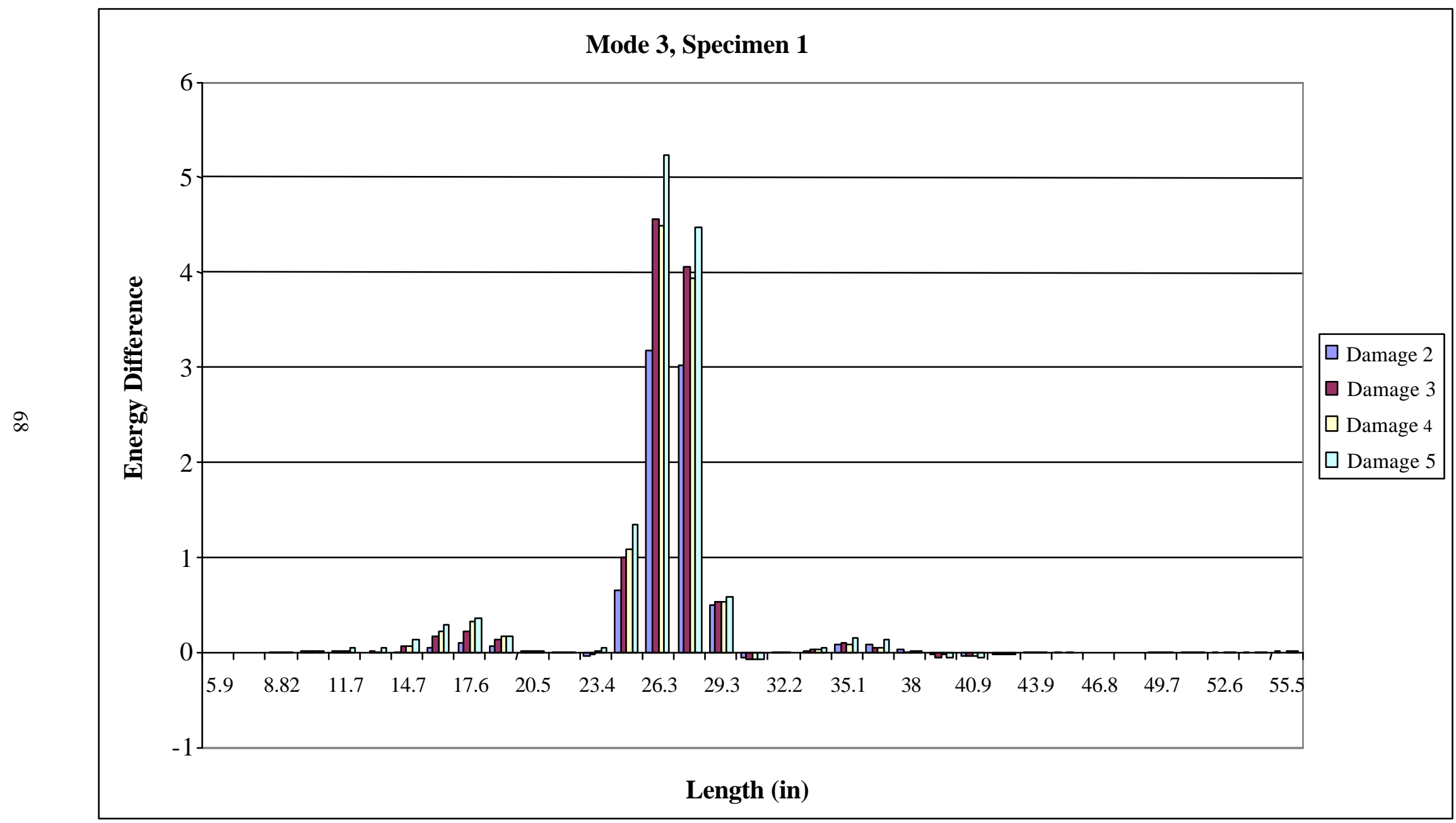

Figure 3.18 Strain-Energy difference in mode 3 for aluminum specimen 1 (continued). 


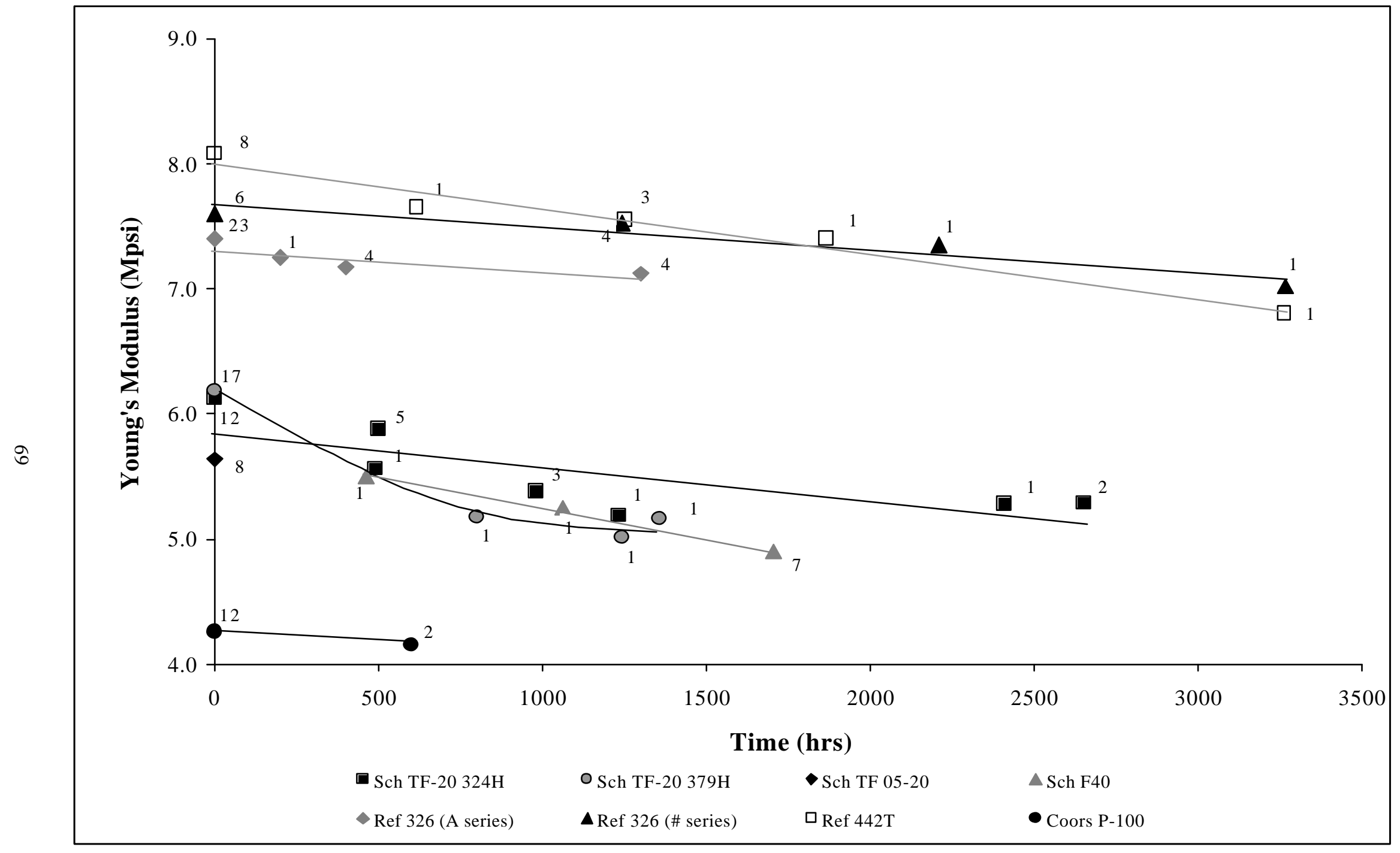

Figure 3.19 Averaged Young's modulus deterioration of ceramic candle filter. 


\section{CHAPTER 4}

\section{EVALUATION OF CERAMIC CANDLE FILTER WITH VARIOUS BOUNDARY CONDITIONS}

\subsection{INTRODUCTION}

This chapter focuses on the study of the boundary condition effects on the candle filter's vibration response and the dynamic response of the filters at two different axes. Dynamic characterization tests are employed to investigate the material properties and boundary constraints of ceramic candle filters. This work also describes the study of non-contact remote sensing for the vibration response of ceramic candle filters. It also compares the vibration response obtained from the non-contact and contact measurements. The study includes Beam Vibration Equations and FEM analysis with different boundary restraints.

In this chapter, seven new ceramic candle filters have been nondestructively tested. The filters were subjected to an excitation force and the vibration responses were recorded using an accelerometer (contact) and/or a laser vibrometer (non-contact). The experimental results were analyzed to determine vibration parameters such as frequency response functions of each candle filter with variable boundary conditions. Experimental, theoretical and finite element methods characteristics were used to calculate the boundary restraints and Young's modulus of the filter, using the filter's second and third bending modes. 


\subsection{EXPERIMENTAL SETUPS}

Two tests setup are used in this chapter, free-free and fixed-free. For the free-free boundary restraint case, the same setup as that of Chapter 3 is used. For the fixed-free setup shown in Figure 4.1, the filter is attached to a frame by using a clamped system. The candle mounting-head was originally designed at the NETL/DOE and was modified to fit the requirements of our tests (Figure 4.2). The mounting-head is bolted by 4 screws to a thick aluminum plate, which is bolted to an optical table.

The same experimental instrumentation as in the previous chapter is used, with the exception that a laser vibrometer is also used to record the filter vibration response. The single-point, stare He-Ne laser vibrometer is a Class II laser and has a velocity frequency range from D.C. to $250-\mathrm{kHz}$. The maximum velocity amplitude is about \pm 10 $\mathrm{m} / \mathrm{s}$ and the resolution is about $2-\mu \mathrm{m} / \mathrm{s}$. The ceramic candle filters that have been tested are three Schumacher TF-20 (Sch TF-20), one Schumacher F-40 (Sch F-40), two Refractron 326 (Pall 326) and one Refractron 442T (Pall 442T).

\subsection{Testing Procedures}

To study the boundary condition effect on the vibration frequencies, the candle filters are placed on the mounting-head base, from which it is possible to change the boundary restraint. First, the clamp system is firmly tightened (T) to simulate a fixed restraint, and then the boundary restraint is changed by unscrewing the clamped system (Lo). The candle filters are also tested on two perpendicular directions (X1 and X2) to determine whether the candle filters are axis-symmetric or not. These tests are conducted using both types of boundary restraints. For all tests conducted, three impacts were 
repeated at each given point of the filter to determine the reproducibility and to obtain average vibration responses.

The Frequency Response Function (FRF) is obtained for the candle filters with different boundary conditions. For the tests conducted with free-free boundary conditions, the first five spikes can be clearly identified from the frequency domain. For the fixed-free boundary conditions tests, the first three spikes are identified, covering a frequency range of up to about $400-\mathrm{Hz}$. Using the frequency and amplitude values from the FRF plot, mode shapes are constructed for each bending mode. Typical vibration responses for both contact and non-contact vibration measurements of a ceramic candle filter with fixed-free boundary conditions are shown in Figure 4.3. The time histories and their frequency domains at one impact location are shown. In order to compare the FRF of both the accelerometer and the LV, the signals from the LV are changed from velocity to acceleration. It is noticed in this figure that the frequency response functions from LV and accelerometer agree well.

\subsection{AnAlysis}

Timoshenko beam equation was studied to simulate the modal frequencies and mode shapes obtained from the experiments. The beam (candle filters) was assumed to be isotropic and homogeneous. The transverse vibration of the beam model was analyzed assuming different boundary conditions. A solution with a general boundary condition was derived during this study. The structural member under consideration is free at one end and the other end is controlled by translational and rotational springs, $\mathrm{k}_{\mathrm{T}}$ and $\mathrm{k}_{\mathrm{R}}$, respectively (Figure 4.4). The stiffness constant of the springs may be changed from zero 
to a full restraint. The boundary conditions and the coupled equations of the Timoshenko's beam for the total deflection Y and the bending slope $\psi$ can be expressed as are as follows

$$
\begin{gathered}
\mathrm{EI}\left(\frac{\mathrm{d} \psi}{\mathrm{dx}}\right)_{\mathrm{x}=0}=\left.\mathrm{k}_{\mathrm{R}} \psi\right|_{\mathrm{x}=0} \quad \mathrm{KAG}\left(\frac{\mathrm{dY}}{\mathrm{dx}}-\psi\right)_{\mathrm{x}=0}=\left.\mathrm{k}_{\mathrm{T}} \mathrm{Y}\right|_{\mathrm{x}=0} \quad\left(\frac{\mathrm{d} \psi}{\mathrm{dx}}\right)_{\mathrm{x}=\mathrm{L}}=0 \quad\left(\frac{\mathrm{dY}}{\mathrm{dx}}-\psi\right)_{\mathrm{x}=\mathrm{L}}=0 \\
\mathrm{EI} \psi^{\prime \prime}+\mathrm{KAG}\left(\mathrm{Y}^{\prime}-\psi\right)-\rho \mathrm{I} \ddot{\psi}=0 \\
\rho \mathrm{\rho} \ddot{\mathrm{Y}}-\mathrm{KAG}\left(\mathrm{Y}^{\prime \prime}-\psi^{\prime}\right)=0
\end{gathered}
$$

The dependent variable $\mathrm{Y}=\mathrm{Y}(x, t)$ represent the lateral displacement at time $t$ of a cross section located at $x$ distance from the end of the beam. $\psi=\psi(x, t)$ is the cross sectional rotation due to bending. The parameters in these equations are Young's modulus E, shear coefficient K (Cowper 1965), shear modulus G, cross section area A, moment of inertia of the cross section I, and mass density $\rho$. Either $\psi$ or Y terms can be eliminated from these equations. Hence two decoupled fourth-order ordinary differential equation can be obtained. When $\mathrm{E}, \mathrm{K}, \mathrm{G}, \mathrm{A}, \mathrm{I}$, and $\rho$ are constant, the value problem defined by Equation (4.2) can be simplified using

$$
\begin{array}{ll}
\xi=\mathrm{x} / \mathrm{L} & \mathrm{b}^{2}=\mathrm{\rho AL}^{4} \omega^{2} /(\mathrm{EI}) \\
\mathrm{r}^{2}=\mathrm{I} /\left(\mathrm{AL}^{2}\right) & \mathrm{s}^{2}=\mathrm{EI} /\left(\mathrm{KAGL}^{2}\right)
\end{array}
$$

The general solutions to Equation (4.2), valid when $b^{2} r^{2} s^{2}$ is neither 1 nor 0 (Huang 1961) can be found as 


$$
\begin{aligned}
& \mathrm{Y}=\mathrm{C}_{1} \cosh (\mathrm{b} \alpha \xi)+\mathrm{C}_{2} \sinh (\mathrm{b} \alpha \xi)+\mathrm{C}_{3} \cos (\mathrm{b} \beta \xi)+\mathrm{C}_{4} \sin (\mathrm{b} \beta \xi) \\
& \psi=\mathrm{D}_{1} \sinh (\mathrm{b} \alpha \xi)+\mathrm{D}_{2} \cosh (\mathrm{b} \alpha \xi)+\mathrm{D}_{3} \sin \mathrm{s}(\mathrm{b} \beta \xi)+\mathrm{D}_{4} \cos (\mathrm{b} \beta \xi)
\end{aligned}
$$

where ${ }_{\alpha}^{\beta}=1 /(2)^{1 / 2}\left\{ \pm\left(\mathrm{r}^{2}-\mathrm{s}^{2}\right)+\left[\left(\mathrm{r}^{2}-\mathrm{s}^{2}\right)^{2}+4 / \mathrm{b}^{2}\right]^{1 / 2}\right\}^{1 / 2}$.

The $C_{i}(i=1$ to 4$)$ constants may be determined in terms of the $D_{i}$ by substituting the general solutions for $\mathrm{Y}$ and $\xi$ into Equation (4.2); $\mathrm{Y}$ can then be expressed in terms of the $\mathrm{D}_{\mathrm{i}}$ constants. The application of the boundary conditions defined by Equation (4.1) to the general solution yield a set of four homogeneous linear algebraic equations with four constant $\mathrm{D}_{1}$ to $\mathrm{D}_{4}$.

$\left[\begin{array}{cccc}\frac{\mathrm{k}_{\mathrm{T}} \mathrm{L} \alpha}{\mathrm{b}\left(\alpha^{2}+\mathrm{s}^{2}\right)} & -\frac{\mathrm{KAG} \mathrm{s}^{2}}{\alpha^{2}+\mathrm{s}^{2}} & \frac{\mathrm{k}_{\mathrm{T}} \mathrm{L} \beta}{\mathrm{b}\left(\beta^{2}-\mathrm{s}^{2}\right)} & \frac{\mathrm{KAG} \mathrm{s}^{2}}{\beta^{2}-\mathrm{s}^{2}} \\ \frac{\mathrm{E} \mathrm{Ib} \alpha}{\mathrm{b}\left(\alpha^{2}+\mathrm{s}^{2}\right)} & -\mathrm{k}_{\mathrm{R}} & \frac{\mathrm{E} \mathrm{Ib} \beta}{\mathrm{b}\left(\beta^{2}-\mathrm{s}^{2}\right)} & -\mathrm{k}_{\mathrm{R}} \\ -\frac{\mathrm{s}^{2} \sinh (\mathrm{b} \alpha)}{\left(\alpha^{2}+\mathrm{s}^{2}\right)} & -\frac{\mathrm{s}^{2} \cosh (\mathrm{b} \alpha)}{\left(\alpha^{2}+\mathrm{s}^{2}\right)} & \frac{\mathrm{s}^{2} \sinh (\mathrm{b} \beta)}{\left(\beta^{2}-\mathrm{s}^{2}\right)} & \frac{\mathrm{s}^{2} \cosh (\mathrm{b} \beta)}{\left(\beta^{2}-\mathrm{s}^{2}\right)} \\ \mathrm{b} \alpha \cosh (\mathrm{b} \alpha) & \mathrm{b} \alpha \sinh (\mathrm{b} \alpha) & \mathrm{b} \beta \cos (\mathrm{b} \beta) & -\mathrm{b} \beta \sin (\mathrm{b} \beta)\end{array}\right]\left\{\begin{array}{l}\mathrm{D}_{1} \\ \mathrm{D}_{2} \\ \mathrm{D}_{3} \\ \mathrm{D}_{4}\end{array}\right\}=0$

In order to obtain a nontrivial solution, the determinant of the matrix must be equal to zero. When $b>0$ and $b \neq 1 / r s$, the equations of boundary value will have nontrivial solution if and only if the determinant of the matrix is equal to 0 . Thus, the frequency equation is obtained from which the natural frequency values $(\omega)$ can be determined. After carrying out some calculations, it can be shown that 


$$
\begin{aligned}
0 & =\mathrm{b}^{2} \mathrm{EI} \mathrm{KAGs}{ }^{2}\left[2-2 \cosh (\mathrm{b} \alpha) \cos (\mathrm{b} \beta)+\frac{\mathrm{b}\left[\mathrm{b}^{2} \mathrm{r}^{2}\left(\mathrm{r}^{2}-\mathrm{s}^{2}\right)+\left(3 \mathrm{r}^{2}-\mathrm{s}^{2}\right)\right]}{\left(1-\mathrm{b}^{2} \mathrm{~s}^{2} \mathrm{r}^{2}\right)^{1 / 2}} \sinh (\mathrm{b} \alpha) \sin (\mathrm{b} \beta)\right] \\
& +\mathrm{k}_{\mathrm{R}} \mathrm{k}_{\mathrm{T}} \mathrm{L}^{2}\left[2+\left[\mathrm{b}^{2}\left(\mathrm{r}^{2}-\mathrm{s}^{2}\right)^{2}+2\right] \cosh (\mathrm{b} \alpha) \cos (\mathrm{b} \beta)-\frac{\mathrm{b}\left(\mathrm{r}^{2}+\mathrm{s}^{2}\right)}{\left(1-\mathrm{b}^{2} \mathrm{~s}^{2} \mathrm{r}^{2}\right)^{1 / 2}} \sinh (\mathrm{b} \alpha) \sin (\mathrm{b} \beta)\right] \\
& +\mathrm{k}_{\mathrm{T}} \mathrm{EI} \mathrm{L} \mathrm{b}{ }^{3}\left(\beta^{2}+\alpha^{2}\right)\left[\alpha\left(\alpha^{2}+\mathrm{s}^{2}\right) \sinh (\mathrm{b} \alpha) \cos (\mathrm{b} \beta)-\beta\left(\beta^{2}-\mathrm{s}^{2}\right) \cosh (\mathrm{b} \alpha) \sin (\mathrm{b} \beta)\right] \\
& -\mathrm{k}_{\mathrm{r}} \text { KAG L b } \mathrm{s}^{3} \frac{\left(\beta^{2}+\alpha^{2}\right)}{\alpha \beta}\left[\beta\left(\beta^{2}-\mathrm{s}^{2}\right) \sinh (\mathrm{b} \alpha) \cos (\mathrm{b} \beta)+\alpha\left(\alpha^{2}+\mathrm{s}^{2}\right) \cosh (\mathrm{b} \alpha) \sin (\mathrm{b} \beta)\right]
\end{aligned}
$$

Three common types of beams can be identified from Equation (4.6) by assigning values of 0 or $\infty$ to the stiffness constant $k_{T}$ and $k_{R}$. They are: fixed-free when both $k_{T}$ and $\mathrm{k}_{\mathrm{R}}$ are equal $\infty($ Case $\mathrm{B})$, hinge-free when $\mathrm{k}_{\mathrm{R}}$ is 0 and $\mathrm{k}_{\mathrm{T}}$ is $\infty($ Case $\mathrm{C})$, and free-free when $k_{T}$ and $k_{R}$ are equal 0 (Case D). In the current study, we are specifically interested in the case where $k_{R}$ is a positive number and $k_{T}$ is $\infty($ Case $A)$. The frequency equations for case A, B, C, and D have been obtained directly using (4.6). The frequency equation for the Case A is shown as

$$
\begin{aligned}
0 & =K^{\wedge}\left[2+\left[b^{2}\left(r^{2}-s^{2}\right)^{2}+2\right] \cosh (b \alpha) \cos (b \beta)-\frac{b\left(r^{2}+s^{2}\right)}{\left(1-b^{2} s^{2} r^{2}\right)^{1 / 2}} \sinh (b \alpha) \sin (b \beta)\right] \\
& +b^{3}\left(\beta^{2}+\alpha^{2}\right)\left[\alpha\left(\alpha^{2}+s^{2}\right) \sinh (b \alpha) \cos (b \beta)-\beta\left(\beta^{2}-s^{2}\right) \cosh (b \alpha) \sin (b \beta)\right]
\end{aligned}
$$

where, $\mathrm{K}^{\wedge}=\mathrm{L} \mathrm{k}_{\mathrm{R}} /(\mathrm{EI})$, is the nondimensional rotational spring. The transverse vibration of a beam can be simplified using the Bernoulli-Euler beam equation, which neglects the shear and rotary inertia effect from Equation (4.2). Therefore, $d Y / d x=\psi$, the values of $\beta, \alpha$ are $=1 / \sqrt{ } b$, and the lateral displacement $Y$ in Equation (4.4) is enough to solve the Bernoulli-Euler beam equation. Thus general solution Y can be rewrite as 


$$
\mathrm{Y}=\mathrm{C}_{1} \cosh (\gamma \xi)+\mathrm{C}_{2} \sinh (\gamma \xi)+\mathrm{C}_{3} \cos (\gamma \xi)+\mathrm{C}_{4} \sin (\gamma \xi)
$$

where $\gamma^{4}=b^{2}$. Using the boundary conditions defined in Equation (4.1), the following frequency equation is obtained:

$$
\begin{aligned}
0=1 & +\left(\mathrm{L}^{4} \mathrm{k}_{\mathrm{T}} \mathrm{k}_{\mathrm{R}}\right) /\left(\gamma^{4} \mathrm{E}^{2} \mathrm{I}^{2}\right)+\cos (\gamma) \cosh (\gamma)\left\lfloor\left(\mathrm{L}^{4} \mathrm{k}_{\mathrm{T}} \mathrm{k}_{\mathrm{R}}\right) /\left(\gamma^{4} \mathrm{E}^{2} \mathrm{I}^{2}\right)-1\right] \\
& +\mathrm{L} /\left(\gamma^{3} \mathrm{EI}\right)\left[\left(\mathrm{L}^{2} \mathrm{k}_{\mathrm{T}}-\gamma^{2} \mathrm{k}_{\mathrm{R}}\right) \cos (\gamma) \sinh (\gamma)-\left(\mathrm{L}^{2} \mathrm{k}_{\mathrm{T}}+\gamma^{2} \mathrm{k}_{\mathrm{R}}\right) \sin (\gamma) \cosh (\gamma)\right]
\end{aligned}
$$

and the frequency equation obtained for the Case A (Figure 4.4) boundary conditions is

$$
0=-\mathrm{K}^{\wedge}(1+\cos (\gamma) \cosh (\gamma))+\gamma(\sin (\gamma) \cosh (\gamma)-\cos (\gamma) \sinh (\gamma))
$$

The first five solutions of the Bernoulli- Euler frequency equation are summarized in terms of the frequency parameter $\gamma$ for various boundary restraints as shown in Table 4.1. It is noted that the frequencies increase when $\mathrm{K}^{\wedge}$ increases. Natural frequencies at higher modes are insensitive to the change of boundary restraints. The natural frequency of the $\mathrm{m}^{\text {th }}$ bending mode is divided by the natural frequency of an arbitrary bending mode. Therefore, the frequency ratio depends only on the nondimensional $\mathrm{K}^{\wedge}$ value and is independent of the material properties and dimensions of the structure. In the fixedfree tests, the second bending mode was chosen to be the arbitrary mode. The frequency ratio equation is given by 


$$
\frac{f_{m}}{f_{2}}=\frac{\left(\gamma_{m}\right)^{2}}{\left(\gamma_{2}\right)^{2}}
$$

\subsection{Finite ELEMENT ANALYSIS}

The numerical simulation was conducted using finite element models to evaluate the dynamic response of the candle filters. The FEM built for the Pall filters was made of 3390 brick elements with 4985 nodes. The weight density input used for the Pall 442 T filters was $0.072 \mathrm{lb} / \mathrm{in}^{3}$ and for the Pall 326-series model was $0.069 \mathrm{lb} / \mathrm{in}^{3}$. For Sch TF-20 filters the model was also made of 3390 brick elements with 4985 nodes. The weight density in this model was $0.073 \mathrm{lb} / \mathrm{in}^{3}$. For the Sch F- 40, 3270 elements with 4893 nodes model were used to build the model. The weight density used in this model was 0.069 b/in ${ }^{3}$.

Clamped-free boundary conditions were simulated by using elastic-translation springs. Figure 4.5 is a typical clamped-free setup of the candle filter's FEM model. This setup of boundary conditions is capable of simulating the vibration response from hinge-free to complete fixed-free restraint by increasing the stiffness $\left(\mathrm{k}_{\mathrm{x}}\right)$ of the spring on the $\mathrm{X}$-axis. The models will deflect then in the $\mathrm{Y}$ direction. There is no restraint in the $\mathrm{Z}$ direction. Young's modulus and the boundary conditions of the filter can be estimated when FEM's frequency values are close to experimental results. To compare the rotational restraints between FEM and theoretical calculation, the following relationships were used:

$$
\mathrm{k}_{\mathrm{R}}=\mathrm{k}_{\mathrm{x}} \cdot \mathrm{h}^{2}
$$




$$
\therefore \mathrm{K}^{\wedge}=\frac{\mathrm{k}_{\mathrm{R}} \mathrm{L}}{\mathrm{EI}}=\frac{\mathrm{k}_{\mathrm{x}} \mathrm{h}^{2} \mathrm{~L}}{\mathrm{EI}}
$$

where, $\mathrm{h}$ is the width of the filter's head.

\subsection{RESUlts}

Theoretical frequencies are calculated using Equations (7) and (10) for various boundary restraints. Displacements due to both shear and rotatory inertia in the Timoshenko equation lead to a reduction in the flexural frequencies, $\mathrm{f}_{\mathrm{T}}$, relative to the value $\mathrm{f}_{\mathrm{BE}}$ calculated from the elementary Bernoulli-Euler theory. Figure 4.6 shows the values of $f_{\mathrm{T}} / \mathrm{f}_{\mathrm{BE}}$ over a wide range of dimensionless inverse slenderness, $r$, and dimensionless rotational spring, $\mathrm{K}^{\wedge}$. There is a decrease in the ratio $\mathrm{f}_{\mathrm{T}} / \mathrm{f}_{\mathrm{BE}}$ with the increment of the inverse slenderness ratio. In addition, the decrease in the ratio becomes bigger at higher vibration modes. The decrease in the ratio is also bigger with larger rotational spring. Results of the ratio $\mathrm{f}_{\mathrm{T}} / \mathrm{f}_{\mathrm{BE}}$ for the first vibrational mode $(\mathrm{n}=1)$ were not included in Figure 4.6. The variation of $\mathrm{f}_{\mathrm{T}} / \mathrm{f}_{\mathrm{BE}}$ for the first mode is about 0.992 when $\mathrm{K}^{\wedge}$ $\geq 1$ and about 0.997 when $\mathrm{K}^{\wedge}=1$, at $\mathrm{r}=0.03$.

The natural frequencies and mode shapes obtained experimentally are tabulated along with the finite element analysis and theoretical values. The experimental values are obtained using either an accelerometer or a laser vibrometer.

\subsubsection{Natural Frequencies}

The experimental natural frequencies with various boundary conditions are compared with the analytical equations and the FEM models. 
Contact and non-contact experimental measurements of the candle filters with free-free boundary conditions are first studied. For these boundary restraint tests, the tapping is able to excite the first five bending modes. Table 4.2 shows the frequency results for the 335I-161 Sch TF-20 filter. The frequency values are very close between the accelerometer and LV measurements. The difference in results between these two sensors is less than $0.5 \%$ on the first five frequency modes. Similar results for both measurements are obtained for all ceramic candle filters tested. This shows that the accelerometer and the LV have compatible outputs when measuring the filter's vibration frequencies with free-free restraints. The natural frequencies from the FEM analysis also match the LV experimental results with less than $0.5 \%$ difference. For the theoretical analysis, when the nominal length (L) is used the difference between the LV frequencies and the B-E result range from $3.5 \%$ to $9.5 \%$. The LV frequencies and the Timoshenko results are about $2.6 \%$ difference. An effective length $\left(\mathrm{L}_{\text {eff }}\right)$ which considers the change of the candle filter's cross-section at the ends is used. This effective length is obtained by dividing the total volume of the candle filter by the typical cross section area.

When $\mathrm{L}_{\text {eff }}$ is used, these differences decrease to about $1.3 \%$ to $7.3 \%$ for the B-E frequencies and less than $0.5 \%$ for the Timoshenko frequencies. The good agreement of the frequencies, especially in the higher modes, in the Timoshenko results is because the shear effect is considered. Young's moduli obtained from the FEM analysis and the theoretical equations are $5.66 \times 10^{6} \mathrm{psi}$ and $5.58 \times 10^{6} \mathrm{psi}$, respectively, based on the above frequencies.

Table 4.3 shows the frequency results of contact and non-contact measurements of the same candle filter but with fixed-free boundary condition. The experimental 
results from accelerometer and LV are about $4.6 \%$ difference in the first frequency mode and less than $0.6 \%$ difference in the second and third modes. The large frequency difference in the first mode is due to the insensitivity of the accelerometer at the low frequency range. The Young's Moduli used in FEM and theoretical equations are the

same as Table 4. 2. The boundary restraint values, $\mathrm{k}_{\mathrm{x}}$ and $\mathrm{k}_{\mathrm{R}}$, are $1.0 \times 10^{5} \mathrm{lb} / \mathrm{in}$ and $8 \times 10^{5}$ lb-in, respectively. These values give identical boundary restraints of the candle filter. The difference between LV experimental frequencies and FEM results is about $1 \%$. The $\mathrm{LV}$ frequencies and Timoshenko results, when $\mathrm{L}_{\text {eff }}$ is used have less than $1 \%$ difference in the second and third modes.

\subsubsection{Mode Shapes}

The mode shapes from the experiments and the FEM analysis are compared graphically. Ten data points along the candle filter length are used to plot the mode shapes. For the purpose of comparison, the experimental and numerical mode shapes are normalized at the same points. For each candle filter, the second and third bending modes under fixed-free conditions are studied. The mode shape of the first vibration mode is not retrievable due to the accelerometer resolution. Figure 4.7 shows the experimental mode shapes of the 2-1355 Pall 326 candle filter compared with the FEM simulation. The Young's Modulus and $\mathrm{k}_{\mathrm{x}}$ restraint used in the FEM are $7.46 \times 10^{6} \mathrm{psi}$ and $1.59 \times 10^{5} \mathrm{lb} / \mathrm{in}$, respectively. The second and third mode shapes are normalized at points $\mathrm{x}=0.4 \mathrm{~L}$ and $\mathrm{x}=0.2 \mathrm{~L}$, respectively. Results from both sensors agree well with the FEM simulation. 
Figure 4.8 shows the influences of $\mathrm{k}_{\mathrm{x}}$ in the mode shapes from FEM simulations. Two sets of boundary conditions are used with a constant Young's modulus value. The first set has a $\mathrm{k}_{\mathrm{x}}$ value equal to $1.00 \times 10^{4} \mathrm{lb} / \mathrm{in}\left(\mathrm{K}^{\wedge}=0.81\right)$ and the second set has $\mathrm{k}_{\mathrm{x}}$ equal to $2.60 \times 10^{6} \mathrm{lb} /$ in $\left(\mathrm{K}^{\wedge}=13.80\right)$. When comparing these two sets of mode shapes, it is noticed that when the $\mathrm{k}_{\mathrm{x}}$ restraint is higher the curve has less rotation at the fixed end. Therefore, the $\mathrm{k}_{\mathrm{x}}$ restraint not only affects the frequency values, but also the mode shapes. If $\mathrm{k}_{\mathrm{x}}$ is kept constant and different Young's moduli are used, the normalized vibration mode shape remains the same.

The experimental mode shapes from two perpendicular axes with fixed-free boundary conditions are also compared with FEM simulations. The experimental and FEM mode shapes match well. Good agreement between both axes is also observed for the first five mode shapes when free-free boundary condition is considered.

\subsubsection{Axisymmetry of Candle Filters}

The percentage differences of natural frequencies between two perpendicular directions (X1 and X2) for all candle filters with free-free boundary condition are shown in Table 4.4. The difference in natural frequencies between the two axes is generally very small (less than 1\%). Sch TF-20 335I-161, 326i-147 and Pall 326 5-1365 candle filters have identical frequency values in the two perpendicular axes. These seven candle filters can be considered to behave axisymmetrically.

In order to test the candle filters' axisymmetric behavior when fixed-free boundary condition is used, impacts are given on the $\mathrm{X} 1$ and $\mathrm{X} 2$ axes. When the $\mathrm{X} 1$ test is completed, the screws used for mounting are removed and then tightened again after 
rotating the filter $90^{\circ}$. Hence, the $\mathrm{X} 2$ test is performed with a different boundary restraint. Table 4.5 shows the results obtained for the 2-286 Pall 442T candle filter. Experimental LV, FEM and calculated frequencies for fixed-free tests in both axes are listed. It is noticed that even though the natural frequencies are different in both axes, the Young's modulus used remains the same. The change in natural frequencies between the axes due to the variation of the boundary conditions is small.

\subsubsection{Boundary Restraint Effects}

The analytical and FEM results are used to describe the boundary conditions effect and to determine the Young's modulus of each ceramic candle filter. The relationship between the frequency ratio of the third and second vibration modes $\left(f_{3} / f_{2}\right)$ and the boundary restraint of these twelve FEM models is illustrated in Figure 4.9. For each type of candle filter, the respective FEM model runs four times. Each time the Young's modulus changes while the rest of the material properties are kept constant. The weight density used in the FEM models for the Pall 326, Pall 442T, and SchTF-20 are $0.0691 \mathrm{~b} / \mathrm{in}^{3}, 0.072 \mathrm{lb} / \mathrm{in}^{3}$, and $0.073 \mathrm{lb} / \mathrm{in}^{3}$, respectively. These three filters types have the same cross section dimensions (inner/outer radius equal to 0.66 ). The horizontal axis represents the nondimensional rotational spring stiffness $\left(\mathrm{K}^{\wedge}\right)$ and the vertical axis represents the $f_{3} / f_{2}$ frequency ratio. When the $K^{\wedge}$ approaches 0 , the boundary condition becomes a pinned restraint and when $\mathrm{K}^{\wedge}$ increases, the boundary condition is closer to a fixed restraint. The influence of the $\mathrm{K}^{\wedge}$ factor on the frequency ratio is greater when the boundary restraint approximates the pinned restraint. When $\mathrm{K}^{\wedge}$ is greater than 25 , the change in frequency ratio is insignificant. 
The Young's moduli used for the Pall 326 and $442 \mathrm{~T}$ model are $6.0 \times 10^{4} \mathrm{psi}$, 7.0x $10^{4} \mathrm{psi}, 8.0 \times 10^{4} \mathrm{psi}$, and $9.0 \times 10^{4} \mathrm{psi}$. For the Sch TF-20 model the Young's moduli used are $4.0 \times 10^{4} \mathrm{psi}, 5.0 \times 10^{4} \mathrm{psi}, 6.0 \times 10^{4} \mathrm{psi}$, and $7.0 \times 10^{4} \mathrm{psi}$.

All FEM results have the same $f_{3} / f_{2}$ frequency ratios, which converged into one curve. Therefore, the frequency ratios do not depend on the structural properties of the filter such as Young's modulus, length and weigh density. The only factor that affects the frequency ratios on this curve is the boundary restraint $\mathrm{K}^{\wedge}$. The results of the Timoshenko and Bernoulli-Euler follow the same patterns as the FEM analysis. The B-E calculations do not consider the shear effect and only represent outcomes from a one dimensional finite beam. Therefore the boundary condition $\left(\mathrm{k}_{\mathrm{R}}\right)$ obtained from BernoulliEuler calculation will not be as accurate as that obtained from FEM simulation or Timoshenko’s analysis.

In order to verify the cross section influence on the frequency ratios, two different hollow circle cross sections are used in the FEM simulation and the Timoshenko equation. One cross section has an inner/outer radius of 0.66 (Sch Tf-20, Pall 326, and Pall 442T) and the other has an inner/outer radius of 0.5 (Sch F40). The results from FEM and Timoshenko analysis are similar. The $\mathrm{f} 3 / \mathrm{f} 2$ curves from both inner/outer radius have similar results at small $\mathrm{K}^{\wedge}$, but when the boundary restraint increases the 0.5 inner/outer radius curve has the biggest curvature. Hence, the frequency ratios not only depend on the boundary restraint, $\mathrm{K}^{\wedge}$, but also on the cross section of the candle filter.

Using the boundary restraint $\mathrm{K}^{\wedge}$ obtained from Figure 4.9 and the nondimensional variable $b$ defined previously (Equation 4.3), the Young's modulus of the ceramic candle filters can be obtained. Figure 4.10 shows the results of the variable $b$ from the analytical 
and the FEM analysis for various boundary restraints, $\mathrm{K}^{\wedge}$. The variable $b$ is independent of the types of ceramic candle filter that are tested, as long as the inner/outer radius ratio remains the same. The FEM models with different length, mass density and Young's modulus have equal $b$ values. The same results are observed when the Timoshenko beam equation is used.

The FEM curves from Figures 4.9 and 4.10 can now be used to determine the Young's moduli of the ceramic candle filters with inner/outer radius of 0.66 under controlled fixed-free boundary conditions. Figure 4.11 shows the experimental f3/f2 frequency ratio of six candle filters (Sch TF-20, Pall 326 and Pall 442T groups) tested using the LV measurements with tight (T) and loose (Lo) boundary restraints. There are two loosely-restrained Sch TF-20 H179 filters tested to represent different levels of loosening boundary conditions. The nondimensional $\mathrm{K}^{\wedge}$ value is obtained for each candle filter by using the experimental frequency ratios in this figure. For example, for a Pall 442T 2-286 filter with restraint $\mathrm{T}$ that has a frequency ratio of 2.81 , the $\mathrm{K}^{\wedge}$ value is about 14.1.

Figure 4.12 shows the dimensionless variable $b$ obtained for the ceramic candle filters using the FEM analysis. The variable $b$ is obtained by intersecting each experimental $\mathrm{K}^{\wedge}$ value with the curve. The $\mathrm{K}^{\wedge}$ value used for each filter is the respective value obtained from Figure 4.11. Once the variable $b$ is known, Equation 4.3 is used to determine the Young's modulus of the candle filter. For example, for the Sch TF-20 379 H-179 (T, Lo, and Lo1) filter ( $\square, \square$, and $\square)$, the $\mathrm{K}^{\wedge}$ restraints from Figure 4.11 are about $11.2,8.6$ and 3.1, respectively. The values of $b$ obtained by plugging these $\mathrm{K}^{\wedge}$ results into Figure 4.12 are about 58.5, 57.3, and 52.45, respectively. The Young's modulus results 
found using Equation 4.3 are the same, $E=5.60 \times 10^{6} \mathrm{psi}( \pm 0.3 \%$ due to the three different boundary restraints).

For the Sch F-40, different f3/f2 and $b$ curves are used to determine the Young's modulus (Figures 4.13 and 4.14). These curves correspond to filters with an inner/outer radius of 0.5 . Table 4.6 shows the comparison of the Young's modulus values obtained for all the filters evaluated with controlled fixed-free and free-free boundary conditions using the FEM charts. The difference between the Young's moduli of the filters obtained with the free-free and controlled fixed-free boundary conditions is less than about $2.0 \%$. Following the same procedure, $\mathrm{K}^{\wedge}, b$, and the Young's modulus values for all candle filters are obtained using the Timoshenko beam equation. The difference between the FEM and the Timoshenko results is less than 3.0\%. Hence, both FEM and Timoshenko beam results can provide reasonably accurate prediction of the boundary restrains and stiffness of the ceramic candle filter.

For a candle filter in the in-situ situation, the boundary conditions and material properties are both unknowns. Hence, the method described in this chapter is more applicable than the free-free NDE method described in Chapter 3 for in-situ inspection. For the determination of the in-situ stiffness properties of a particular candle filter without taking it out of the mounting plenum, the method shown in this chapter is more applicable. However, it should also be noted that the method in Chapter 3 has a better accuracy in the estimation of the Young's modulus of the candle filter because of the free-free boundary conditions. 


\subsection{SUMMARY}

The vibration signatures can be used as a tool to evaluate the boundary restraints and the material properties of a ceramic candle filter. Both the accelerometer and the laser vibrometer show the same results in detecting the vibration frequency values of the filters using either free-free or fixed-free boundary conditions. Experimental frequencies are compatible with the FEM and theoretical frequencies. The differences of dynamic responses from excitations at two different perpendicular axes are small. However, one should inspect the same axis of a candle filter in order to assess accurately the structural properties of the filter.

Frequency ratio curves can be used to evaluate the boundary restraints. These curves are independent of the filter's Young's modulus. The modal frequency values of the candle filters increase with an increase of their boundary restraints. This phenomenon is observed in numerical and theoretical analyses as well as in the experimental results. Results show that the boundary restraints and Young's modulus of a filter can be predicted using a combination of the third/second frequency ratio and the dimensionless $b$-parameter. 
Table 4.1 Dimensionless frequency $(\gamma)$ of Bernoulli-Euler beam with various boundary conditions.

\begin{tabular}{||c|c|c|c|c|c|c||}
\hline \hline Case & $\gamma_{\mathbf{0}}$ & $\gamma_{1}$ & $\gamma_{2}$ & $\gamma_{3}$ & $\gamma_{4}$ & $\gamma_{5}$ \\
\hline hinge-free $\left(\mathbf{K}^{\wedge}=\mathbf{0}\right)$ & 0 & 3.927 & 7.069 & 10.21 & 13.35 & 16.49 \\
\hline $\mathbf{K}^{\wedge}=\mathbf{1}$ & 1.248 & 4.031 & 7.134 & 10.26 & 13.39 & 16.52 \\
\hline $\mathbf{K}^{\wedge}=\mathbf{1 0}$ & 1.723 & 4.400 & 7.451 & 10.52 & 13.61 & 16.72 \\
\hline $\mathbf{K}^{\wedge}=\mathbf{1 0 0}$ & 1.857 & 4.650 & 7.783 & 10.90 & 14.01 & 17.13 \\
\hline fixed-free $\left(\mathbf{K}^{\wedge}=\infty\right)$ & NA & 1.875 & 4.694 & 7.855 & 11.00 & 14.14 \\
\hline
\end{tabular}

Table 4.2 Free-free experimental frequencies using laser vibrometer and accelerometer.

\begin{tabular}{|c|c|c|c|c|c|c|c|}
\hline & \multicolumn{7}{|c|}{ Sch TF-20 335I-161 } \\
\hline & \multicolumn{2}{|c|}{ Experimental } & \multirow{2}{*}{$\begin{array}{c}\text { FEM } \\
\mathrm{E}=5.66 \mathrm{Mpsi}\end{array}$} & \multicolumn{2}{|c|}{ Bernoulli-Euler } & \multicolumn{2}{|c|}{ Timoshenko } \\
\hline Mode & LV & Acc & & $\mathrm{L}=59.8$ in & $\mathrm{L}_{\mathrm{eff}}=60.6 \mathrm{in}$ & $\mathrm{L}=59.8$ in & $\mathrm{L}_{\mathrm{eff}}=60.6 \mathrm{in}$ \\
\hline \# & $\mathrm{Hz}$ & $\mathrm{Hz}$ & $\mathrm{Hz}$ & $\mathrm{Hz}$ & $\mathrm{Hz}$ & $\mathrm{Hz}$ & $\mathrm{Hz}$ \\
\hline 1 & 115.97 & 115.94 & 116.82 & 119.95 & 117.51 & 119.68 & 116.74 \\
\hline 2 & 318.90 & 317.38 & 319.41 & 330.66 & 323.93 & 327.51 & 319.01 \\
\hline 3 & 619.51 & 621.03 & 617.36 & 648.31 & 635.11 & 633.43 & 617.20 \\
\hline 4 & 1004.02 & 999.45 & 1000.65 & 1071.58 & 1049.77 & 1028.55 & 1002.60 \\
\hline 5 & 1461.39 & 1454.16 & 1458.47 & 1600.84 & 1568.25 & 1503.87 & 1466.69 \\
\hline
\end{tabular}

Table 4.3 Fixed-free experimental frequencies using laser vibrometer and accelerometer.

\begin{tabular}{|c|c|c|c|c|}
\hline & \multicolumn{4}{|c|}{ Sch TF-20 335I-161 } \\
\hline & \multicolumn{2}{|c|}{ Experimental } & FEM & Timoshenko \\
\hline \multirow{2}{*}{$\begin{array}{c}\text { Mode } \\
\#\end{array}$} & LV & Accelerometer & $\mathrm{k}_{\mathrm{x}}=1.0 \times 10^{5} \mathrm{lb} / \mathrm{in}$ & $\mathrm{k}_{\mathrm{R}}=8.0 \times 10^{5} \mathrm{lb}$-in \\
\hline & $\mathrm{Hz}$ & $\mathrm{Hz}$ & $\mathrm{Hz}$ & $\mathrm{Hz}$ \\
\hline 1 & 14.05 & 13.4 & 14.29 & 14.74 \\
\hline 2 & 99.49 & 100.1 & 99.11 & 98.45 \\
\hline 3 & 283.20 & 282.6 & 283.38 & 283.13 \\
\hline
\end{tabular}


Table 4.4 Natural frequencies for free-free tests on X1 and X2 axes.

\begin{tabular}{|c|c|c|c|c|c|c|c|}
\hline \multicolumn{6}{|c|}{ Sch TF20 } & \multirow{2}{*}{\multicolumn{2}{|c|}{$\begin{array}{c}\text { Sch F-40 } \\
\text { 322B } \\
\end{array}$}} \\
\hline \multicolumn{2}{|c|}{$335 \mathrm{I}-161$} & \multicolumn{2}{|c|}{$379 \mathrm{H}-129$} & \multicolumn{2}{|c|}{$326 \mathrm{I}-147$} & & \\
\hline $\mathrm{X} 1$ & $\mathrm{X} 2$ & $\mathrm{X} 1$ & $\mathrm{X} 2$ & $\mathrm{X} 1$ & $\mathrm{X} 2$ & $\mathrm{X} 1$ & $\mathrm{X} 2$ \\
\hline $\mathrm{Hz}$ & $\mathrm{Hz}$ & $\mathrm{Hz}$ & $\mathrm{Hz}$ & $\mathrm{Hz}$ & $\mathrm{Hz}$ & $\mathrm{Hz}$ & $\mathrm{Hz}$ \\
\hline 115.9 & 115.9 & 115.9 & 117.5 & 119.0 & 119.0 & 110.5 & 109.4 \\
\hline 317.4 & 317.4 & 318.9 & 320.4 & 326.5 & 326.5 & 305.2 & 303.9 \\
\hline 621.0 & 621.0 & 622.6 & 627.1 & 634.8 & 634.8 & 593.9 & 590.7 \\
\hline 999.5 & 999.5 & 1011.7 & 1014.7 & 1029.9 & 1029.9 & 974.1 & 968.8 \\
\hline 1454.2 & 1454.2 & 1475.5 & 1480.1 & 1501.5 & 1501.5 & 1422.1 & 1415.9 \\
\hline \multicolumn{4}{|c|}{ Pall 326} & \multirow{2}{*}{\multicolumn{2}{|c|}{$\begin{array}{c}\text { Pall 442T } \\
2-286\end{array}$}} & & \\
\hline \multicolumn{2}{|c|}{$5-1365$} & \multicolumn{2}{|c|}{$5-1358$} & & & & \\
\hline $\mathrm{X} 1$ & $\mathrm{X} 2$ & $\mathrm{X} 1$ & $\mathrm{X} 2$ & $\mathrm{X} 1$ & $\mathrm{X} 2$ & & \\
\hline $\mathrm{Hz}$ & $\mathrm{Hz}$ & $\mathrm{Hz}$ & $\mathrm{Hz}$ & $\mathrm{Hz}$ & $\mathrm{Hz}$ & & \\
\hline 137.3 & 137.3 & 138.9 & 140.4 & 142.2 & 141.6 & & \\
\hline 373.8 & 373.8 & 376.9 & 379.9 & 386.4 & 385.1 & & \\
\hline 726.3 & 726.3 & 730.9 & 738.5 & 756.2 & 756.2 & & \\
\hline 1171.9 & 1171.9 & 1181.0 & 1191.7 & 1207.3 & 1207.3 & & \\
\hline 1705.9 & 1705.9 & 1719.7 & 1734.9 & 1759.0 & 1757.2 & & \\
\hline
\end{tabular}

Table 4.5 Vibration frequencies of fixed-free test (X1 and X2 axis) for a Pall 442T filter.

\begin{tabular}{|c|c|c|c|c|c|c|}
\hline & \multicolumn{6}{|c|}{ PALL 442T 2-286 } \\
\hline & $\begin{array}{l}\text { EXP. } \\
\text { X1 axis }\end{array}$ & $\begin{array}{c}\text { FEM } \\
\mathrm{k}_{\mathrm{x}}=2.3 \times 10^{5} \mathrm{lb} / \mathrm{in} \\
\mathrm{E}=8.28 \times 10^{6} \mathrm{psi}\end{array}$ & $\begin{array}{c}\text { Theo. } \\
\mathrm{k}_{\mathrm{R}}=1.9 \times 10^{6} \mathrm{lb}-\mathrm{in} \\
\mathrm{E}=8.28 \times 10^{6} \mathrm{psi}\end{array}$ & $\begin{array}{c}\text { EXP. } \\
\text { X2 axis }\end{array}$ & $\begin{array}{c}\text { FEM } \\
\mathrm{k}_{\mathrm{x}}=2.6 \times 10^{4} \mathrm{lb} / \mathrm{in} \\
\mathrm{E}=8.28 \times 10^{6} \mathrm{psi}\end{array}$ & $\begin{array}{c}\text { Theo. } \\
\mathrm{k}_{\mathrm{R}}=2.15 \times 10^{6} \mathrm{lb}-\mathrm{in} \\
\mathrm{E}=8.28 \times 10^{6} \mathrm{psi}\end{array}$ \\
\hline \# & $\mathrm{Hz}$ & $\mathrm{Hz}$ & $\mathrm{Hz}$ & $\mathrm{Hz}$ & $\mathrm{Hz}$ & $\mathrm{Hz}$ \\
\hline 1 & 19.61 & 19.75 & 20.62 & 19.85 & 20.22 & 20.39 \\
\hline 2 & 127.56 & 127.45 & 129.69 & 128.78 & 129.30 & 130.96 \\
\hline 3 & 363.82 & 359.81 & 368.03 & 365.20 & 363.32 & 370.46 \\
\hline
\end{tabular}

Table 4.6 Young's modulus comparison between fixed-free and free-free tests.

\begin{tabular}{||c||c|c|c||c||c||c|c||}
\hline \multicolumn{1}{||c||}{} & \multicolumn{3}{c||}{ Sch TF-20 } & Sch F-40 & Pall 442T & \multicolumn{2}{c||}{ Pall 326 } \\
Filter & $335 \mathrm{i}-161$ & $379 \mathrm{H}-179$ & $335 \mathrm{i}-147$ & 322B & $2-286$ & $2-1355$ & $5-1340$ \\
\hline Young's Modulus & Mpsi & Mpsi & Mpsi & Mpsi & Mpsi & Mpsi & Mpsi \\
Fixed-free & 5.60 & 5.60 & 5.91 & 5.65 & 8.12 & 7.32 & 7.27 \\
Free-free & 5.66 & 5.73 & 6.01 & 5.71 & 8.28 & 7.46 & 7.32 \\
\% Difference & 1.06 & 2.24 & 1.62 & 1.15 & 2.03 & 1.96 & 0.69 \\
\hline \hline
\end{tabular}




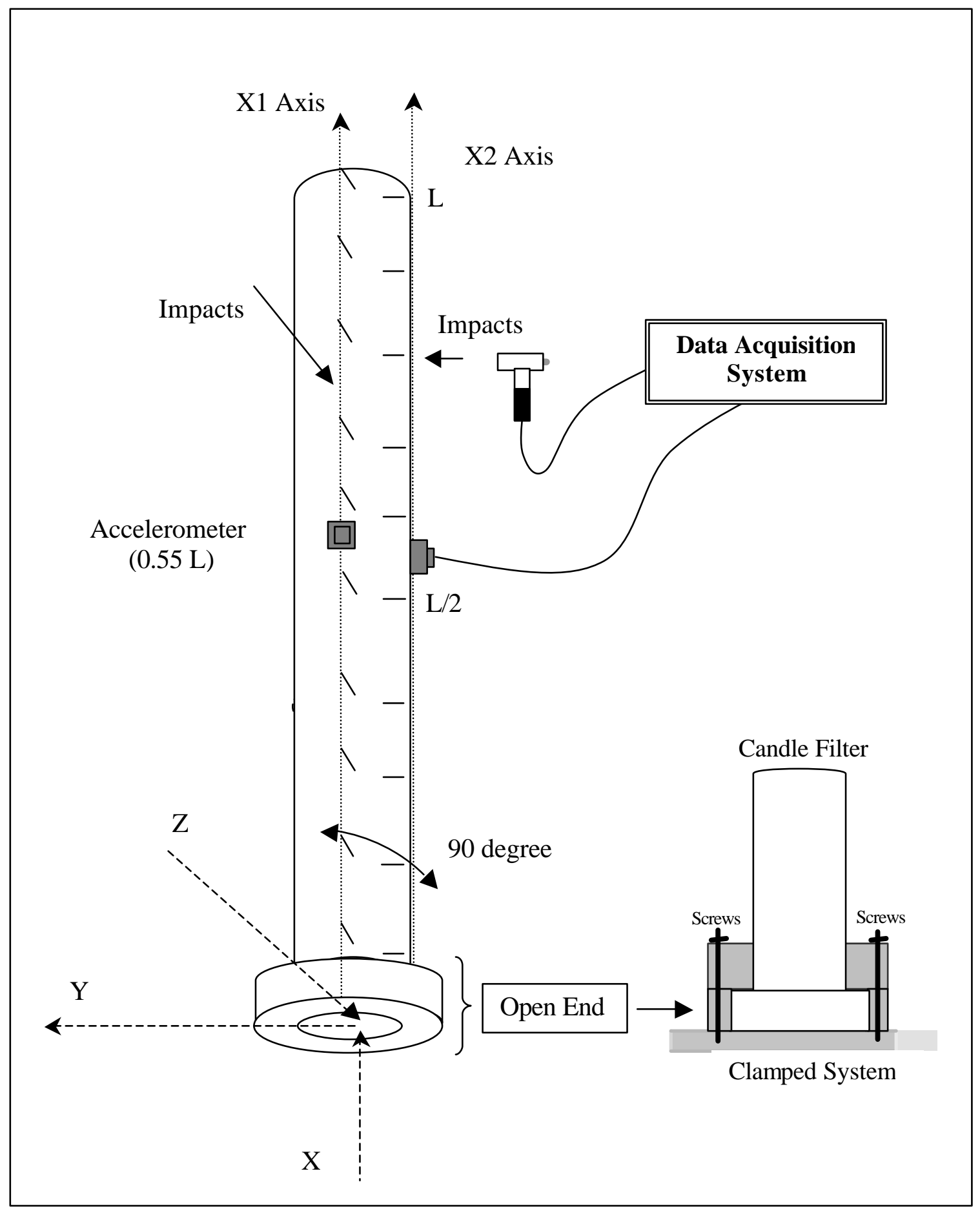

Figure 4.1 Experimental setup for the fixed-free tests. 


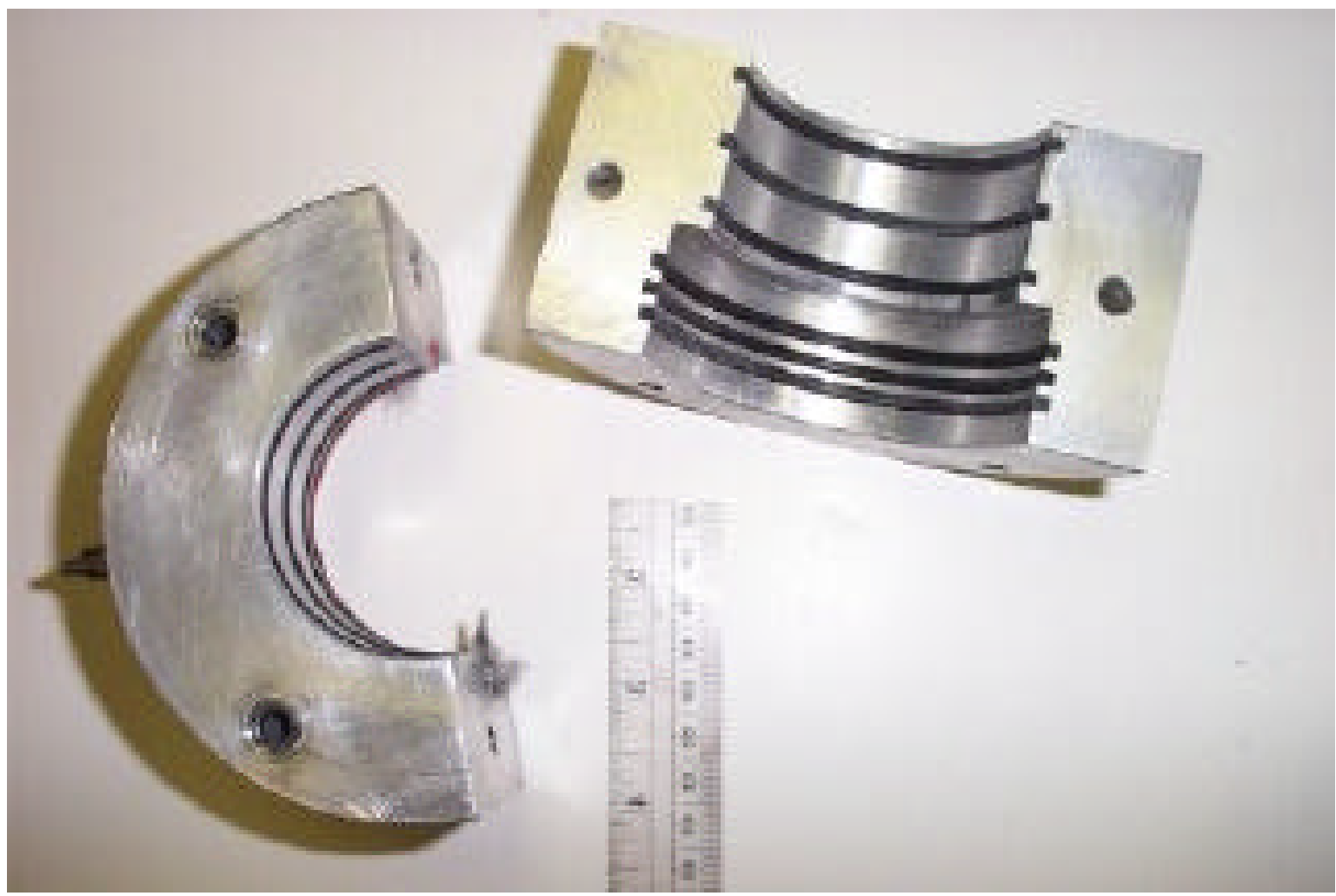

Figure 4.2 Modified candle filter mounting-head. 

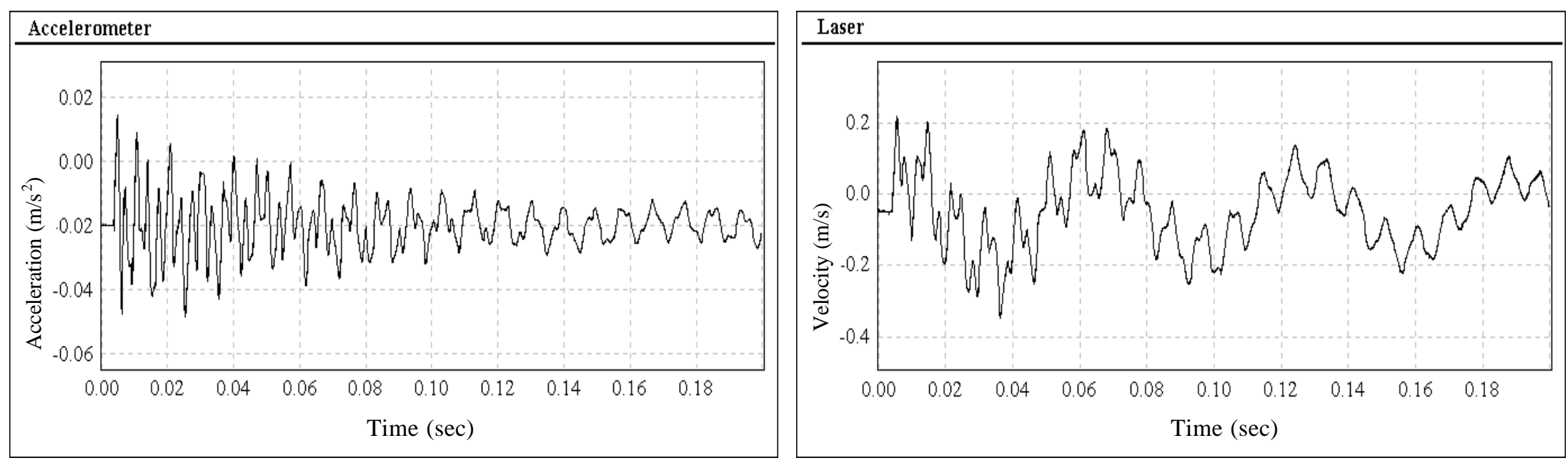

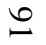
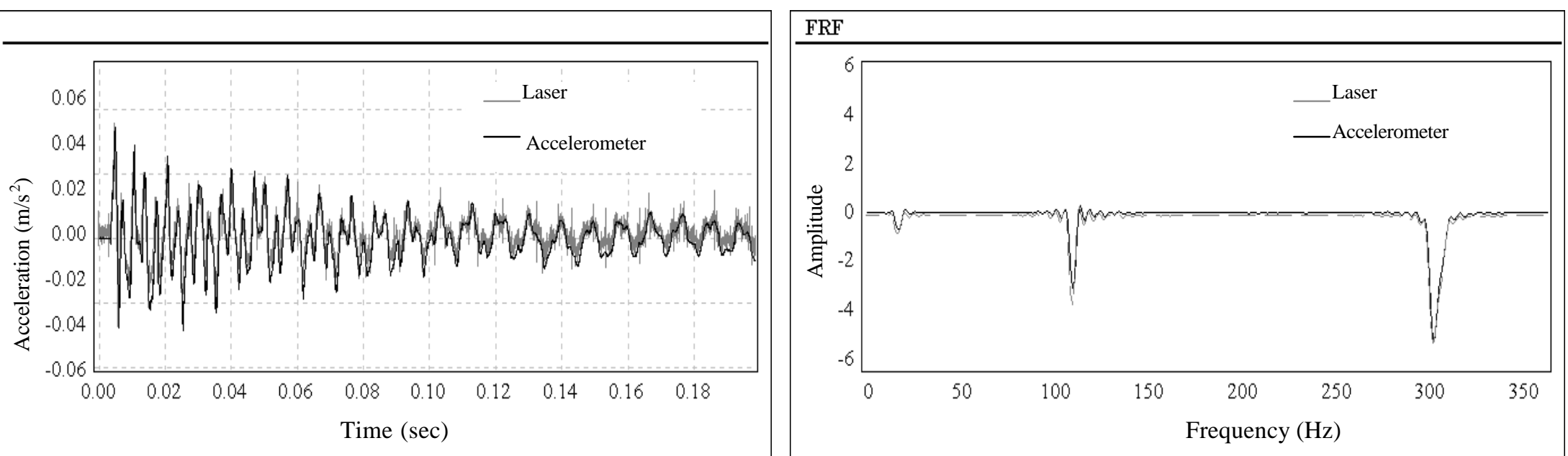

Figure 4.3 Tenth point of contact and non-contact tests of fixed-free 335I-161 Sch TF-20 filter. 


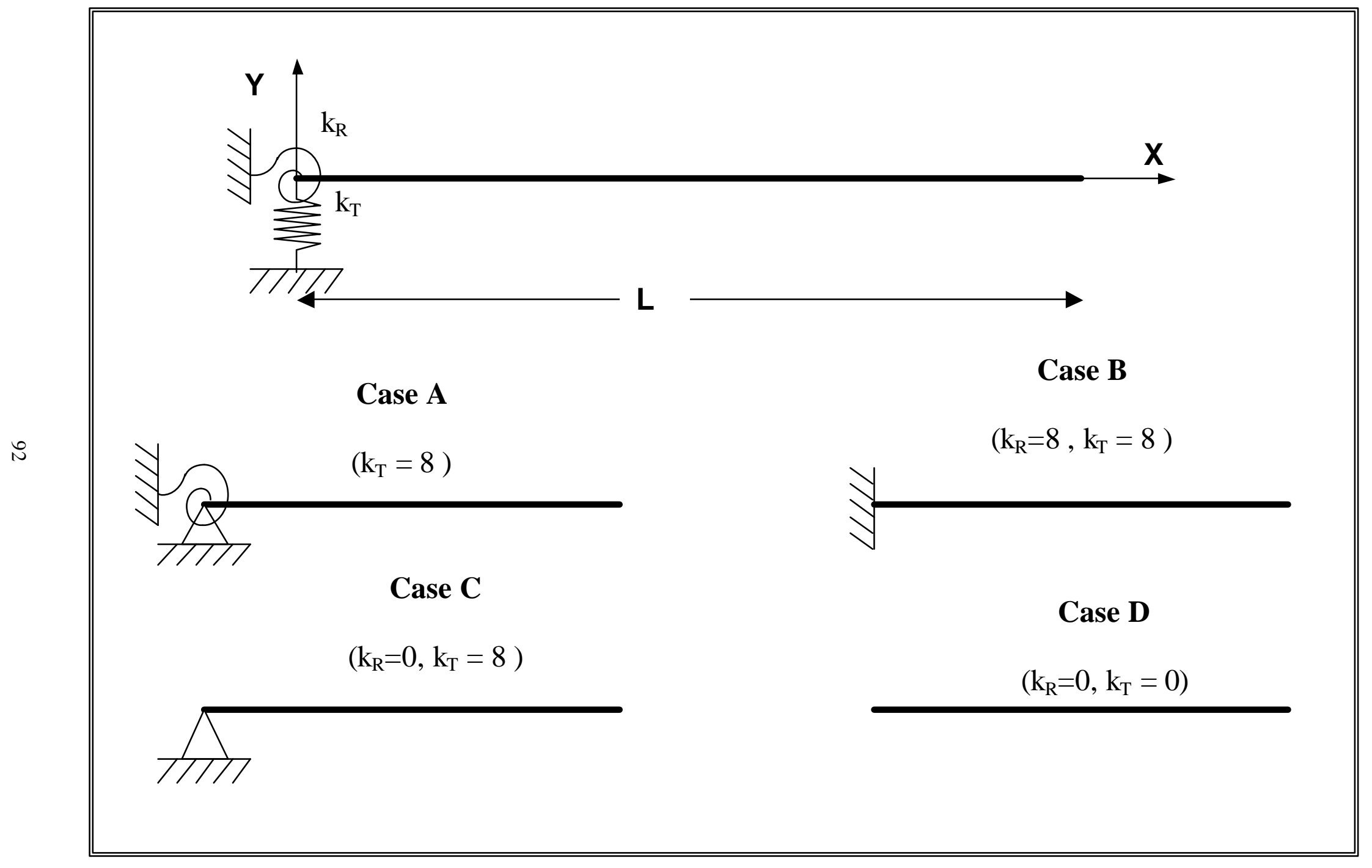

Figure 4.4 Boundary Controllability of a vibrating Timoshenko beam equation. 


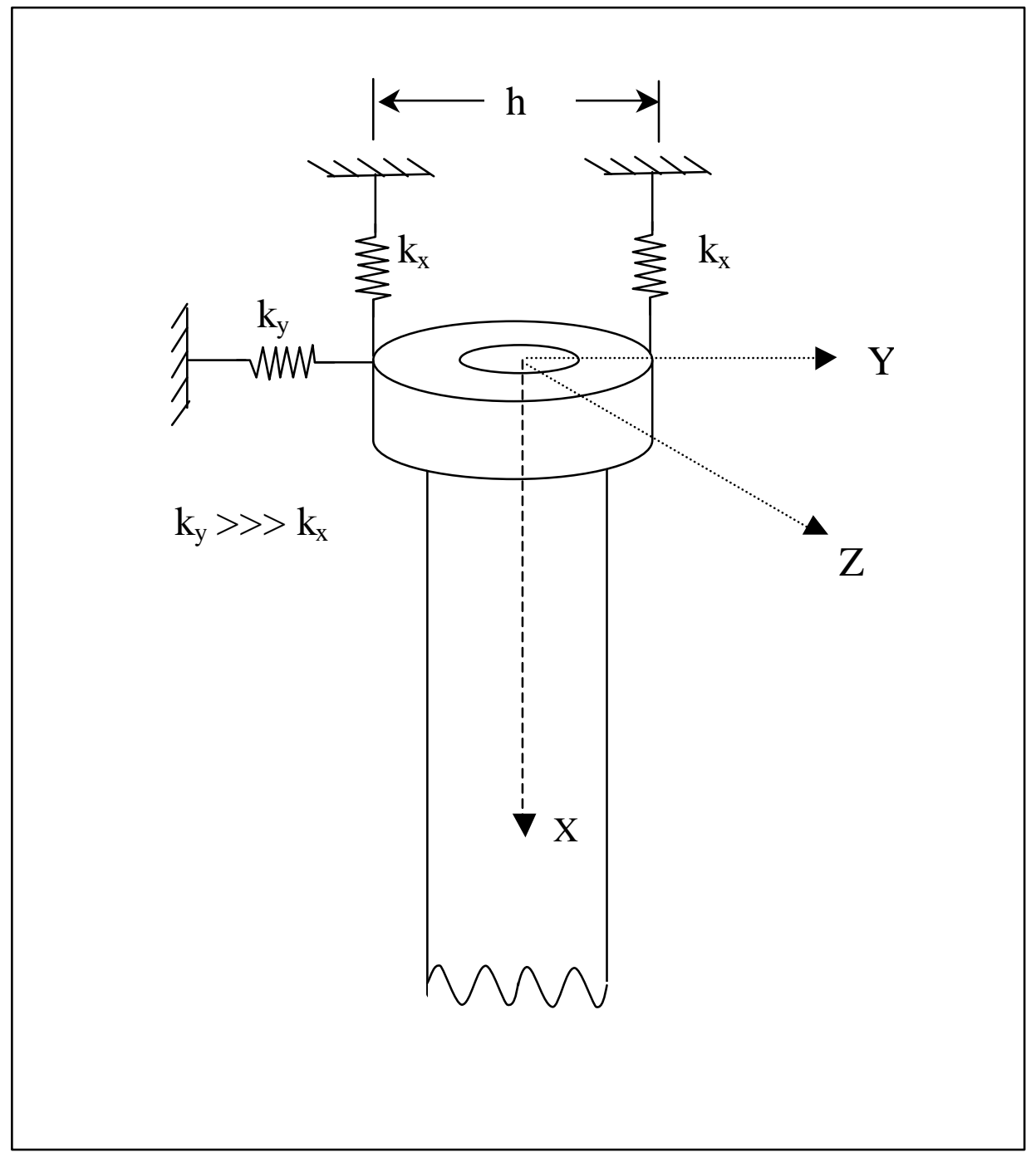

Figure 4.5 Boundary condition setup of FEM model. 


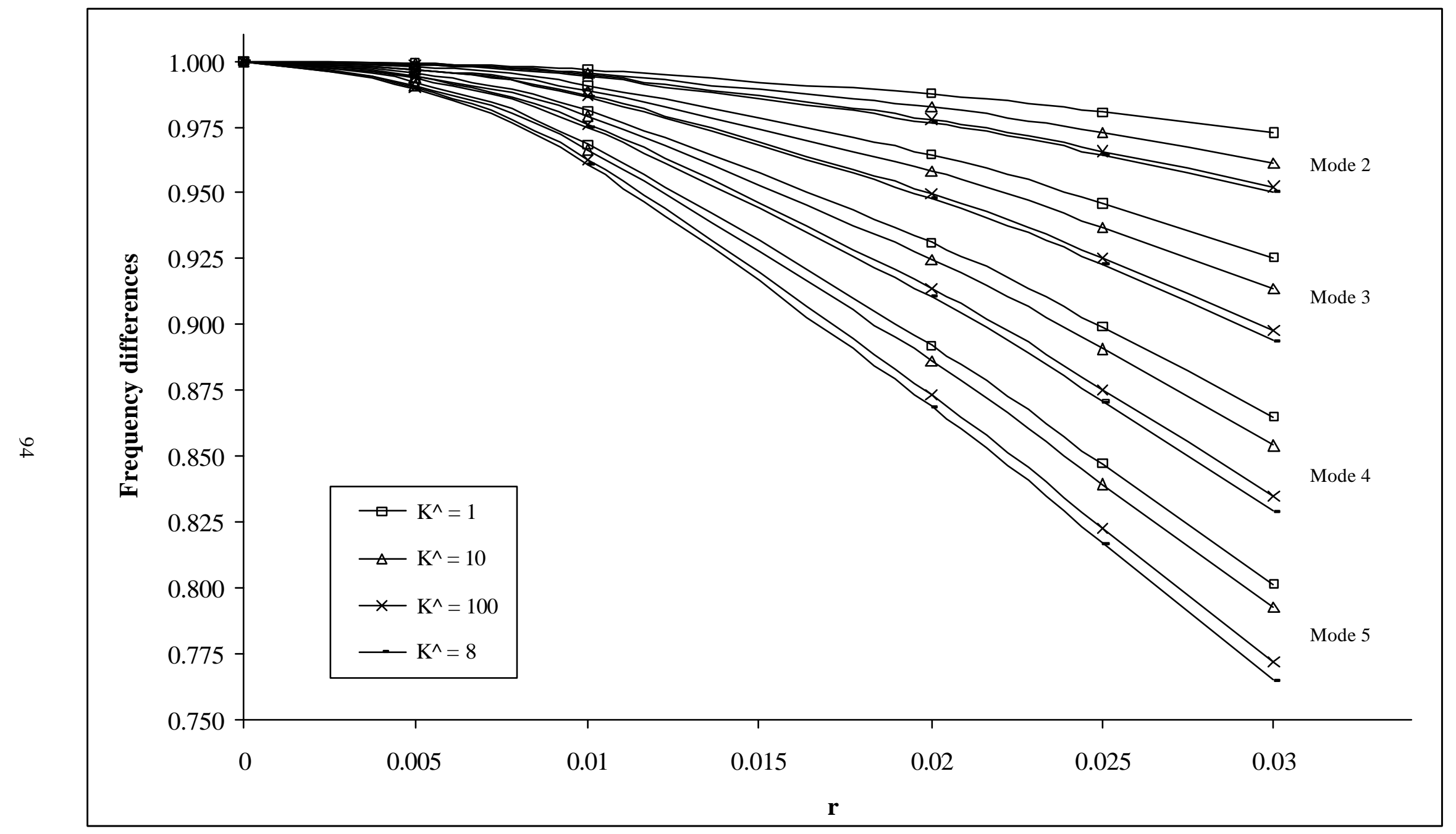

Figure 4.6 Natural frequencies difference between Timoshenko beam and Bernoulli-Euler due to dimensionless rotational spring, $\mathrm{K}^{\wedge}$ and inverse slenderness ratio, $r$. 

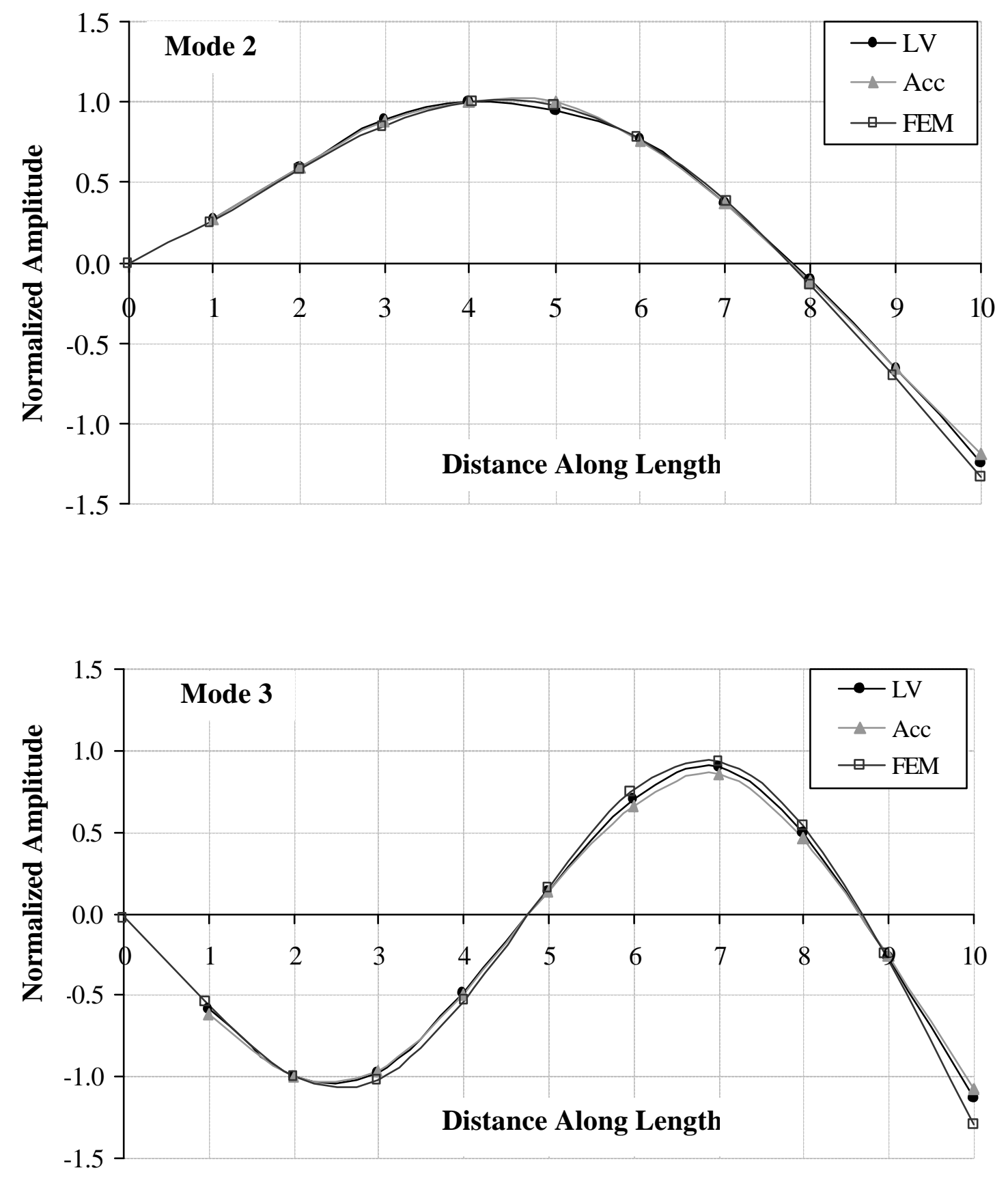

Figure 4.7 Experimental and FEM mode shapes of 2-1355 Pall 326 filter (fixed-free condition). 

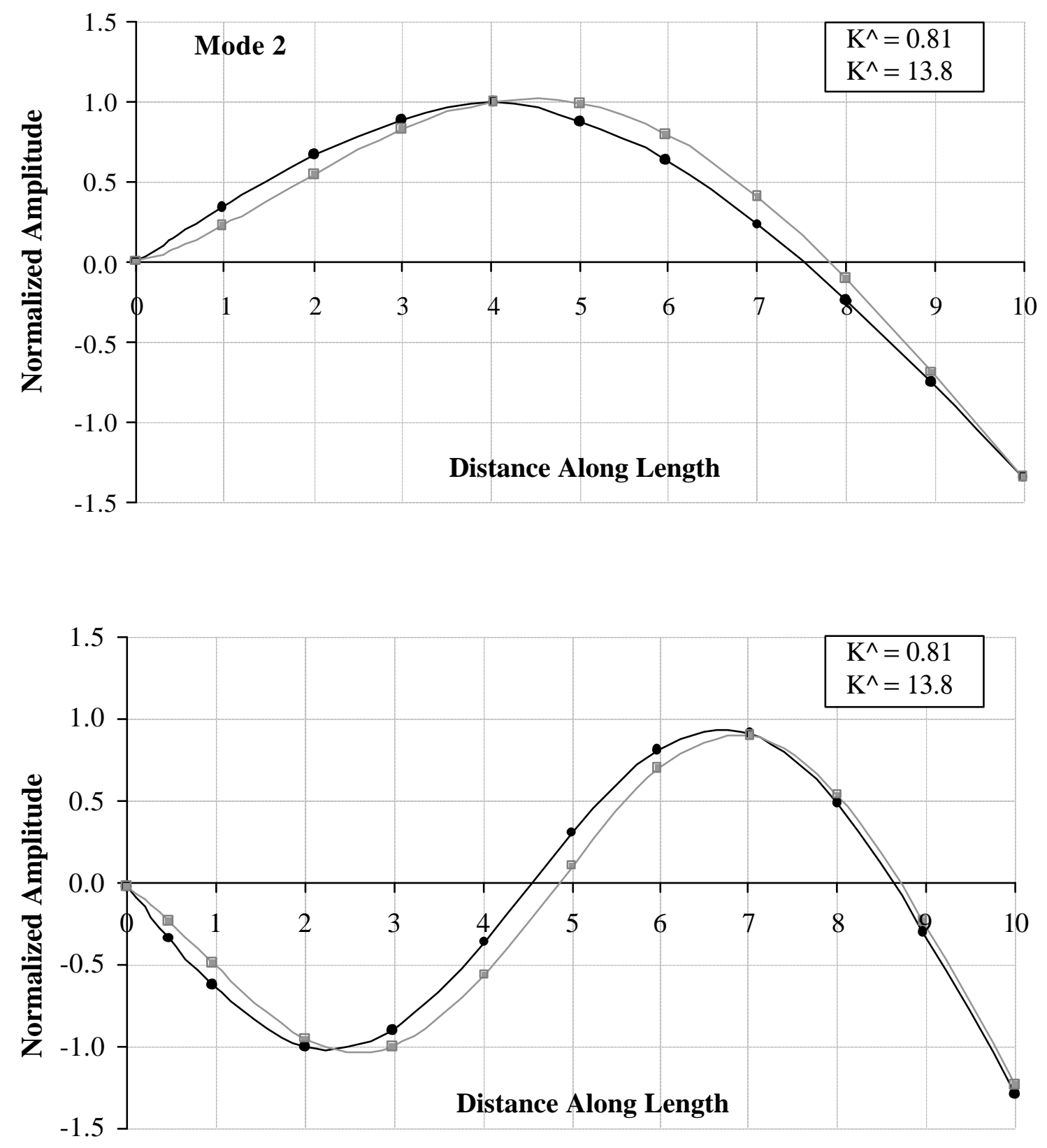

Figure 4.8 Typical mode shapes from FEM simulations with different $\mathrm{K}^{\wedge}$ values. 


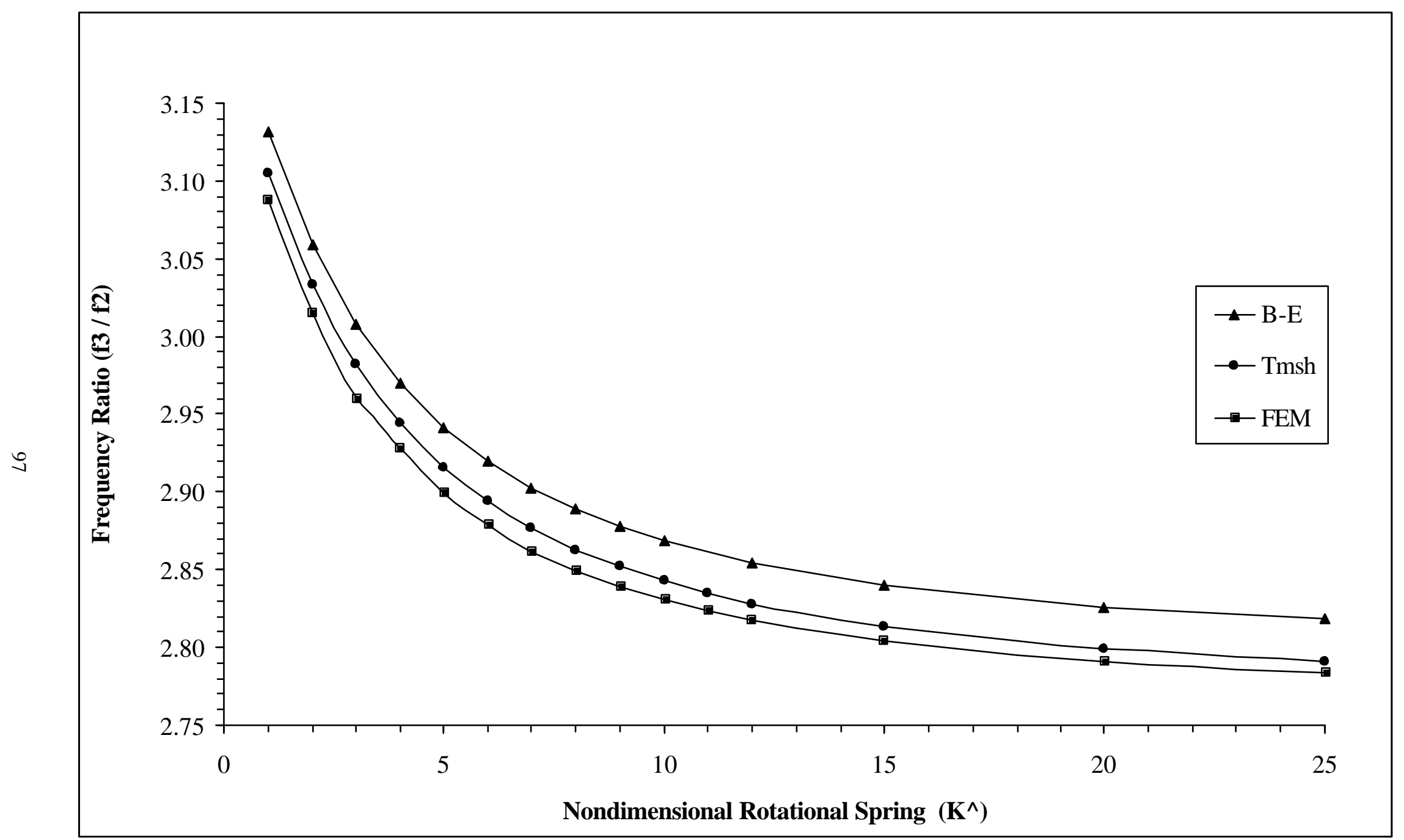

Figure 4.9 Analytical and FEM frequency ratios vs. different $\mathrm{K}^{\wedge}$ values for Sch TF-20, Pall 326, and Pall 442T. 


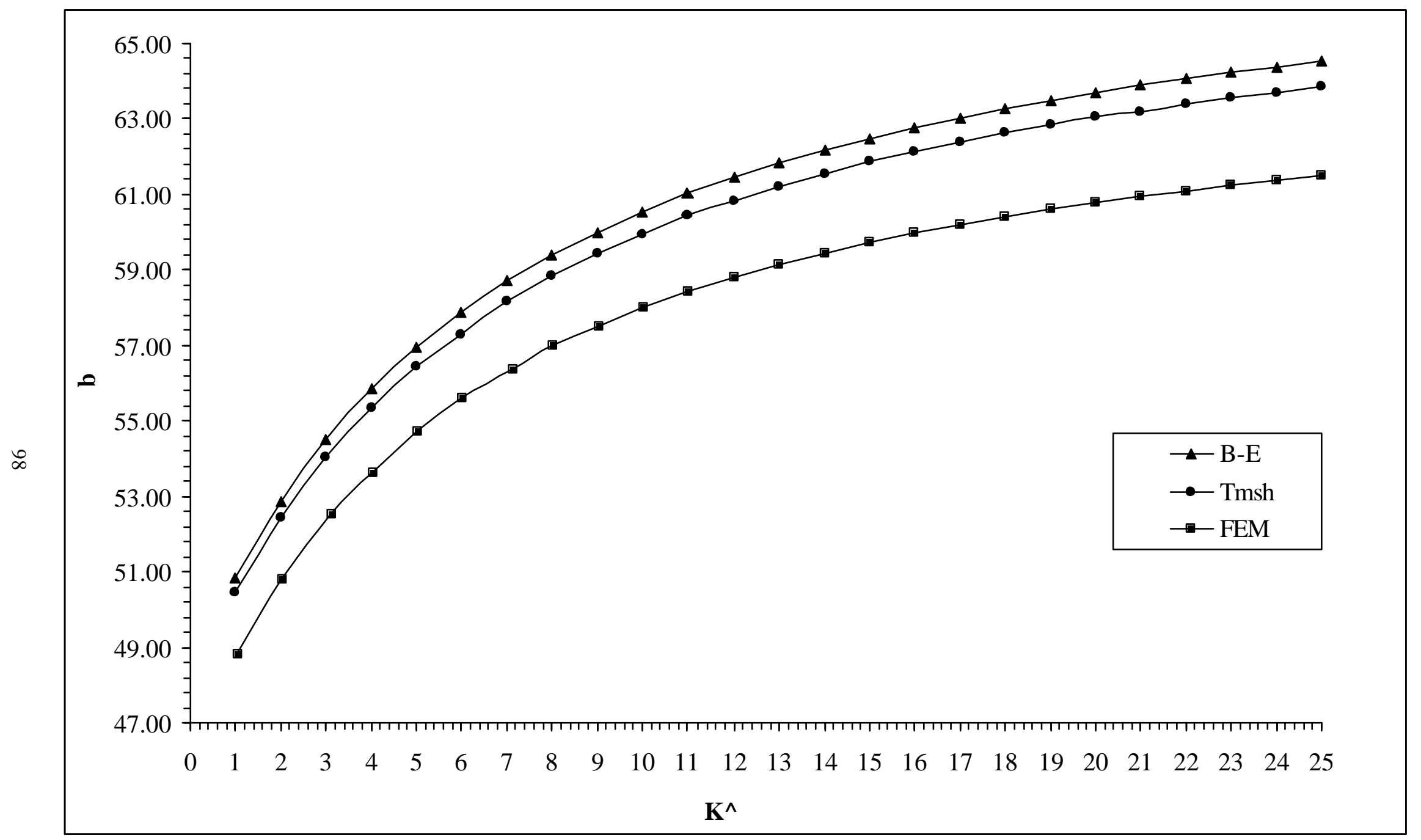

Figure 4.10 Analytical and FEM $b$ results vs. various $\mathrm{K}^{\wedge}$ values for Sch TF-20, Pall 326, and Pall $442 \mathrm{~T}$. 


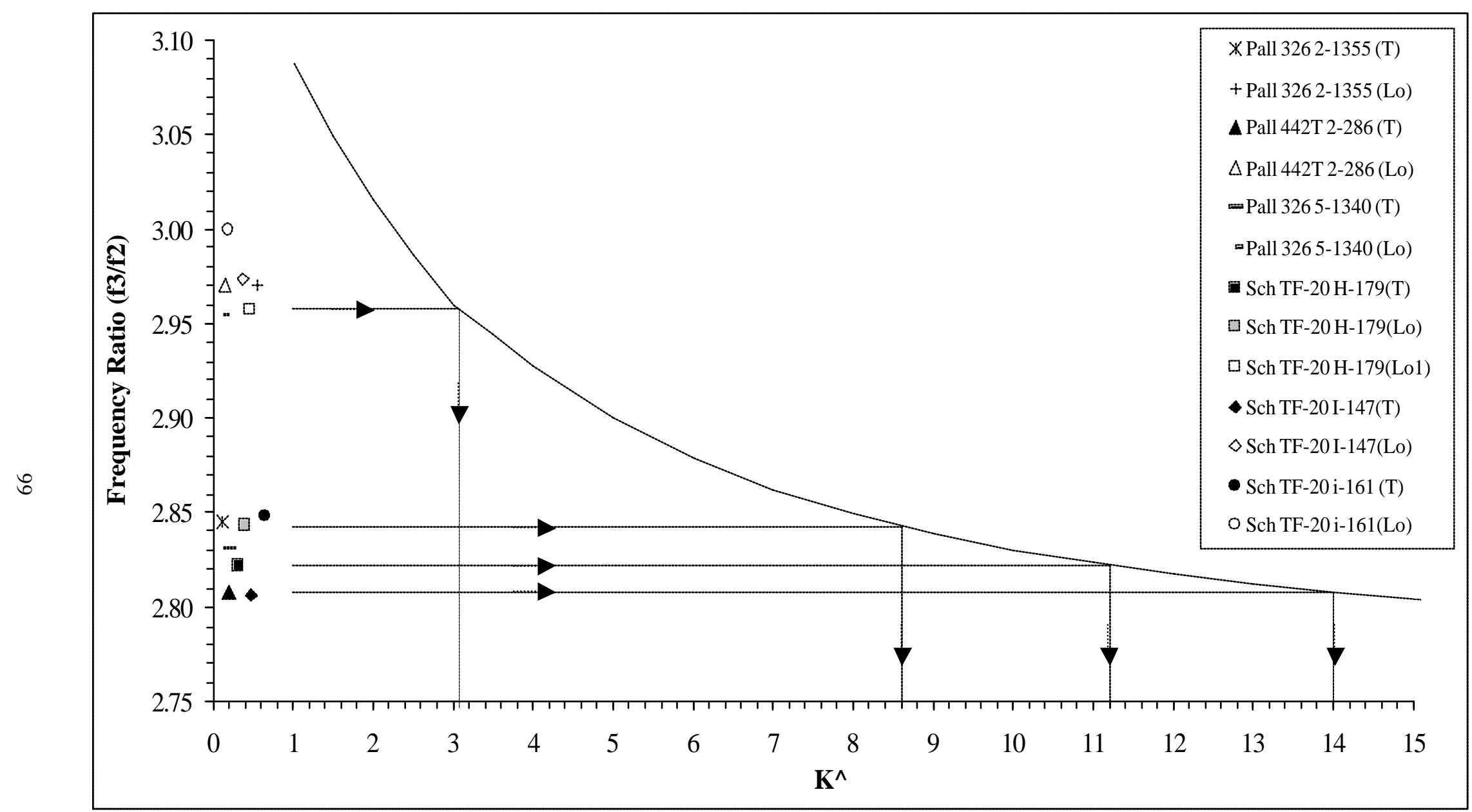

Figure 4.11 Experimental f3/f2 and $\mathrm{K}^{\wedge}$ values for Sch TF-20, Pall 326 and $442 \mathrm{~T}$ filters using FEM curve. 


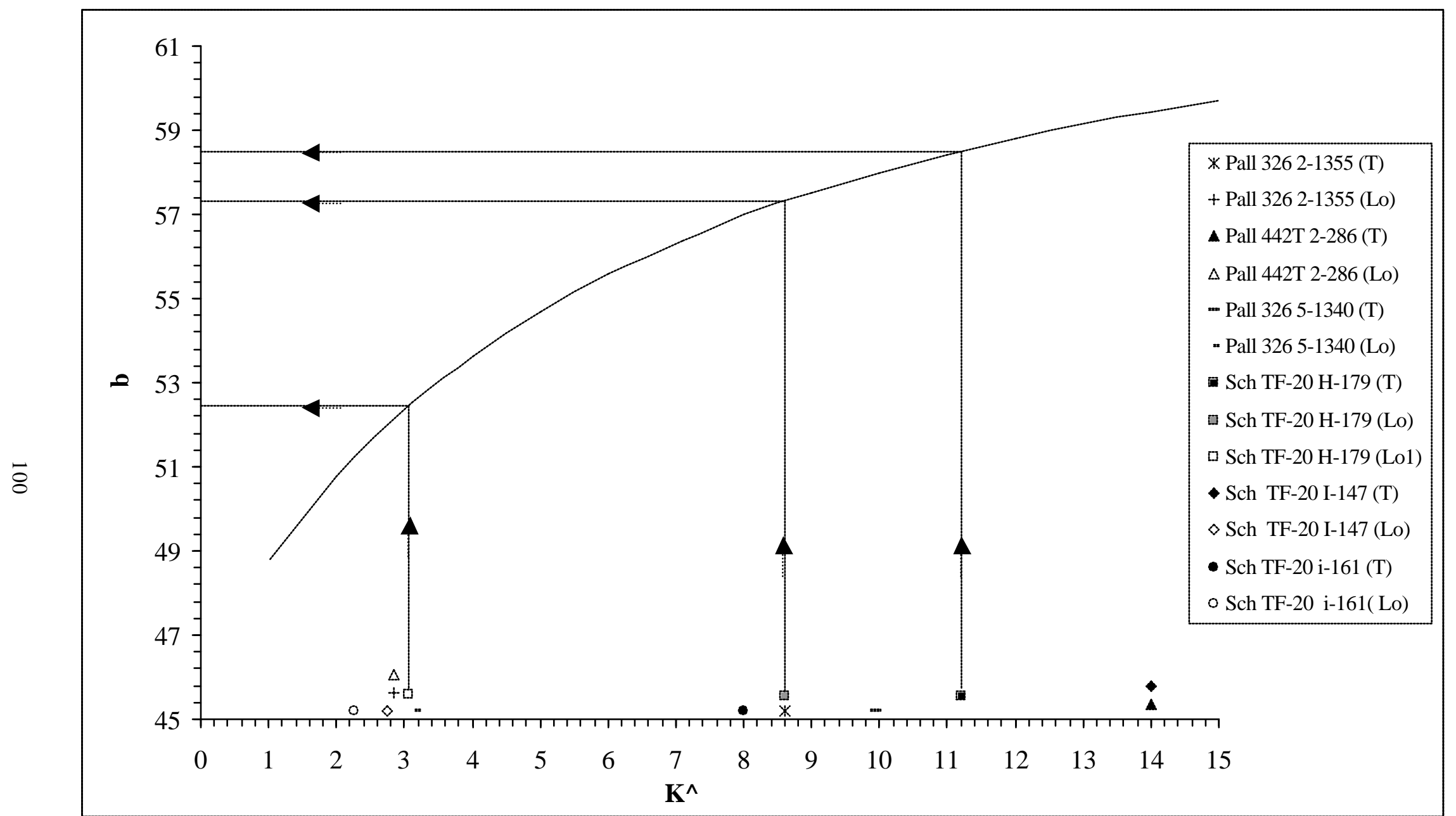

Figure 4.12 Experimental $\mathrm{K}^{\wedge}$ and $b$ values for Sch TF-20, Pall 326 and $442 \mathrm{~T}$ filters using FEM curve. 


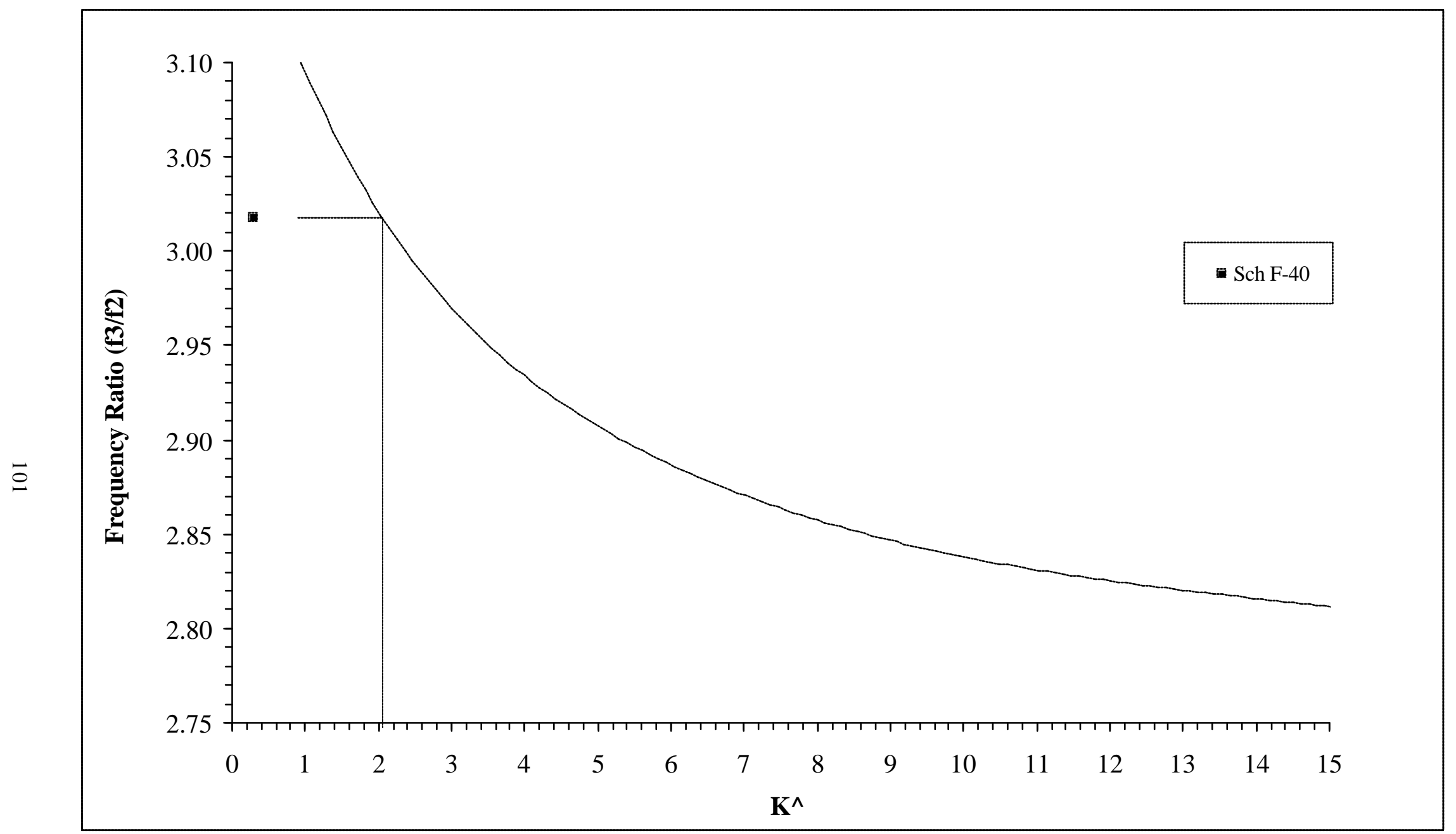

Figure 4.13 Experimental f3/f2 and $\mathrm{K}^{\wedge}$ values for the Sch F-40 filter using FEM curve. 


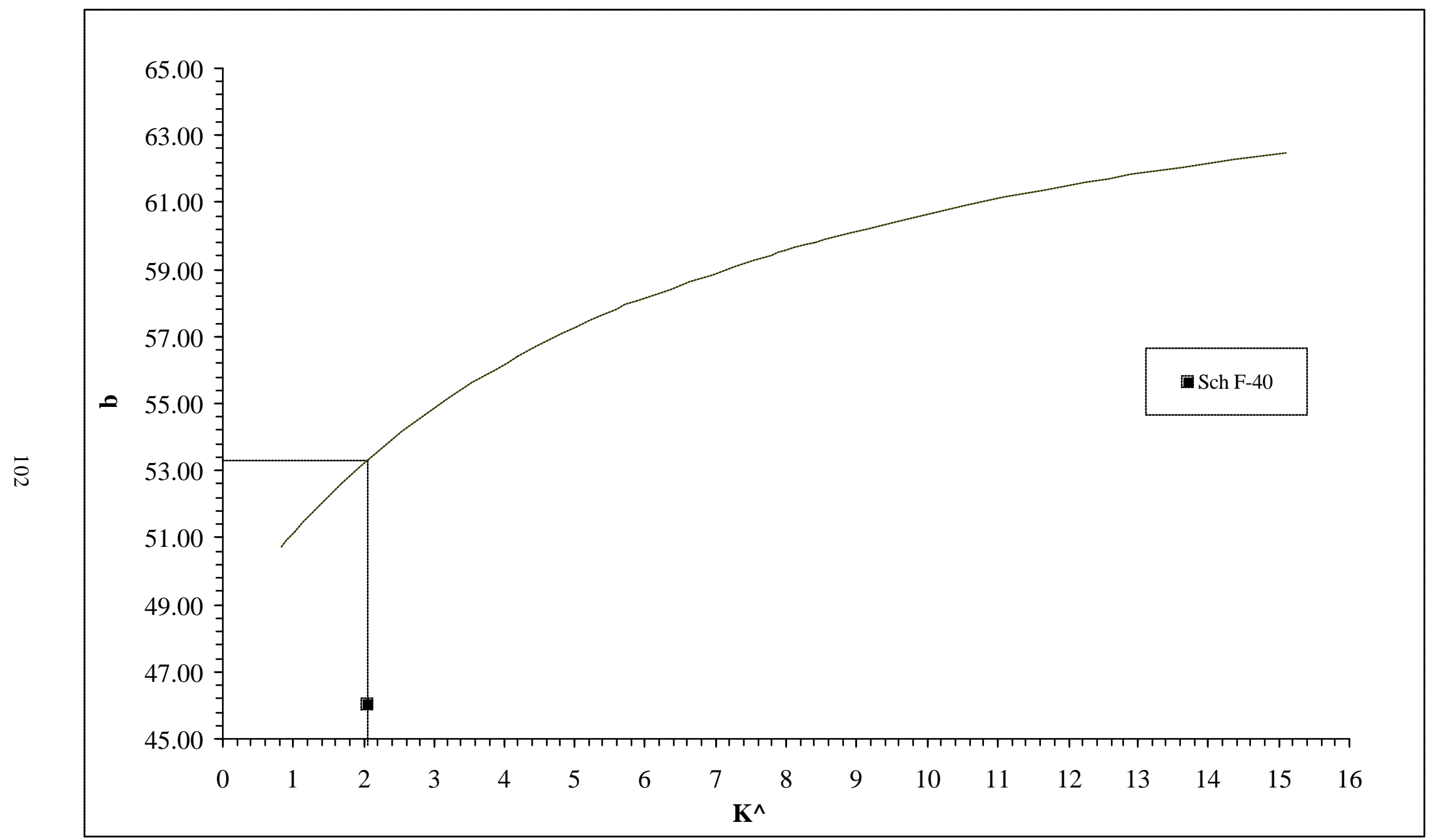

Figure 4.14 Experimental $\mathrm{K}^{\wedge}$ and $\mathrm{b}$ values for the Sch F-40 filter using FEM curve. 


\section{CHAPTER 5}

\section{STIFFNESS OF CERAMIC CANDLE FILTERS AT ELEVATED TEMPERATURE UNDER VIBRATIONAL ENVIRONMENT}

\subsection{INTRODUCTION}

Ceramic candle filters are exposed to extreme thermal environment and vibrationinduced stresses over a great period of time. Therefore, it is important to study the candle filter's behavior under these conditions. This chapter presents the influence of elevated temperatures on the material properties of the candle filters and the changes in boundary restraints due to these temperatures. This chapter also presents investigations on fatigue stresses of the candle filters due to vibration of the plenum or back pulse cleaning.

Four ceramic candle filters were tested nondestructively at different temperatures. They were subjected to an impact excitation force and the response was picked up by a laser vibrometer. During the fatigue stress tests two Pall 326 and four SchTF-20 candle filters were tested. These candle filters were subjected to a shaking vibration force for extended periods of time using an electrodynamic shaker. The experimental data was evaluated using digital signal analysis to obtain the frequency response function and the vibration mode shapes of each filter. Finite element models were built to calculate the filter's dynamic response with different boundary conditions at various temperatures.

\subsection{Experimental Setup and Testing Procedure}

The experimental setup for the temperature testing consisted of a set of heating panels facing each other, and the candle filters were placed in between these panels 
which acted as a toaster-like heating unit (Figure 5.1). The tests were conducted using free-free and fixed-free boundary conditions. The temperatures used in this test were room $\left(\sim 75^{\circ} \mathrm{F}\right), \sim 250^{\circ} \mathrm{F}$, and $\sim 350^{\circ} \mathrm{F}$. The filters were excited using an impulse load and the velocity responses were recorded using a laser vibrometer. Following the procedure detailed in Chapter 3, the vibration frequencies of the filters at each temperature were obtained.

The fatigue experimental setup consisted of a vertically mounted filter on a steel frame using a clamped device on a railing system. This railing acted as a boundary restraint for the filter, allowing the specimen to move freely on one axis and to be fixed on the remaining axes. The instrumentation involved in the testing consists of a dynamic spectrum analyzer (SRS 785) with a built-in pulse generator, an electrodynamic shaker, a laser vibrometer (LV), an accelerometer, and signal conditioners. The filter specimens were tested individually, and each candle filter was weighed and measured geometrically before beginning the testing procedure.

The experimental setup is shown in Figure 5.2. A ceramic candle filter is vertically suspended by its open end using a clamped system. The specimen is excited by a sinusoidal signal source using an electrodynamic shaker. The shaker is attached to the clamp system with an adjustable-length acrylic stringer. Strokes of the shaker are parallel to the railing. The excitation response of the candle filter is picked up by a LV and an accelerometer. The total motion, $v_{\mathrm{T}}(\mathrm{t})$, of the specimen's free end is measured by the single-point laser vibrometer. The velocity resolution of the laser vibrometer is about $2 \mu \mathrm{m} / \mathrm{s}$. The piezoelectric accelerometer is placed at the clamp system, perpendicular to the railing direction. This piezoelectric sensor is used to measure the acceleration of the 
filter's upper end, which is denoted as $\ddot{v}_{\mathrm{g}}(\mathrm{t})$. The sensitivity of the accelerometer is $10.25 \mathrm{mV} / \mathrm{g}$. Time domain waveforms from both LV and accelerometer are stored in the dynamic spectrum analyzer every 17 minutes. A frequency range up to $400 \mathrm{~Hz}$ with a frequency resolution of $0.39 \mathrm{~Hz}$ is used to obtain the signatures. The signals are then processed by using signal processing software.

The circular natural frequency and damping ratio of the system due to the base excitation were obtained using the resonant amplification method (RAM). This method is based on measuring the steady-state amplitudes of the relative displacement response, $v(\mathrm{x}, \mathrm{t})$, due to separate harmonic loadings at discrete values of excitation frequency over a wide range, including the natural frequency of interest. It should be noticed that when the excitation motion is applied to the shaking base of the system instead of applying to the specimen, both the absolute motion of the specimen and the relative motion between the specimen and the support are of interest.

The fatigue tests were conducted on two new Pall 326 and four new Sch TF-20 ceramic candle filters. The frequency of the harmonic forcing function was chosen to be close to the system's natural frequency. The ceramic filters were tested in a series of decreasing stress levels until no failure occurs within a selected number of cycles. In order to increase the stress applied to the filters, a lumped mass was added at the free end of the filter. The lumped mass used was about $3.0 \mathrm{lb}$. The fatigue life curve, also known as $\mathrm{S} / \mathrm{N}$ curve, was plotted based on the number of cycles that the filter went through before it failed. 


\subsection{Formulation Of the Problem}

The essential physical properties of a linear elastic structure subjected to an external source of excitation are its mass, stiffness and energy-loss mechanism. A candle filter subjected to plenum excitation can be approximated by an equivalent or generalized single degree of freedom (SDOF) system by assuming that its displacement field can be represented by a single shape function (Figure 5.3). The shape function will be designated $\psi(\mathrm{x})$ and the amplitude of the motion relative to the moving base will be represented by the generalized coordinate $\mathrm{Z}(\mathrm{t})$. Thus,

$$
v(\mathrm{x}, \mathrm{t})=\psi(\mathrm{x}) \mathrm{Z}(\mathrm{t})
$$

When a virtual displacement of the form $\delta v(x, t)=\psi(x) \delta Z(t)$ is applied, the principle of virtual work leads to the SDOF equilibrium relationship:

$$
\mathrm{m} * \ddot{\mathrm{Z}}(\mathrm{t})+\mathrm{c} * \dot{\mathrm{Z}}(\mathrm{t})+\mathrm{k} * \mathrm{Z}(\mathrm{t})=\mathrm{P} *(\mathrm{t})
$$

where $\mathrm{m}^{*}, \mathrm{c}^{*}, \mathrm{k}^{*}$, and $\mathrm{P}^{*}$ are the generalized mass, damping, flexural stiffness, and effective load, respectively. The candle filters are assumed to have distributed mass and stiffness properties. The generalized terms in Equation 5.2 can be written as:

$$
\mathrm{m}^{*}=\int_{0}^{\mathrm{L}} \mathrm{m}(\mathrm{x}) \psi(\mathrm{x})^{2} \mathrm{dx}+\mathrm{m}_{\mathrm{k}}\left[\psi\left(\mathrm{h}_{\mathrm{k}}\right)\right]^{2}
$$




$$
\begin{aligned}
& \mathrm{c}^{*}=\int_{0}^{\mathrm{L}} \mathrm{c}(\mathrm{x}) \psi(\mathrm{x})^{2} \mathrm{dx} \\
& \mathrm{k}^{*}=\int_{0}^{\mathrm{L}} \mathrm{EI}(\mathrm{x}) \psi^{\prime \prime}(\mathrm{x})^{2} \mathrm{dx} \\
& \mathrm{P}^{*}=-\ddot{v_{\mathrm{g}}} \int_{0}^{\mathrm{L}} \mathrm{m}(\mathrm{x}) \psi(\mathrm{x}) \mathrm{dx}
\end{aligned}
$$

where $\mathrm{m}(\mathrm{x})$ is the filters mass, $\mathrm{m}_{\mathrm{k}}$ is the lumped mass, $\mathrm{h}_{\mathrm{k}}$ represent the lump mass location, $\mathrm{c}_{1}$ is a damping constant, $\ddot{v}_{\mathrm{g}}$ is the ground acceleration, and EI is a constant that is different for each filter. Considering a harmonic support acceleration of the form $\ddot{v}_{\mathrm{g}}(\mathrm{t})$ $=\ddot{v}_{\mathrm{g} 0} \sin (\varpi \mathrm{t})$, the solution of the effective force in Equation 5.3 becomes $\mathrm{P}^{*}=-£ \ddot{v}_{\mathrm{g}} \mathrm{O}$ $\sin (\varpi t)$. Ignoring the sign of the effective load, dividing by the generalized mass and letting $\omega^{2}=\mathrm{k}^{*} / \mathrm{m}^{*}$ and $\xi=\mathrm{c}^{*} /\left(2 \mathrm{~m}^{*} \omega\right)$, Equation 5.2 can be rewritten as:

$$
\ddot{\mathrm{Z}}(\mathrm{t})+2 \xi \omega \dot{\mathrm{Z}}(\mathrm{t})+\omega^{2} \mathrm{Z}(\mathrm{t})=\frac{£}{\mathrm{~m}^{*}} \ddot{\mathrm{v}}_{\mathrm{g} 0} \operatorname{Sin}(\varpi \mathrm{t})
$$

where $\varpi, \omega$ and $\xi$ are applied loading frequency, the natural frequency and damping ratio of the candle filter, respectively. $£$ is the base (plenum) excitation factor representing the extent to which the plenum motion tends to excite response in the assumed shape. If the shape assumed is $\psi(\mathrm{x})=1-\cos (\pi \mathrm{x} / 2 \mathrm{~L})$, the $£ / \mathrm{m}^{*}$ fraction is equal to 1.6 (Clough and Penzien 1993). The steady state solution of Equation 5.4 for the response $Z(t)$ considering low damped systems, can be written as follows 


$$
\mathrm{Z}(\mathrm{t})=1.6 \frac{\ddot{\mathrm{v}}_{\mathrm{g} 0} \mathrm{D}}{\omega^{2}} \operatorname{Sin}(\varpi \mathrm{t}-\theta)
$$

where $r=\varpi / \omega$ and $\theta=\operatorname{Tan}^{-1}\left(2 \xi r / 1-r^{2}\right)$ is the phase angle by which the response lags behind the applied loading. This phase angle is limited to the range $0<\theta<180^{\circ}$. In the above equation $\mathrm{D}$ is the ratio of the resultant harmonic response amplitude to the static displacement that is produced by the force $\mathrm{P}^{*}$ and is called the dynamic magnification factor; thus

$$
\mathrm{D}=\left[\left(1-\mathrm{r}^{2}\right)^{2}+(2 \xi \mathrm{r})^{2}\right]^{-1 / 2}
$$

and hence the relative displacements (from Eq. 5.1) are obtained with

$$
\mathrm{v}(\mathrm{x}, \mathrm{t})=\left(1-\cos \left(\frac{\pi \mathrm{x}}{2 \mathrm{~L}}\right)\right) 1.6 \frac{\ddot{v}_{\mathrm{g} 0} \mathrm{D}}{\omega^{2}} \operatorname{Sin}(\bar{\omega} \mathrm{t}-\theta)
$$

where $\mathrm{L}$ is the length of the candle filter and $\mathrm{x}$ is an arbitrary distance from the fixed end (clamped end). In the present study, the relative displacement of the system is measures at the free end of the filter. Therefore, $\psi(\mathrm{x})$ is equal to 1 and the relative displacement, $v$ $(\mathrm{L}, \mathrm{t})$ becomes $\mathrm{Z}(\mathrm{t})$.

An approximate value of damping for the SDOF assumed is obtained by using RAM plots. The relation between the damping of the system and the resonant peak can be written as

$$
\mathrm{RAM}=v(\mathrm{~L}, \mathrm{t}) / \rho o
$$


where $v(\mathrm{~L}, \mathrm{t})=v^{\mathrm{t}}(\mathrm{t})-v_{\mathrm{g}}(\mathrm{t})$ and $\rho \mathrm{o}=\left(1.6 \ddot{v}_{\mathrm{g} 0}\right) / \omega^{2}$. The maximum value of RAM, which occurs at resonance, is referred to as the $\mathrm{Q}$ of the system and is equal to $1 / 2 \xi$. When RAM is equal to $\mathrm{Q} / \sqrt{2}$, the points at each side of the resonant peak are called half power points and the frequency ratios of these points are determined as:

$$
\left(\frac{\mathrm{Q}}{\sqrt{2}}\right)^{2}=1 / 2\left(\frac{1}{2 \xi}\right)^{2}=\frac{1}{\left(1-\mathrm{r}^{2}\right)^{2}+(2 \xi \mathrm{r})^{2}}
$$

Assuming light damping $(\xi<<1)$ and neglecting the higher order terms, the solution of Equation 5.8 can be written as $r_{1,2}=1 \pm \xi$. Therefore the approximate damping ratio of the system can be obtained from the RAM by

$$
\mathrm{r}_{2}-\mathrm{r}_{1}=2 \xi
$$

Estimations of the elastic forces developed during the cyclic loading for the specimens are represented by $f(x, t)=\omega^{2} m(x) v(x, t)=m(x) \psi(x) 1.6 \ddot{v}_{\mathrm{g} 0} D \operatorname{Sin}(\varpi t-\theta)$. From these distributed forces, expressions for moment and shear at any arbitrary location $\mathrm{h}$ on the structure are given by

$$
\begin{aligned}
& M_{h}(h, t)=\omega^{2} Z(t)\left[\int_{h}^{L} m(x) \psi(x)(x-h) d x+m_{k}\left[\psi\left(h_{k}\right)\right]\left(h_{k}-h\right)\right] \\
& V_{h}(h, t)=\omega^{2} Z(t)\left[\int_{h}^{L} m(x) \psi(x) d x+m_{k}\left[\psi\left(h_{k}\right)\right]\right]
\end{aligned}
$$




\subsection{Finite ELEMENT ANALYSIS}

In this chapter, the problem of thermal stresses within the ceramic candle filters is studied. The effects of temperature variations on the natural frequencies and filters' dimensions are also studied. New FEM models are built for the Pall and Sch filters. In these new models, the thickness of the filter's walls is divided in 8 layers to have better resolution in the radial direction. The new models are made of about 4300 brick elements with 5040 nodes. The thermal properties of the ceramic candle filters considered in this study are presented in Table 5.1. The FEM models are subjected to $250^{\circ} \mathrm{F}, 350^{\circ} \mathrm{F}$, and $1500^{\circ} \mathrm{F}$ steady-state temperatures. The models are also used to simulate time dependent heat transfer that occurs during back pulse cleaning. For this scenario, the model is subjected to $1500^{\circ} \mathrm{F}$ and then a constant $77^{\circ} \mathrm{F}$ heat load (Alvin 1999) is applied in the interior wall of the filter for 0.5 seconds. The solution time step used in this analysis is $0.05 \mathrm{sec}$.

The thermal stress analysis is conducted in two steps. The first step is to determine the amount of heat moving into or out of the candle filter. For the steady-state heat case, this step is conducted by using Heat-Transfer analysis. For the time dependent heat case, a Transient Heat Transfer analysis is used in the first step. Once the nodal temperatures are calculated, the same FEM models are used in the linear stress analysis (step 2) by inputting the obtained nodal temperatures in the models to obtain the transient thermal stress field. 


\subsection{RESULTS AND DISCUSSIONS}

The natural frequencies and mode shapes obtained from the thermal dynamic testing are tabulated along with those from the finite element analysis. The experimental values are obtained using a laser vibrometer. Room, $250^{\circ} \mathrm{F}$ and $350^{\circ} \mathrm{F}$ temperatures are used to test 2 new Sch TF20 and 2 new Pall 326 filters. In the FEM models, $1500{ }^{\circ} \mathrm{F}$ is also used. In the fatigue tests, the experimental values are obtained using a combination of laser vibrometer and accelerometer measurements. The stresses and the number of cycles through the ceramic filters' failure are used to determine the useful life of the specimens.

\subsubsection{Thermal Dynamic Characterization}

Table 5.2 lists the natural frequencies of the Sch TF20 335i-173 filter at different temperatures with free-free boundary conditions. At $250^{\circ} \mathrm{F}$ the natural frequency values drop about $1.58 \%$ and at $350^{\circ} \mathrm{F}$ they decreases about $3.75 \%$. Figure 5.4 shows the percentage frequency shift along the first six flexural modes. This frequency shift can be due to a reduction of Young's modulus and/or change in the filters dimension (thermal expansion). When comparing the frequency ratio of two consecutive frequencies, the values are approximately the same at all three temperatures. This result implies that there is no change in the setup boundary restraint. The natural frequencies with fixed-free boundary conditions are also listed in this table. Again, there is a clear reduction of the natural frequencies with temperature increments. There is about $1.43 \%$ and $3.18 \%$ reduction at $250^{\circ} \mathrm{F}$ and $350^{\circ} \mathrm{F}$, respectively. The frequency ratios between third and second vibration modes decrease at elevated temperature. Therefore the boundary 
restrain $\mathrm{K}^{\wedge}$ increases with the increment of temperature. The nondimensional $\mathrm{K}^{\wedge}$ factor are 2.75 for room temperature, 2.82 for $250^{\circ} \mathrm{F}$, and 3 for $350^{\circ} \mathrm{F}$. These values are obtained using Figure 4.9.

Table 5.3 lists the thermal result for the Pall 326 5-1365 filter. The percentage reduction in the frequency results for the free-free test is about $1.51 \%$ for $250^{\circ} \mathrm{F}$ and about $2.26 \%$ for $350^{\circ} \mathrm{F}$. In the free-free test, the elevated temperature effect on the boundary restraint is minimal. With the fixed-free boundary restraints, there is a reduction of about $0.86 \%$ and $2.61 \%$, respectively. The frequency ratio $\mathrm{f} 3 / \mathrm{f} 2$ decreases with the increment of temperature. The nondimensional $\mathrm{K}^{\wedge}$ factors are 10.45 for room temperature, 10.6 for $250^{\circ} \mathrm{F}$, and 11.15 for $350^{\circ} \mathrm{F}$.

Table 5.4 lists the thermal result for the Pall 326 5-1340 and the Sch TF20 335i161 filters. Similar thermal behavior, when compared with the same filter's type, is observed in these two filters. These filters were only tested with free-free boundary conditions. The percentage reduction in the frequency results of the Pall 326 5-1340 is about $1.40 \%$ for $250^{\circ} \mathrm{F}$ and about $2.15 \%$ for $350^{\circ} \mathrm{F}$. The frequency reduction of the Sch TF20 $335 \mathrm{i}-161$ is about $1.67 \%$ at $250^{\circ} \mathrm{F}$ and about $3.87 \%$ at $350^{\circ} \mathrm{F}$.

The FEM results using steady-state thermal analysis for the Sch TF-20 335i-173 and the Pall 326 6-1365 filters are listed in Tables 5.5 and 5.6. Two sets of natural frequency values are shown at each elevated temperature. The first represents the natural frequencies obtained with the original dimensions of the candle filters, while the second are obtained using the modified filter dimensions considering the thermal expansion coefficient of the candle filters. The Young's modulus of each filter is obtained for the first case by matching the natural frequency results, and then the same Young's modulus 
is used in the case with thermal expansion coefficient. As expected, the frequency shift in both filters is bigger at higher temperatures due to thermal expansion. Comparing the FEM results between these filters, the frequencies decrease more rapidly in the Pall filter because this type of filter has a slightly higher thermal expansion coefficient. Although both filters present a thermal induced frequency reduction, it can be said that the filters' thermal expansion at $250^{\circ} \mathrm{F}$ and $350^{\circ} \mathrm{F}$ has minimal influence in the natural frequencies reduction. Hence, the measured frequency reduction of each filter at elevated temperature is mainly due to the stiffness reduction of the filter. The Sch filter has more stiffness reduction than the Pall filter at those two elevated temperatures. The Young's modulus obtained for the Sch filter at $250^{\circ} \mathrm{F}$ is about $5.62 \times 10^{6}$-psi and at $350^{\circ} \mathrm{F}$ is about $5.38 \times 10^{6}$ psi. These values represent a $2.85 \%$ and $7.43 \%$ stiffness reduction. For the Pall filter, the Young's moduli are about $7.25 \times 10^{6} \mathrm{psi}$ or $2.76 \%$ reduction and $7.1 \times 10^{6} \mathrm{psi}$ or $4.7 \%$ reduction, respectively.

In order to determine the influence of the thermal expansion in the filters at the high operational temperature, the FEM models are subjected to a $1500^{\circ} \mathrm{F}$ steady-state temperature. An arbitrary Young's modulus that is about $10 \%$ lower than that at room temperature is selected for each FEM model type. The results show that even at hightemperature the influence of thermal expansion on the natural frequencies is minimal. For the Sch model the influence is about $0.23 \%$ and for the Pall is about $0.39 \%$.

FEM models are also used to simulate the transient thermal event that occurs during the back pulse. The initial temperature is assumed to be $1500^{\circ} \mathrm{F}$ for the entire filter. A constant $77^{\circ} \mathrm{F}$ thermal loading is applied in the inner wall of the filter during 0.5 seconds. After that the model is analyzed for 2 more seconds without the loading. Figure 
5.5 shows the FEM temperature distribution for the Pall 326 model at $0.5 \mathrm{sec}$ of the applying load. The FEM analysis results indicate that the minimum temperature of the inner wall of this filter due to the back pulse is about $1412^{\circ} \mathrm{F}$, which correspond to a temperature drop of about $88^{\circ} \mathrm{F}$. For the Sch TF20 model, maximum temperature drop, which also occurs at $0.5 \mathrm{sec}$, is about $65^{\circ} \mathrm{F}$. The temperate in the outer wall for both filters' models remains at $1500^{\circ} \mathrm{F}$.

Figure 5.6 shows the temperature distribution with respect to time at different thickness of the Pall 326-filter model. During the first 0.5 seconds the temperature decreases fast in a concave way. After the thermal load is removed (at $0.5 \mathrm{sec}$ ) the fitter's temperature increases. It takes about 2 extra seconds for the filter to reach back to the steady state temperature condition of $1500^{\circ} \mathrm{F}$. The maximum temperature difference occurs at the surface of the inner wall at 0.5 seconds. The temperature between $0.215 \mathrm{in}$ and 0.304in from the inner wall reaches its minimum temperature at about 0.6 second. Alvin (1999) reported the experimental thermal transient event occurred during back pulse cleaning. Her results are also shown in Figure 5.6. The experimental temperature drop during back pulse and the current FEM simulation result for the Pall 326 seems to match well.

Figure 5.7 shows the temperature distribution of the Sch TF20 filter model along the thickness with respect to time. The maximum temperature difference also occurs at the surface of the inner wall at $0.5 \mathrm{sec}$. After 2.5 seconds, the filter goes back to $1500^{\circ} \mathrm{F}$ uniform temperature.

The nodal temperature distribution obtained at different times is used as nodal thermal loading input in the FEM stress analysis. Linear stress analysis is performed on 
both filter models. Figure 5.8 shows the maximum principal stresses (circumferential stresses) of the Pall 326 FEM model after $0.5 \mathrm{sec}$ of the back pulse. The maximum stress is observed in the inner wall of the model and is about 2055psi in tension. The outer wall has no stress because there is no change in the surface temperature.

The circumferential stress distributions along the wall of the filters at $0.5 \mathrm{sec}$, $0.55 \mathrm{sec}, 0.60 \mathrm{sec}$ and $0.65 \mathrm{sec}$ time periods are plotted. Figure 5.9 shows the thermal stresses of the Pall 326 model. The maximum stress (about 2055psi) is found in the inner wall at $0.5 \mathrm{sec}$. A maximum stress of about $919 \mathrm{psi}$ is noticed at $0.15 \mathrm{in}$ from the inner wall at $0.55 \mathrm{sec}$. Between 0.22in and 0.3in from the inner wall the maximum stress values happen at $0.6 \mathrm{sec}$ and $0.65 \mathrm{sec}$. These stresses are about 570psi and 201psi, respectively. Figure 5.10 shows the thermal stresses distribution of the Sch TF20 model. A maximum stress of about $1346 \mathrm{psi}$ is found in the inner wall at $0.5 \mathrm{sec}$. The maximum stress found at 0.15in, $0.22 \mathrm{in}$ and $0.3 \mathrm{in}$ from the inner wall are about 624psi $(0.55 \mathrm{sec}), 396 \mathrm{psi}(0.60 \mathrm{sec})$, and 138psi $(0.65 \mathrm{sec})$, respectively.

The thermal stress values obtained using FEM are significant if they are compared with the as-manufactured material strength of the Pall and Sch TF-20 filters. These stresses have been obtained assuming constant back pulse temperatures of $77^{\circ} \mathrm{F}$. The actual back pulse temperature applied to the candle filters may be much higher than $77^{\circ} \mathrm{F}$ because the back pulse gas might travel through a number of hot pipes inside the plenum. Therefore the maximum thermal stresses that the filters will be subjected to can be much lower than the assumed $77^{\circ} \mathrm{F}$ back pulse.

Simha (1998) studied the formation of residual ash deposits on hot gas filtration systems. The initial temperature of the back pulse air was considered to be about $392^{\circ} \mathrm{F}$. 
Figures 5.11 and 5.12 show the temperature distribution along the thickness, using constant $400{ }^{\circ} \mathrm{F}$ back pulse temperature, of the Pall and the Sch TF20 filter models, respectively. The maximum temperature drop is about $36^{\circ} \mathrm{F}$, for the $\mathrm{Sch} \mathrm{TF} 20$ model and about $50^{\circ} \mathrm{F}$, for the Pall model. The stress distributions along the wall of the Pall and Sch TF-20 models at $0.5 \mathrm{sec}, 0.55 \mathrm{sec}, 0.60 \mathrm{sec}$ and $0.65 \mathrm{sec}$ time periods are plotted in Figures 5.13 and 5.14, respectively. The maximum stresses found in the inner wall at $0.5 \mathrm{sec}$ are about 1400psi (Pall model) and about 750psi (Sch TF-20 model).

\subsubsection{Fatigue}

In the first phase of this fatigue analysis, the vibration properties of the candle filter are determined. Because of the difficulty in obtaining the static structural response using the harmonic vibration generator (shaker), the natural frequency and damping ratio are determined experimentally using the frequency response curve. The shaker is operated at a selected frequency, the candle filter response is observed while the transient part damps out, and the amplitude of the steady state is recorded. The shaking frequency is changed to a new value and the measurement is repeated. Figure 5.15 shows the frequency response curve obtained for the Sch TF20 326I-147. The forcing frequency used ranges from $8 \mathrm{~Hz}$ to $14 \mathrm{~Hz}$. The damping ratio for the Sch TF20 326I-147 is also obtained from this Figure. When the RAM is equal to $5.06(7.15 / \sqrt{ } 2)$ the half power points are 1.012 and 0.984 . Therefore the damping ratio of the system obtained using Equation 5.10 is about 0.014 . The first natural frequency of the system with the Sch TF20 335i-159, 379H-129, and 335I-173 filters are about $10 \mathrm{~Hz}, 10.2 \mathrm{~Hz}$, and $8 \mathrm{~Hz}$, 
respectively. The damping ratios are about $0.014,0.041$, and 0.048 , respectively. Figure 5.16 shows the frequency response curve obtained for these three Sch TF20 filters.

These four candle filters were used to build the fatigue life curve for the Schumacher TF20 filters. The maximum amplitude of the ground acceleration used to excite the Sch 326I-147, 335I-159, and 335I-173 filters were about 0.27g, 0.31g, and $0.65 \mathrm{~g}$, respectively. A $31 \mathrm{~b}$ lumped mass was attached at the bottom of these three filters. The shaking frequencies used were $9.75 \mathrm{~Hz}, 9.75 \mathrm{~Hz}$, and $7.5 \mathrm{~Hz}$, respectively. Therefore the stresses obtained at the base of these filters were about 938psi for the 326I-147 filter, 994psi for the 335I-159 filter, and 1036psi for the 335I-173 filter. For the Sch filter 379H-129 no lamp mass was attached to the bottom of the filter. Hence, higher ground excitation was needed in order to obtain the stress level desired (884psi). The maximum amplitude of the ground acceleration used was about $1.85 \mathrm{~g}$ with a shaking frequency of $10 \mathrm{~Hz}$.

Figure 5.17 shows S/N curve for the Sch TF-20 filters. With this curve, the number of cycles that the Sch filters go through before failure is determined. It is noticed that when the filters are subjected to stress about 1036psi, the number of fatigue cycles needed to cause a catastrophic failure is about 8,100 cycles. If the stress is reduced to about $884 p s i$, the number of cycles increases dramatically (about 4,906,650 cycles). The S/N curve will reach a nearly horizontal slope when the stresses are reduced to a level where no failure occurs within a maximum number of cycles. This portion of the curve will define the fatigue or endurance limit for the test material.

The natural frequencies of the shaking system with the Pall filters are also obtained using the RAM methodology. The damping ratios of the Pall 5-1365 and 2- 
1355 are about 0.010 and 0.0012 respectively. Figure 5.18 shows the frequency response curve obtained for these two Pall 326 filters. The maximum amplitude of the ground acceleration used to excite these filters was about $0.78 \mathrm{~g}$ and $0.34 \mathrm{~g}$, respectively. The $31 \mathrm{~b}$ lumped mass was also used in the bottom of the filters. The shaking frequencies used were $7.5 \mathrm{~Hz}$ and $10.25 \mathrm{~Hz}$, respectively. The filters were subjected to a base stress of about 1346psi (Pall 5-1365 filter) and 1145psi (Pall 2-1355 filter).

Figure 5.19 shows S/N curve for the two Pall 326 filters tested. The number of cycles necessaries for the Pall filters to fail at the corresponding stress levels are plotted. For a stress level of about 1346psi, the number of cycles needed to cause a catastrophic failure is about 32,250 cycles. If the stress is reduced to about $1145 \mathrm{psi}$, the number of cycles increases to about $1,219,035$ cycles.

\subsection{SUMMARY}

The vibration signature can be used as a tool to evaluate the stiffness and boundary restraints of the ceramic candle filters at different temperatures. The laboratory testing setup developed in this study allowed us to observe changes in the vibration response of the ceramic candle filters due to elevated temperatures. It also permitted us study the effect of various temperatures on the fixed boundary restraint for different candle filter groups. The behavior of the candle filters at operational temperature and the corresponding thermal stresses were successfully obtained using FEM modeling with transient thermal stress analysis.

The fatigue vibration induced to the filters due to plenum vibration or back pulse shaking was simulated experimentally for the Pall 326 and the Schumacher TF-20 filters. 
The stresses needed to produce failure in the filter with respect to the number of cycles were obtained. The fatigue results obtained with this study show the importance in considering the operational vibration as a factor that may produce sudden fracture failure in the ceramic candle filters. Figure 5.20 shows the pictures of the fracture profile of four Sch TF-20 filters tested that failed at different number of fatigue cycles $(8,100$ cycles, 15,800 cycles, 846,000 cycles, and 4,906,650 cycles). Figure 5.21 shows the fracture profile of two Pall 326 filters tested that failed at 32,250 cycles and at 1,219,000 cycles. Both of these specimens failed at about 1 inch from the head of the filter. 
Table 5.1 Thermal properties of Pall 326, Pall 442T and Schumacher TF-20 (Spain and Starret 1999).

\begin{tabular}{|c|c|c|}
\hline Thermal Properties & Value & Units \\
\hline \multicolumn{3}{|l|}{ Refractron 326 and $442 T$} \\
\hline $\begin{array}{l}\text { Coefficient of thermal } \\
\text { expansion }\end{array}$ & $2.8 \times 10^{-6}$ & $/^{\circ} \mathrm{F}$ \\
\hline $\begin{array}{l}\text { Thermal Conductivity (at } \\
1000^{\circ} \mathrm{F} \text { ) }\end{array}$ & 39 & BTU-in / hr- $\mathrm{ft}^{2}-{ }^{\circ} \mathrm{F}$ \\
\hline Specific Heat & 0.155 & BTU / Slug- ${ }^{\circ} \mathrm{F}$ \\
\hline \multicolumn{3}{|l|}{ Schumacher TF-20 } \\
\hline $\begin{array}{l}\text { Coefficient of thermal } \\
\text { expansion }\end{array}$ & $2.5 \times 10^{-6}$ & $/{ }^{\circ} \mathrm{F}$ \\
\hline $\begin{array}{l}\text { Thermal Conductivity (at } \\
\left.1000^{\circ} \mathrm{F}\right)\end{array}$ & 51 & BTU-in / hr- $\mathrm{ft}^{2}-{ }^{\circ} \mathrm{F}$ \\
\hline Specific Heat & 0.165 & BTU / Slug- ${ }^{\circ} \mathrm{F}$ \\
\hline
\end{tabular}


Table 5.2 Natural frequencies (Hertz) of a Sch TF20 filter at different temperatures.

\begin{tabular}{||c|c|c|c|c|c||}
\hline \multicolumn{7}{||c||}{ Schumacher TF-20 3-351-173 } \\
\hline FrEe-FreE BC \\
\hline Mode & Room & $250^{\circ} \mathrm{F}$ & $\%$ & $350^{\circ} \mathrm{F}$ & $\%$ \\
\hline 1 & 115.36 & 113.53 & 1.613 & 111.08 & 3.846 \\
\hline 2 & 314.94 & 310.06 & 1.575 & 303.34 & 3.823 \\
\hline 3 & 610.46 & 600.59 & 1.644 & 587.77 & 3.861 \\
\hline 4 & 993.04 & 976.56 & 1.687 & 956.03 & 3.871 \\
\hline 5 & 1452.64 & 1429.44 & 1.623 & 1401.20 & 3.671 \\
\hline 6 & 1974.49 & 1948.96 & 1.310 & 1909.28 & 3.415 \\
\hline FIXED-FREE BC \\
\hline Mode & Room & $250{ }^{\circ} \mathrm{F}$ & $\%$ & $350^{\circ} \mathrm{F}$ & $\%$ \\
\hline 1 & 18.31 & -- & -- & -- & -- \\
\hline 2 & 111.39 & 109.86 & 1.389 & 108.14 & 3.007 \\
\hline 3 & 331.22 & 326.54 & 1.433 & 320.43 & 3.365 \\
\hline \hline
\end{tabular}

Table 5.3 Natural frequencies (Hertz) of a Pall 326 filter at different temperatures.

\begin{tabular}{||c|c|c|c|c|c||}
\hline \multicolumn{7}{||c||}{ Refractron 326 $5-1365$} \\
\hline FrEe-FrEe BC \\
\hline Mode & Room & $250^{\circ} \mathrm{F}$ & $\%$ & $350^{\circ} \mathrm{F}$ & $\%$ \\
\hline 1 & 137.33 & 135.80 & 1.124 & 134.28 & 2.273 \\
\hline 2 & 373.84 & 369.26 & 1.240 & 365.74 & 2.216 \\
\hline 3 & 726.29 & 713.46 & 1.799 & 709.41 & 2.380 \\
\hline 4 & 1171.85 & 1152.04 & 1.720 & 1145.94 & 2.261 \\
\hline 5 & 1705.88 & 1677.42 & 1.697 & 1666.26 & 2.378 \\
\hline 6 & 2311.45 & 2278.13 & 1.463 & 2264.40 & 2.078 \\
\hline FIXED-FREE BC & \multicolumn{5}{|l|}{} \\
\hline Mode & Room & $250{ }^{\circ} \mathrm{F}$ & $\%$ & $350^{\circ} \mathrm{F}$ & $\%$ \\
\hline 1 & 18.31 & -- & -- & -- & -- \\
\hline 2 & 123.60 & 122.57 & 0.837 & 120.54 & 2.532 \\
\hline 3 & 349.43 & 346.37 & 0.881 & 340.27 & 2.691 \\
\hline \hline
\end{tabular}


Table 5.4 Natural frequencies (Hertz) of two ceramic candle filter at different temperatures.

\begin{tabular}{|c|c|c|c|c|c|}
\hline \multicolumn{3}{|c|}{ Refractron 326} & 1340 & & \\
\hline \multicolumn{6}{|c|}{ FREE-FREE BC } \\
\hline Mode & Room & $250^{\circ} \mathrm{F}$ & $\%$ & $350^{\circ} \mathrm{F}$ & $\%$ \\
\hline 1 & 137.33 & 135.63 & 1.24 & 134.01 & 2.41 \\
\hline 2 & 370.21 & 365.41 & 1.30 & 362.71 & 2.03 \\
\hline 3 & 720.20 & 710.27 & 1.38 & 706.27 & 1.93 \\
\hline 4 & 1164.73 & 1146.77 & 1.54 & 1139.77 & 2.14 \\
\hline 5 & 1691.24 & 1666.78 & 1.45 & 1654.42 & 2.18 \\
\hline 6 & 2323.91 & 2289.01 & 1.50 & 2273.01 & 2.19 \\
\hline \multicolumn{6}{|c|}{ Schumacher TF-20 335i-161 } \\
\hline \multicolumn{6}{|c|}{ FREE-FREE BC } \\
\hline Mode & Room & $250^{\circ} \mathrm{F}$ & $\%$ & $350^{\circ} \mathrm{F}$ & $\%$ \\
\hline 1 & 115.96 & 114.01 & 1.67 & 111.14 & 3.91 \\
\hline 2 & 317.38 & 312.23 & 1.63 & 305.02 & 3.89 \\
\hline 3 & 621.04 & 608.91 & 1.95 & 595.11 & 3.98 \\
\hline 4 & 999.45 & 982.10 & 1.74 & 959.78 & 3.97 \\
\hline 5 & 1454.16 & 1429.91 & 1.67 & 1399.67 & 3.75 \\
\hline 6 & 2000.44 & 1973.04 & 1.37 & 1930.54 & 3.49 \\
\hline
\end{tabular}

Table 5.5 Sch TF20 natural frequencies (Hertz) using FEM's steady-state thermal analysis.

\begin{tabular}{|c|c|c|c|c|c|c|c|}
\hline \multicolumn{8}{|c|}{ Sch TF-20 FEM Model $\alpha=2.5 \times 10-6 /{ }^{\circ} \mathrm{F}$} \\
\hline \multirow{2}{*}{ Mode } & \multirow{2}{*}{ Room } & \multicolumn{3}{|c|}{$\mathrm{E}=5.62 \mathrm{e} 6(-2.85 \%)$} & \multicolumn{3}{|c|}{$\mathrm{E}=5.38 \mathrm{e} 6(-7.43 \%)$} \\
\hline & & w/o $\alpha$ & 250.00 & $\%$ & w/o $\alpha$ & $350 \mathrm{~F}$ & $\%$ \\
\hline 1 & 115.96 & 114.34 & 114.30 & 0.04 & 111.88 & 111.80 & 0.07 \\
\hline 2 & 316.61 & 312.20 & 312.06 & 0.04 & 305.46 & 305.25 & 0.07 \\
\hline 3 & 611.37 & 602.85 & 602.57 & 0.04 & 589.83 & 589.42 & 0.07 \\
\hline 4 & 990.39 & 976.60 & 976.15 & 0.05 & 955.51 & 954.84 & 0.07 \\
\hline 5 & 1443.60 & 1423.47 & 1422.83 & 0.04 & 1392.75 & 1391.78 & 0.07 \\
\hline 6 & 1960.32 & 1933.00 & 1932.13 & 0.04 & 1891.27 & 1889.95 & 0.07 \\
\hline \multirow{2}{*}{ Mode } & \multicolumn{3}{|c|}{$\mathrm{E}=5.25 \mathrm{e} 6(-10 \%)$} & & & & \\
\hline & w/o $\alpha$ & $1500 \mathrm{~F}$ & $\%$ & & & & \\
\hline 1 & 110.52 & 110.27 & 0.23 & & & & \\
\hline 2 & 301.75 & 301.06 & 0.23 & & & & \\
\hline 3 & 582.66 & 581.35 & 0.23 & & & & \\
\hline 4 & 943.89 & 941.76 & 0.23 & & & & \\
\hline 5 & 1375.82 & 1372.61 & 0.23 & & & & \\
\hline 6 & 1868.28 & 1863.90 & 0.23 & & & & \\
\hline
\end{tabular}


Table 5.6 Pall 326 natural frequencies (Hertz) using FEM's steady-state thermal analysis.

\begin{tabular}{|c|c|c|c|c|c|c|c|}
\hline \multicolumn{8}{|c|}{ PALL 326 FEM Model $\alpha=2.8 \times 10^{-6} /{ }^{\circ} \mathrm{F}$} \\
\hline \multirow{2}{*}{ Mode } & \multirow{2}{*}{ Room } & \multicolumn{3}{|c|}{$\mathrm{E}=7.25 \mathrm{e} 6(-2.76 \%)$} & \multicolumn{3}{|c|}{$\mathrm{E}=7.1 \mathrm{e} 6(4.7 \%)$} \\
\hline & & w/o $\alpha$ & 250.00 & $\%$ & w/o $\alpha$ & $350 \mathrm{~F}$ & $\%$ \\
\hline 1 & 137.27 & 135.42 & 135.35 & 0.05 & 134.01 & 133.91 & 0.08 \\
\hline 2 & 375.11 & 370.04 & 369.85 & 0.05 & 366.19 & 365.91 & 0.08 \\
\hline 3 & 724.73 & 714.09 & 714.57 & -0.07 & 707.50 & 706.95 & 0.08 \\
\hline 4 & 1174.43 & 1158.56 & 1157.98 & 0.05 & 1146.50 & 1145.62 & 0.08 \\
\hline 5 & 1712.13 & 1688.99 & 1688.14 & 0.05 & 1671.43 & 1670.12 & 0.08 \\
\hline 6 & 2325.01 & 2293.59 & 2292.44 & 0.05 & 2269.74 & 2267.96 & 0.08 \\
\hline \multirow{2}{*}{ Mode } & \multicolumn{3}{|c|}{$\mathrm{E}=6.74 \mathrm{e} 6(-10 \%)$} & & & & \\
\hline & w/o $\alpha$ & $1500 \mathrm{~F}$ & $\%$ & & & & \\
\hline 1 & 130.58 & 130.07 & 0.39 & & & & \\
\hline 2 & 356.79 & 355.41 & 0.39 & & & & \\
\hline 3 & 689.33 & 686.67 & 0.39 & & & & \\
\hline 4 & 1117.07 & 1112.75 & 0.39 & & & & \\
\hline 5 & 1628.50 & 1622.20 & 0.39 & & & & \\
\hline 6 & 2211.45 & 2202.88 & 0.39 & & & & \\
\hline
\end{tabular}




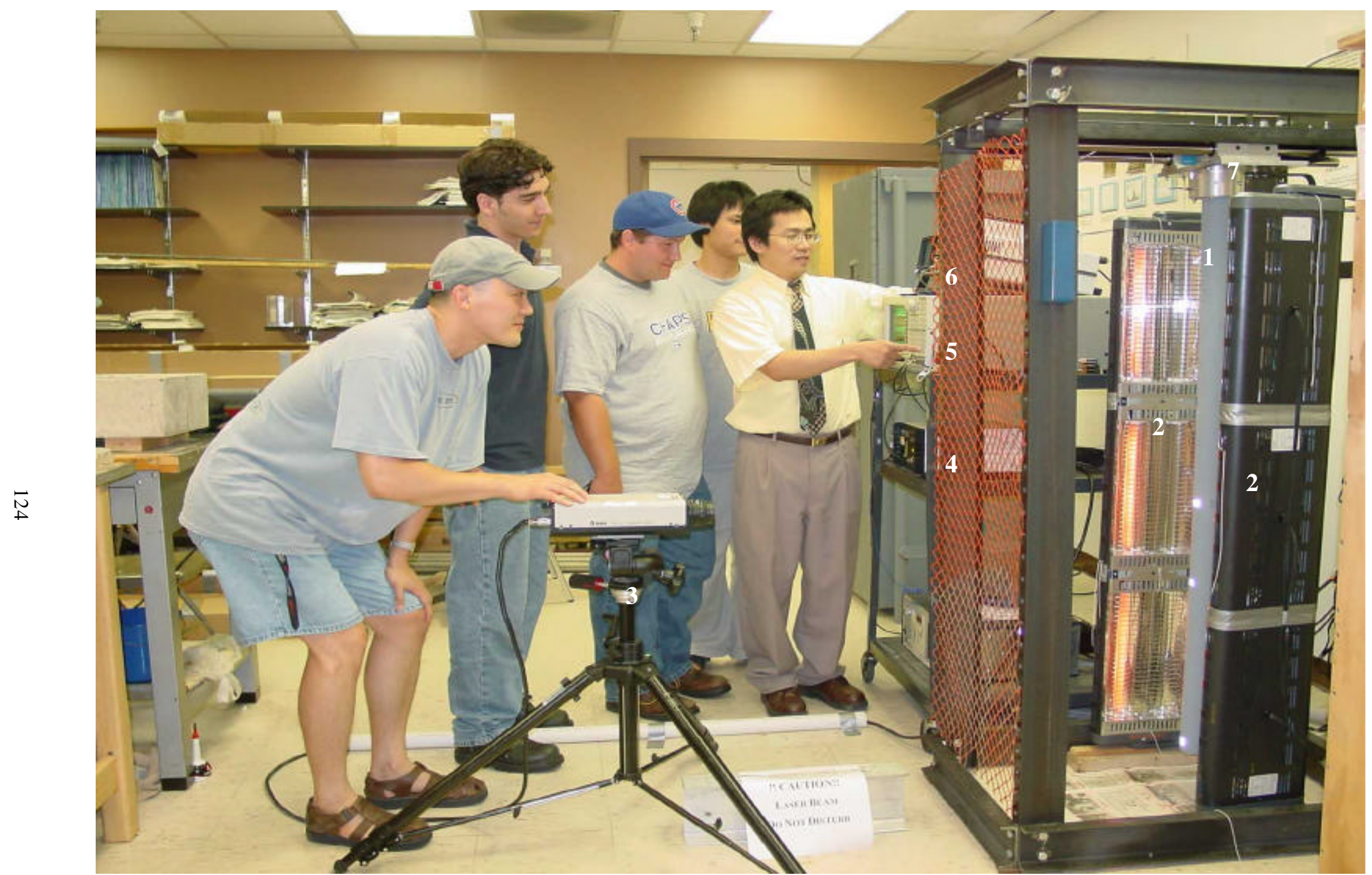

Figure 5.1 Test setup for the thermal and fatigue tests. Picture notation: 1) Ceramic Candle Filter, 2) Heating Panels, 3) Laser Vibrometer, 4) Signal Conditioners, 5) Spectrum Analyzer - SRS 785, 6) Oscilloscope, 7) Shaking Table. 


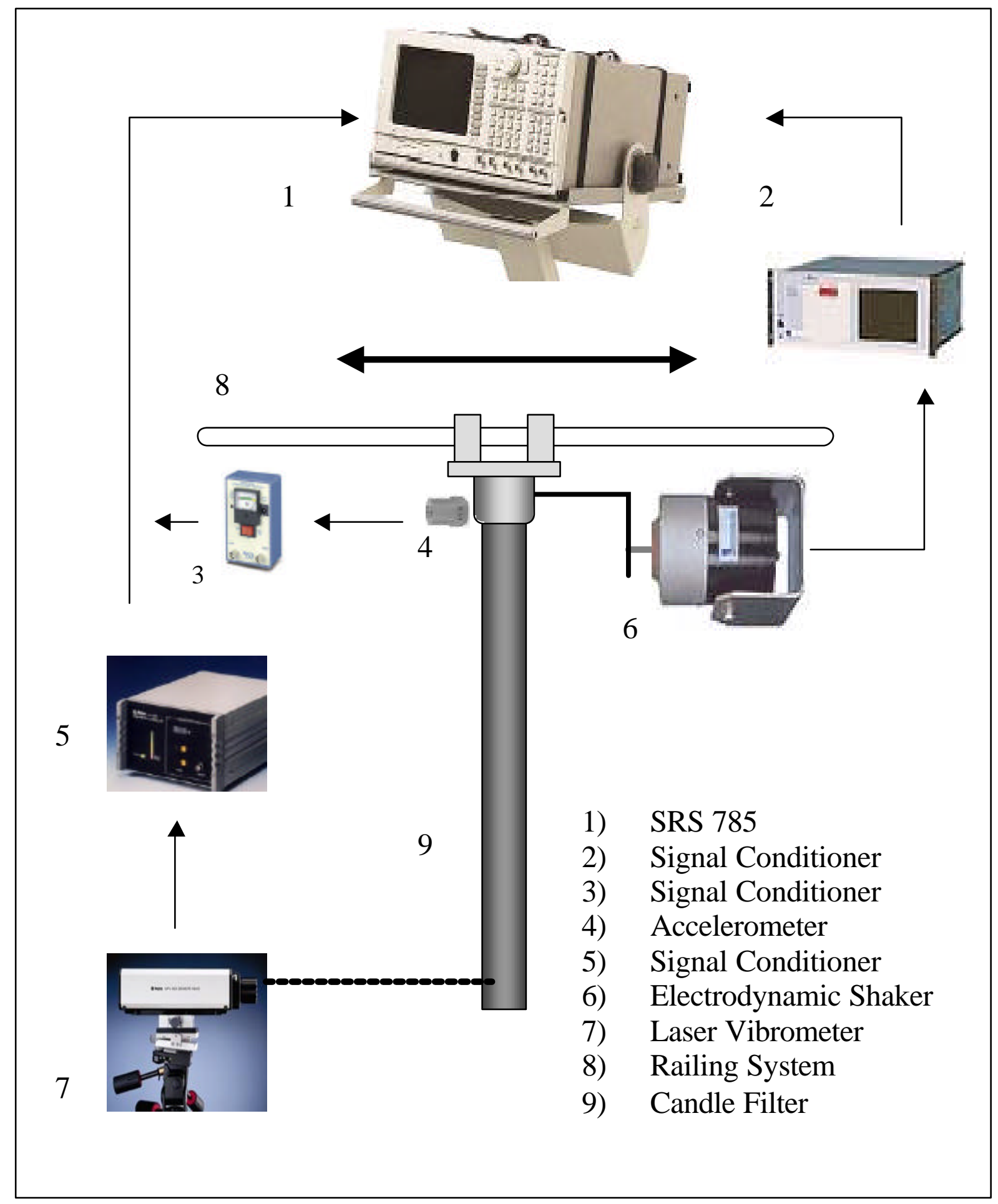

Figure 5.2 Test setup for the dynamic damage procedure. 


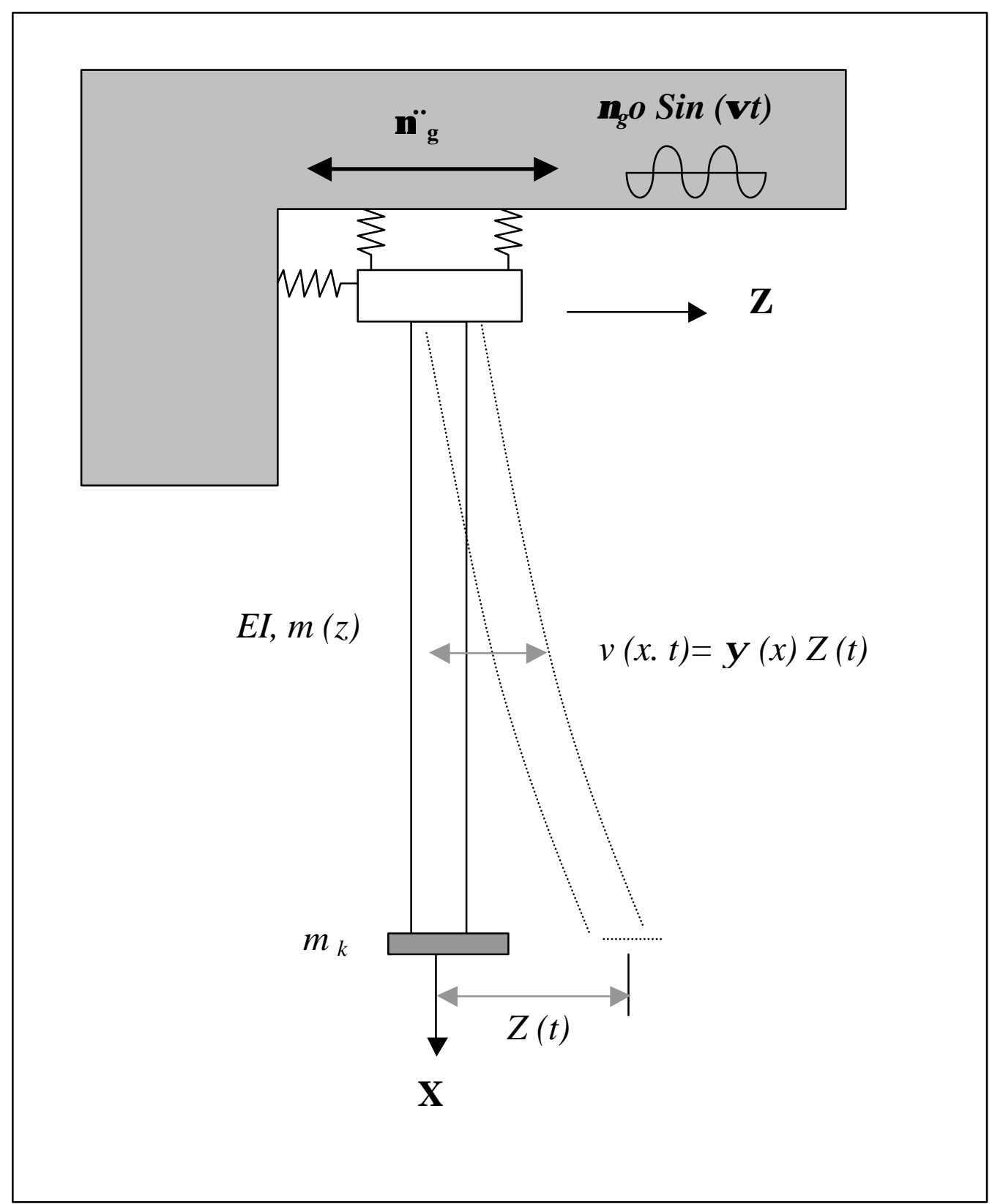

Figure 5.3 SDOF system exited by harmonic base motion. 


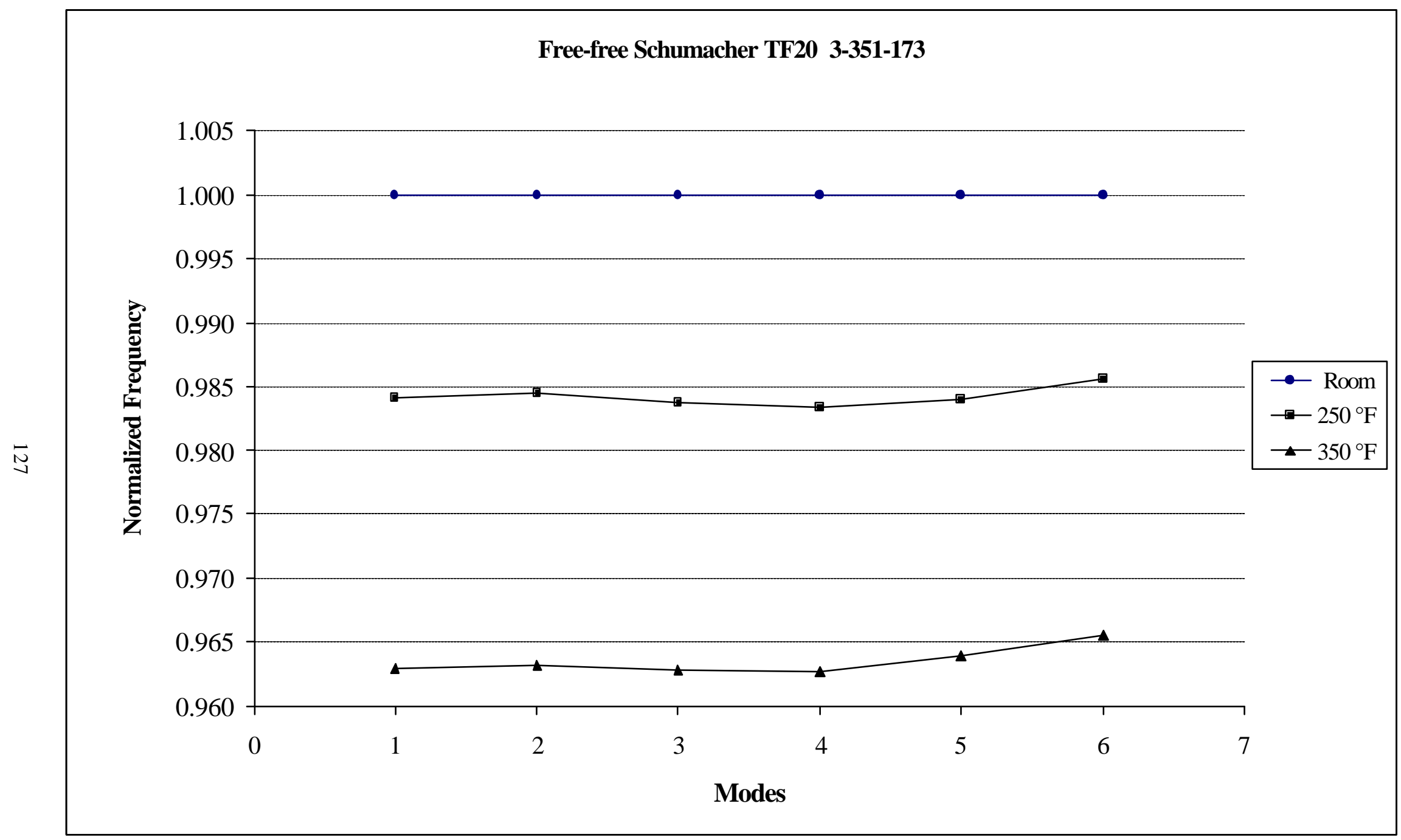

Figure 5.4 Percentage frequency shift along the first six flexural modes. 


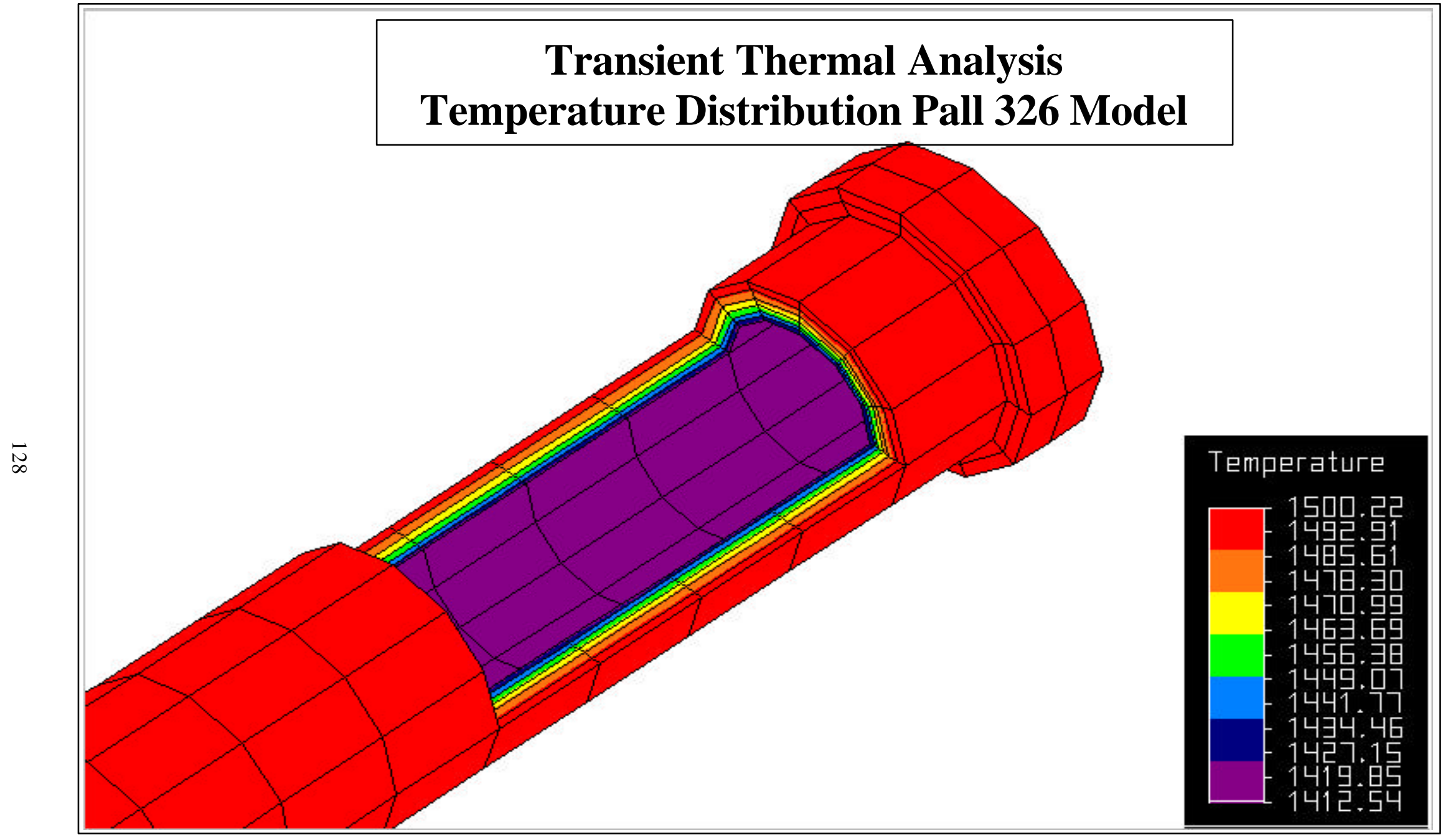

Figure 5.5 FEM temperature distribution for the Pall 326 model at 0.5 -sec. 


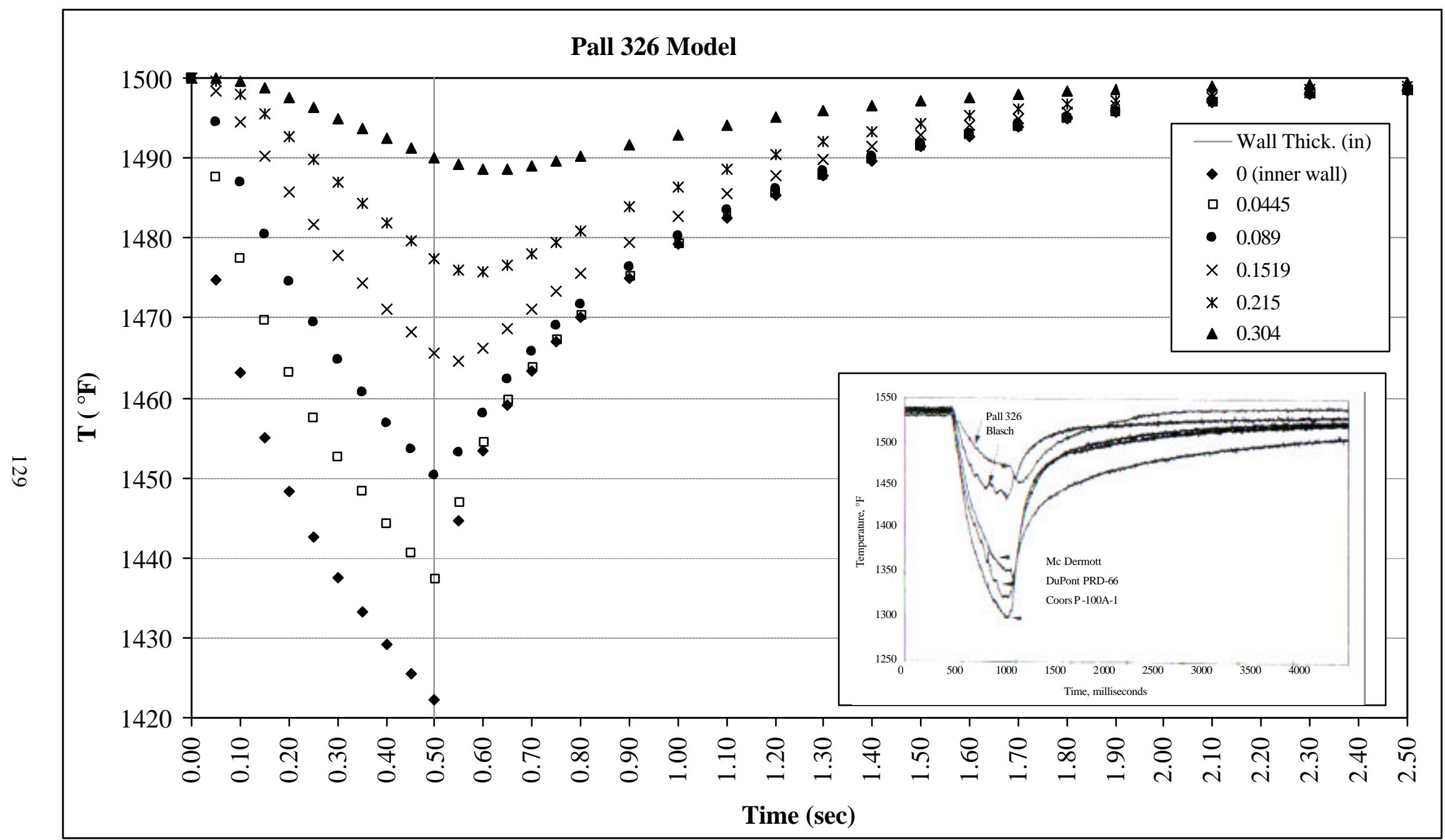

Figure 5.6 Pall 326 temperature distribution time history along the thickness - back pulse temperature $70^{\circ} \mathrm{F}$ (PIP from Alvin 1999 ). 


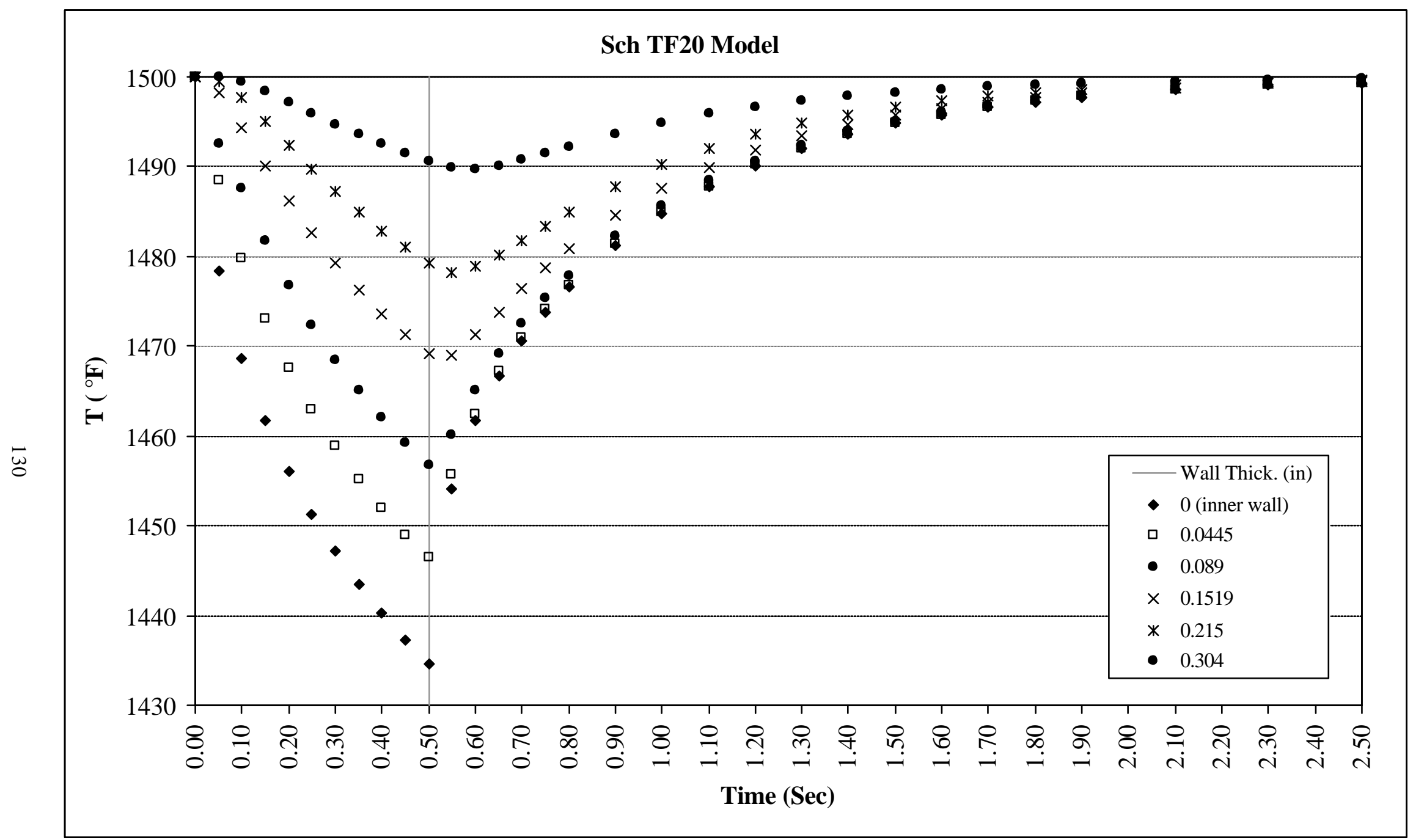

Figure 5.7 Schumacher TF-20 temperature distribution time history along the thickness - back pulse temperature $70^{\circ} \mathrm{F}$. 


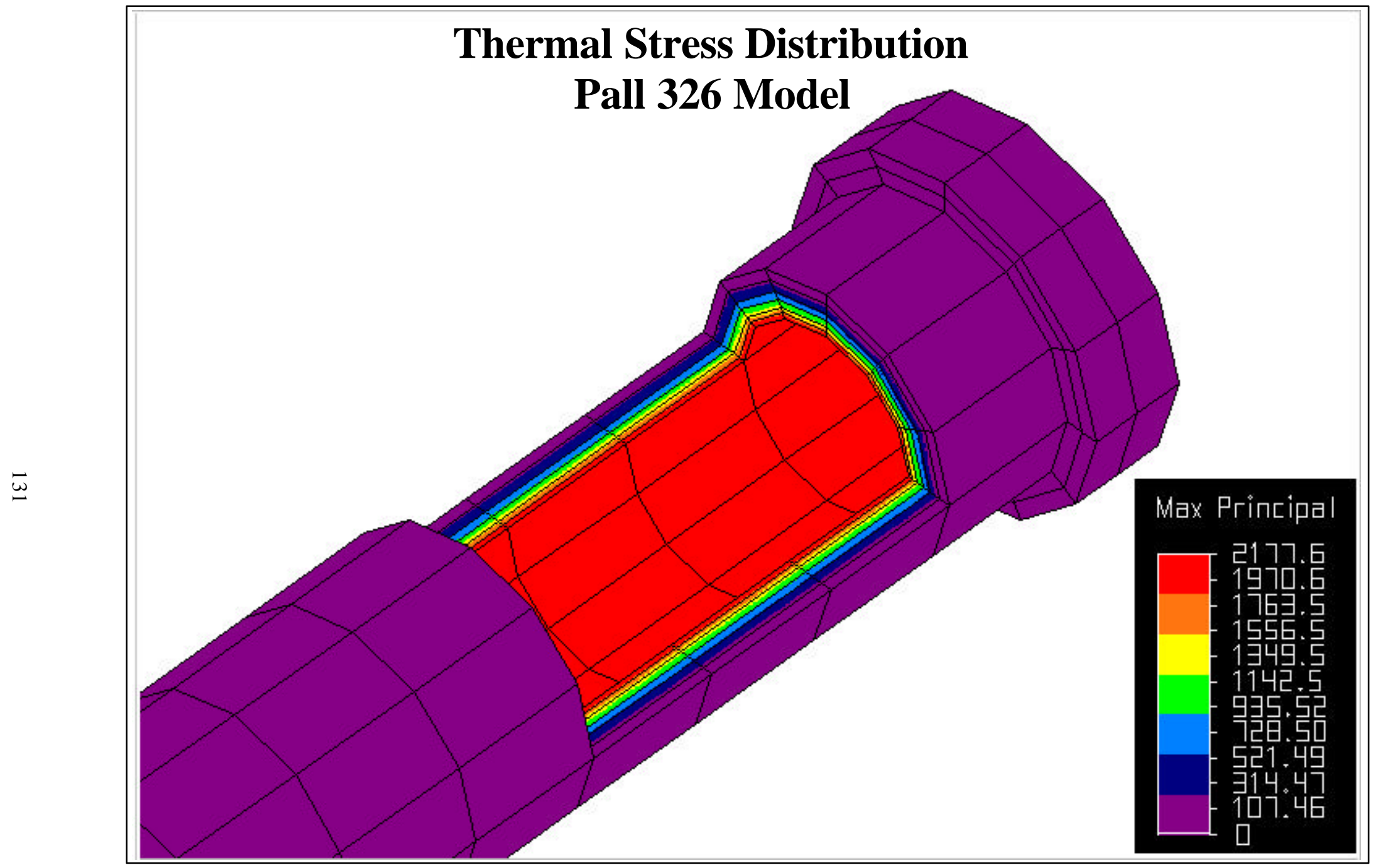

Figure 5.8 Maximum principal stresses (psi) of the Pall 326 FEM model after 0.5-sec of the back pulse. 


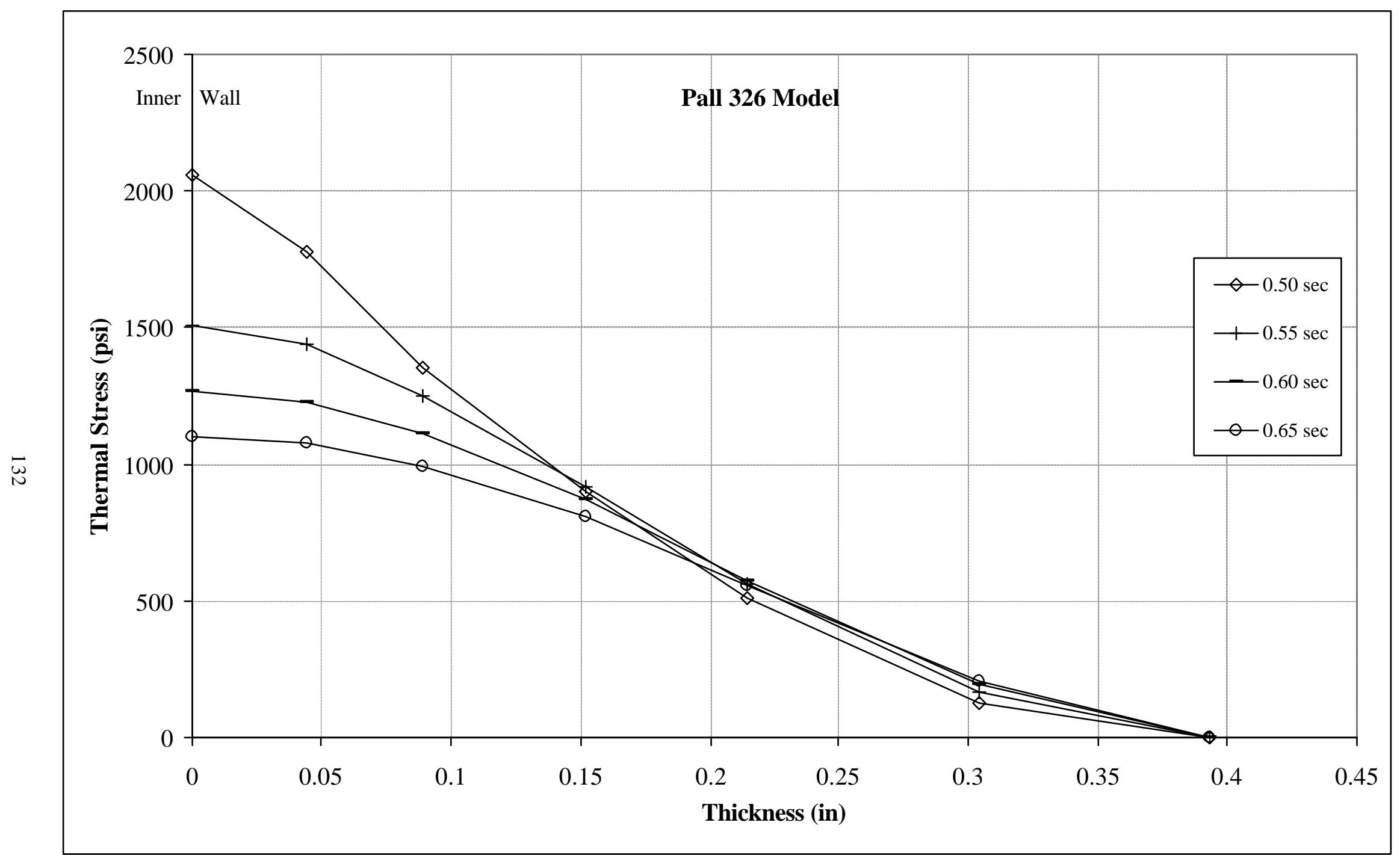

Figure 5.9 Thermal stresses of the Pall 326 model - back pulse temperature $70^{\circ} \mathrm{F}$. 


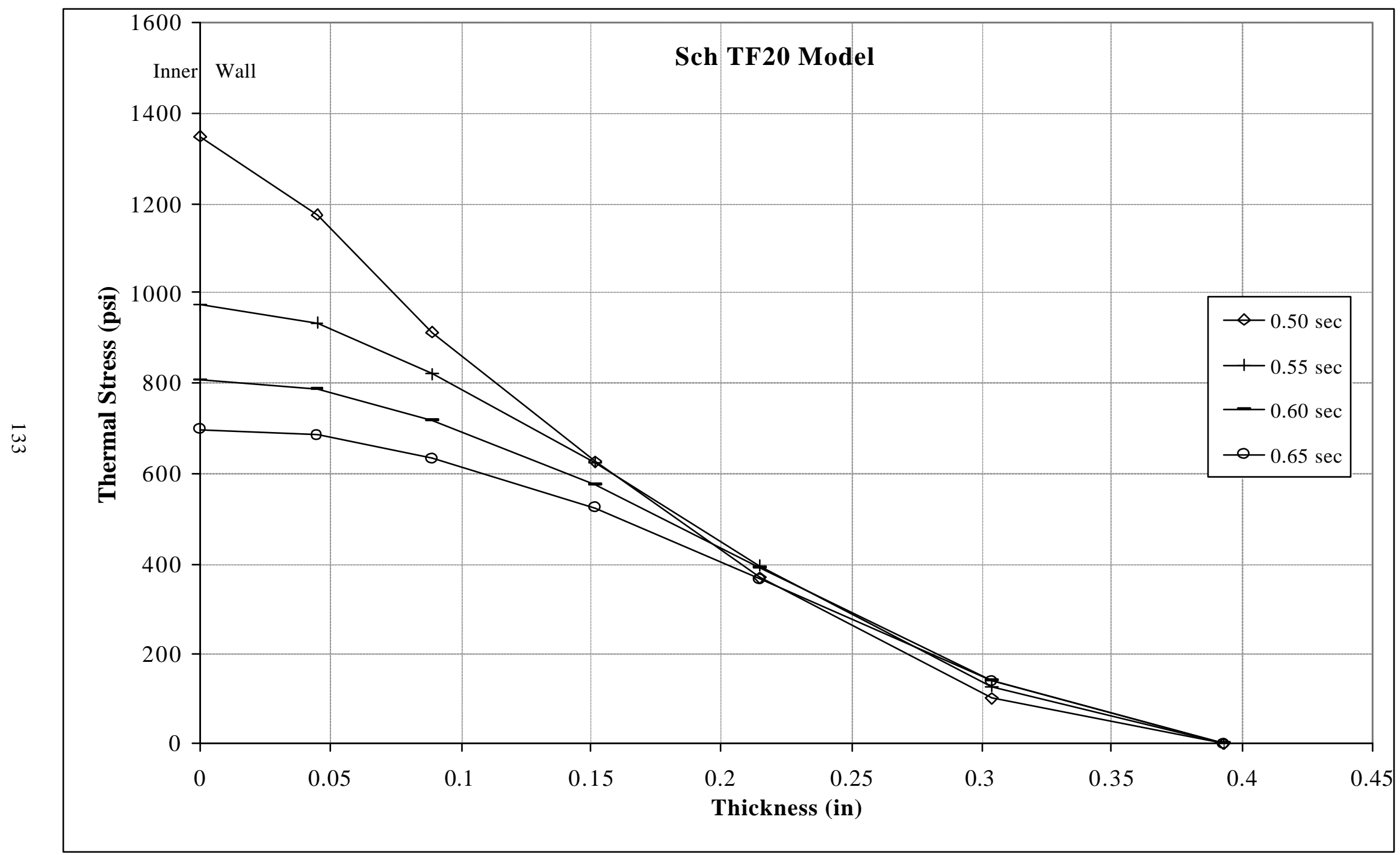

Figure 5.10 Thermal stresses distribution of the Sch TF20 model - back pulse temperature $70^{\circ} \mathrm{F}$. 


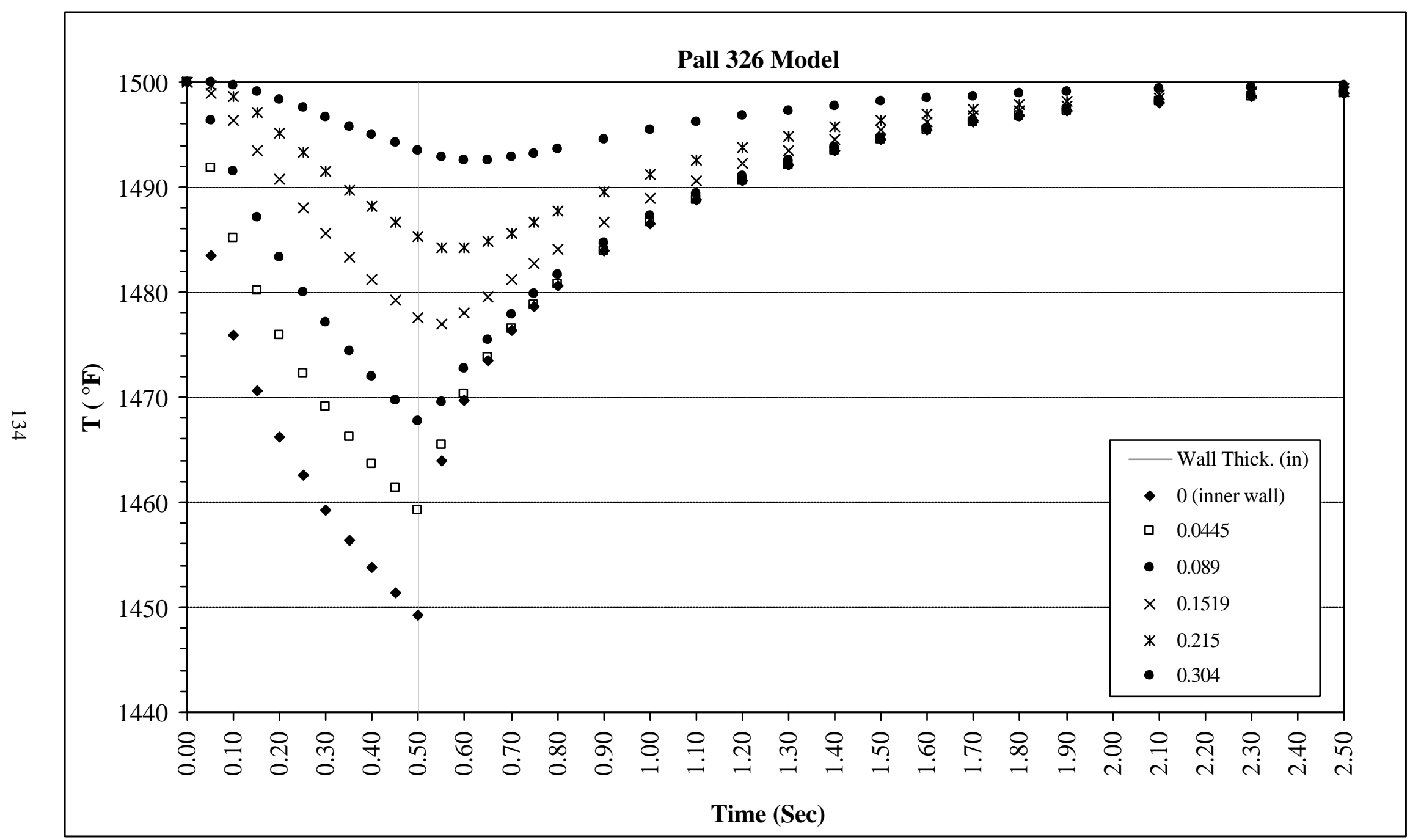

Figure 5.11 Pall 326 temperature distribution time history along the thickness - back pulse temperature $400^{\circ} \mathrm{F}$. 


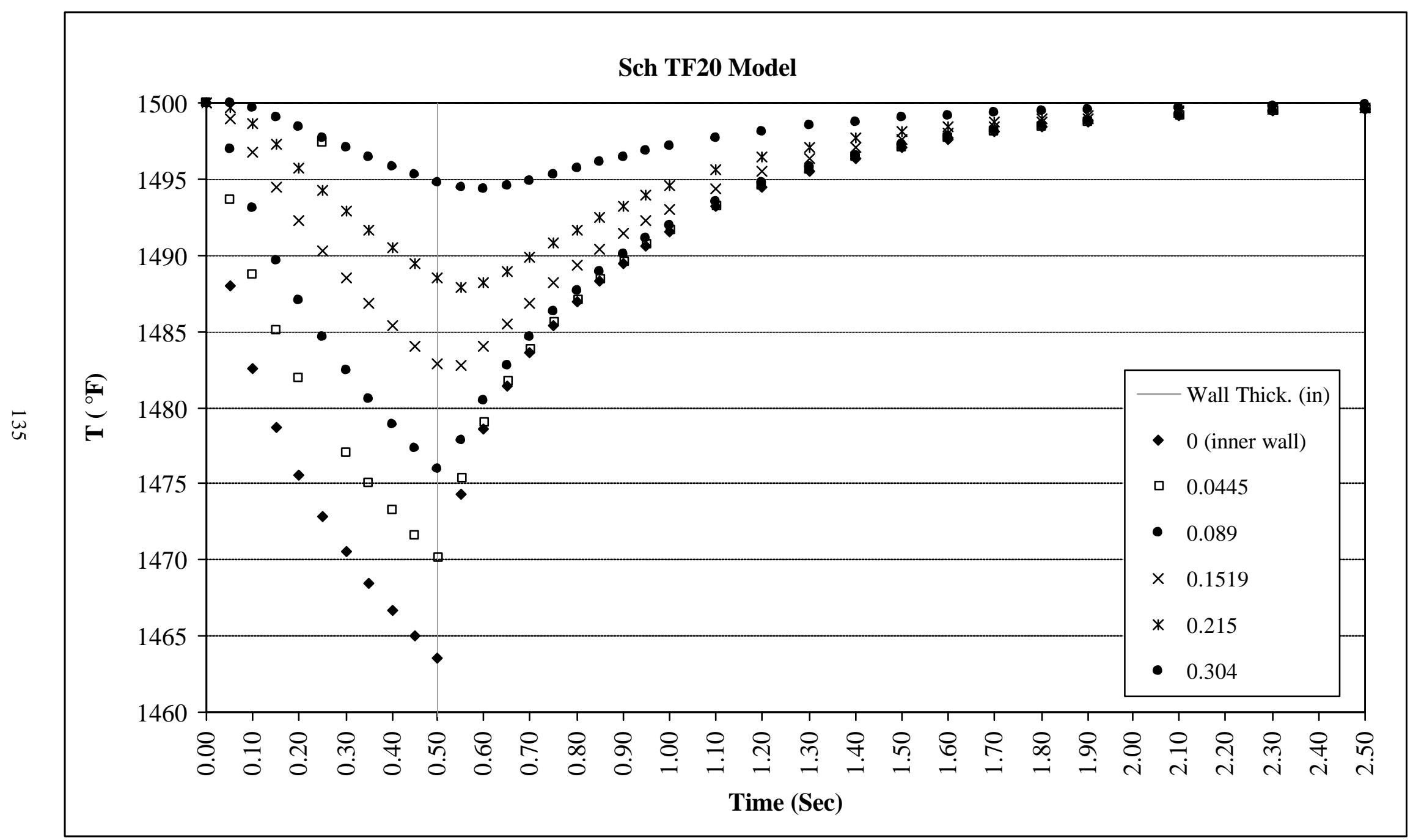

Figure 5.12 Sch TF-20 temperature distribution time history along the thickness - back pulse temperature $400^{\circ} \mathrm{F}$. 


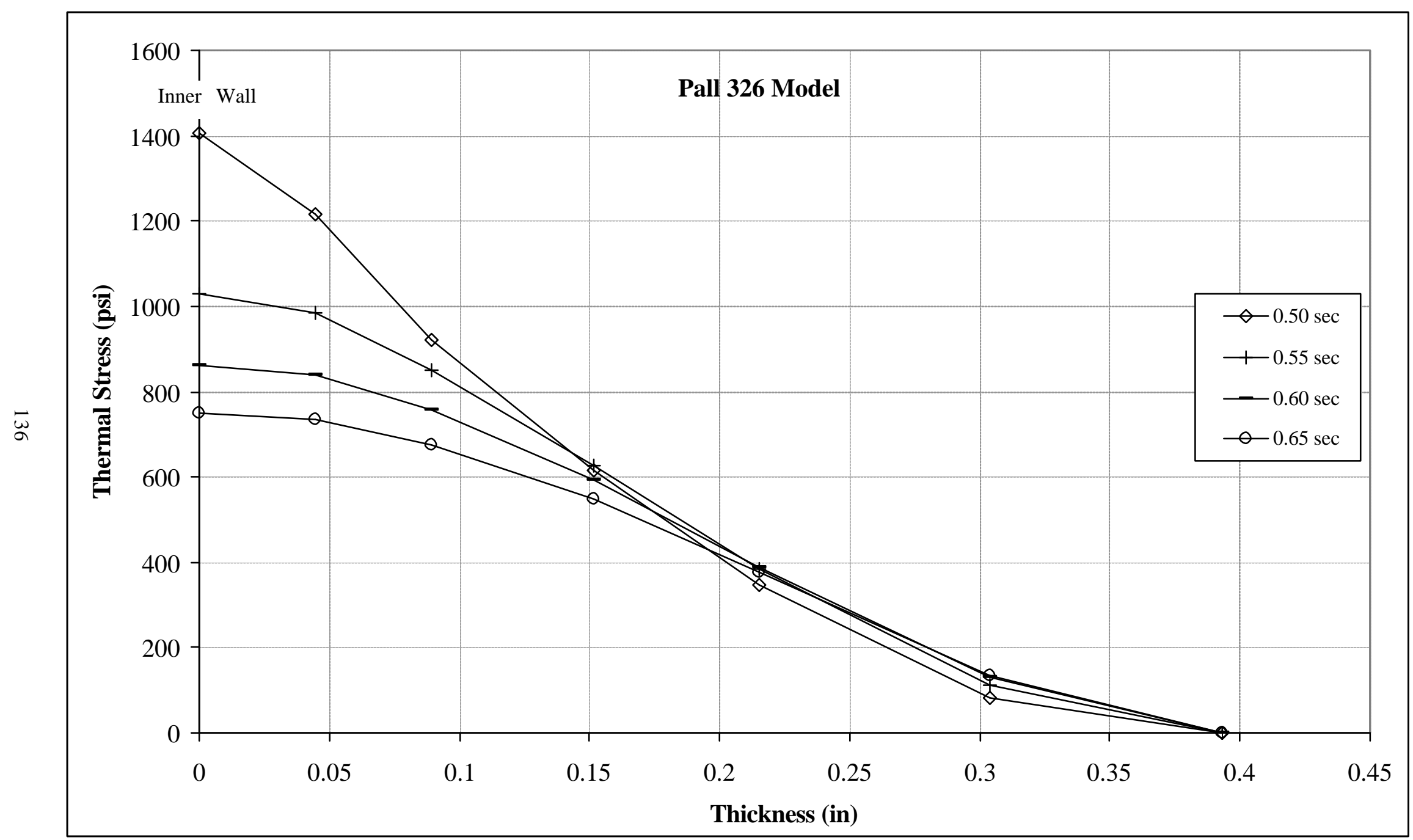

Figure 5.13 Thermal stresses of the Pall 326 model - back pulse temperature $400^{\circ} \mathrm{F}$. 


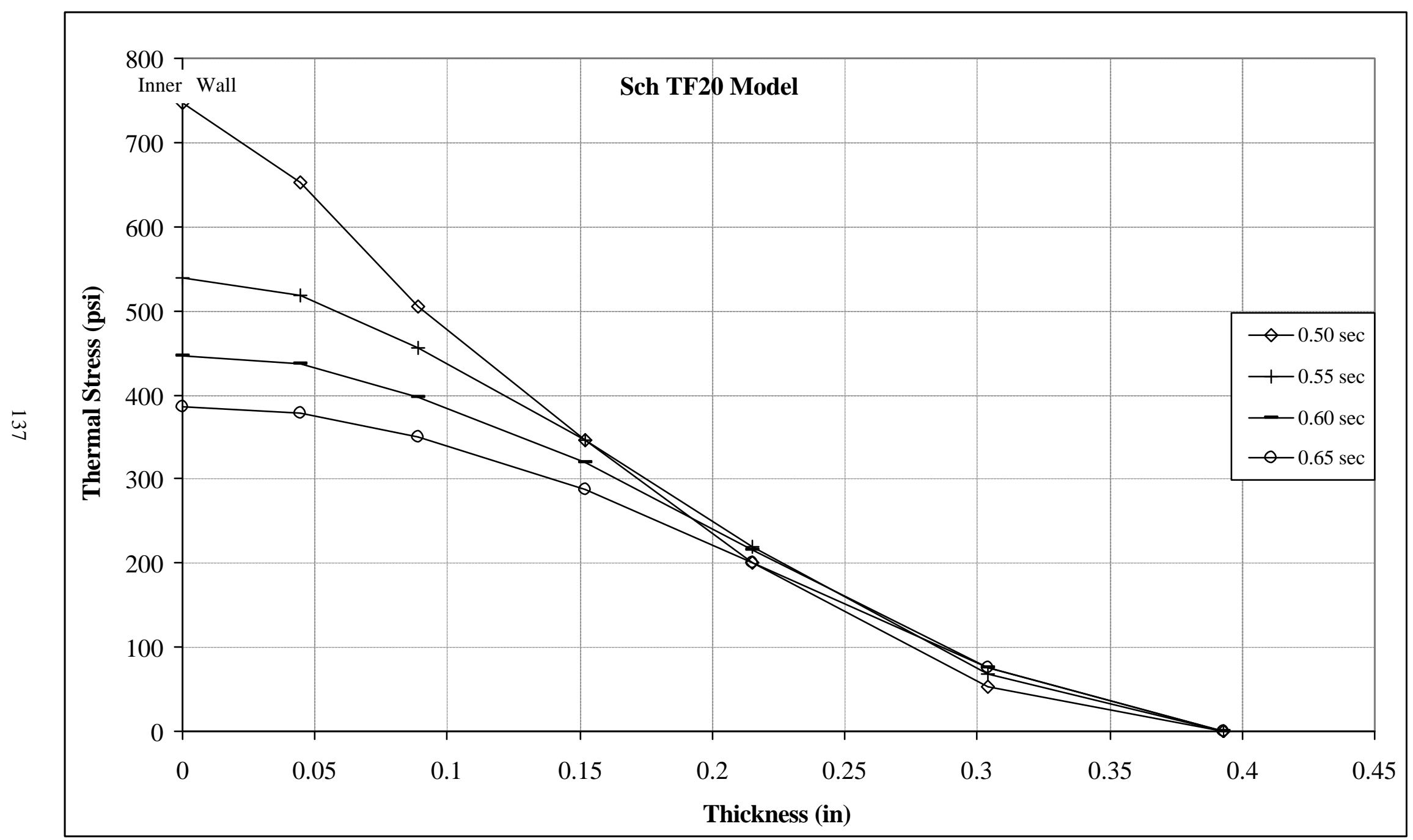

Figure 5.14 Thermal stresses distribution of the Sch TF20 model - back pulse temperature $400^{\circ} \mathrm{F}$. 


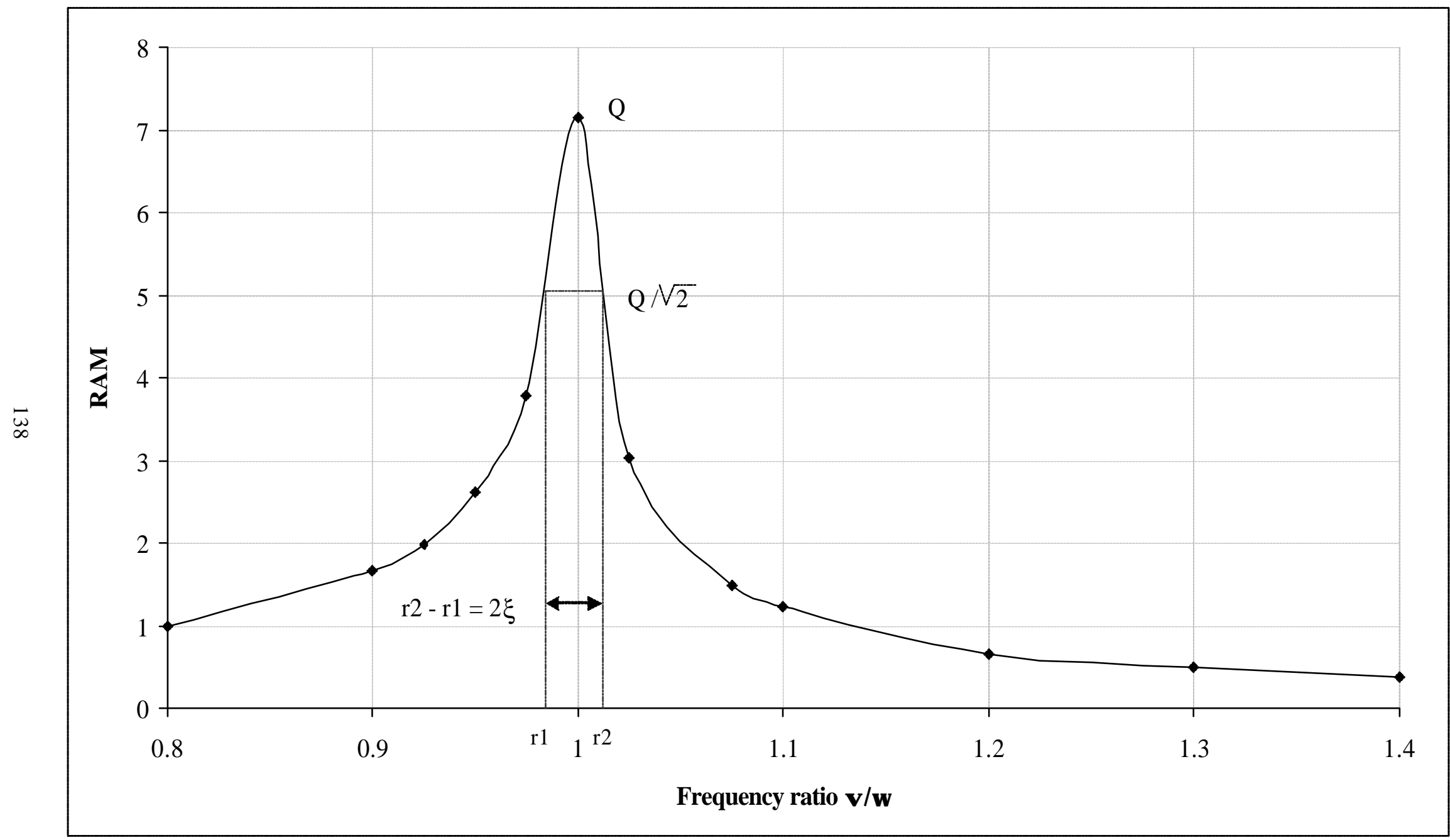

Figure 5.15 Frequency response curve for the Sch TF20 326I-147. 


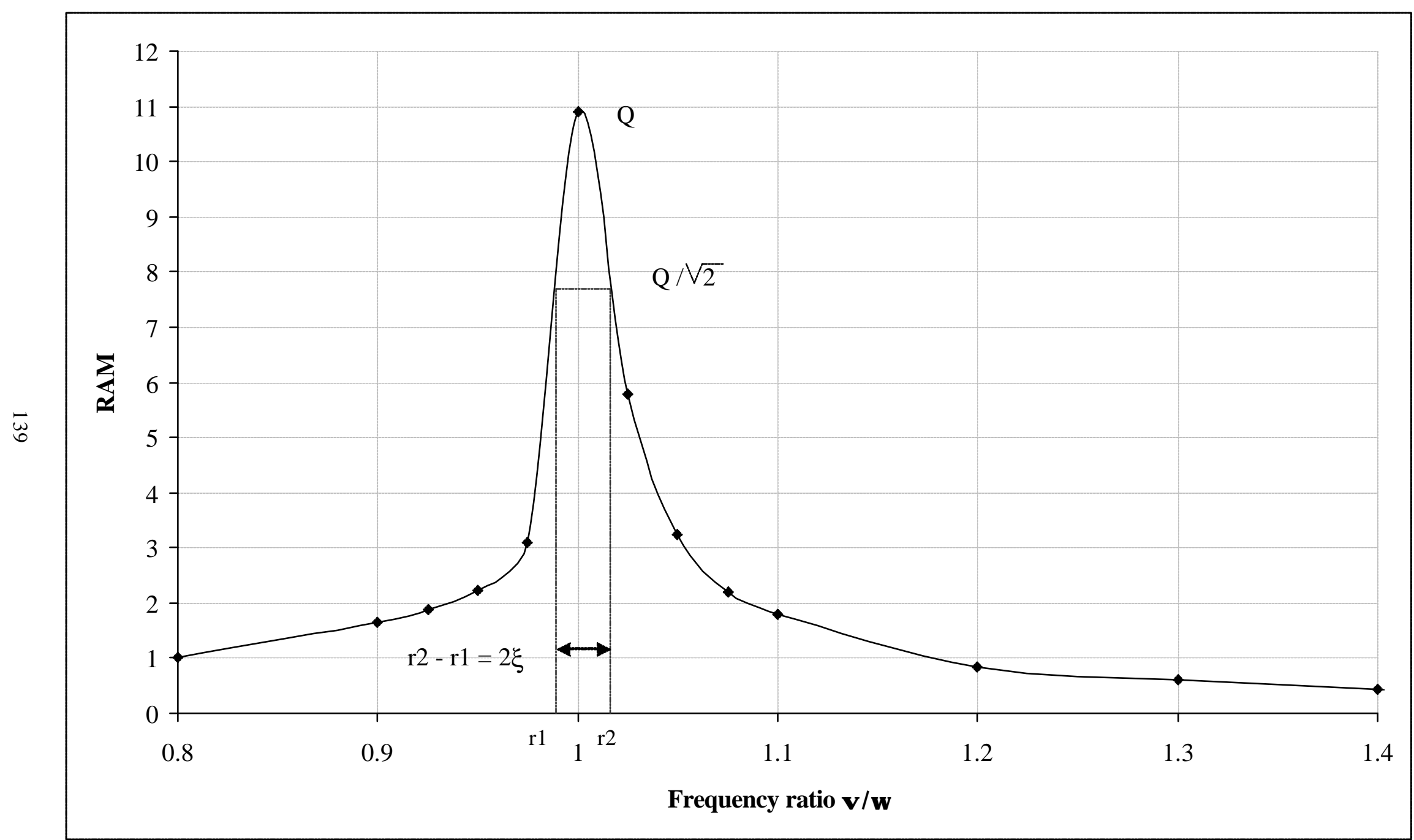

Figure 5.16 Frequency response curve for the Sch TF20 335I-159. 


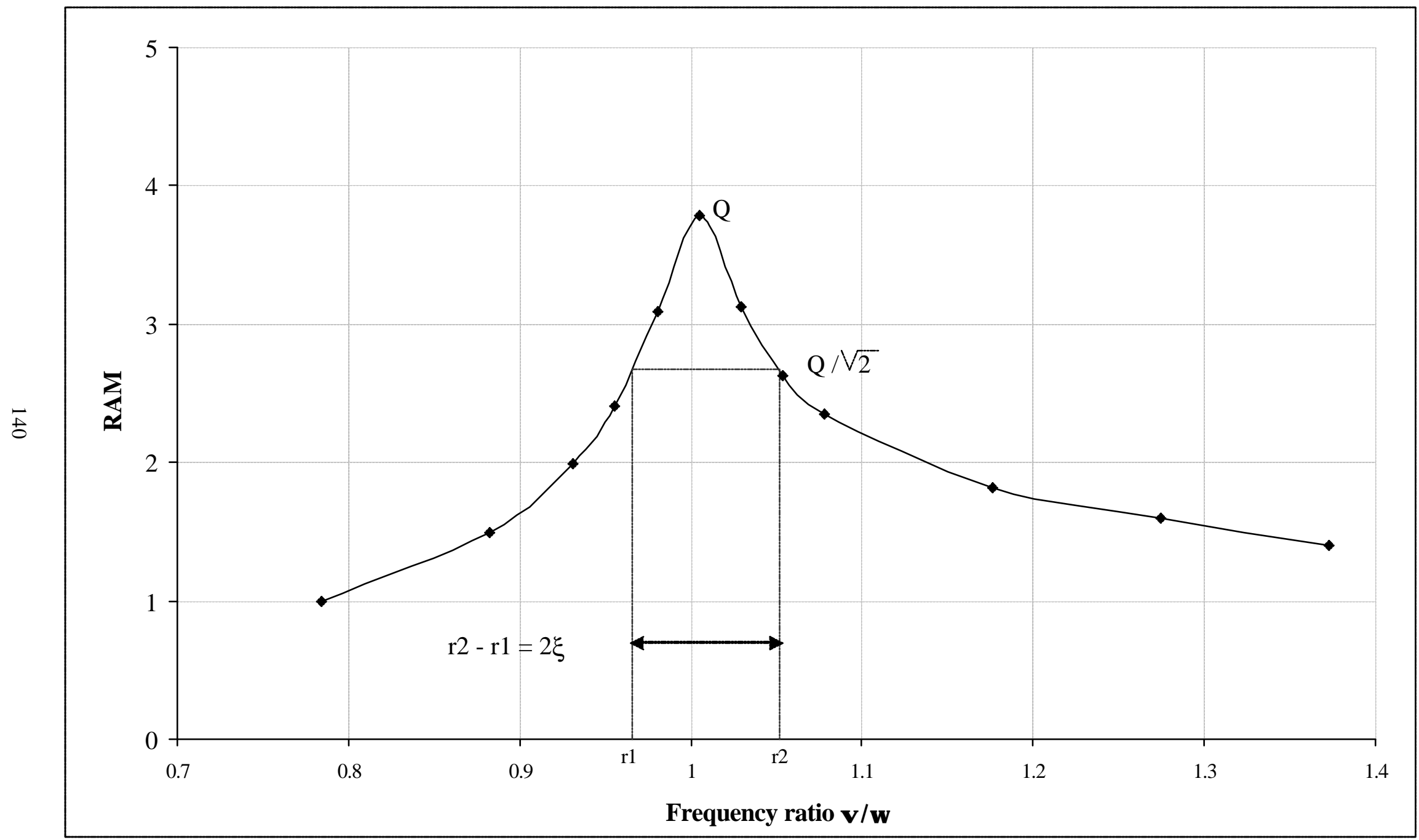

Figure 5.16 Frequency response curve for the Sch TF20 379H-129 (continued). 


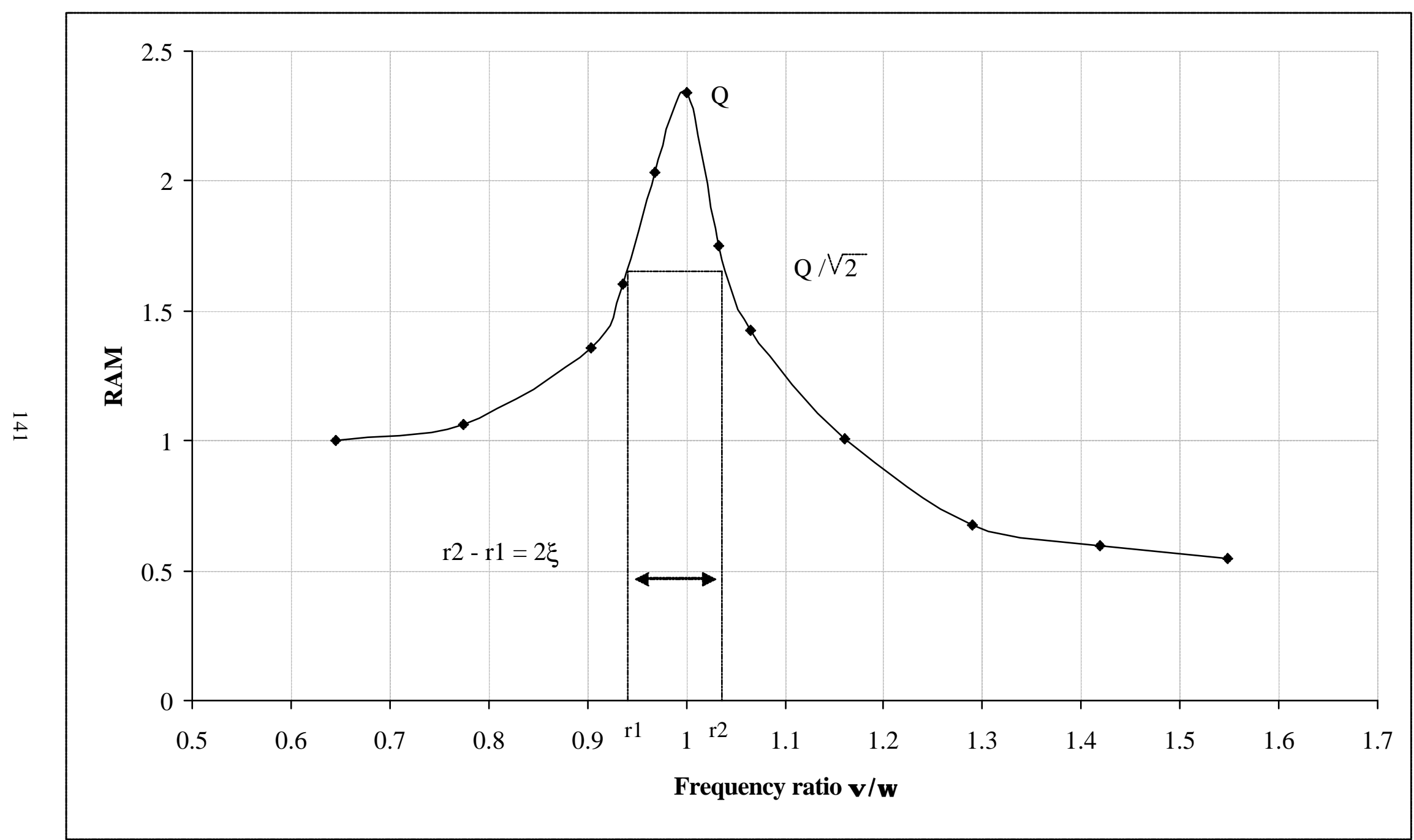

Figure 5.16 Frequency response curve for the Sch TF20 335I-173 (continued). 


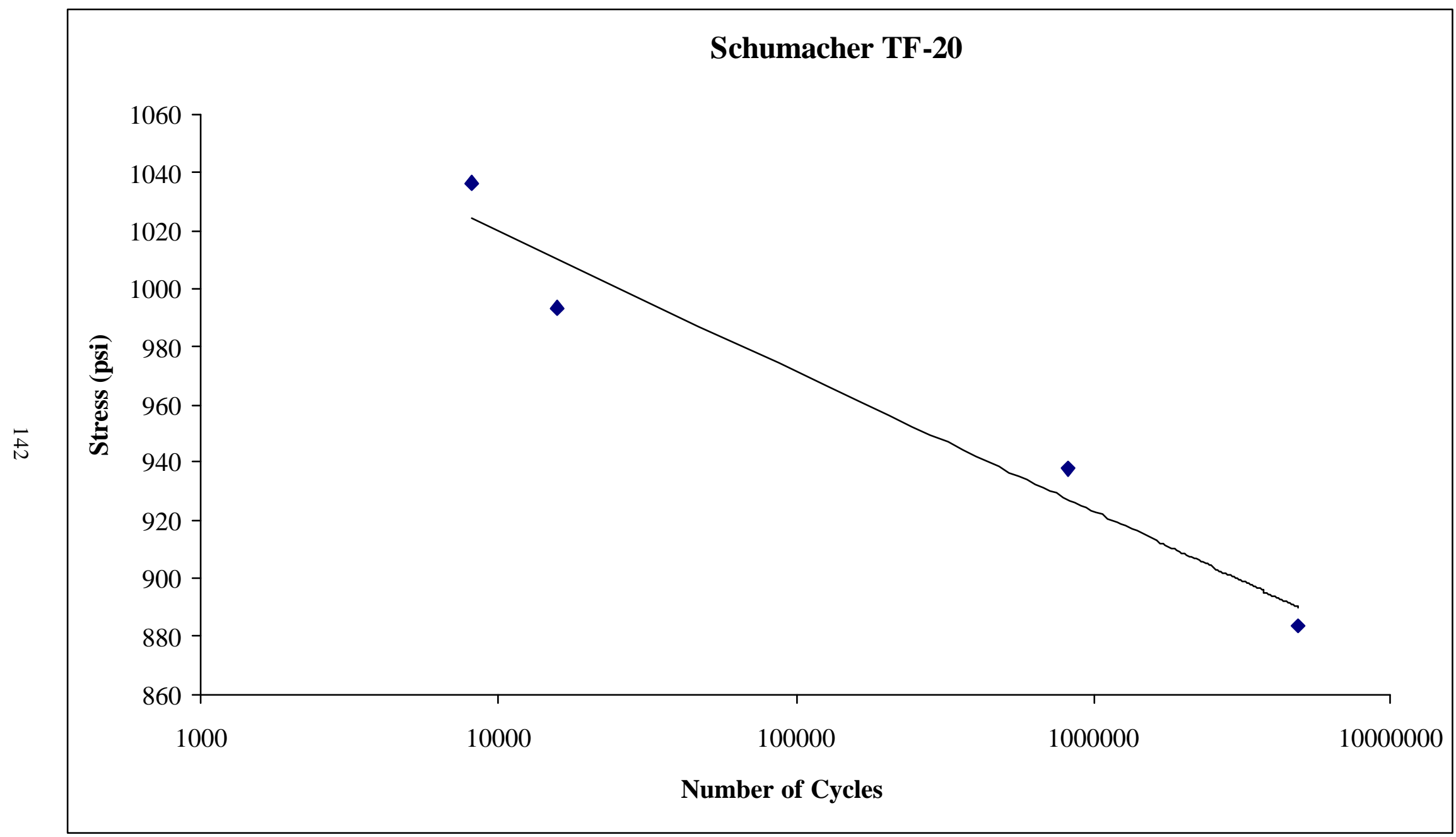

Figure 5.17 Stress / number of cycles (S/N) curve for four Sch TF-20 filters. 


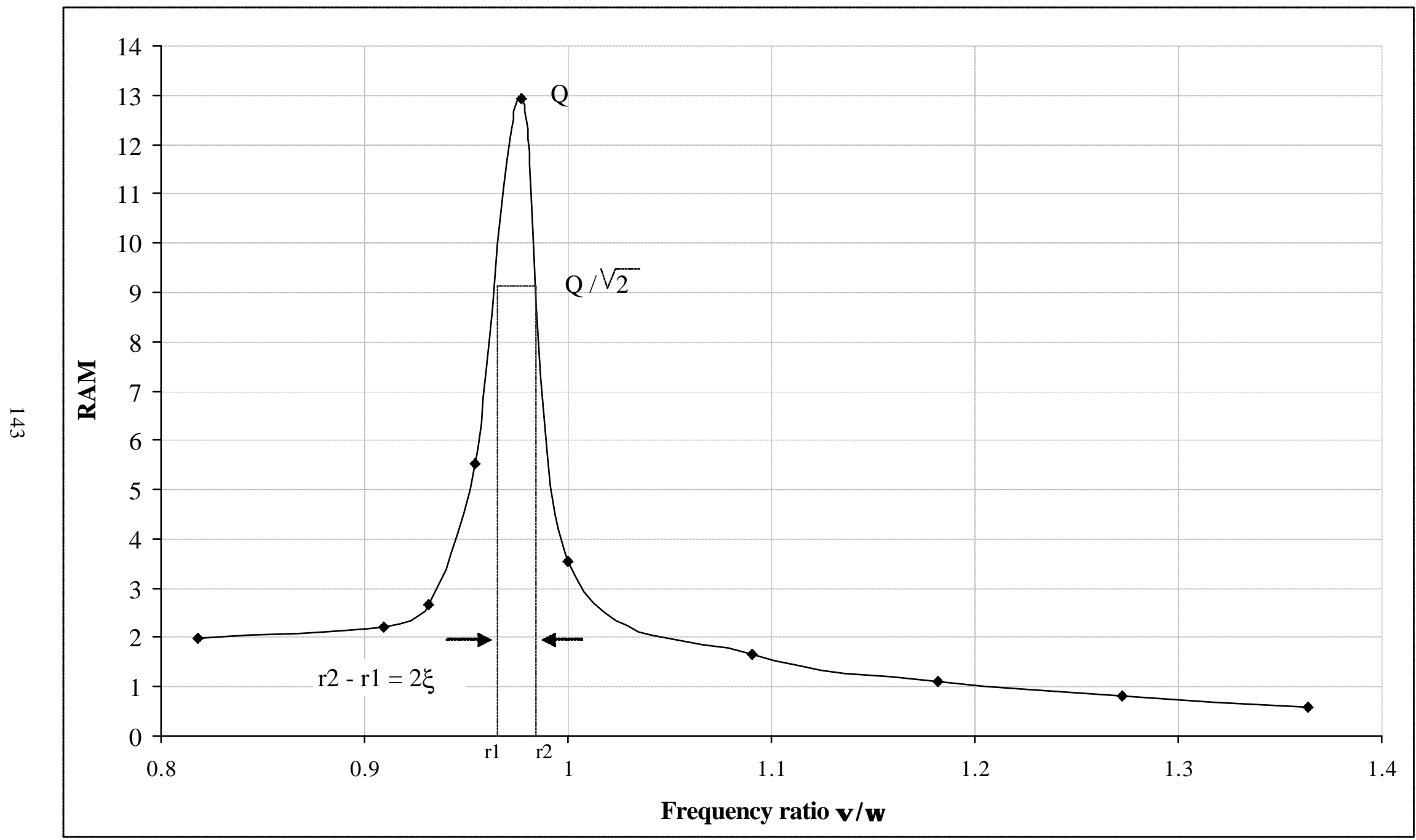

Figure 5.18 Frequency response curve for the Pall 326 5-1365. 


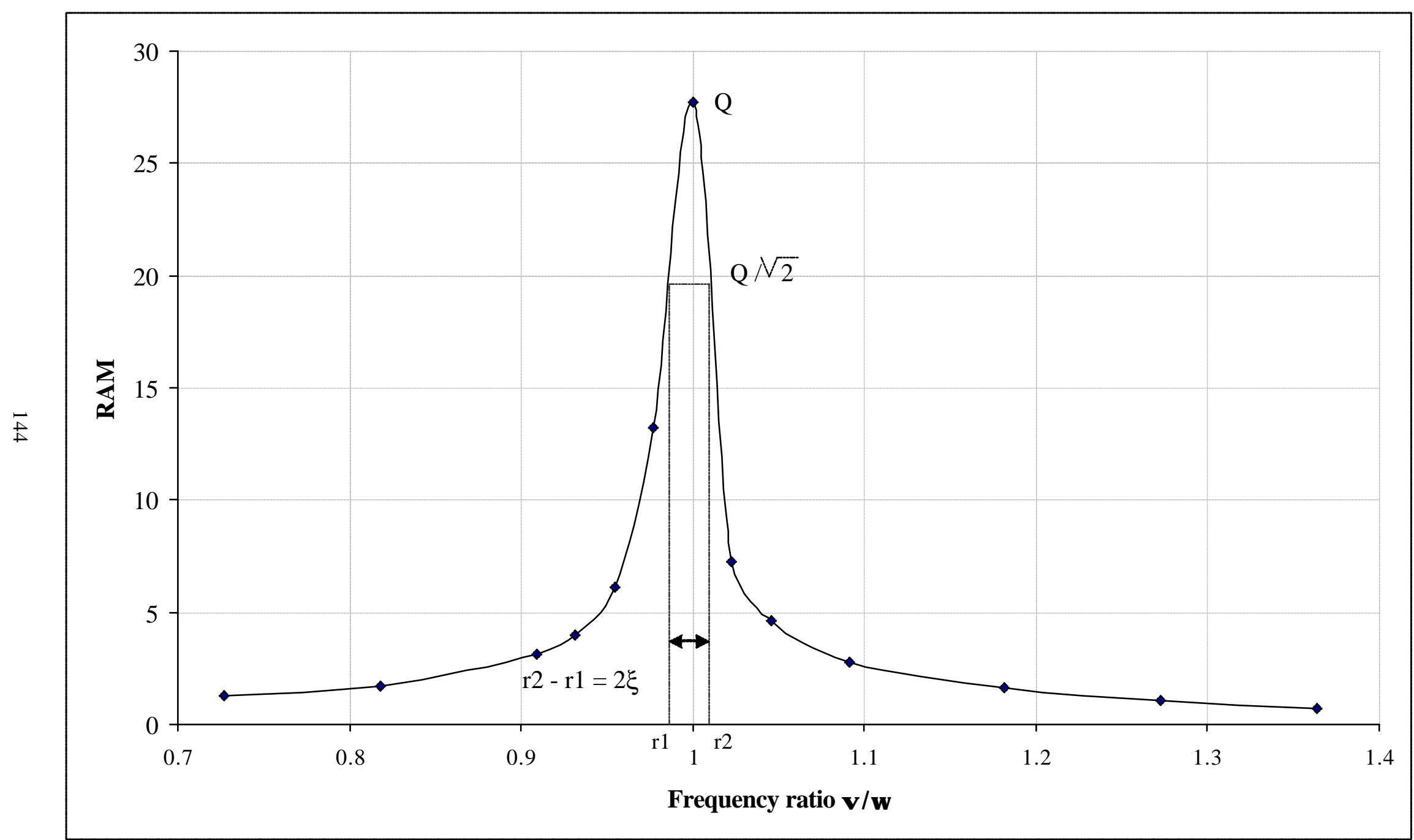

Figure 5.18 Frequency response curve for the Pall 326 2-1355 (continued). 


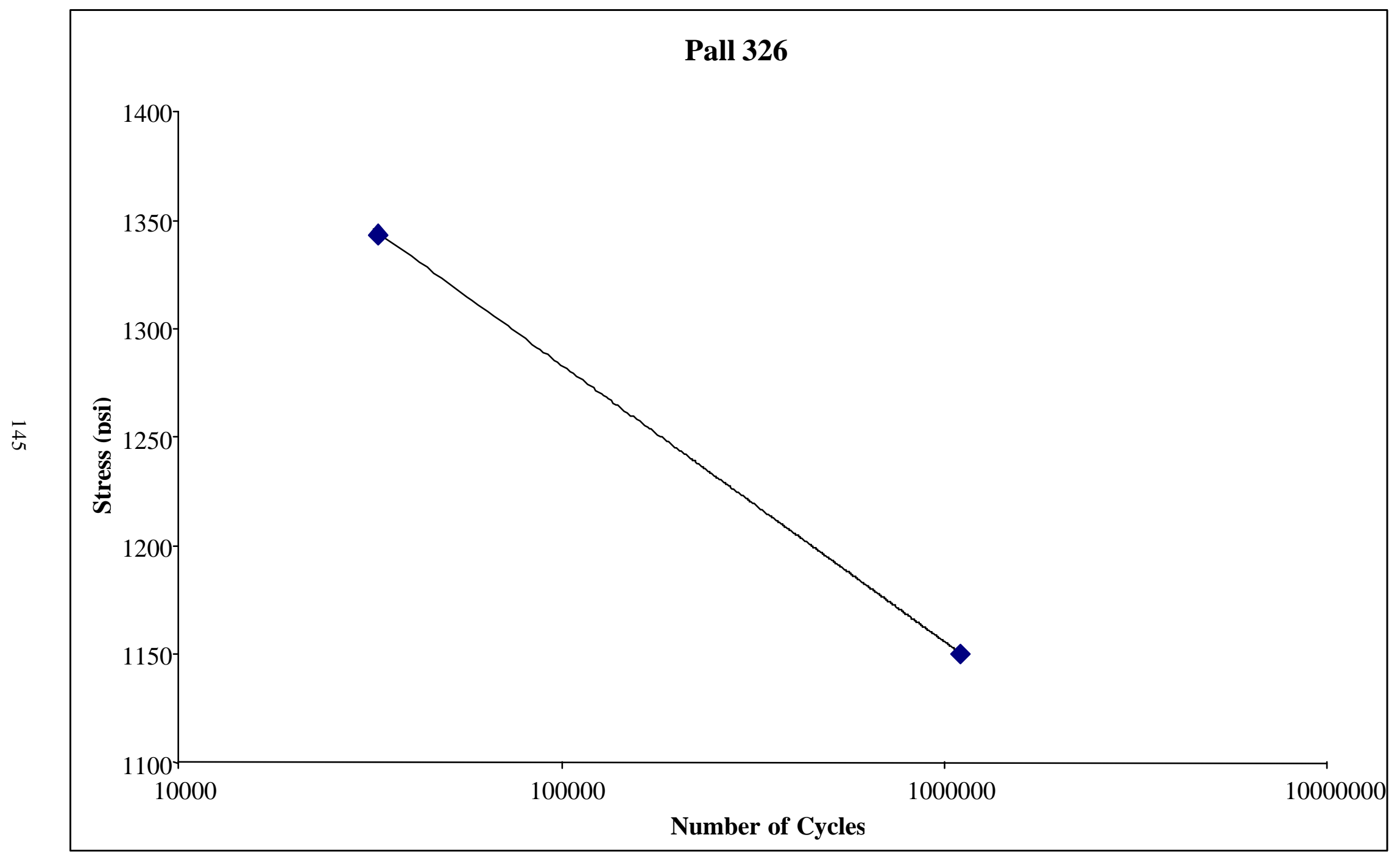

Figure 5.19 S/N curve for two Pall 326 filters. 


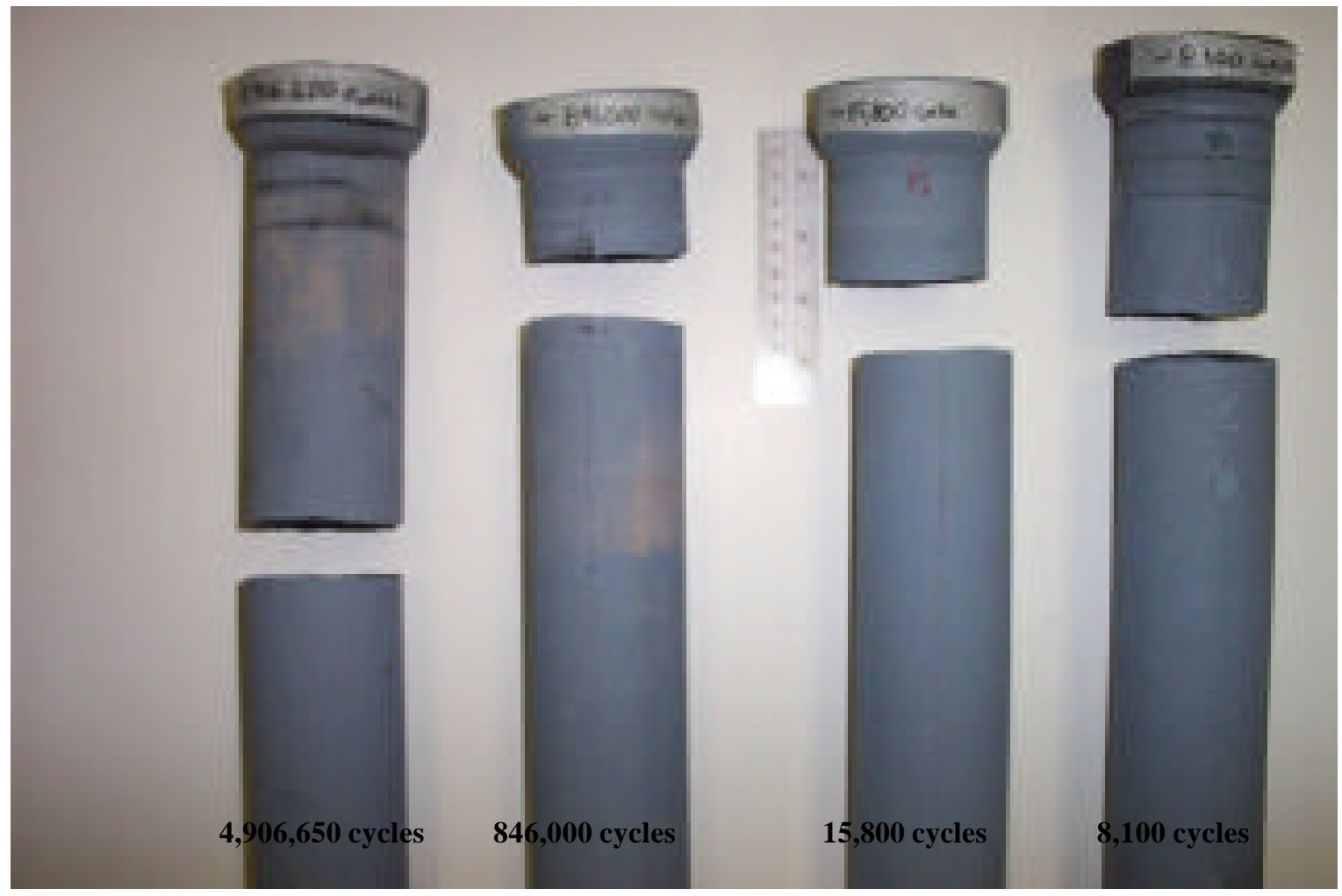

Figure 5.20 Fatigue fracture profile of four Sch TF-20 filters. 


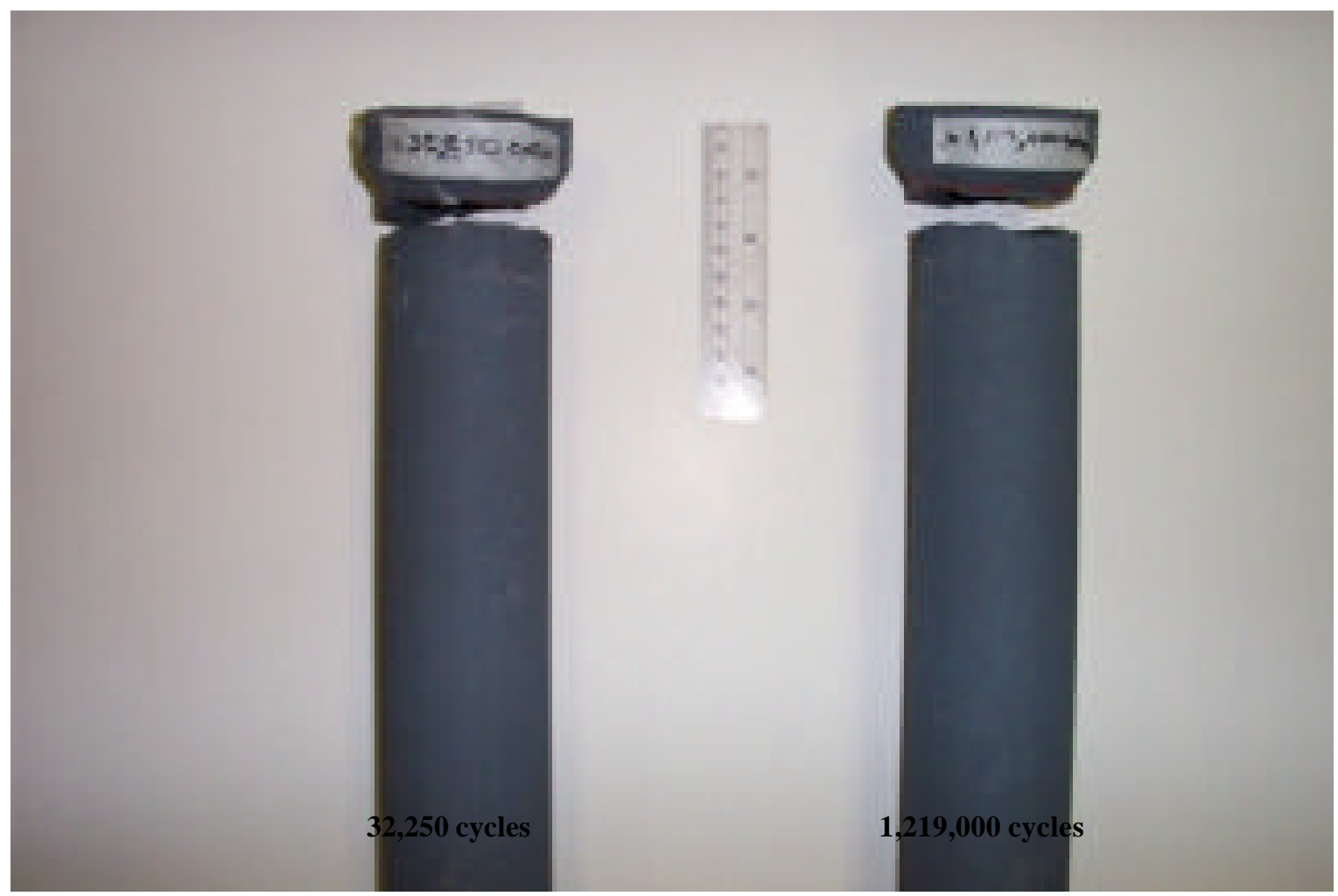

Figure 5.21 Fatigue fracture profile of two Pall 326 filters. 


\section{CHAPTER 6}

\section{REMAINING LIFE IDENTIFICATION OF CERAMIC CANDLE \\ FILTERS}

\subsection{INTRODUCTION}

This chapter describes the remaining life assessment of used ceramic candle filters through the application of system identification techniques using various damage factors input and measured response data. At present, there exists a need to define the structural damage of candle filters in a meaningful and practical manner. Although different damage assessments involving particular damage events have been obtained, a complete analytical solution for damage assessment of used ceramic candle filters is not yet available.

The procedure to find an approach for the remaining life assessment of an existing structure employed the following steps: (a) the search for suitable damage factors, (b) the development of a reliable method for identifying the damage factors of interest, and (c) the establishment of a relationship between damage factors and the actual damage of the structure. The first two steps have been presented in detail in the previous chapters. In this chapter, the changes in stiffness during the different damage stages are studied for the correlation with the physical structural damage.

\subsection{DETERMINATION OF RELIABILITY}

In this section the expressions for determining the probability for safety, $\mathrm{L}_{\mathrm{T}}$, of ceramic candle filters subjected to operational conditions for extended periods of time are 
presented. The assessment of reliability is based on analysis of a reliability function representing the interaction of the load response and the carrying capacities limit state values. The limit states of carrying capacities are states beyond which the structure no longer satisfies the design safety and durability performance requirements.

When structures are subjected to repeated applications of severe random forces, the maximum load effect necessary to produce failure may be far below the critical strength level of the structure. Estimation of the probability that the structure will survive a series of loads during a given period of time may be used to determine the safe operating life of the structure, to schedule necessary maintenance or to replace the structural elements. The probability of failure $\left(\mathrm{P}_{\mathrm{f}}\right)$ of $\mathrm{x}$ which falls between two specified values, 0 and $t$, is the area under the probability density function from 0 to $t$, which

$$
\begin{array}{r}
P_{f}(x)=1-L_{T}(x)=P(x \leq t) \\
=P[D(x)>1]
\end{array}
$$

where $\mathrm{D}(\mathrm{x})$ denotes random processes representing the cumulative damage of the structure at a given time $\mathrm{x}$. Literature review regarding the damage index is presented in the Appendix A. The term damage refers to any deficiency and/or deterioration of strength caused by external loading and environmental conditions. The gradual accumulation of damage is evaluated based on a specific load effect history. The reliability condition is that the damage accumulated during the intended life of the structure does exceed, with some assigned probability, the defined total damage limit.

In the classical theory of structure reliability a structure either fails or survives external random loads. The probability of safety, $\mathrm{L}_{\mathrm{T}}$, which is usually referred to as 
reliability, is the complement of the probability of failure, $\mathrm{P}_{\mathrm{f}}$. The probability that the component survives during the interval $(0, t)$ is then

$$
\mathrm{L}_{\mathrm{T}}(\mathrm{x})=1-\mathrm{P}_{\mathrm{f}}(\mathrm{x}) \equiv \mathrm{P}(\mathrm{x}>\mathrm{t})
$$

Alternatively the reliability function is also given by (Yao 1985)

$$
\mathrm{L}_{\mathrm{T}}(\mathrm{x})=\mathrm{L}_{\mathrm{T}}\left(\mathrm{t}_{\mathrm{i}}\right) \exp \left[-\int_{0}^{\mathrm{x}} \mathrm{h}_{\mathrm{T}}(\xi) \mathrm{d} \xi\right]
$$

where the initial value of reliability, $\mathrm{L}_{\mathrm{T}}\left(\mathrm{t}_{\mathrm{i}}=0\right)$, is assumed to be 1 . The function $\mathrm{h}_{T}(\mathrm{x})$ is called the hazard function. It is introduced because certain general characteristics of the performance of the system subjected to repeated loads are easily studied by the behavior of their hazard functions. For example, in a deterioration process such as fatigue, $\mathrm{h}_{\mathrm{T}}(\mathrm{x})$ is increased monotonically with the progressive irreversible accumulation of the microstructural damage. If the hazard function is a constant value, $\lambda$, then the reliability function becomes $\mathrm{L}_{\mathrm{T}}(\mathrm{x})=\exp (-\lambda \mathrm{x})$. While the applicability of the exponential distribution is limited because of the assumption of constant hazard rate, the Weibull distribution can be written to include increasing hazard rates as well. The Weibull hazard function and reliability function are (Dodson and Nolan 1999)

$$
\begin{aligned}
& \mathrm{h}_{\mathrm{T}}(\mathrm{x})=\frac{\beta}{\theta}\left(\frac{\mathrm{x}}{\theta}\right)^{\beta-1} \\
& \mathrm{~L}_{\mathrm{T}}(\mathrm{x})=\exp \left[-\left(\frac{\mathrm{x}}{\theta}\right)^{\beta}\right]
\end{aligned}
$$


where $\beta$ is the shape parameter and $\theta$ is a scale parameter. For the case of $\beta<1$, the reliability initially increases sharply and then flattens out. For the case of $\beta=1$, the reliability gradually decreases, which is the result of a constant failure rate. When $\beta>1$, the reliability slowly decreases initially and then decreases as the characteristic life is approached. The effects of $\beta$ on the hazard function are shown in Figure 6.1.

\subsection{Safety Analysis of Ceramic Candle Filters}

To place the deterioration performance of the ceramic candle filters in its proper perspective for the application of reliability analysis technique, there are a number of factors to be considered. Physical and mechanical environmental loadings are independent functions that can affect the life of the candle filters. The degree of the influence is dependent upon the actual rather than the predicted exposure environment. Physical effects from plenum and back pulse vibration, temperature and pressure level history, and chemical attack history due to different coal chemical components usually have deleterious effects on the ceramic candle filters.

Consider the case where the only parameter that affects the deterioration of the filters is the exposure time at the PSDF and that all other factors (mentioned previously) are constants. A simplified hazard function from the experimental results of the ceramic candle filters can be assumed as

$$
\mathrm{h}_{\mathrm{T}}\left(\mathrm{D}_{\mathrm{E}}\right)=\beta \mathrm{b}\left(\mathrm{bD}_{\mathrm{E}}\right)^{\beta-1}
$$

where $\mathrm{b}$ is a distribution parameters that is obtained experimentally. $\mathrm{D}_{\mathrm{E}}(\mathrm{t})=\left(\mathrm{E}_{0}-\mathrm{E}(\mathrm{t})\right) / \mathrm{E}_{0}$, is the percentage of deterioration of the Young's modulus. $E_{0}$ is the Young's modulus of 
the filter in the as-manufactured state and $\mathrm{E}(\mathrm{t})=\mathrm{E}_{\mathrm{t}}$ is the Young's modulus after $\mathrm{t}$ exposure hours. Therefore, the reliability function for the ceramic candle filters can be written as

$$
\mathrm{L}_{\mathrm{T}}\left(\mathrm{D}_{\mathrm{E}}\right)=\exp \left[-\left(\mathrm{bD} \mathrm{E}_{\mathrm{E}}\right)^{\beta}\right]
$$

\subsection{Results}

Figure 6.2 shows the deterioration curve for the Sch TF-20 filters obtained from the Young's modulus deterioration curve (Chapter 3). The filters that reside on the lefthand side of the "median curve" are considered safe. The filters that are in between the median curve and the "upper-bound curve" need close structural property evaluations and the filters that fall on the right-hand side of the "upper-bound curve," away from the curve are considered unsafe. The values of $\beta$ and $b$ in Equation 6.6 are obtained using this figure. Comparing the shape of both curves from Figure 6.2 with Figure 6.1, the value of $\beta$ is assumed to be 3.6. The maximum Young's modulus deterioration at 2650 exposure hours for the median curve is about $12.9 \%$ and for the upper bound curve 16.7\%. The variable $\mathrm{b}$ is obtained using Equation 6.6 by letting $\mathrm{L}_{\mathrm{T}}\left(\mathrm{D}_{\mathrm{E}}\right)$ approach to 0 at the maximum deterioration values and solve for $b$. The value of $b$ for the median curve is about 0.1326 and for the upper bound curve is about 0.1012 .

It is important to observe that the limit state conditions for Sch TF-20 candle filters used in this work consider a maximum exposure time of $2650 \mathrm{hr}$, which is the maximum time that a Sch TF-20 candle filter had been exposed and evaluated during this

study. If candle filters with more exposure hours are included, new values for the 
distribution parameter, $b$, will need to be recalculated. The reliability equations for the median and the upper-bound curves can be formulated using Equation 6.6 as

$$
\begin{aligned}
& \mathrm{L}_{\mathrm{T}}(\mathrm{t})=\exp \left(-\left[0.1326\left(\frac{6.16-\mathrm{E}_{\mathrm{t}}}{6.16}\right)\right]^{3.6}\right) \quad \text { median curve } \\
& \mathrm{L}_{\mathrm{T}}(\mathrm{t})=\exp \left(-\left[0.1012\left(\frac{6.16-\mathrm{E}_{\mathrm{t}}}{6.16}\right)\right]^{3.6}\right) \quad \text { upper - bound curve }
\end{aligned}
$$

Figure 6.3 shows the deterioration curve for the Pall 326 \#-series. The filters to the left-hand side are considered safe, the filters in between both curves need close structural property evaluation, and the specimens to the right-hand side are considered unsafe. For the Young's modulus deterioration of this filters, the shape factor $(\beta)$ is assumed to be 2 because the deterioration rate increases linearly. The maximum allowable deterioration is about $6.42 \%$ for the median curve and $7.62 \%$ for the upper bound curve. Thus, the value of $b$ for the median curve is about 0.3981 and for the upper bound curve is about 0.3458. The results are shown in Equation 6.8, considering a maximum exposure time of $3214 \mathrm{hr}$, which is the maximum exposure time accumulated by the Pall 326 candle filters tested. The reliability equations can be written as follows

$$
\begin{aligned}
& \mathrm{L}_{T}(\mathrm{t})=\exp \left(-\left[0.3981\left(\frac{7.59-\mathrm{E}_{\mathrm{t}}}{7.59}\right)\right]^{2}\right) \text { for the median curve } \\
& \mathrm{L}_{\mathrm{T}}(\mathrm{t})=\exp \left(-\left[0.3458\left(\frac{7.59-\mathrm{E}_{\mathrm{t}}}{7.59}\right)\right]^{2}\right) \text { for the upper - bound curve }
\end{aligned}
$$


Figure 6.4 the deterioration curve for the Pall 326 A-series filters. The experimental data is too scattered to formulate a reliability equation. More data points are required to develop a significant reliability approach for these ceramic candle filters.

Figure 6.5 shows the deterioration curve for the Pall 442T filters. The experimental data for this group of filters has been used to plot the median and the upper bound curves. Equation 6.9 considers that the maximum exposure time accumulated by a Pall $442 \mathrm{~T}$ candle is about $3262 \mathrm{hr}$. The maximum allowable damage is about $18.0 \%$ for the median curve and $21.2 \%$ for the upper bound curve. The shape factor $(\beta)$ is also assumed to be 2 in this group of filters due to the pattern of the damageability curve. The value of the parameter $b$ for the median curve is about 0.1460 and for the upper bound curve is about 0.1239 . Thus, the reliability equations can be written as follow

$$
\begin{aligned}
& \mathrm{L}_{\mathrm{T}}(\mathrm{t})=\exp \left(-\left[0.1460\left(\frac{8.16-\mathrm{E}_{\mathrm{t}}}{8.16}\right)\right]^{2}\right) \text { for the median curve } \\
& \mathrm{L}_{\mathrm{T}}(\mathrm{t})=\exp \left(-\left[0.1239\left(\frac{8.16-\mathrm{E}_{\mathrm{t}}}{8.16}\right)\right]^{2}\right) \text { for the upper - bound curve }
\end{aligned}
$$

Figures 6.6, 6.7, and 6.8 show the reliability curves for the Sch TF-20, the Pall 326 \#-series and the Pall 442 filters. These curves were plotted using equations 6.7, 6.8, and 6.9, respectively. Both the median and the upper bound reliability curves are plotted together. The reliability obtained for the upper bound curve in each figure has been divided by a safety factor because the filters that reside in the "inspection recommended area" in the deterioration curves are still useful but are deteriorating at a faster rate than the filters in the safe area. The safety factor used for each type of candle filters is such 
that it will increase the reliability values by following the upper-bound curve when they are below $50 \%$ reliability. The safety factor assumed for the Sch TF20 filters is 1.55 , for the Pall 326 filters is 1.19 , and for the Pall 442 T filters is 1.20 .

In these reliability figures, 1 means that the filter is in $100 \%$ good condition and 0 means that the probability of failure is maximized, which means that it is recommended to replace the specimen before failure. Failure does not imply that the filter is broken, what it means is that the deterioration of the filter is higher than the limit state value assumed or the percentage of damage allowed.

\subsection{EXAMPLE}

A numerical example with two different filters that have been tested at different exposures hours is presented and discussed as follows.

Consider the $324 \mathrm{H} 07$ Sch TF-20 filter, which has been tested at 500hr and 2650hrs. The Young's modulus reductions of this filter are $4.8 \%$ and $10.19 \%$ respectively. Using Figure 6.2 it is noted that the filter is in the safe region at both exposure times. This result could be empirically confirmed if the stiffness reduction of this filter is compared with the behavior of other filters with the same exposure hours. The reliability of this filter (Figure 6.6) at 500hrs is about 0.83 (83\% reliable) and after $2650 \mathrm{hrs}$ the reliability is about 0.21 , which means that even though this filter has been used for about $2650 \mathrm{hrs}$, it can still be used with close attention paid to the filter's future stiffness deterioration. It is noted that the $21 \%$ reliability obtained at $2650 \mathrm{hrs}$ for this filter is based on the current damage limit state assumption. The actual remaining life of 
this filter might be much higher than 2650 hrs. However more data from filters under high exposure hours need to be collected to verify such assumption.

Now let's consider the 324 H03 Sch TF-20 filter, which has been tested at $~ 980 \mathrm{hr}$ and 2410hrs. The Young's modulus reductions of this filter are $13.8 \%$ and $16.4 \%$ respectively. Using Figure 6.2 it is noticed that the filter at $\sim 980 \mathrm{hrs}$ is already somehow off from the median serviceability curve. The discrepancy become greater after the filter is used for 1430 extra hours. Although, in both exposure times the filter falls into the "inspection recommended" area, after 2410 exposure hours the filter is already on the upper-bound limit. The reliability of this filter (Figure 6.6 ) is $\sim 0.02$ and $\sim 0$, respectively, which means that the filter should be replaced because it is equal to the upper damage limit state assumed for this group of filters.

\subsection{Summary}

A preliminary relationship between the NDE technique and the reliability of the ceramic candle filters due to exposure hours has been presented in this chapter. The primary emphasis of this study is that only one operational loading factor has been considered to produce stiffness deterioration of the candle filters. Previous chapters have shown the influence of multiple factors in the candle filters' stiffness degradation such as high temperature and fatigue vibration. Inspection and replacement decisions for ceramic candle filters can be made with guidelines based on risk assessments, which are a function of the probability of failure and the consequences of failure. 


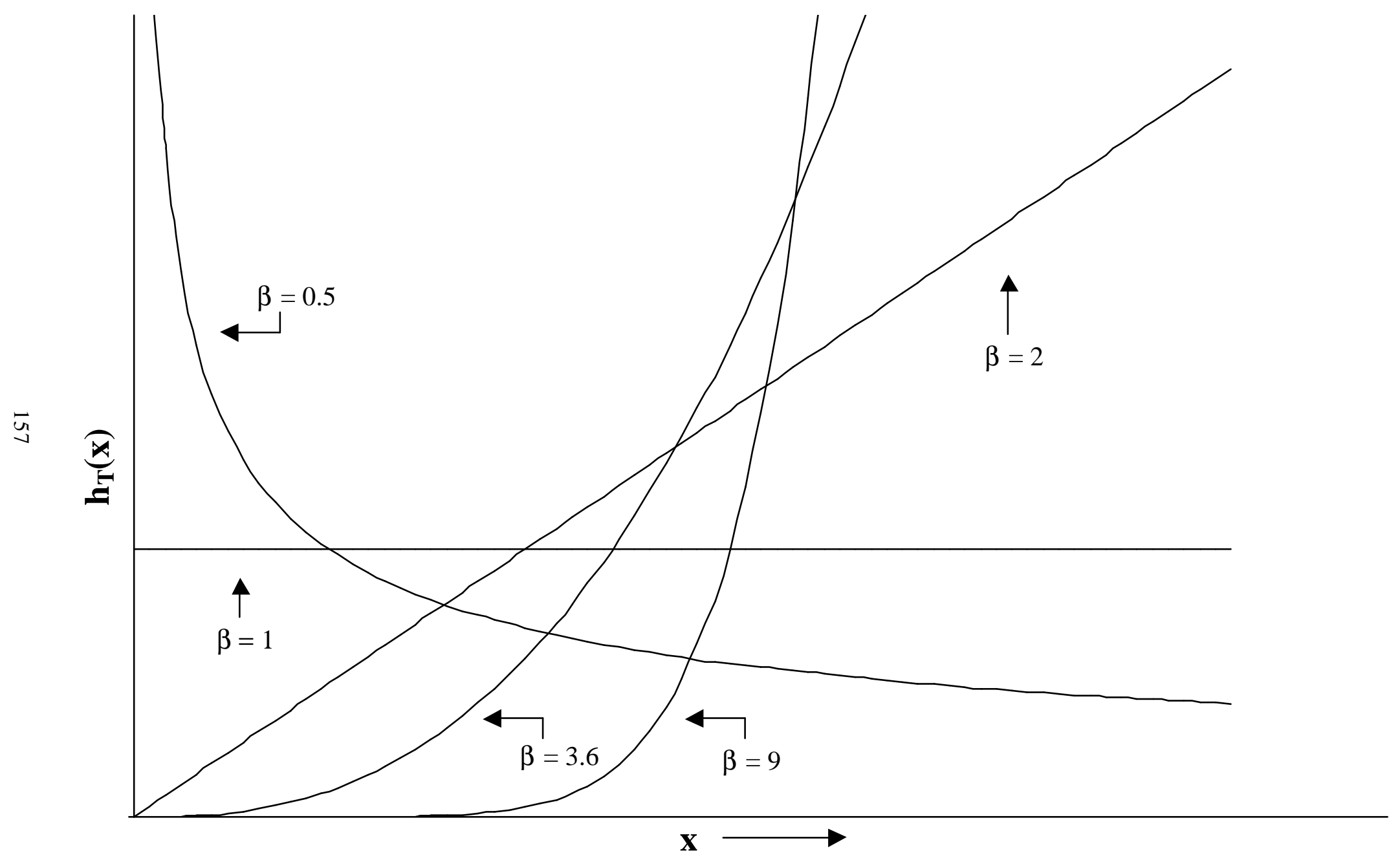

Figure 6.1 Weibull Hazard functions. 


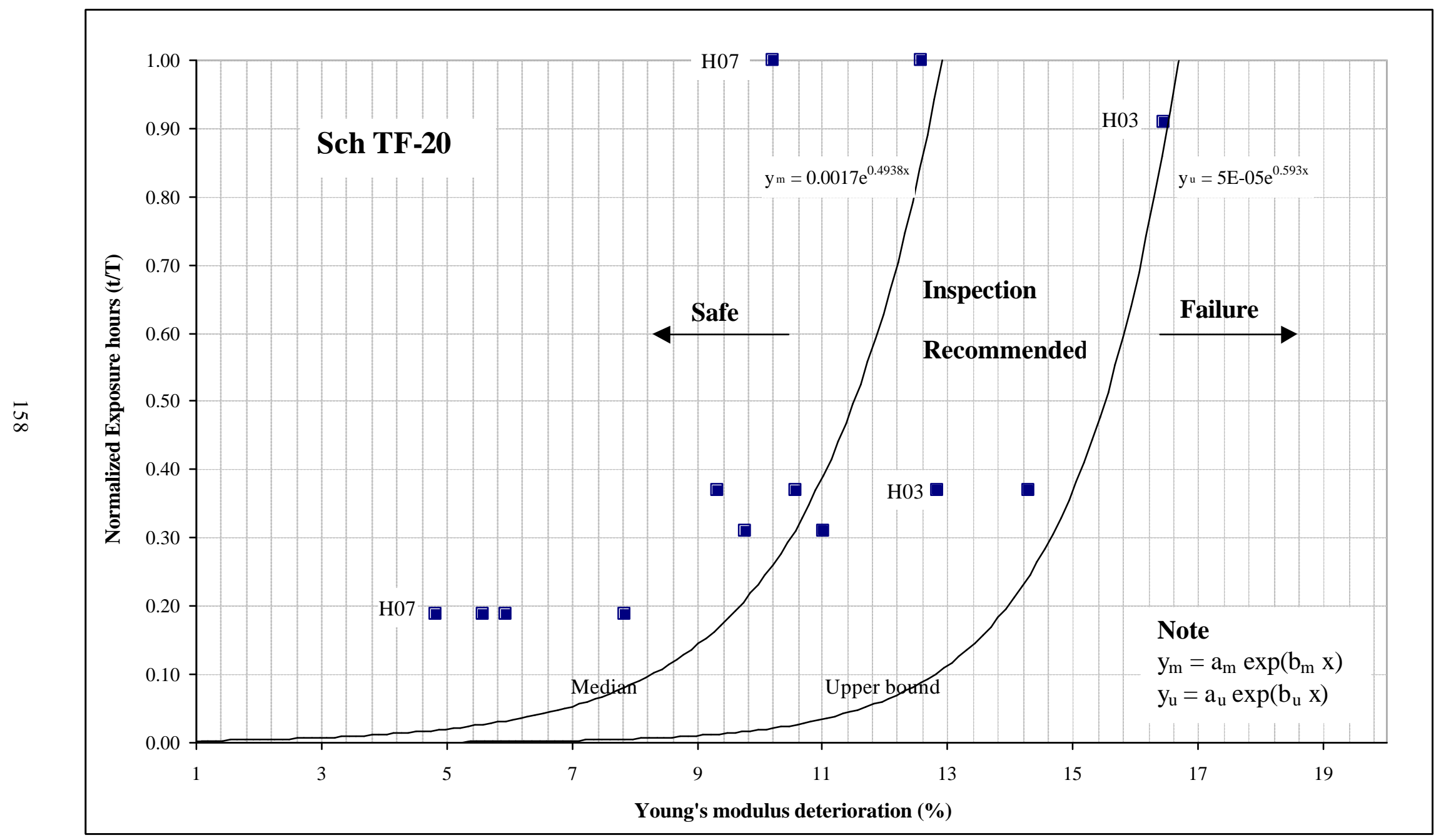

Figure 6.2 Percentage deterioration of Sch TF-20 filters with respect to exposure hours. 


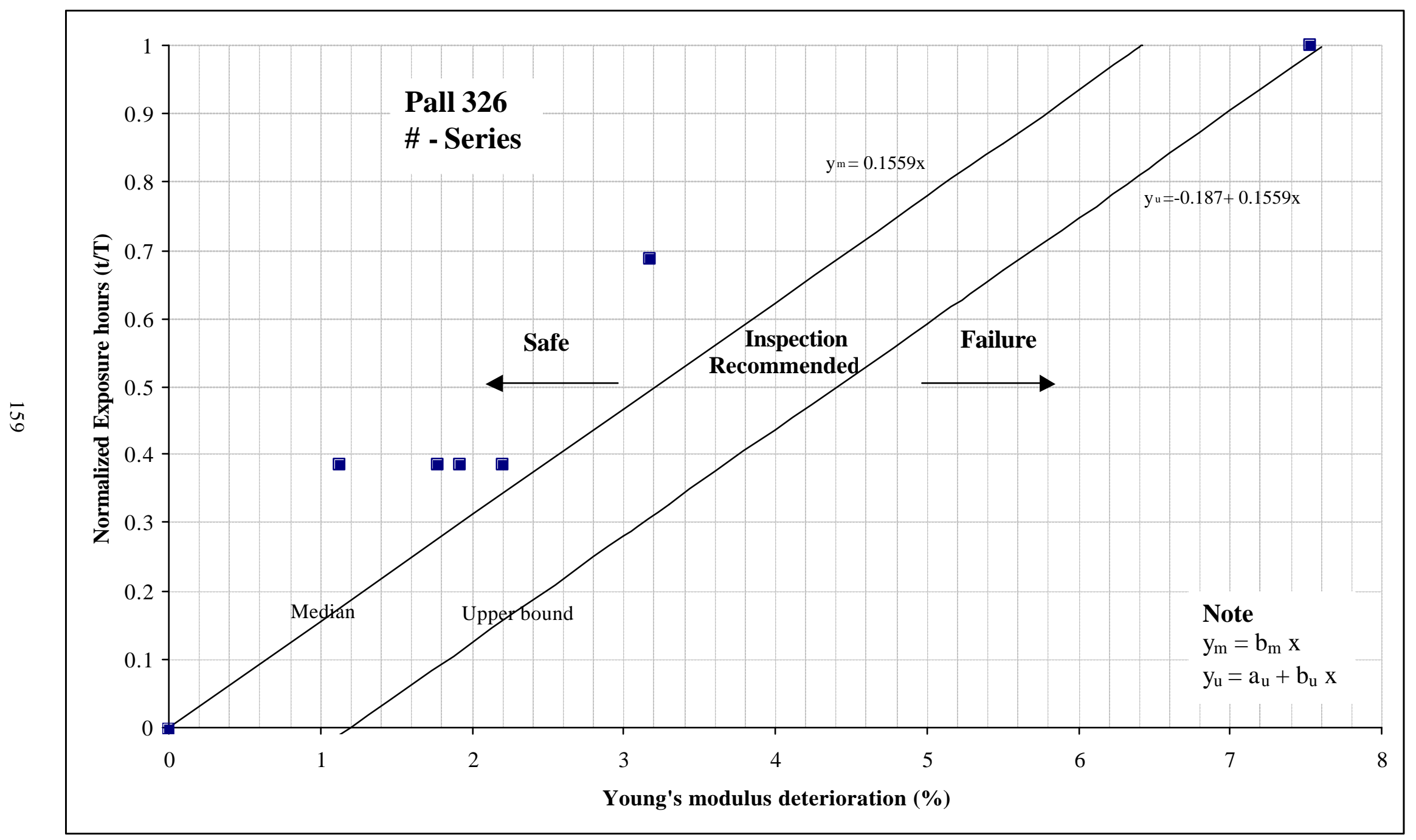

Figure 6.3 Deterioration of Pall 326 \#-Series filters with respect to exposure hours. 


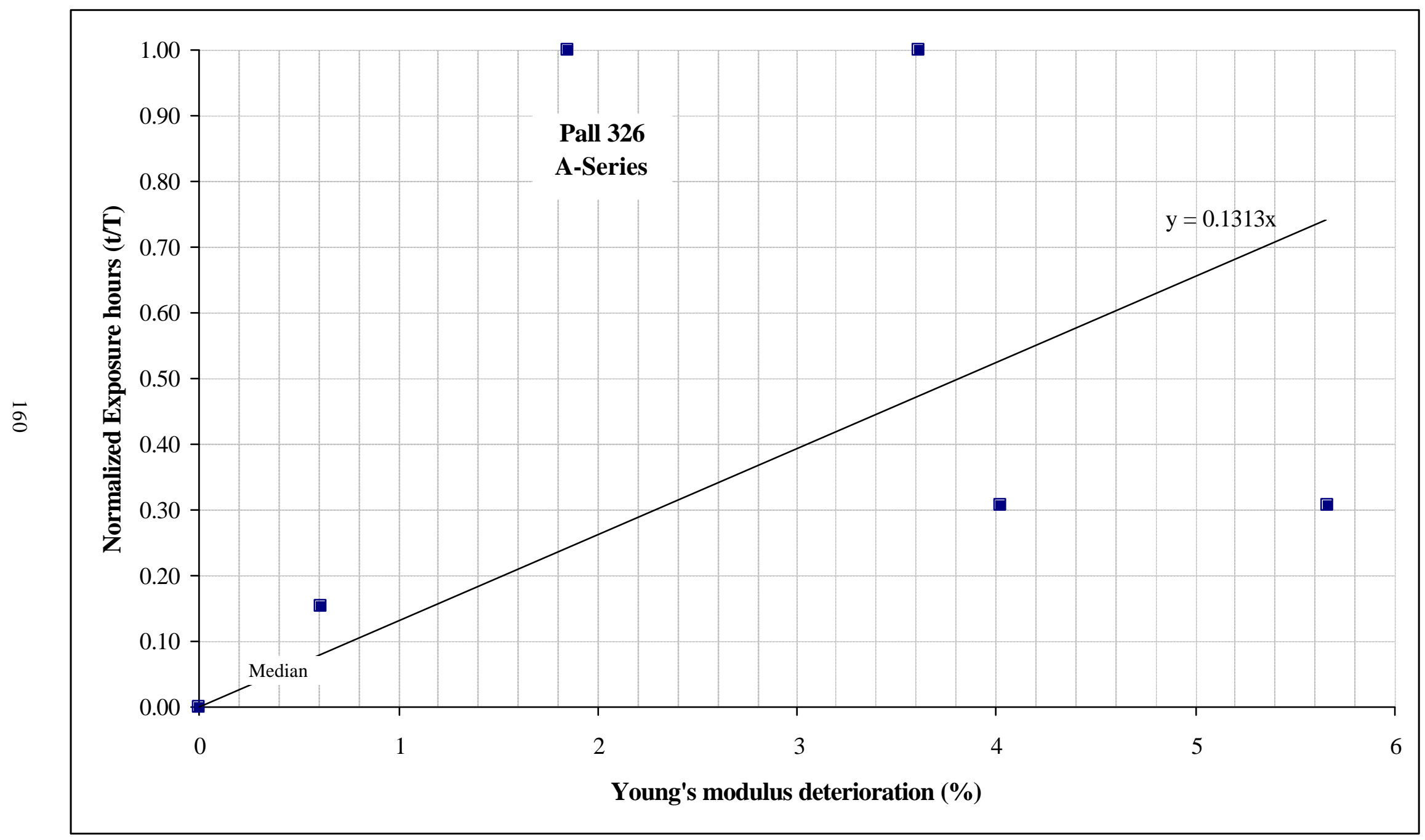

Figure 6.4 Deterioration of Pall 326 A-series filters with respect to exposure hours. 


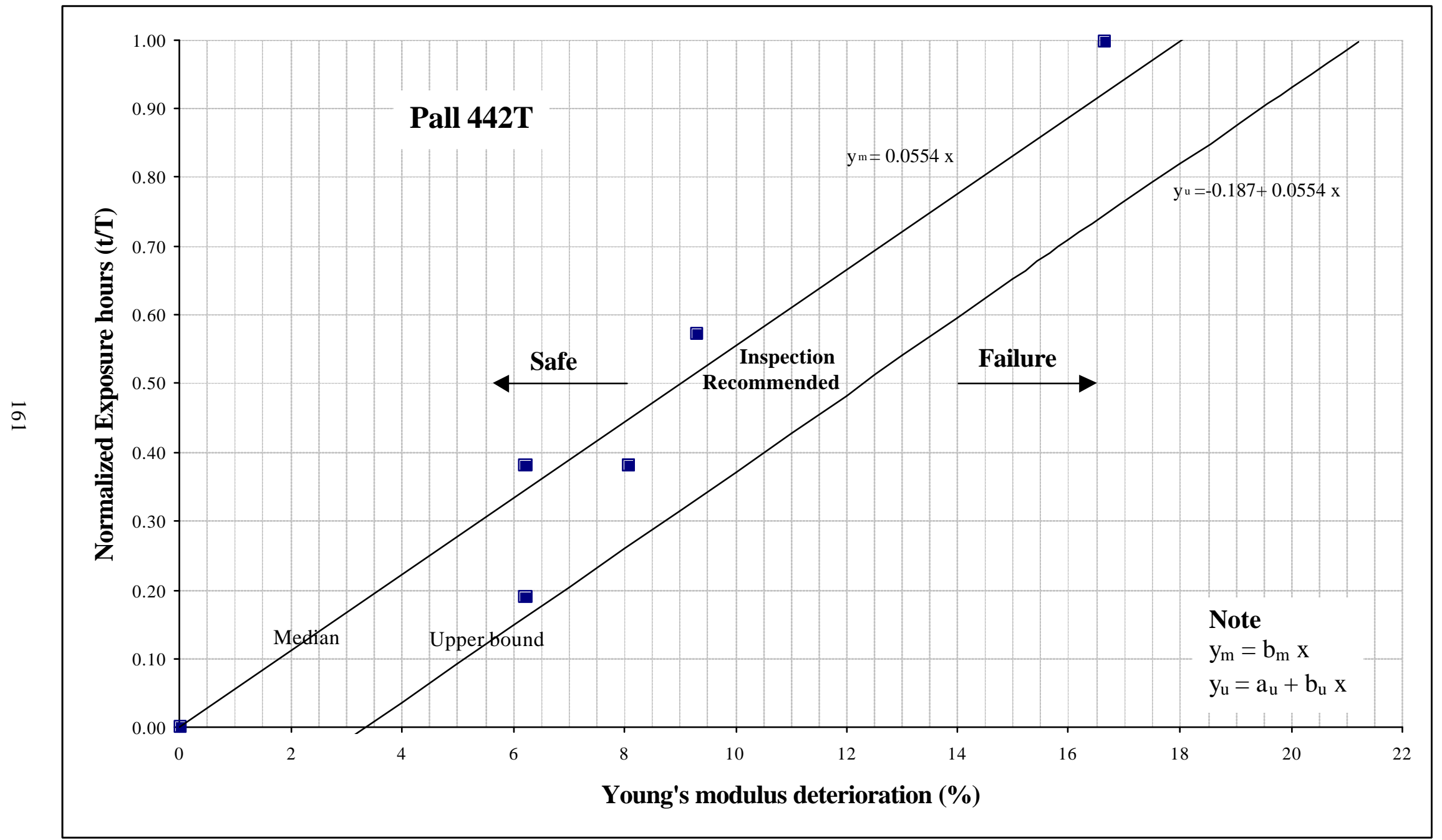

Figure 6.5 Deterioration of Pall 442T filters with respect to exposure hours. 


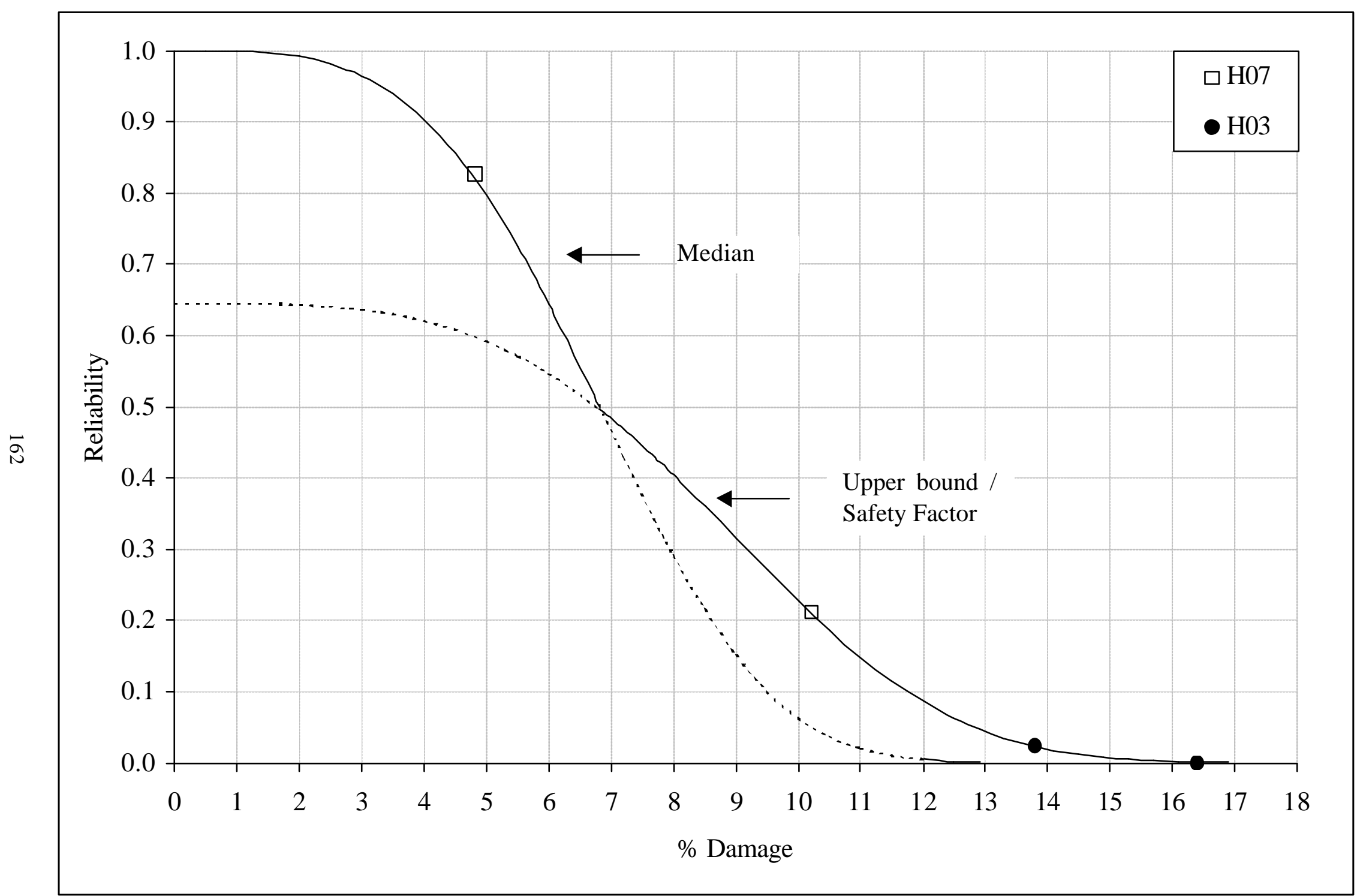

Figure 6.6 Reliability of Sch TF-20 filters. 


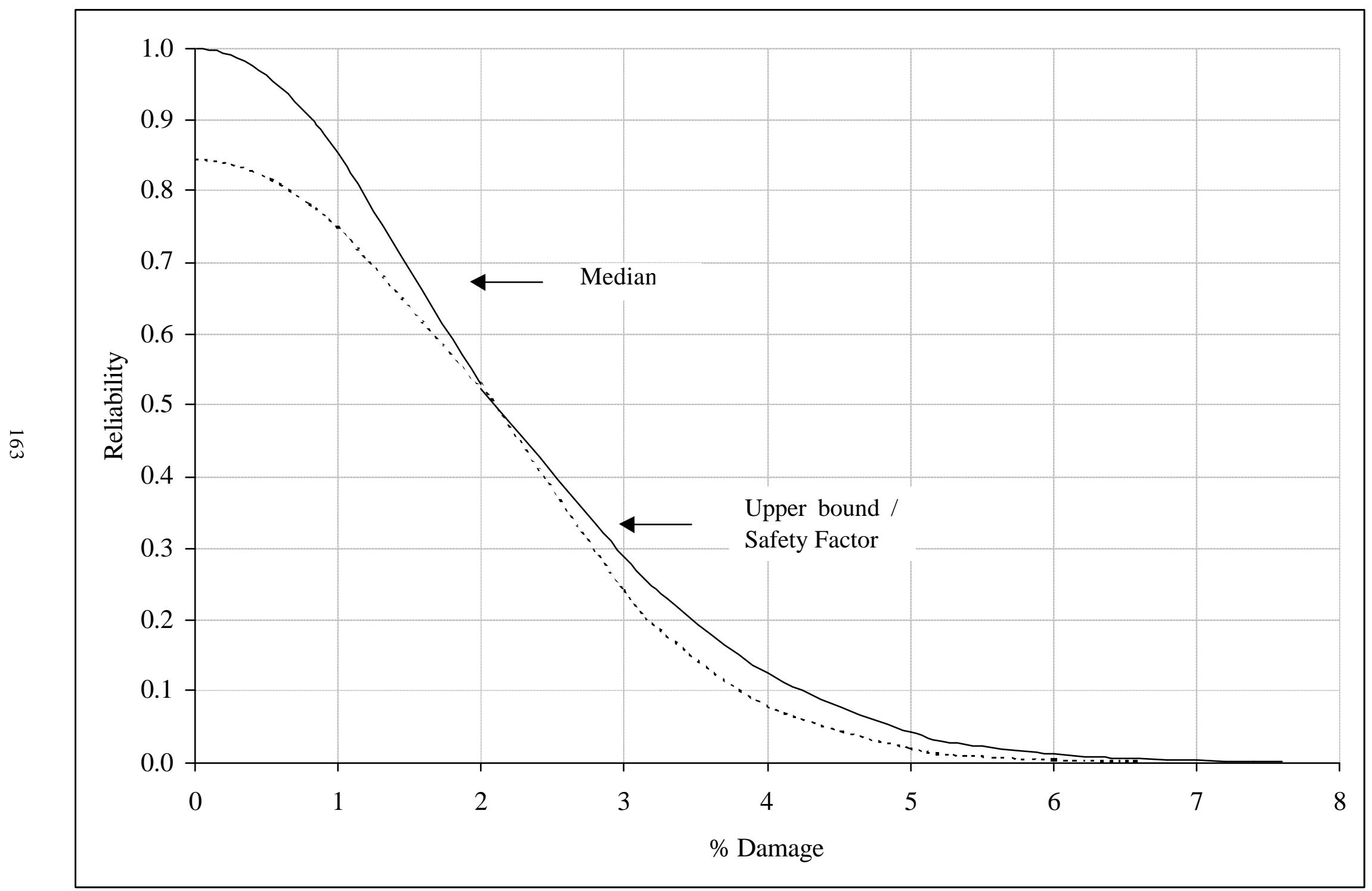

Figure 6.7 Reliability of Pall 326 \#-Series filters. 


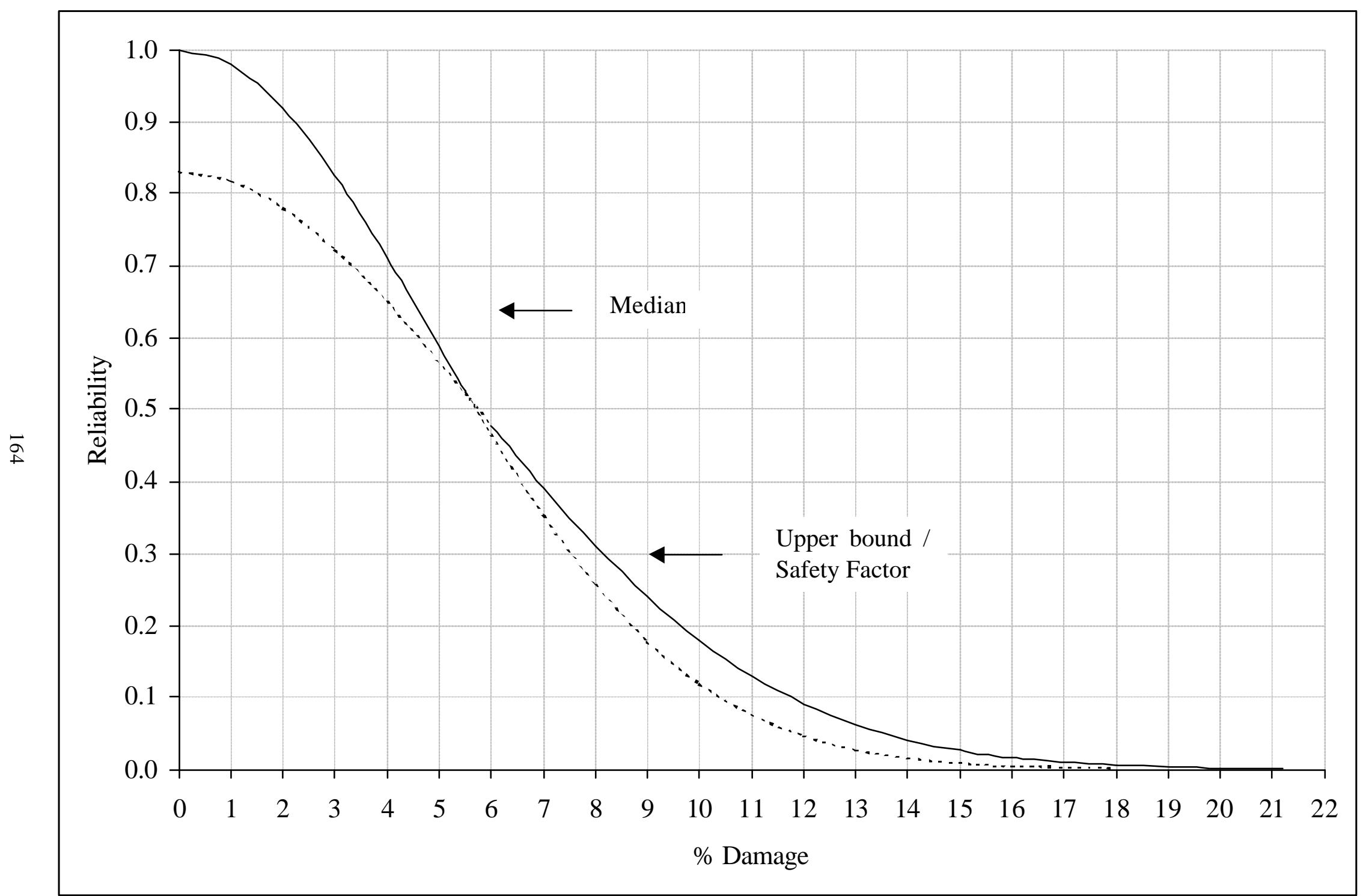

Figure 6.8 Reliability of Pall 442T filters. 


\section{CHAPTER 7}

\section{CONCLUSIONS AND RECOMMENDATIONS}

\subsection{Conclusions}

The natural frequencies and mode shapes acquired for the filter specimens can be used as an index to quantify the structural stiffness and the stiffness reduction due to exposure hours at the PSDF. Contact and non-contact sensing systems show the same results in detecting the vibration frequency values of the candle filters. Results show that used candle filters have lower natural frequencies, which also indicate lower stiffness, than the new filters of the same type. The vibration frequencies are independent of the impact locations along the same axis. They also have small variation at different perpendicular axes. However, one should inspect the same axis of a candle filter in order to assess accurately the structural properties of the filter.

The effect of dust-cake accumulated on the filter specimens after they have been used for a period of time increases the natural vibration frequencies without producing significant changes in the specimen's weight. These temporary dust-cake layers are washable and the natural frequency is reduced after the filters have been cleaned.

A technique that uses the frequency ratios of the second and the third vibration bending modes to evaluate the boundary restraints of the candle filters was developed. These frequency ratios curves are independent of the filter's Young's modulus. The modal frequency values of the candle filters increase with an increase of their boundary restraints. The boundary restraints and Young's modulus of a candle filter can be predicted simultaneously using this technique. 
A Timoshenko beam equation that includes a boundary restraint parameter is developed in this study. This equation may reduce the deviation between the experimental and the theoretical frequency values that conventional frequency equations have, especially in the higher modes. The accuracy of the modal data from the experiment was successfully verified by the beam equation and the FEM analysis. The FEM models built can accurately simulate the vibration response of new as well as used ceramic candle filters with different boundary conditions. A combination of mode shape and strain energy analysis worked successfully in detecting damage zones along the filter span. The FEM analysis using localized damage sections successfully verified the accuracy of the damage zone algorithm.

Results from this study indicated that the vibration signature can be also used to evaluate the stiffness and boundary restraints of the ceramic candle filters at elevated temperatures. Changes in the natural frequency of the ceramic candle filters due to different temperatures were observed. The boundary restraints also change with various temperatures. The results of the thermal experiments were verified by using FEM analysis with steady-state thermal analysis. The vibration response of the candle filters during back pulse operational conditions and the corresponding thermal stresses were successfully simulated using FEM modeling with transient thermal stress analysis.

The fatigue results from the present study show the importance of considering the operational vibration as a factor that may produce failure in the ceramic candle filters. A shaking set-up was successfully developed for studying the candle filter vibration response under cyclic excitation. The fatigue behavior induced to the filters by the plenum vibration was simulated experimentally under cyclic fatigue loading. The 
stresses needed to produce sudden failure in the candle filter are smaller than the ultimate stresses reported by conventional static tests.

A preliminary relationship between the stiffness reduction and the reliability of the ceramic candle filters due to exposure hours has been presented. It is noted that only one operational loading factor (exposure hours) has been included in the current reliability model to predict the stiffness deterioration of the candle filters. Previous chapters have shown the influence of multiple factors in the candle filters' stiffness degradation such as high temperature variation and fatigue vibration that need further investigation. Inspection and replacement decisions for ceramic candle filters can be made with guidelines based on risk assessments, which are a function of the probability of failure and the consequences of failure.

\subsection{APPLICATION AND RECOMMENDATIONS}

The knowledge of the dynamic behavior of ceramic candle filters is essential and can be used to measure changes in the mechanical properties of the filters, nondestructively. The nondestructive evaluation (NDE) technique developed in this study not only improves the understanding of the filter's dynamic behavior but also can help ensure the efficient and safe performance of the ceramic candle filters and the power systems. The degradation of the filters due to long exposure hours is reflected in the shift of natural vibration frequency and the filter's localized damage can be detected through the modal shapes.

Attractive features of the proposed NDE method include low cost, nondestructive nature, ease of operation and adequate sensitivity to identify stiffness degradation in the 
filters. Failures of ceramic candle filters during operation at the PSDF have been reported but the causes of these failures are not yet fully understood. Using the techniques developed in this study to determine the degradation and the remaining life of the ceramic candle filters can lead to a more efficient power generation process, avoiding unexpected shut downs due to candle filter failures.

More data should be collected with filters of varying ages. Specifically, more data are required for further validation of the reliability analysis for filters with longer heating cycles. For a complete reliability equation that includes all the hazard factors that are present during the regular operational conditions, a more detailed study of each hazardous factor is needed.

The studies conducted on the filter specimens at WVU work successfully in laboratory conditions, which does not conform to the actual in-situ operational conditions. Further studies are suggested to investigate the in-situ operational variations, and to establish a systematic testing procedure for field application. Even though several important parameters have been studied during this research for the remaining life prediction of the ceramic candle filter, the actual in-situ environments may present many important physical effects needed to be considered further. For example, fatigue and large amplitude shaking due to plenum vibration and back-pulse shaking, thermal attack due to back pulse temperature-drop, the pressure-level history and the temperature history in the plenum and the possible chemical attack due to various coals. The actual operating history of the candle filter is the key aspect for the prediction of the remaining life. The above physical effects need to be included in the description of the operating history. The exposure hours that have been reported by the power plant are only one aspect of the 
actual history of the filter. Further development of an in-situ remaining life prediction of the candle filter system which will consider the detailed operation history of the candle filters is proposed. 


\section{REFERENCES}

Alvin, M. A., Tressler, R. E., Lippert, T. E., and Diaz, E. S., (1994), "Durability of Ceramic Filters," Advances in IGCC and PFBC Review Meeting, DOE/METC94/1008, Vol 2, DE-94012252, 545-571.

Alvin, M. A., Lippert, T.E., Diaz, E. S., and Smeltzer, E.E., (1995), "Thermal and Chemical Stability of Ceramic Candle Filters," Proceedings of the Coal-Fired Power System 95 Review Meeting, DOE/METC-95/1018, Vol 2, DE-95009733, 485-509.

Alvin, M.A., (1999), "Hot Gas Filter Development and Performance," High temperature Gas Cleaning, Institut für Mechanische Verfahrenstechnik und Mechanik Universität Karlsruhe - Germany 1999, Vol 2, 455-467.

ALGOR User's Manual - First Edition (1988), Algor Interactive Systems, Inc., Pittsburgh, PA.

CFFR/CSSRSD (Committee on Fatigue and Fracture Reliability of the Committee on Structural Safety and Reliability on the Structural Division), (1982), "Fatigue Reliability: Introduction," Journal of the Structural Division, ASCE, Vol 108 (ST1), $3-23$.

Chen, S. J. H., (1980), System Identification and Damage Assessment of Existing Structures, Ph. D Thesis, School of Civil Engineering, Purdue University, W. Lafayatte, IL.

Chen L., Chen, S.E., Lin, Y.H., and Chen H.L., (1999), "Development of Laser-Based Nondestructive Evaluation of Ceramic Candle Filter," Report to FETC/DOE, Morgantown, WV. 
Chen, H. L. and Kiriakidis, A., (1998), "Nondestructive Dynamic Characterization of Ceramic Candle Filters," Proceedings of the Symposium on High Temperature Particulate Cleanup for Advanced Coal-Based Power System, Sponsored by DOE and EPRI, 20-23.

Chen, H. L. and Kiriakidis, A., (1999), Nondestructive Evaluation of Ceramic Candle Filters, Final Report No DE-FG21-97MC34160 to FETC/DOE, Morgantown, WV.

Chen, H.L. and Kiriakidis, A., (2000), "Stiffness Evaluation and Damage Detection of Ceramic Candle Filters," Journal of Engineering Mechanics, Vol. 126(3), 308-319.

Chen, H.L. and Kiriakidis, A., (2001), "Evaluation Structural Properties of New Ceramic Candle Filters Using Dynamic Characterization Method," Material Evaluation, Vol. 59(1), 63-69.

Chen, H. L., Spyrakos, C. C., Venkatesh, G., (1995), "Evaluating Structural Deterioration by Dynamic Response," Journal of Structural Engineering, 121(8), 1197-1204.

Chen, S.J., (1980), System Identification and Damage Assessment of Existing Structures, Thesis submitted to Purdue University, W. Lafayette, IN.

Clough, R. W. and Penzien, J., (1993), Dynamic of Structures, McGraw-Hill, Inc., Second Edition, New York.

Cowper, C. R., (1966)," The Shear Coefficient in Timoshenko's Beam Theory," Journal of Applied Mechanics, ASME, 66, 335-340.

Dennis, R., McMahon, T., Dorchak, T., Chiang, T., (1999), “U.S. of Energy's HighTemperature and High-Pressure Particulate Cleanup Program for Advanced CoalBased Power System," High Temperature Gas Cleaning, Institut für Mechanische 
Verfahrenstechnik und Mechanik Universität Karlsruhe - Germany 1999, Vol 2, 303-314.

Davidson, M., Guan, X., Hendrix, H., and Scarborough, P., (1999), "Power System Development Facility: High-Temperature, High Pressure Filter System Operations in a Combustion Gas," High Temperature Gas Cleaning, Institut für Mechanische Verfahrenstechnik und Mechanik Universität Karlsruhe - Germany 1999, Vol 2, 315-334.

Ewins, D. J. (1985), Modal Testing: Theory and Practice, John Wiley \& Sons, New York.

Freudenthal, A. M. and Heller, R.A., (1967), "On Stress Interaction in Fatigue and Cumulative Damage Rule,” Journal of Aerospace Science, Vol 26 (7).

Graff, K. F., (1975), Wave Motion in Elastic Solids, Ohio State University Press, OH.

Gilbert, C. J., Bloyer, D. R., Barsoum, M., Raghy, T., Tomsia, A., and Ritchie, R., (2000), "Fatigue Crack Growth and Fracture Properties of Coarse and Fine Grained $\mathrm{Ti}_{3} \mathrm{SIC}_{2}$," Scripta Materialia, Vol 42, 761-767.

Hearn, G. and Testa, R., (1991), "Modal Analysis for Damage Detection in Structures," Journal of Structure Engineering, ASCE, 117(10), 3042-306.

Helanti, V., Nikkila, A. P., Pastila, P., and Mantyla, T., (1999), "Microstructural Characteristic of Ceramic Hot Gas Filters," High Temperature Gas Cleaning, Institut für Mechanische Verfahrenstechnik und Mechanik Universität Karlsruhe - Germany 1999, Vol 2, 405-413.

Hendrix, H., (1998), Filter Element Workshop, Power System Demonstration Facility, Southern Company Services, Inc., Alabama. 
Huang, T.C., (1961), "The effect of rotary inertia and shear deformation on the frequency and normal mode equations of uniform beams with simple end conditions," Journal of Applied Mechanics, No.61, APM 25, 579-584.

Huque, Z., Mei, D., and Zhou, J., (1996), "Initial Failure Analysis of Ceramic Filters," Proceedings Advanced Coal-Fired Power Systems- Review Meeting, http://www.netl.doe.gov, PB6.

Huynh, D., Anderson, B., Johnson, T. R., and Wilson D., (1998), "Particulate Cleanup for Integrated Drying Gasification Combined-Cycle," Proceeding of the Symposium High-Temperature Particulate Cleanup for Advanced Coal-Based Power System, Sponsored by DOE and EPRI.

Jaleel, K.M.A., and Sundararajan, V., (1993), "Finite-Element Simulation of Elastic Wave Propagation in Orthotropic Materials," Journal of Materials Evaluation, ASNT, Vol 51 (7), 830-838.

Kamiya, H., Sekiya, Y., and Hori, M., (1998), "Thermal Stress Fracture of Rigid Ceramic Filters Due to Char Combustion in Collected Dust Layer on Filter Surface," Proceeding of the Symposium on High-Temperature Particulate Cleanup for Advanced Coal-Based Power System, Sponsored by DOE and EPRI

Kiriakidis A. (1998), Structural Properties Evaluation of Ceramic Candle Filters Using Vibration Response, M.S.C.E. Problem Report, West Virginia University, Morgantown.

Littman, W. and Tylor, S. W. (1992), "Smoothing Evolution Equations and Boundary Control Theory," Journal of Analyze Mathematics., Vol 59, 117-131. 
Lippert,T. E., Bruck, G. J., Sanjana, Z. N., and Newby, R. A. (1994), "Westinhouse Advanced Particle Filter System," Advances in IGCC and PFBC Review Meeting, DOE/METC-94/1008, Vol 1, DE-94012252, 152-165.

Lippert,T. E., Newby, R. A, Alvin, M. A., Bruck, G. J, .Sanjana, Z. N., and Smeltzer, E. E., (1999), "Hot Gas Filter for Advanced Power System," High Temperature Gas Cleaning, Institut für Mechanische Verfahrenstechnik und Mechanik Universität Karlsruhe - Germany 1999, Vol. 2, 291-302.

Lybas, J. M. and Sozen, M.A., (1977), "Effect of Beam Strength and Stiffness on Dynamic Behavior of R/C Coupled Walls," Report No UILU-ENG-77-2016, Department of Civil Engineering, University of Illinois, IL.

Mann, N. R., Schafer, R.E., and Singpurwalla, N. D., (1974), Methods for Statistical Analysis of Reliability and Life Data, John Wiley \& Sons, New York.

Madsen, H. O., Krenk, S., and Lind, N.C., (1986), Methods of Structural Safety, Prentice Hall, Inc., New Jersey.

Miner, M. A. (1945), "Cumulative Damage in Fatigue," Journal of Applied Mechanics, Vol. $12(1)$.

Pontius, D. H. and Starret, H. S., (1994), "Properties of Ceramic Candle Filters," Proceedings of the Coal-Fired Power System 94, DOE/METC-94/1008, Vol 2, DE94012252, Vol.2, 572-574.

Sawada, Y., Hiramatsu, K., Kawamoto, H., Araki, T., Yamada, M., and Iida, J., (1999), "Evaluation on Fundamental Properties of Filter Materials at High Temperature," High Temperature Gas Cleaning, Institut für Mechanische Verfahrenstechnik und Mechanik Universität Karlsruhe - Germany 1999, Vol 2,, 393-404. 
Sawyer, J. W. and June, M., (1997), "Iron Aluminide Hot Gas Filter Development," Proceedings the Advanced Coal-Based and Environmental Systems, http://www.netl.doe.gov, Section 3A2.

Schanz, M. and Antes, H., (1999), "A Boundary Integral Formulation for the Dynamic Behavior of a Timoshenko Beam,” Computational Mechanics, Vol. 20 (5), 452-459.

Shanley, F., (1959)," Discussion of methods of Fatigue Analysis," Fatigue of Aircraft Structure: Proc, WADC - TR- 59-507.

Simha, S. (1998), Investigation of the formation of residual ash on candle filters, M.S.M.E. Thesis, West Virginia University, Morgantown.

Spain, J. D. and Starrett, H. S., (1994), "Physical, Mechanical and Thermal Properties of Refractron Filter Materials," Report to US Department of Energy, National Energy Technology Center.

Spain, J. D. and Starrett, H. S., (1999), "Characterization of Monolithic and Composite Filter Elements," High Temperature Gas Cleaning, Institut für Mechanische Verfahrenstechnik und Mechanik Universität Karlsruhe - Germany 1999, Vol 2, 414-427.

Shanley, F., (1959), "Discussion of methods of fatigue analysis," Proceedings Fatigue of Aircraft Structures, WADC-TR59, 507.

Timoshenko, S., Young, D. H., and Weaver, W. Jr., (1974), Vibration Problems in Engineering, Fourth Edition, John Wiley and Sons, New York.

Vaubert, V., Stinton, D. P., Barra, C., and Limaye, S., (1999), "Design and Development of Monolithic Cross-Flow Ceramic Hot-Gas Filters," High Temperature Gas 
Cleaning, Institut für Mechanische Verfahrenstechnik und Mechanik Universität Karlsruhe - Germany 1999, Vol 2, 480-491.

Venkatappa, S., Chen, S. E., Petro, S. and GangaraRao, H. V. S., (1999), "Study of modal Behavior of a Hinged Girder Using Scanning Laser Vibrometer," Proceedings $17^{\text {th }}$ International Modal Analysis Conference, FL.

Venkatesh, G. (1990), Dynamic Characterization of Prestressing Rods in Stressed Timber Decks and Steel Channel Beams, MS Thesis, West Virginia University, WV.

Wagner, R. A., (1998), "Ceramic Composite Hot Gas Filter Development," Proceedings of the Advanced Coal-Based Power and Environmental Systems, http://www.netl.doe.gov, PB.4.

Wang, T.Y., Bertero, V. V., and Popov, E. P., (1975), "Hysteretic Behavior of Reinforced Concrete Frame Walls", Report No. EERC 75-23, Earthquake Engineering Research Center, University of California Berkeley, CA.

Yao, J.T.P., (1985), Safety and reliability of Existing Structures, First edition, Pitman advanced Publishing Program, Boston.

Yao, J.T.P., and Munsen, w. h., (1962), Low-Cycle Axial Fatigue Behavior of Mild Steel,” ASTM Special Technical Publication, No 338, 5-24. 


\section{APPENDIX A \\ STRUCTURAL DAMAGE METHODS}

\section{A.1 General Remarks}

A key to the development of a structure reliability analysis is the precise description of the structure behavior under a definite external loading and environmental condition by a statistical simulation. There are several theories, which have been developed in an attempt to improve the accuracy time to failure prediction methods. These cumulative damage theories can be classified as linear or non-linear theories.

The linear damage theories are based on experimentally determined $\mathrm{S}-\mathrm{N}$ data for various combinations of materials, temperature, geometry, stress, loading type and other parameters. Linearity refers to the method of summing the fractions of consumed life and does not mean that the damage process itself is linear. These theories are considered interaction-free because the damage accumulation after $\mathrm{n}$ stress cycles is independent of the order in which the stress cycle occurs. In that case the damage increment in a stress cycle depends only on the damage accumulated at the beginning of the stress cycle and on the stress cycle itself. For example, suppose that a sample of material has been subjected to prior cyclic stresses until it has arrived at a specific degree of damage. If a new cycle of a particular stress is now applied, the damage accumulated during this cycle would be the slope of the damaged-cycle curve prior to this cycle multiplied by the increment of the cycle ratio. The damage accumulated can be written as follows (Madsen et al. 1986)

$$
\Delta D_{n}=\xi\left(D_{n-1}, S_{n}\right), \quad n=1,2, \ldots
$$


where $\xi$ is a non-negative function, which can depend on variables such as the environmental condition and the average stress in the $\mathrm{n}^{\text {th }}$ cycle The damage accumulation is determine entirely by the stress variation and stresses are assumed to vary in cycles with stress ranges $S_{n}$. The damage increment $\Delta D_{n}$ in the nth stress cycle depends on the damages accumulated at the end of each of the preceding n- 1 stress cycles and on the stress range of the $n^{\text {th }}$ stress cycle.

Nonlinear cumulative damage theories are different than the linear theories in that the result is achieved by assuming that there is interaction between the external loading and the amount of damage. The amount of damage experienced at any particular load level is depending upon both the magnitude and the number of occurrences of prior loads. The damage increment $\Delta D_{n}$ in the $n^{\text {th }}$ stress cycle depends on the damages accumulated at the end of each of the preceding n-1 stress cycle and on the stress range of the $n^{\text {th }}$ stress cycle (Madsen et al. 1986)

$$
\Delta D_{n}=D_{n}-D_{n-1}=\xi\left(D_{1}, D_{2}, \ldots, D_{n-1}, S_{n}\right), \quad n=1,2, \ldots
$$

When the damage is a slowly varying function of the number of stress cycles the finite difference $\Delta D_{n}$ in Equation $A 1$ can be replaced by the derivative $\mathrm{dD} / \mathrm{dn}$. This leads to the kinetic equation for damage accumulation (Boltin 1981) $\mathrm{dD} / \mathrm{dn}=\xi(\mathrm{D}, \mathrm{S})$. For a stress-independent theory the damage index is denoted $\mathrm{D}=\mathrm{D}(\mathrm{n} / \mathrm{N}, \mathrm{S})=\eta(\mathrm{n} / \mathrm{N})$, since there is a one-to-one correspondence between $\mathrm{N}$ and $\mathrm{S}$. Where the number of stress cycles with stress range $S$ necessary to cause failure is denoted $N=N(S)$. The kinetic equation for damage accumulation is then 


$$
\frac{\mathrm{dD}}{\mathrm{dn}}=\frac{1}{\mathrm{~N}(\mathrm{~S})} \eta^{\prime}\left(\frac{\mathrm{n}}{\mathrm{N}}\right)=\frac{1}{\mathrm{~N}(\mathrm{~S})} \eta^{\prime}\left(\eta^{-1}(\mathrm{D})\right)
$$

or

$$
\frac{\mathrm{dD}}{\eta^{\prime}\left(\eta^{-1}(\mathrm{D})\right)}=\frac{\mathrm{dn}}{\mathrm{N}(\mathrm{S})}
$$

where $\mathrm{dn}$ is the number of stress cycles with stress range between $\mathrm{S}$ and $\mathrm{S}+\mathrm{dS}$. Since $\eta(0)$ and $\eta(1)=1$ it follows by a variable substitution $D=\eta(n / N)$ that

$$
\int_{D=0}^{1} \frac{d D}{\eta^{\prime}\left(\eta^{-1}(D)\right)}=\int_{n / N=0}^{1} d(n / N)=1
$$

Integrating both sides of Equation $\mathrm{A} 4$, the following fundamental condition is found at failure

$$
1=\sum_{i=1}^{m}\left(\frac{n}{N_{1}}\right)_{i}
$$

The linear cumulative-damage theory from Equation A6 is attributed to Miner (1945). The theory is important and has had extensive use because of its simplicity and general agreement with reality. The theory simply assumed that the fraction of life consumed by stress cycles of any amplitude is equal to the ratio of the number of cycles applied to the total number of such stress cycle, which would produce failure. Where m 
is the number of application cyclic load prior to failure. $\mathrm{n}$ is the number of cycles, and $\mathrm{N}_{\mathrm{i}}$ is the number of cycles required to cause failure. It is asserted that failure will occur when the damage index $\mathrm{D}$ reaches approximately unity. In general, all cumulative damage theories that reduce to stress-independent cycle relationship and are interactionfree are comparable to Miner's theory.

Yao and Munse (1962) suggested the following damage function for axially loaded steel members that are subjected to low cyclic and high amplitude reversed deformation

$$
D=\sum_{i=1}^{m}\left[\left(\frac{\Delta q}{\Delta q_{1}}\right)^{1 / r}\right]_{i}
$$

where $1 / \mathrm{r}$ is a parameter depending upon the ratio of the cyclic compressive change in plastic strain by the subsequent change in plastic strain. $m$ is the number of tensile load applied prior to failure. $\Delta \mathrm{q}$ is the percent cyclic tensile change in plastic true strain and $\Delta \mathrm{q}_{1}$ is the percent cyclic tensile change in plastic true strain at $\mathrm{m}=1$. Letting $\Delta \mathrm{q}, \Delta \mathrm{q}_{1}$ and $1 / \mathrm{r}$ be equal to $\mathrm{Z}-\mathrm{Y}_{\mathrm{d}}, \mathrm{C}-\mathrm{Y}_{\mathrm{d}}$, and $\mathrm{b}$, respectively, the damage function can be expressed in terms of displacement parameters. Where $\mathrm{Y}_{\mathrm{d}}$ is the yield displacement and $\mathrm{C}$ is the collapse displacement. $\mathrm{Z}$ is the maximum displacement response and $\mathrm{b}$ is a parameter that depends of the material and the structure.

The degradation of natural frequencies and stiffness of a structure after it is significantly damaged have also been used as damage factors. Lybas and Sozen (1977) introduce an analytical study of the static hysteretic response of a reinforced concrete wall to seismic loads. The main experimental variables used were the strength and the 
stiffness of the connecting beams. The damage function used for an element of a linearly elastic substitute structure was expressed as the ratio of the spring stiffness, which has not yet yielded by the spring stiffness, reduced for equivalent linear response, of a SDOF system. The apparent natural frequencies of the structure tested decreased continuously as the structure deteriorates under successive and increasingly application of the base motion.

Freudenthal and Haller (1967) presented an interaction type theory based on the premise that a fictitious S-N curve can be found such that the application of Miner's theory to this curve is valid and those interaction effects are such that the interaction $\mathrm{S}-\mathrm{N}$ curve has an equation of the form:

$$
N_{I}=\frac{K}{\sigma_{a}^{x}}
$$

where $\mathrm{N}_{\mathrm{I}}$ is a revised number cycles to failure for the ith stress amplitude which is to be used in the damage-accumulation relationship. $\sigma_{\mathrm{a}}$ is the cyclic stress amplitude and $\mathrm{K}$ is a constant to be determined experimentally. Using a extensive series of test a simple relationship for the value of $\mathrm{x}$. related to the applied stress and the S-N curve was found experimentally.

Shanley (1959) proposed a theory which involves an exponential relationship for fatigue crack growth, and which recognizes that fatigue crack tends to increase with crack depth. The damage function was defined as 


$$
D=\sum_{i=1}^{m}\left(\frac{n_{i}}{N^{*}{ }_{i}}\right)
$$

with $\mathrm{N}_{\mathrm{i}}^{*}=\mathrm{N}_{\mathrm{i}}^{2} / \mathrm{N}_{\mathrm{e}}$, where $\mathrm{Ni}$ is the number of cycle to failure and $\mathrm{N}_{\mathrm{e}}$ is the number of cycles representing the endurance limit at a given stress level.

The damage accumulation assumptions reviewed in this section operate with the simplified measure of damage in term of a scalar damage index D. The value of D is taken as zero in the initial state and as one at failure. The damage index is a nondecreasing function of the number of external loading cycles. Stress dependent and stress independent theories may be interaction free. This information is used in Chapter 6 . 


\section{APPENDIX B}

\section{NATURAL FREQUENCIES FROM FINITE ELEMENT MODAL ANALYSIS}

Table B.1 FEM natural frequencies $(\mathrm{Hz})$ for the Schumacher TF-20 mode (free-free)

\begin{tabular}{|c|c|c|c|c|}
\cline { 2 - 5 } \multicolumn{1}{c|}{} & \multicolumn{4}{c|}{ Sch TF-20 FEM $\left(\rho=0.073 \mathrm{lb} / \mathrm{in}^{3}, v=0.20\right)$} \\
\hline Mode & E=5.0e06 psi & E=5.41e06 psi & E=6.05e06 psi & E=6.5e06 psi \\
\hline 1 & 109.70 & 113.98 & 120.30 & 123.60 \\
2 & 299.99 & 311.67 & 327.89 & 337.22 \\
3 & 579.81 & 602.22 & 635.48 & 657.65 \\
4 & 939.66 & 975.61 & 1029.50 & 1071.17 \\
5 & 1369.69 & 1421.46 & 1500.00 & 1560.97 \\
\hline
\end{tabular}

Table B.2 FEM natural frequencies (Hz) for the Pall 326 model (free-free)

\begin{tabular}{|c|c|c|c|c|c|}
\cline { 2 - 6 } \multicolumn{1}{c|}{} & \multicolumn{5}{c|}{ Pall 326 FEM $\left(\rho=0.069 \mathrm{lb} / \mathrm{in}^{3}, v=0.25\right)$} \\
\hline Mode & E=6.6e06 psi & E=7.1e06 psi & E=7.5e06 psi & E=8.0e06 psi & E=8.5e06 psi \\
\hline 1 & 129.49 & 134.31 & 138.04 & 142.57 & 148.67 \\
2 & 353.97 & 367.13 & 377.33 & 389.70 & 406.40 \\
3 & 683.72 & 709.15 & 728.85 & 752.75 & 785.00 \\
4 & 1107.24 & 1148.41 & 1180.32 & 1219.03 & 1271.24 \\
5 & 1612.63 & 1672.60 & 1719.07 & 1775.45 & 1851.49 \\
\hline
\end{tabular}




\section{VITA}

Alejandro C. Kiriakidis was born in Barquisimeto, Venezuela on August 27, 1971. In June 1988, he graduated with a high school diploma from Liceo Rioclaro in Barquisimeto. He attended Metropolitan University and received his Bachelor of Engineering degree in June 1994. In the Fall of 1996, he was admitted to the graduate program in Civil and Environmental Engineering at West Virginia University where he received his MSCE degree in December 1998. He entered the Ph. D. program in Civil and Environmental Engineering at West Virginia University in the Spring of 1999.

For the past six years, Mr. Kiriakidis has been working as a graduate research assistant at West Virginia University. His research interest is in the area of nondestructive testing of materials using vibration measurements. He is currently a candidate for the degree of Doctor of Philosophy in Civil Engineering.

\section{Refereed Articles}

-Chen, H. L. and Kiriakidis, A., "Evaluating Structural Properties of New Ceramic Candle Filters Using Dynamic Characterization Method", Material Evaluation, Journal of ASNT, Vol.59, No.1, Paper 2085, pp.63- 69, January 2001

-Chen, H. L. and Kiriakidis, A., "Stiffness Evaluation and Damage Detection of Ceramic Candle Filters", Journal of Engineering Mechanics, ASCE, Vol.126, No.3, pp.308-318, March 2000

-Chen, H. L. and Kiriakidis, A., "Nondestructive Evaluation of Ceramic Candle Filters with Various Boundary Conditions", Submitted to the Journal of Engineering Mechanics, ASCE.

- Kiriakidis, A. and, Chen, H. L. "Safety and Reliability of Ceramic Candle Filters", To Be Submitted to Material Evaluation, Journal of ASNT.

- Kiriakidis, A. and, Chen, H. L. "Study of Stresses of Ceramic Candle Filters at Elevated Temperature under Vibrational Environment", To Be Submitted to the Journal of Engineering Mechanics, ASCE. 


\section{Conference Proceedings and Invited Papers}

-Chen, H. L. and Kiriakidis, A., "Nondestructive Dynamic Characterization of Ceramic Candle Filters", Symposium of High Temperature Particulate Cleanup for Advanced Coal-Based Power System, Birmingham, AL, April 20-23, 1998.

-Chen, H. L. and Kiriakidis, A., "Evaluation of Ceramic Filters Using Vibration Response", Proceedings of Advanced Coal-Based Power and Environmental System '98 Conference, Morgantown, WV, July 12-23, 1998.

-Chen, H. L. and Kiriakidis, A., "Vibration Response Testing of Candle Filter Elements", Filter Element Workshop, Power System Development Facility, Alabama, November 4$5,1998$.

-Chen, H. L. and Kiriakidis, A., "Evaluation of Ceramic Candle Filters Using Structural Vibration", the $13^{\text {th }}$ Engineering Mechanics Conference, ASCE, Baltimore, June 1999.

-Chen, H. L. and Kiriakidis, A., " Nondestructive Evaluation of Ceramic Candle Filters Using Vibration Response," High temperature Gas Cleaning, Institut für Mechanische Verfahrenstechnik und Mechanik Universität Karlsruhe - Germany, Vol 2, September 22-24, 1999.

-Kiriakidis, A. and Chen, H. L., "Study of Mechanical Properties and Boundary Conditions of Ceramic Candle Filters Using Vibration Measurements", Review of Progress in Quantitative Nondestructive Evaluation, Edited by D. O. Thompson and D. E. Chimenti, Vol.21, 2001.

- Chen, H.L. and Kiriakidis, A., "Nondestructive Evaluation of Stiffness and Stresses of Ceramic Candle Filters at Elevated Temperature under Vibrational Environment", $5^{\text {th }}$ International Symposium on Gas Cleaning at High Temperature, Morgantown, WV, September 17-20, 2002. 